Membranes for ethylene/ethane separation

Jeroen Ploegmakers 


\section{MEMBRANES FOR ETHYLENE/ETHANE SEPARATION}


The research presented in this thesis was financially supported by AgentschapNL

\section{MESA+ \\ $\overline{\text { INSTITUTE FOR NANOTECHNOLOGY }}$}

\section{Promotion committee}

Prof. dr. ir. D.C. Nijmeijer (promotor)

University of Twente

Prof. dr. K. Seshan

University of Twente

Prof. dr. S.R.A. Kersten

University of Twente

Prof. dr. ir. I.F.J. Vankelecom

Katholieke Universiteit Leuven, Belgium

Prof. dr. B.D. Freeman

University of Texas, Austin, USA

Prof. dr. G. Mul

University of Twente

Prof. dr. ir. R.G.H. Lammertink (chairman)

University of Twente

\section{Cover design:}

Jeroen Ploegmakers

Illustration by J. Bennink (www.tingle.nl)

\section{Membranes for ethylene/ethane separation}

ISBN: 978-90-365-3595-3

DOI-number: 10.3990/1.9789036535953

http://dx.doi.org/10.3990/1.9789036535953

Ipskamp Drukkers B.V., Enschede, 2013

No part of this work may be reproduced by print, photocopy, or any other means without permission in writing from the author 


\title{
MEMBRANES FOR ETHYLENE/ETHANE SEPARATION
}

\author{
PROEFSCHRIFT
}

ter verkrijging van

de graad van doctor aan de Universiteit Twente,

op gezag van de rector magnificus,

prof. dr. H. Brinksma

volgens besluit van het College voor Promoties

in het openbaar te verdedigen op

vrijdag 13 december 2013 om 16:45 uur

door

Jeroen Ploegmakers

geboren op 13 november 1984

te Utrecht 
Dit proefschrift is goedgekeurd door:

promotor:

Prof. dr. ir. D.C. Nijmeijer 


\section{Table of Contents}

$\begin{array}{lr}\text { Chapter } 1 & 1\end{array}$

General introduction

Chapter 2

Economic evaluation of membrane potential for ethylene/ethane separation in a retrofitted hybrid membrane-distillation plant using UniSim ${ }^{\circledR}$ Design

\section{Chapter 3}

Penetrant induced sorption and swelling phenomena in thin PPO films resolved by spectroscopic ellipsometry

\section{Chapter 4}

Thin polymer film behavior for gas separation membrane applications

\section{Chapter 5}

Mixed matrix membranes containing MOFs for $\mathrm{C}_{2} \mathrm{H}_{4} / \mathrm{C}_{2} \mathrm{H}_{6}$ separation:

Membrane preparation and characterization

\section{Chapter 6}

Mixed matrix membranes containing MOFs for $\mathrm{C}_{2} \mathrm{H}_{4} / \mathrm{C}_{2} \mathrm{H}_{6}$ separation:

Effect of $\mathrm{Cu}_{3} \mathrm{BTC}_{2}$ on membrane transport properties

Chapter 7

Epilogue

Summary

Samenvatting 



\section{Chapter 1}

General introduction 


\subsection{Introduction}

Separation of olefins from paraffins is one of the most important separation processes in the petrochemical industry. $\mathrm{C}_{2} \mathrm{H}_{4}$ and $\mathrm{C}_{3} \mathrm{H}_{6}$ are crucial resources for the production of other chemicals such as polyethylene, ethylene oxide, polypropylene, styrene, ethyl benzene, ethylene dichloride, acrylonitrile and isopropanol [1,2]. They are currently being separated from their corresponding paraffins by cryogenic distillation. However, due to the similar boiling points of the olefins and their corresponding paraffins, cryogenic distillation requires tremendous amounts of energy [3]. Therefore, research is directed towards alternative separation technologies, such as extractive distillation, chemical and physical adsorption and membrane technology, to reduce the energy consumption of this energy intensive separation.

This chapter describes briefly the most important alternative technologies for cryogenic separation of light olefin/paraffin mixtures $\left(<\mathrm{C}_{4}\right)$. Subsequently, the selection of membranes as the most promising separation technology is discussed, followed by the inherit problems of membrane based $\mathrm{C}_{2} \mathrm{H}_{4} / \mathrm{C}_{2} \mathrm{H}_{6}$ separation. Finally, the scope of this thesis is described.

\subsection{Alternative separation technologies to cryogenic distillation}

\subsubsection{Extractive distillation}

Extractive distillation utilizes a solvent to extract the olefin from the olefin/paraffin mixture. Kumar et al. discussed this technology for the separation of $\mathrm{C}_{3} \mathrm{H}_{6}$ from $\mathrm{C}_{3} \mathrm{H}_{8}$ [4]. Their modeling results showed that extractive distillation offers no advantages over traditional cryogenic distillation. The thermodynamic properties of the investigated extraction solvents exhibited insufficient selectivity to yield an economically viable process. Ongoing research focusses on improving the solvent characteristics such as a high capacity and selectivity for the olefin in combination with a high degree of contaminant tolerance [5].

A patent from Munson et al. showed that ionic liquids combined with group 11 (i.e. $\mathrm{Cu}, \mathrm{Ag}$, $\mathrm{Au}$ ) metal salts could be a viable solvent for extractive distillation [6]. These metallic salts can from a selective reversible complex with olefins. This complexation is well explained by the Dewar-Chatt-Duncanson model, in which d-electrons from the metal ion are donated to the empty $\pi^{*}$ antibonding orbitals of the olefin (Figure 1.1a), while electrons from the olefin`s $\pi$-orbital are back-donated to the empty s-orbital of the metal ion (Figure 1.1b) $[7,8]$. 


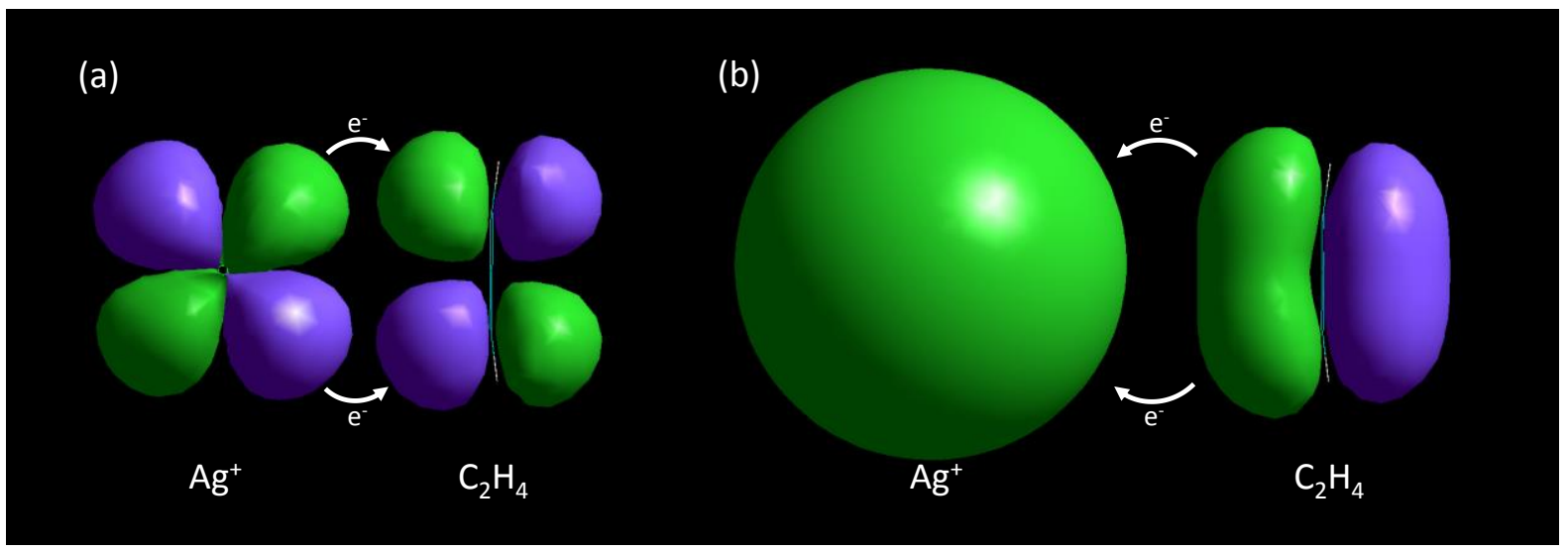

Figure 1.1. Complexation between $\mathrm{Ag}^{+}$and $\mathrm{C}_{2} \mathrm{H}_{4}$, according to the Dewar-Chatt-Duncanson model.

Due to this selective complexation, higher selectivities can be obtained. Yet the use of metallic salts yields additional problems. The complexing agent should be protected from feed contaminants such as $\mathrm{H}_{2} \mathrm{~S}$ and $\mathrm{CO}_{2}$. In addition, $\mathrm{Cu}^{+}, \mathrm{Ag}^{+}$and $\mathrm{Au}^{+}$are prone to reduction, thereby losing a significant part of the selectivity. Finally, complexation with $\mathrm{C}_{2} \mathrm{H}_{2}$ forms an explosive mixture [9]. As $\mathrm{C}_{2} \mathrm{H}_{2}$ is an often present compound in olefin/paraffin streams, the use of metal-ions for separation processes is undesirable.

\subsubsection{Adsorption}

Adsorption is another route to achieve olefin/paraffin separation. By means of molecular sieves, zeolites or metal-organic frameworks (MOFs), olefins are selectively adsorbed, which is currently widely investigated [10-19]. Selectivity is obtained from differences in sorption equilibria between the olefins and paraffins. Physical adsorption is based on kinetic differences between the olefins and paraffins, whereas chemical adsorption usually involves complexation of the olefins double bond with a group 11 metal ion, similar as discussed in the previous section. By changing the pressure or temperature, the olefin can be selectively sorbed and desorbed. However, adsorption is a batch process and requires usually several adsorption steps to reach a desirable product purity. Physical adsorbents offer lower selectivities as compared to chemical adsorbents [20]. Depending on the efficiency of the adsorbent, the capital costs of such a system can be even higher than a comparable distillation process [21]. Without higher selective adsorbents, adsorption as replacement for cryogenic distillation is not economically feasible. 


\subsubsection{Membrane separation}

Membrane based gas permeation can be described by the solution-diffusion model [22]. The permeability of a gas through a membranes can be calculated according to Equation 1.1:

$$
P=D \cdot S
$$

where $\mathrm{P}$ is the permeability coefficient $\left(\mathrm{mol} \mathrm{m} /\left(\mathrm{m}^{2} \mathrm{~Pa} \mathrm{~s}\right)\right), \mathrm{D}$ the diffusion coefficient $\left(\mathrm{m}^{2} / \mathrm{s}\right)$ and $\mathrm{S}$ the solubility coefficient $\left(\mathrm{mol} /\left(\mathrm{m}^{3} \mathrm{~Pa}\right)\right)$. The diffusivity of a gas depends on its Lennard-Jones $(\mathrm{LJ})$ diameter, while the solubility depends on its critical temperature $\left(\mathrm{T}_{\mathrm{c}}\right)$. Gas permeation through a membrane is then accomplished in three steps:

1. Sorption of the gas into the membrane at the feed side.

2. Diffusion of the gas through the membrane.

3. Desorption of the gas out of the membrane at the permeate side.

In a in binary mixture, membrane selectivity $\left(\alpha_{\mathrm{ij}}\right)$ is defined as the ratio of the two individual permeability coefficients $\left(\mathrm{P}_{\mathrm{i}} / \mathrm{P}_{\mathrm{j}}\right)$ :

$$
\alpha_{i j}=\frac{P_{i}}{P_{j}}=\left(\frac{D_{i}}{D_{j}}\right) \cdot\left(\frac{S_{i}}{S_{j}}\right)
$$

where $D_{i} / D_{j}$ and $S_{i} / S_{j}$ are the diffusivity selectivity and the solubility selectivity of components $\mathrm{i}$ and $\mathrm{j}$, respectively. Equation 1.2 shows that the highest selectivity is obtained when both the difference in solubility and diffusivity between the two components is large.

Membrane based gas separation technology is already commercially applied for e.g. $\mathrm{O}_{2} / \mathrm{N}_{2}$, $\mathrm{CO}_{2} / \mathrm{N}_{2}$ and $\mathrm{CO}_{2} / \mathrm{CH}_{4}$ separations. Economical evaluations suggest that membranes in hybrid-membrane-distillation plants are feasible for $\mathrm{C}_{2} \mathrm{H}_{4} / \mathrm{C}_{2} \mathrm{H}_{6}$ separation, once sufficiently high selectivities and permeabilities are obtained [23-25]. 


\subsection{Inherit problems of polymeric membrane based $\mathrm{C}_{2} \mathrm{H}_{4} / \mathrm{C}_{2} \mathrm{H}_{6}$ separation}

As discussed in the previous section, membrane based olefin/paraffin separation is economically viable once sufficiently high selectivities and permeabilities are obtained. A recent overview by Fuertes et al. [26] shows that significantly higher selectivities are obtained for polymeric based $\mathrm{C}_{3} \mathrm{H}_{6} / \mathrm{C}_{3} \mathrm{H}_{8}$ membrane separations $(10<\alpha<50)$ as compared to $\mathrm{C}_{2} \mathrm{H}_{4} / \mathrm{C}_{2} \mathrm{H}_{6}(2<\alpha<11)$. Equation 1.2 showed that the highest selectivity is obtained when both the diffusion selectivity and the solubility selectivity is high, or the difference in both LJ-diameter and $T_{c}$, respectively, is the largest. The $L J$ diameter and $\mathrm{T}_{\mathrm{c}}$ of $\mathrm{C}_{2} \mathrm{H}_{4}, \mathrm{C}_{2} \mathrm{H}_{6}, \mathrm{C}_{3} \mathrm{H}_{6}$ and $\mathrm{C}_{3} \mathrm{H}_{8}$, are shown in Table 1.1 .

Table 1.1. General properties of $\mathrm{C}_{2} \mathrm{H}_{4}, \mathrm{C}_{2} \mathrm{H}_{6}, \mathrm{C}_{3} \mathrm{H}_{6}$ and $\mathrm{C}_{3} \mathrm{H}_{8}$.

\begin{tabular}{ccccc}
\hline Gas & $\begin{array}{c}\text { Molecular mass } \\
(\mathrm{g} / \mathrm{mol})\end{array}$ & $\begin{array}{c}\text { LJ diameter } \\
\mathrm{d}_{\mathrm{LJ}}(\AA)[27]\end{array}$ & $\begin{array}{c}\text { Van der Waals } \\
\text { constant, } \mathrm{b}\left(\mathrm{cm}^{3} / \mathrm{mol}\right) \\
{[28]}\end{array}$ & $\begin{array}{c}\text { Critical temperature } \\
\mathrm{T}_{\mathrm{c}}(\mathrm{K})\end{array}$ \\
\hline $\mathrm{C}_{2} \mathrm{H}_{4}$ & 28.05 & 4.16 & 58.2 & 282.5 \\
$\mathrm{C}_{2} \mathrm{H}_{6}$ & 30.07 & 4.44 & 65.1 & 305.3 \\
$\mathrm{C}_{3} \mathrm{H}_{6}$ & 42.08 & 4.68 & 82.4 & 365.2 \\
$\mathrm{C}_{3} \mathrm{H}_{8}$ & 44.10 & 5.12 & & 369.9 \\
\hline
\end{tabular}

The difference in $\mathrm{T}_{\mathrm{c}}$ is the largest between $\mathrm{C}_{2} \mathrm{H}_{4}$ and $\mathrm{C}_{2} \mathrm{H}_{6}$ as opposed to $\mathrm{C}_{3} \mathrm{H}_{6}$ and $\mathrm{C}_{3} \mathrm{H}_{8}$. This suggests that $\mathrm{C}_{2} \mathrm{H}_{4}$ and $\mathrm{C}_{2} \mathrm{H}_{6}$ separation based on solubility will be easier as compared to $\mathrm{C}_{3} \mathrm{H}_{6}$ and $\mathrm{C}_{3} \mathrm{H}_{8}$ separation. On the other hand, the difference in LJ diameter is smaller between $\mathrm{C}_{2} \mathrm{H}_{4}$ and $\mathrm{C}_{2} \mathrm{H}_{6}$ than it is for $\mathrm{C}_{3} \mathrm{H}_{6}$ and $\mathrm{C}_{3} \mathrm{H}_{8}$. This indicates that $\mathrm{C}_{2} \mathrm{H}_{4} / \mathrm{C}_{2} \mathrm{H}_{6}$ separation will be more difficult based on diffusivity alone, compared to its $\mathrm{C}_{3}$ counterpart.

Polymer membranes are either rubbery or glassy, depending on their operating temperature in respect to their glass transition temperature. At operating temperatures above the polymers 
$\mathrm{T}_{\mathrm{g}}$, separation occurs primarily based on solubility differences as the rubbery polymer chains are too mobile for any form of molecular sieving. Oppositely, at operating temperatures below the $T_{g}$, glassy polymer chains are less flexible, which allows separation to primarily take place based on diffusion and to a lesser extent on solubility.

As $\mathrm{C}_{2} \mathrm{H}_{4}$ and $\mathrm{C}_{2} \mathrm{H}_{6}$ have the largest difference between their $\mathrm{T}_{\mathrm{c}}$, a rubbery membrane would initially be the preferred choice. Unfortunately, olefin/paraffin selectivity in a rubbery membrane such as poly(dimethylsiloxane) (PDMS) is very low [30, 31], indicating that separation based on solubility alone is difficult. Therefore the combination of solubility and diffusivity selectivity has to be utilized to achieve a reasonable selectivity, which limits the potential membranes to glassy materials. Unfortunately glassy polymers favor diffusion based separations, which only have limited effect on $\mathrm{C}_{2} \mathrm{H}_{4} / \mathrm{C}_{2} \mathrm{H}_{6}$ separation because of their similar LJ-diameter. This results in low $\mathrm{C}_{2} \mathrm{H}_{4} / \mathrm{C}_{2} \mathrm{H}_{6}$ selectivities, which are inherit to the use of polymeric membranes.

With the low inherit polymer membrane selectivity towards $\mathrm{C}_{2} \mathrm{H}_{4}$ and $\mathrm{C}_{2} \mathrm{H}_{6}$, several questions arise. Initially, it should be evaluated which $\mathrm{C}_{2} \mathrm{H}_{4} / \mathrm{C}_{2} \mathrm{H}_{6}$ selectivities and $\mathrm{C}_{2} \mathrm{H}_{4}$ permeabilities are required for a viable process. It should be clear whether membrane research should focus on increasing the selectivity, permeability, or both and to what extent. In addition, the amount of publications on membrane based olefin/paraffin separation is limited, especially compared to e.g. $\mathrm{CO}_{2} / \mathrm{CH}_{4}$ separation. Also, the limited number of papers that is available usually investigated dense membranes, while industrial applications usually use composite membrane modules due to their higher area/volume ratio. Such membranes contain increasingly thinner separation layers to enhance the flux. However, it is unclear if thin layers $(<100 \mathrm{~nm})$ behave similar to bulk materials $(>1 \mu \mathrm{m})$ [32]. Most of the thin film investigations focus on $\mathrm{CO}_{2}$, yet no publications exist on the effect of $\mathrm{C}_{2} \mathrm{H}_{4}$ and $\mathrm{C}_{2} \mathrm{H}_{6}$ on thin film membrane properties and performance. Once $\mathrm{C}_{2} \mathrm{H}_{4}$-polymer and $\mathrm{C}_{2} \mathrm{H}_{6}$-polymer interactions are better understood, it might be possible to increase the selectivity and/or permeability. Additional functionalities to a polymer matrix to increase the solubility and/or diffusivity selectivity are most probably required. However, often used addition of $\mathrm{Cu}^{+} / \mathrm{Ag}^{+}$salts do not yield long term stable membranes, because of similar problems that exist with chemical adsorbents [33]. Stabilization of these metal ions seems a plausible route to obtain long term stable, selective and permeable membranes. 


\subsection{Scope of this thesis}

As olefin/paraffin separation is a very energy intensive process, alternatives are being investigated. This thesis investigates the applicability of membranes as a replacement for current cryogenic distillation processes. Especially the separation of $\mathrm{C}_{2} \mathrm{H}_{4}$ from $\mathrm{C}_{2} \mathrm{H}_{6}$ is important because of the vast quantities of $\mathrm{C}_{2} \mathrm{H}_{4}$ that are required for further processing.

Chapter 2 describes the economical evaluation that is performed to determine the ethylene permeability and $\mathrm{C}_{2} \mathrm{H}_{4} / \mathrm{C}_{2} \mathrm{H}_{6}$ selectivity required to have an economical viable process in a hybrid membrane-distillation plant. Two different configurations are investigated and optimized accordingly with respect to the necessary $\mathrm{C}_{2} \mathrm{H}_{4}$ permeability and $\mathrm{C}_{2} \mathrm{H}_{4} / \mathrm{C}_{2} \mathrm{H}_{6}$ selectivity of the membrane. The process conditions such as feed pressure, permeate pressure and membrane area are further optimized for the most promising configuration. The chapter concludes with guidelines for membrane material scientists to prioritize increasing membrane $\mathrm{C}_{2} \mathrm{H}_{4} / \mathrm{C}_{2} \mathrm{H}_{6}$ selectivity or $\mathrm{C}_{2} \mathrm{H}_{4}$ permeability.

Chapter 3 investigates interactions of poly(2,6-dimethyl-phenylene oxide) PPO thin films with $\mathrm{C}_{2} \mathrm{H}_{4}$ and $\mathrm{C}_{2} \mathrm{H}_{6}$. Membranes become increasingly thinner and interactions of $\mathrm{C}_{2} \mathrm{H}_{4}$ and $\mathrm{C}_{2} \mathrm{H}_{6}$ with thin films are unknown. Therefore, spectroscopic ellipsometry is used to investigate $\mathrm{C}_{2} \mathrm{H}_{4}$ and $\mathrm{C}_{2} \mathrm{H}_{6}$ induced swelling in thin PPO films. A thorough characterization is performed on $\mathrm{C}_{2} \mathrm{H}_{4}$ and $\mathrm{C}_{2} \mathrm{H}_{6}$ induced PPO swelling and compared to $\mathrm{CO}_{2}$ and $\mathrm{N}_{2}$. An optical model is used that assumes the penetrants inside the polymer matrix being in a gaseous state as opposed to a (supercritical) fluid. Furthermore, partial molar volumes of the penetrants inside the thin PPO films are calculated and their deviation from a constant value, as assumed in the solution-diffusion model, is evaluated. Finally, the gas concentrations in thin PPO films are compared to bulk films and the differences are assessed.

Chapter 4 extends the range of the investigated polymers from the previous chapter to PDMS, P84 ${ }^{\circledR}$ and sulfonated PPO (SPPO). Differences between $\mathrm{N}_{2}, \mathrm{CO}_{2}, \mathrm{C}_{2} \mathrm{H}_{4}$ and $\mathrm{C}_{2} \mathrm{H}_{6}$ sorption induced swelling in both rubbery and glassy polymer films are investigated. This chapter especially focusses on the interaction differences of polar $\left(\mathrm{CO}_{2}\right)$ and apolar $\left(\mathrm{C}_{2} \mathrm{H}_{4}\right.$, $\mathrm{C}_{2} \mathrm{H}_{6}$ ) penetrants with polar (P84, SPPO) and apolar (PDMS, PPO) thin films. The chapter concludes with estimations of penetrant partial molar volumes and the comparison of $\mathrm{C}_{2} \mathrm{H}_{6}$ concentrations in thin and bulk films.

Based on the previously obtained knowledge of $\mathrm{C}_{2} \mathrm{H}_{4} / \mathrm{C}_{2} \mathrm{H}_{6}$-polymer interactions, chapter 5 describes the preparation and characterization of mixed matrix membranes (MMMs) to 
increase the separation performance. Three different MOFs, i.e. $\mathrm{Cu}_{3} \mathrm{BTC}_{2}$, FeBTC and MIL$53(\mathrm{Al})$, are incorporated in a polymer matrix. P84 is chosen as matrix as the previous chapter showed that this polymer exhibits the least amount of $\mathrm{C}_{2} \mathrm{H}_{4}$ and $\mathrm{C}_{2} \mathrm{H}_{6}$ induced swelling. Additionally, it is expected that the polar structure of P84 is the most compatible with the most promising MOF, $\mathrm{Cu}_{3} \mathrm{BTC}_{2}$. The presence of non-selective voids between the MOFs and the polymer matrix is analyzed by means of various analysis techniques. Their performance regarding $\mathrm{C}_{2} \mathrm{H}_{4}$ permeability and $\mathrm{C}_{2} \mathrm{H}_{4} / \mathrm{C}_{2} \mathrm{H}_{6}$ selectivity for mixed gases is investigated.

Chapter 6 describes more in depth the effect of the $\mathrm{Cu}_{3} \mathrm{BTC}_{2}$ MOF in P84 MMMs on the $\mathrm{C}_{2} \mathrm{H}_{4}$ permeability and $\mathrm{C}_{2} \mathrm{H}_{4} / \mathrm{C}_{2} \mathrm{H}_{6}$ selectivity. The effect of various $\mathrm{Cu}_{3} \mathrm{BTC}_{2}$ concentrations inside the P84 matrix is investigated by means of mixed gas permeation experiments and static and dynamic sorption experiments. The obtained permeability, diffusion and solubility coefficients are discussed in light of the solution-diffusion model. Based on this, conclusions on $\mathrm{C}_{2} \mathrm{H}_{4}-\mathrm{Cu}_{3} \mathrm{BTC}_{2} \mathrm{MOF}$ interactions are drawn.

Chapter 7 summarizes and discusses all obtained findings. 


\section{Bibliography}

1. Ravanchi, M.T., T. Kaghazchi, and A. Kargari, Application of membrane separation processes in petrochemical industry: a review. Desalination, 2009. 235(1-3): p. 199244.

2. $232^{\text {nd }}$ ACS National Meeting, San Francisco, Sept. 10-14. Chemical and Engineering News 2006. 84(34): p. 59-236.

3. Eldridge, R.B., Olefin/paraffin separation technology: A review. Industrial and Engineering Chemistry Research, 1993. 32(10): p. 2208-2212.

4. Kumar, R., M. Prausnitz John, and J. King C, Process Design Considerations for Extractive Distillation: Separation of Propylene-Propane, in Extractive and Azeotropic Distillation1974, AMERICAN CHEMICAL SOCIETY. p. 16-34.

5. Safarik, D.J. and R.B. Eldridge, Olefin/Paraffin Separations by Reactive Absorption: A Review. Industrial \& Engineering Chemistry Research, 1998. 37(7): p. 2571-2581.

6. Munson, C.L., et al., Separation of olefins from paraffins using ionic liquid solutions, 2002, Chevron U.S.A. Inc., San Ramon, CA (US). p. 8.

7. Dewar, M.J.S., A review of the pi-complex theory. Bull. Soc. Chim., 1951. 18(C): p. 8.

8. Chatt, J. and L.A. Duncanson, Olefin co-ordination compounds. Part III. Infra-red spectra and structure: Attempted preparation of acetylene complexes. Journal of the Chemical Society (Resumed), 1953: p. 2939-2947.

9. Guo, G.-C., Synthesis and characterization of Ag2C2[middle dot]2AgClO4[middle dot]2H2O: a novel layer-type structure with the acetylide dianion functioning in a [small micro]6-[small eta]1,[small eta]1:[small eta]2,[small eta]2:[small eta]2,[small eta]2 bonding mode inside an octahedral silver cage. Chemical Communications, 1998(3): p. 339-340.

10. Aguado, S., et al., Absolute molecular sieve separation of ethylene/ethane mixtures with silver zeolite A. Journal of the American Chemical Society, 2012. 134(36): p. 14635-14637.

11. Bao, Z., et al., Adsorption of ethane, ethylene, propane, and propylene on a magnesium-based metal-organic framework. Langmuir, 2011. 27(22): p. 1355413562.

12. Bux, H., et al., Ethenelethane separation by the MOF membrane ZIF-8: Molecular correlation of permeation, adsorption, diffusion. Journal of Membrane Science, 2011. 369(1-2): p. 284-289.

13. Chmelik, C., et al., Ethenelethane mixture diffusion in the MOF sieve ZIF-8 studied by MAS PFG NMR diffusometry. Microporous and Mesoporous Materials, 2012. 147(1): p. 135-141.

14. Geier, S.J., et al., Selective adsorption of ethylene over ethane and propylene over propane in the metal-organic frameworks $M 2(d o b d c)(M=M g, M n, F e, C o, N i, Z n)$. Chemical Science, 2013. 4(5): p. 2054-2061.

15. Granato, M.A., et al., From molecules to processes: Molecular simulations applied to the design of simulated moving bed for ethane/ethylene separation. Canadian Journal of Chemical Engineering, 2013.

16. Granato, M.A., et al. Ethanelethylene separation by simulated moving bed: From molecular simulations to process design. 2012. Pittsburgh, PA.

17. Kim, J., et al., Large-scale computational screening of zeolites for ethanelethene separation. Langmuir, 2012. 28(32): p. 11914-11919.

18. Mofarahi, M. and S.M. Salehi, Pure and binary adsorption isotherms of ethylene and ethane on zeolite 5A. Adsorption, 2013. 19(1): p. 101-110. 
19. Rawat, D.S. and A.D. Migone, Ethylene films adsorbed onto purified HiPco single walled carbon nanotubes: A comparison with ethane and longer alkanes. Adsorption Science and Technology, 2011. 29(8): p. 723-731.

20. Faiz, R. and K. Li, Olefin/paraffin separation using membrane based facilitated transport/chemical absorption techniques. Chemical Engineering Science, 2012. 73(0): p. 261-284.

21. Shu, C.M., et al., Experimental and computational studies on propane-propylene separation by adsorption and variable-temperature stepwise desorption. Separations Technology, 1990. 1(1): p. 18-28.

22. Wijmans, J.G. and R.W. Baker, The solution-diffusion model: A review. Journal of Membrane Science, 1995. 107(1-2): p. 1-21.

23. Motelica, A., et al., Membrane retrofit option for paraffin/olefin separation-a technoeconomic evaluation. Industrial and Engineering Chemistry Research, 2012. 51(19): p. 6977-6986.

24. Kookos, I.K., Optimal design of membrane/distillation column hybrid processes. Industrial and Engineering Chemistry Research, 2003. 42(8): p. 1731-1738.

25. Caballero, J.A., et al., Design of hybrid distillation-vapor membrane separation systems. Industrial and Engineering Chemistry Research, 2009. 48(20): p. 9151-9162.

26. Fuertes, A.B. and I. Menendez, Separation of hydrocarbon gas mixtures using phenolic resin-based carbon membranes. Separation and Purification Technology, 2002. 28(1): p. 29-41.

27. Poling, B.E., J.M. Prausnitz, and J.P. O`Connell, The Properties of Gases and Liquids. Fifth ed2000, New York: McGraw-Hill.

28. Reid, R.C., J.M. Prausnitz, and B.E. Poling, The Properties of Gases and Liquids. Fourth ed1987, New York: McGraw-Hill.

29. NIST Chemistry WebBook. Available from: http://webbook.nist.gov/chemistry/.

30. Kim, J.H., et al., Membranes comprising silver salts physically dispersed in poly(dimethyl siloxane) for the separation of olefin/paraffin. Journal of Industrial and Engineering Chemistry, 2006. 12(4): p. 594-600.

31. Jiang, X. and A. Kumar, Performance of silicone-coated polymeric membrane in separation of hydrocarbons and nitrogen mixtures. Journal of Membrane Science, 2005. 254(1-2): p. 179-188.

32. Pham, J.Q., K.P. Johnston, and P.F. Green, Retrograde Vitrification in CO2/Polystyrene Thin Films. The Journal of Physical Chemistry B, 2004. 108(11): p. 3457-3461.

33. Hamouda, S.B., et al., Facilitated transport of ethylene in poly (amide 12-block tetramethylenoxide) copolymer/AgBF $<$ sub $>4</$ sub $>$ membranes containing silver (I) and copper (I) ions as carriers. Journal of Applied Sciences, 2008. 8(7): p. 13101314. 
Chapter 1.

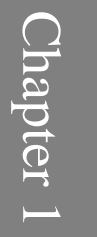




\section{Chapter 2}

\section{Economic evaluation of membrane potential for \\ $\mathrm{C}_{2} \mathrm{H}_{4} / \mathrm{C}_{2} \mathrm{H}_{6}$ separation in a retrofitted hybrid} membrane-distillation plant using $\mathrm{UniSim}^{\circledR}$ Design

This chapter has been published as:

J.Ploegmakers, A.R.T. Jelsma, A.G.J. van der Ham and K. Nijmeijer, Economic Evaluation of Membrane Potential for Ethylene/Ethane Separation in a Retrofitted Hybrid MembraneDistillation Plant Using Unisim Design, Ind. Eng. Chem. Res., 2013, 52(19), pp 6524-6539. 


\section{Abstract}

Since $\mathrm{C}_{2} \mathrm{H}_{4} / \mathrm{C}_{2} \mathrm{H}_{6}$ separation by cryogenic distillation is one of the most energy intensive processes, it can be economically interesting to combine it with energy efficient membrane technology. The effect on the viability of different process configurations in relation to the $\mathrm{C}_{2} \mathrm{H}_{4}$ permeance $\left(2.8 \cdot 10^{-6}-2.8 \cdot 10^{-5} \mathrm{~mol} /\left(\mathrm{m}^{2} \mathrm{~s} \mathrm{kPa}\right)\right)$ and $\mathrm{C}_{2} \mathrm{H}_{4} / \mathrm{C}_{2} \mathrm{H}_{6}$ selectivity (3-1000) of the membrane is investigated using Honeywells Unisim Design Suite R390. Results are compared to conventional distillation. In addition, the membrane feed pressure, permeate pressure and membrane surface area have been optimized to obtain the highest possible cost savings. It is concluded that the series configuration is the most beneficial with savings of $16 \%$ on the total annualized costs. Hybrid membrane-distillation technology is interesting for membranes having $\mathrm{C}_{2} \mathrm{H}_{4}$ permeances and selectivities beyond $2.8 \cdot 10^{-5} \mathrm{~mol} /\left(\mathrm{m}^{2} \mathrm{~s} \mathrm{kPa}\right)$ and 30 , respectively. Increasing the membrane feed pressure towards its critical pressure $\left(\mathrm{P}_{\mathrm{c}}=\right.$ $4850 \mathrm{kPa}$ ) is always beneficial and the optimal permeate pressure increases to 2,050 $\mathrm{kPa}$ with increasing $\mathrm{C}_{2} \mathrm{H}_{4}$ permeance. For material scientists it is advised to focus on increasing membrane selectivity once an $\mathrm{C}_{2} \mathrm{H}_{4}$ permeance of $1 \cdot 10^{-5} \mathrm{~mol} /\left(\mathrm{m}^{2} \mathrm{~s} \mathrm{kPa}\right)$ is obtained, since higher permeances beyond this point yield less additional cost savings compared to increments in selectivity. 


\subsection{Introduction}

Olefin/paraffin separation is one of the most energy intensive separation processes due to the close boiling points of the components and the need for cryogenic conditions for distillation.[1, 2] Since $\mathrm{C}_{2} \mathrm{H}_{4}$ is one of the most produced and used compounds in the chemical industry, significant energy reductions and savings are essential.[1,3] One possibility for energy reduction is the retrofitting of an existing distillation plant into a hybrid membrane-distillation plant.[4-13] Gas permeation through membranes has already been studied for over 70 years.[14] The separation mechanism depends on the differences in diffusivity and solubility between the two permeating species, which are very similar in the case of $\mathrm{C}_{2} \mathrm{H}_{4}$ and $\mathrm{C}_{2} \mathrm{H}_{6}$, resulting in relatively lower membrane performances compared to other gas pairs.[15, 16] Nevertheless, in the last decades, much effort was put into improving membrane performance by developing carbon membranes [17, 18], mixed matrix membranes [19-22] and facilitated transport membranes [23-28], which significantly increased the $\mathrm{C}_{2} \mathrm{H}_{4}$ permeability and $\mathrm{C}_{2} \mathrm{H}_{4} / \mathrm{C}_{2} \mathrm{H}_{6}$ selectivity. Pinnau et al. reported an $\mathrm{C}_{2} \mathrm{H}_{4}$ permeance of 2.7 . $10^{-6} \mathrm{~mol} /\left(\mathrm{m}^{2} \mathrm{~s} \mathrm{kPa}\right)$ and a mixed gas selectivity of 240 [25] through addition of $\mathrm{AgBF}_{4}$ to poly $\left(\mathrm{C}_{2} \mathrm{H}_{4}\right.$ oxide). This justifies an evaluation of the $\mathrm{C}_{2} \mathrm{H}_{4}$ permeabilities and $\mathrm{C}_{2} \mathrm{H}_{4} / \mathrm{C}_{2} \mathrm{H}_{6}$ selectivities required to reduce energy demands and reduce the total annualized costs (TAC) in a hybrid membrane-distillation unit.

Pressly and $\mathrm{Ng}$ investigated the effect of various possible hybrid membrane-distillation configurations and concluded that series or parallel configurations were preferred over top or bottom configurations for propylene/propane separations.[4] Moganti et al. found that for propylene/propane hybrid configurations, an optimum membrane feed flow to membrane surface area ratio exists, that is close to $0.1 \mathrm{~mol} /\left(\mathrm{m}^{2} \mathrm{~s}\right)$, due to a lower efficient membrane separation at higher membrane areas. By applying this ratio, they found that a reduction of $30 \%$ in tray number is possible.[5] Caballero reached a $20 \%$ reduction in annualized costs by simulating a hybrid membrane-distillation unit in the parallel configuration.[10] He obtained these results by feeding $80 \%$ of the vapor flow inside the column $(=320 \%$ of the column feed) to the membrane, which had a selectivity of 4.7. Pettersen and Lien reported that increasing the membrane feed pressure could give significant membrane area reductions up to 50\%.[8] They also mentioned a trade-off between lower permeate pressures, which reduces the required membrane area, and increased compression costs. In a later study, they investigated a parallel configuration for propylene/propane separation and found the optimum membrane stream composition to be near the column feed stream composition, so the 
membrane performs the separation at that composition where distillation is the least efficient.[12] Benali et al. also investigated the effect of different hybrid configurations for a membrane with fixed performance properties and concluded that the series configuration is the most suitable for the retrofit of an $\mathrm{C}_{2} \mathrm{H}_{4}$ plant with a total savings of 61\%.[29] $\mathrm{A}$ membrane cascade configuration was found to have significantly higher capital and operating costs, thereby reducing the total savings to $54 \%$ but yielding a $0.20 \%$ higher product purity of $99.99 \% \mathrm{C}_{2} \mathrm{H}_{4}$. Finally, Motelica et al. found that energy reductions for a series configuration are possible with membranes having selectivities of 60 or higher and $\mathrm{C}_{2} \mathrm{H}_{4}$ permeances of at least $1 \cdot 10^{-4} \mathrm{~mol} /\left(\mathrm{m}^{2} \mathrm{~s} \mathrm{kPa}\right)$.[13] However, the $\mathrm{C}_{2} \mathrm{H}_{6}$ permeance remained fixed in their optimization methodology, preventing the independent variation of the $\mathrm{C}_{2} \mathrm{H}_{4}$ permeance and the $\mathrm{C}_{2} \mathrm{H}_{4} / \mathrm{C}_{2} \mathrm{H}_{6}$ selectivity. Also, nothing was reported about optimizing process conditions like membrane feed pressure, permeate pressure or membrane surface area.

This paper will not only investigate the effect of retrofitting an existing distillation column with a membrane unit on the total obtainable annual cost savings, but also investigates the effect of process and membrane parameters on this hybrid configuration, since this is often excluded but can yield significant additional savings. The effect of different configurations (parallel and series) is investigated for membrane selectivities between 3 and 1000 and $\mathrm{C}_{2} \mathrm{H}_{4}$ permeances between $2.8 \cdot 10^{-6}$ and $2.8 \cdot 10^{-5} \mathrm{~mol} /\left(\mathrm{m}^{2} \mathrm{~s} \mathrm{kPa}\right)$. Subsequently, the most energy efficient configuration is further optimized in terms of membrane feed pressure, permeate pressure and membrane surface area. By optimizing all parameters mentioned above, a comprehensive overview of required membrane properties (i.e. $\mathrm{C}_{2} \mathrm{H}_{4}$ permeance and $\mathrm{C}_{2} \mathrm{H}_{4} / \mathrm{C}_{2} \mathrm{H}_{6}$ selectivity) is obtained, which guides future membrane research to reduce the energy requirements for $\mathrm{C}_{2} \mathrm{H}_{4} / \mathrm{C}_{2} \mathrm{H}_{6}$ separation. 


\subsection{Models and methods}

All modeling is performed with Honeywells Unisim Design Suite R390. First, a distillation column is designed and optimized. Second, the gas separation membrane unit for the hybrid membrane-distillation process is designed. Third, two different hybrid configurations are considered i.e. a parallel and a series configuration. Finally, the economical calculations are defined.

\subsubsection{Base case distillation unit for $\mathrm{C}_{2} \mathrm{H}_{4} / \mathrm{C}_{2} \mathrm{H}_{6}$ separation}

\subsubsection{Process conditions}

To mimic an existing cryogenic distillation process as much as possible, the conditions of the feed, distillate and bottom streams as specified for an industrial scale $\mathrm{C}_{2} \mathrm{H}_{4}$-separation plant are given in Table 2.1.[30] These parameters will be fixed during all simulations.

Table 2.1. Feed, distillate and bottom stream specifications.[30]

\begin{tabular}{lccccc}
\hline Stream & $\mathrm{T}\left({ }^{\circ} \mathrm{C}\right)$ & $\mathrm{P}(\mathrm{kPa})$ & $\mathrm{n}(\mathrm{kmol} / \mathrm{hr})$ & $\mathrm{x}_{\mathrm{F}}$ & Phase \\
\hline Feed & -18.00 & 2,000 & 2,500 & 0.8 & Vapor \\
Distillate & -31.07 & 1,900 & 1,996 & 0.9995 & Liquid \\
Bottom & -8.04 & 2,000 & 504 & 0.01 & Liquid \\
\hline
\end{tabular}

The feed enters the distillation column as a pressurized vapor. A high $\mathrm{C}_{2} \mathrm{H}_{4}$ purity of $99.95 \%$ is required in the distillate stream. To control the temperature and pressure of the various streams, different utilities can be applied with various costs. The prices of utilities for $\mathrm{C}_{2} \mathrm{H}_{4} / \mathrm{C}_{2} \mathrm{H}_{6}$ separation are taken from [31] and shown in Table 2.2.

Table 2.2 shows that cooling with the less expensive cooling water instead of the expensive refrigerant is preferred. Therefore, all streams that require cooling will first be cooled with cooling water till $30^{\circ} \mathrm{C}$, after which they will be further cooled with refrigerant if necessary. At these set process conditions, the distillation base case can be modeled, after which the total costs for the $\mathrm{C}_{2} \mathrm{H}_{4} / \mathrm{C}_{2} \mathrm{H}_{6}$ separation using distillation can be calculated and compared to the hybrid membrane-distillation unit. 
Table 2.2. Costs of utilities for $\mathrm{C}_{2} \mathrm{H}_{4} / \mathrm{C}_{2} \mathrm{H}_{6}$ separation.[31]

\begin{tabular}{cc} 
Utility & Cost $(\$ / \mathrm{GJ})$ \\
\hline Cooling water $\left(20{ }^{\circ} \mathrm{C}\right)$ & 0.354 \\
Refrigerant $\left(-50{ }^{\circ} \mathrm{C}\right)$ & 13.11 \\
Residual heat $\left(90^{\circ} \mathrm{C}\right)$ & 0.354 \\
Electrical power & 16.80 \\
\hline
\end{tabular}

\subsubsection{Distillation model}

For the design of the distillation column, a binary system consisting of $\mathrm{C}_{2} \mathrm{H}_{4}$ and $\mathrm{C}_{2} \mathrm{H}_{6}$ is assumed, which requires an Equation of State (EOS) to accurately describe vapor/liquid equilibria. The Peng-Robinson (PR) and Soave-Redlich-Kwong (SRK) EOS are widely used in the petrochemical industry because of their accuracy to describe small, non-polar hydrocarbons.[32, 33] SRK has been used in several studies regarding $\mathrm{C}_{2} \mathrm{H}_{4}$ and $\mathrm{C}_{2} \mathrm{H}_{6}[10$, $29,34]$ and is therefore chosen as EOS in this study as well.

By varying the number of stages, the minimum number of theoretical stages $\mathrm{N}_{\min }$ and the minimum reflux ratio $R_{\min }$ were found to be 32 and 3.1 respectively. The optimal $\mathrm{N}$ was calculated to be $1.2 \cdot \mathrm{R}_{\min }$, which resulted in $\mathrm{N}=75$ and $\mathrm{R}=3.7$. The optimal inlet stream for the feed $\left(\# N_{F}\right)$ was obtained at stage 54 by trial-and-error. The pressure drop inside the distillation column was assumed to be 1 bar. Figure 2.1 shows the final process scheme for the base case distillation of $\mathrm{C}_{2} \mathrm{H}_{4}$ and $\mathrm{C}_{2} \mathrm{H}_{6}$. 


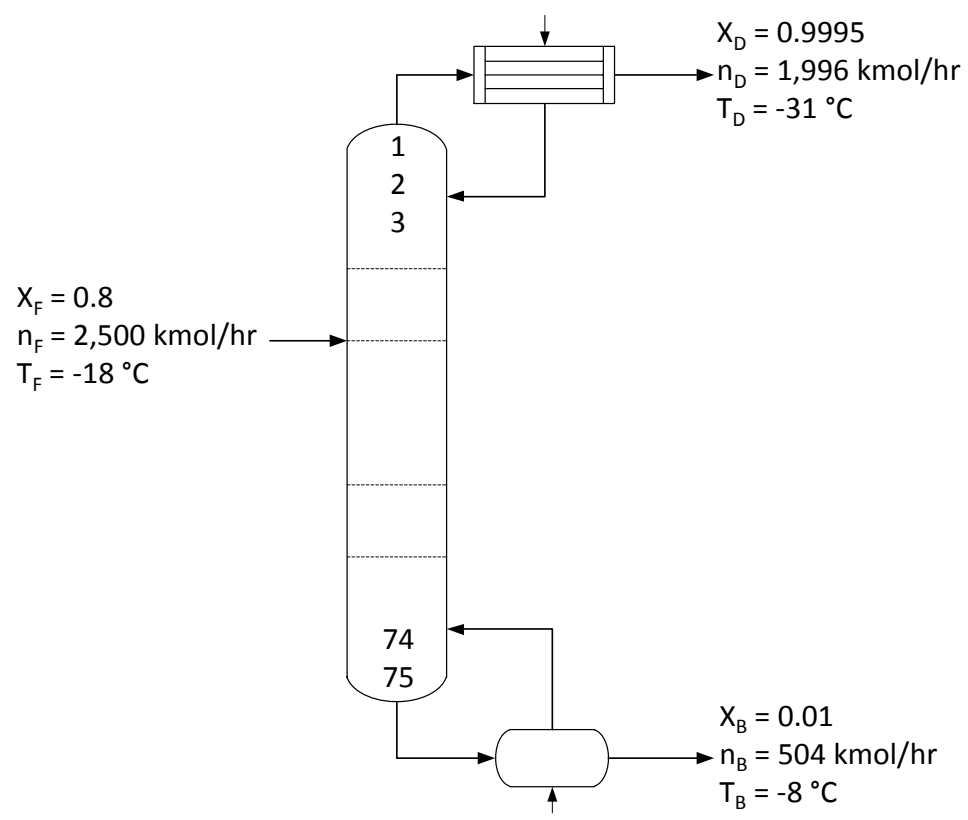

Figure 2.1. Process scheme of base case distillation unit for $\mathrm{C}_{2} \mathrm{H}_{4} / \mathrm{C}_{2} \mathrm{H}_{6}$ separation.

\subsubsection{Membrane unit model design}

The mathematical description of the membrane unit model used for this study has been given by Davis.[35] It is used throughout this study because of its applicability to hollow fiber modules, which are often used in membrane gas separation processes. The membrane model consists of an ideal counter current plug flow pattern, which is schematically shown in Figure 2.2 .

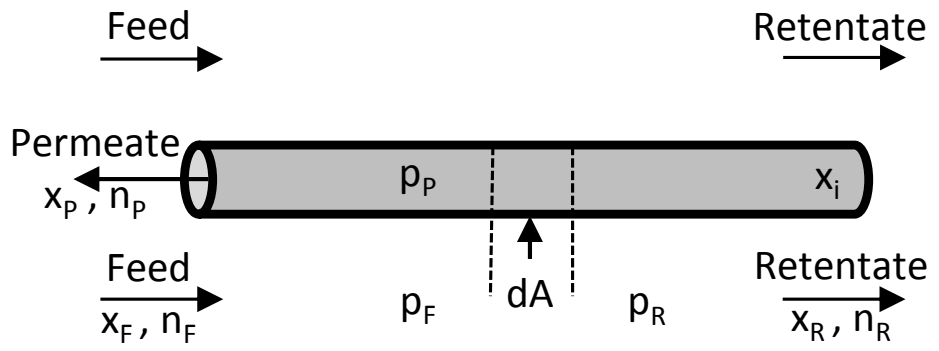

Figure 2.2. Ideal dead end membrane counter current plug flow [35].

where $x_{F}, x_{P}, x_{R}, n_{F}, n_{P}, n_{R}, p_{F}, p_{P}$ and $p_{R}$ are the $\mathrm{C}_{2} H_{4}$ mol fraction (x), molar flow (n) and partial pressure $(\mathrm{p})$ on the feed side $\left({ }_{\mathrm{F}}\right)$, permeate side $\left({ }_{\mathrm{P}}\right)$ and retentate side $\left({ }_{\mathrm{R}}\right)$, respectively. 
Logically, all $\mathrm{C}_{2} \mathrm{H}_{4}$ and $\mathrm{C}_{2} \mathrm{H}_{6}$ fractions sum up to 1 . $\mathrm{dA}$ is the differential membrane surface area and $\mathrm{x}_{\mathrm{i}}$ is the permeate compositions at the dead end of the inside of the membrane fiber.

This membrane model is based on the following assumptions:

- Steady state process

- Ideal heat exchange

- Constant temperature in the membrane unit

- Counter current operation

- Plug flow along the feed and permeate side of the membrane

- Negligible pressure drop along the membrane $\left(p_{R}=p_{F}\right)$

The selectivity of the membrane $(\alpha)$ is given by Equation 2.1 and is equal to the ratio of the permeances of the two permeating species:

$\alpha=\frac{Q_{f}}{Q_{s}}$

Equation 2.1

where $\mathrm{Q}_{\mathrm{f}}$ and $\mathrm{Q}_{\mathrm{s}}$ are the permeances of the fast and slow permeating species respectively. $\mathrm{x}_{\mathrm{i}}$ is calculated from the ratio of the permeation rates for each species in the binary mixture and shown in Equation 2.2:

$\frac{x_{i}}{1-x_{i}}=\frac{Q_{f}\left(x_{R} p_{F}-x_{i} p_{P}\right)}{Q_{S}\left[\left(1-x_{R}\right) p_{F}-\left(1-x_{i}\right) p_{P}\right]}$

Equation 2.2

The stage cut $(\theta)$, defined as the ratio of permeate flow over the feed flow of a specific compound (i.e. $\mathrm{C}_{2} \mathrm{H}_{4}$ ), is given by Equation 2.3: 


$$
\begin{aligned}
\theta=\frac{x_{P} n_{P}}{x_{F} n_{F}}= & \frac{Q\left(\frac{\left(x_{F} p_{F}-x_{P} p_{P}\right)-\left(x_{R} p_{F}-x_{i} p_{P}\right)}{\ln \left(\frac{x_{F} p_{F}-x_{P} p_{P}}{x_{R} p_{F}-x_{i} p_{P}}\right)}\right) A_{m}}{x_{F} n_{F}} \\
= & \frac{Q \cdot \Delta P_{l m} \cdot A_{m}}{x_{F} n_{F}}
\end{aligned}
$$

where $\mathrm{A}_{\mathrm{m}}$ is the membrane surface area and $\Delta \mathrm{P}_{\mathrm{lm}}$ the logarithmic mean driving force over the membrane. The Chen approximation (Equation 2.4) can be used to avoid divergent solutions due to the logarithmic term. It introduces an additional error of only $2 \%$ and will therefore be used in this study.[36]

$\frac{x_{1}-x_{2}}{\ln \left(\frac{x_{1}}{x_{2}}\right)} \cong\left[x_{1} x_{2}\left(\frac{x_{1}+x_{2}}{2}\right)\right]^{3}$

Equation 2.4

Once the feed composition is given and $\theta$ is initialized, the retentate and permeate compositions and flows $\left(\mathrm{x}_{\mathrm{R}}, \mathrm{x}_{\mathrm{P}}, \mathrm{n}_{\mathrm{R}}\right.$ and $\left.\mathrm{n}_{\mathrm{P}}\right)$ are calculated according to the Fletcher-Reeves algorithm [37], which minimizes $\mathrm{f}_{\min }$ by iterating $\theta$, according to Equation 2.5:

$f_{\text {min }}=\sum\left[\theta x_{F} n_{F}-Q\left(\frac{\left(x_{F} p_{F}-x_{P} p_{P}\right)-\left(x_{R} p_{F}-x_{i} p_{P}\right)}{\ln \left(\frac{x_{F} p_{F}-x_{P} p_{P}}{x_{R} p_{F}-x_{i} p_{P}}\right)}\right) A_{m}\right]^{2}$

Equation 2.5

To achieve accurate convergences, a tolerance of $10^{-8}$ and a step-size of $10^{-4}$ is chosen for the convergence of $\theta$. Also, the membrane model equations are independent of the feed stream temperatures. However, a temperature change does occur because of the reduced pressure at the permeate side. Since ideal heat exchange is assumed, the permeate temperature is equal to the retentate temperature. The latter and higher one, is adjusted with a tolerance of $1{ }^{\circ} \mathrm{C}$ and a 
$0.1{ }^{\circ} \mathrm{C}$ step-size to fulfill this assumption during the simulations. The total membrane area for all simulations is initially set at $15,000 \mathrm{~m}^{2}$.

\subsubsection{Parallel configuration}

The membrane unit model can be combined with the distillation base case as shown in Figure 2.1, to obtain a hybrid membrane-distillation process. We consider two possible configurations, i.e. the parallel configuration, which is shown in Figure 2.3 and the series configuration, which will be discussed in the following section.

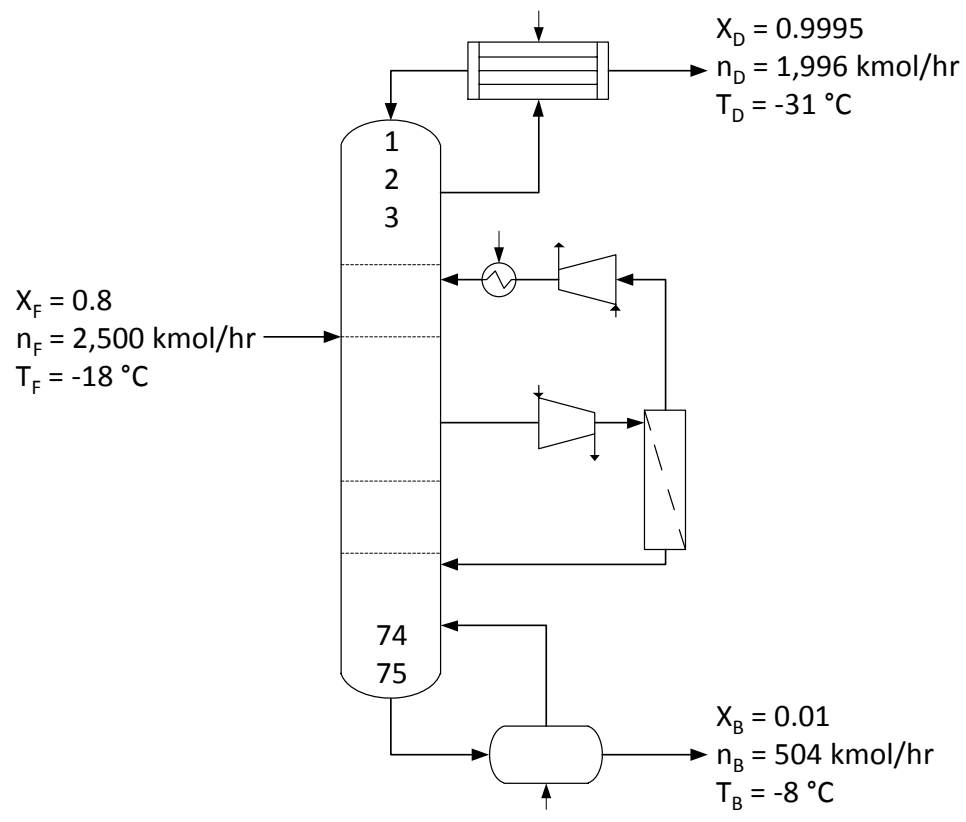

Figure 2.3. Process scheme of a parallel configured hybrid membrane-distillation unit.

Figure 2.3 shows that the membrane unit is positioned after the distillation column. A stream is withdrawn from the distillation column and fed to the membrane unit. The advantage of this parallel configuration is that the feed composition to the membrane unit can be varied and optimized accordingly, by changing the side draw stage $\left(\# N_{S}\right)$. It has been frequently reported that the membrane performance in terms of permeability and selectivity is dependent on the feed composition.[38-41] Membrane selectivity increases when the membrane feed stream has a low molar fraction of the fast permeating component. This makes it more beneficial to have the membrane feed drawn from the bottom of the column. It must be noted that this effect depends on unknown membrane parameters (e.g. polymer type) and therefore 
cannot be accurately implemented in our model. Therefore, the selectivity is assumed to be independent on feed composition. On the other hand, by selecting the membrane feed from a bottom stage with a low molar fraction of a fast permeating component, the total molar flow rate of the fast permeating component also decreases, since the maximum volumetric side draw from the distillation column is limited. Consequently, the molar flow of the fast permeating component in the permeate stream is reduced, which lowers the possible energy and total cost savings. Consequently, there exists a tradeoff between the amount of fast moving component and the purity, which results in an optimum stage for the side draw to the membrane unit. However, it is already reported frequently that the optimum stage of the side draw is close to the composition of the feed, since this is the position where the distillation column has the lowest efficiency.[5, 10-12]

Besides the membrane unit, also two compressors and a heat exchanger need to be installed. The compressors require electrical energy to operate while the heat exchanger cools the permeate stream to $30{ }^{\circ} \mathrm{C}$ with cooling water. The compressor prior to the membrane unit allows for compression of the membrane feed stream such that the driving forces over the membrane can be optimized. Compression adds additional heat to the membrane feed stream, which increases its temperature. Although excessive heat has to be removed before streams can re-enter the distillation column, operating membranes at temperatures above $-20{ }^{\circ} \mathrm{C}$ is favorable in terms of permeability.[42] The compressor at the permeate side of the membrane is required to compress the permeate stream back to the column pressure of 2,000 $\mathrm{kPa}$. Similar to the compression of the membrane feed stream, compression of the permeate stream supplies additional heat and therefore also the permeate needs to be cooled to $-20^{\circ} \mathrm{C}$ before it can re-enter the distillation column.

A heat exchanger is implemented to remove this excess heat. The heat exchanger is assumed to have a pressure drop of $50 \mathrm{kPa}$.[29] Since no pressure drop along the membrane is assumed, an additional compressor and heat exchanger are not required for the retentate stream. This assumption does imply that compression of the membrane feed stream also increases the retentate pressure. This requires the need for installation of a valve (not shown in Figure 2.3) that reduces the pressure to $2,000 \mathrm{kPa}$. This expansion of the retentate stream is accompanied by a decrease in temperature. Simulations will reveal the need for a heat exchanger in the expanded retentate stream to adjust the temperature before re-entering the distillation column. 
A possible disadvantage of this system is that the maximum available flow that can be fed to the membrane unit is limited by the hydrodynamic constraints of the distillation column as also encountered in other studies.[10, 11, 34] Also, the amount of side draw that is fed to the membrane unit varies in these studies between $10 \%-80 \%$ of the vapor flow in the distillation column. Therefore, in the present study, the maximum molar flow rate fed to the membrane unit for this configuration will be set at $1,500 \mathrm{kmol} / \mathrm{hr}$, that corresponds to $20 \%$ of the vapor flow rate inside the rectifying section of the column (assuming $\mathrm{R} \geq 3$ ), which is assumed to be a realistic value to achieve.[10,13]

\subsubsection{Series-configuration}

An alternative configuration for the hybrid-membrane distillation process is shown in Figure 2.4. Here, the membrane unit is placed in series, before the distillation column. This means that contrary to the parallel configuration, the feed composition to the membrane unit is fixed at $\mathrm{x}_{\mathrm{F}}=0.8$. On the other hand, the maximum flow that can be fed to the membrane unit is not limited by hydrodynamics of the column. Two compressors are added, one in the feed and one in the permeate stream of the membrane unit to optimize the driving force over the membrane and re-pressurize the permeate stream back to 2,000 $\mathrm{kPa}$. Also, similar to the parallel configuration, a heat exchanger is added after the compressor in the permeate stream to withdraw excess heat added by the compression and a valve is installed (not shown in Figure 2.4) in the retentate stream to reduce the pressure to $2,000 \mathrm{kPa}$. 


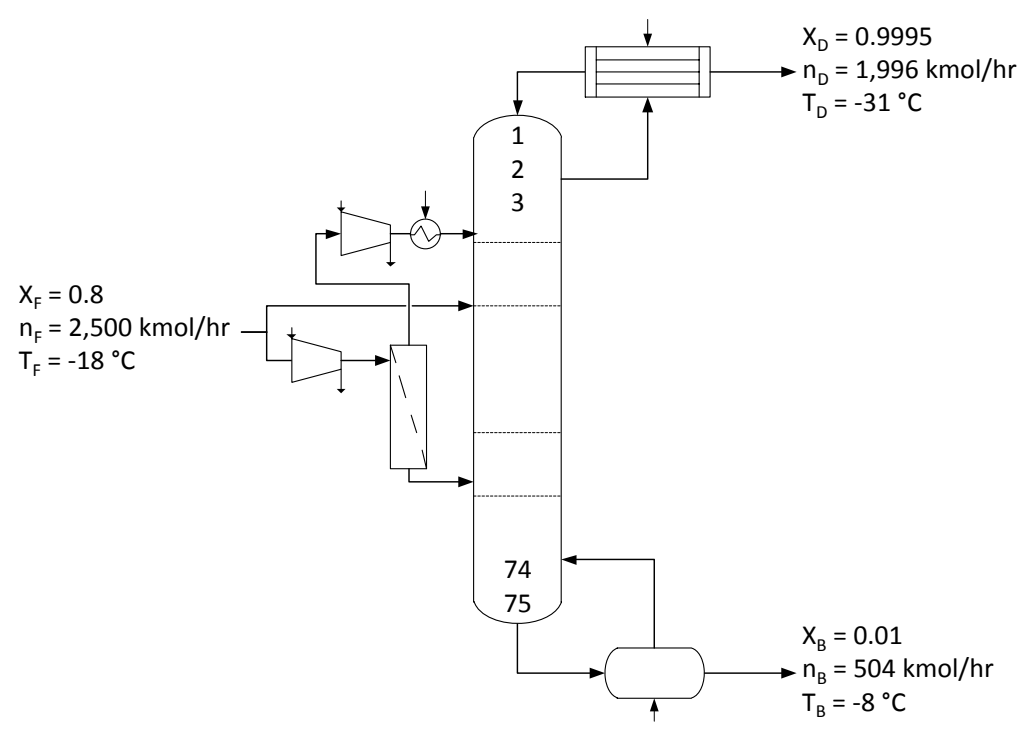

Figure 2.4. Process scheme of a series configured hybrid membrane-distillation unit.

In order the make a fair comparison between the performance of the parallel and the series configuration, two different membrane feed flows are considered for the series configuration. The first series of simulations splits the feed stream into two streams. One stream of 1,500 $\mathrm{kmol} / \mathrm{hr}$ is fed to the membrane unit, while the remaining $1,000 \mathrm{kmol} / \mathrm{hr}$ is fed to the distillation unit directly. Although this allows for a fair comparison of performance in terms of feed flow, it can already be expected that the parallel configuration is more beneficial, since that configuration has the benefit of selecting the most efficient membrane feed composition, which e.g. can prevent the production of a product purity beyond product specifications of $99.95 \%$. Therefore, the second series of simulations directs the total feed of 2,500 $\mathrm{kmol} / \mathrm{hr}$ to the membrane unit. By lifting this arbitrary maximum feed flow boundary of $1,500 \mathrm{kmol} / \mathrm{hr}$, a realistic estimate on the hybrid membrane-distillation performance can be made.

\subsubsection{Simulations}

When the simulations of the base case distillation column have been performed, the properties of the membrane unit in all hybrid membrane-distillation configurations can be systematically varied. To limit the number of variables and focus on the effect of the membrane unit in different configurations, a number of parameters is initially fixed in the base case, parallel and series configurations and these are shown in Table 2.3. By doing so, 
the performance of the membrane unit and the overall process depend on two membrane properties, i.e. the $\mathrm{C}_{2} \mathrm{H}_{4} / \mathrm{C}_{2} \mathrm{H}_{6}$ selectivity and the $\mathrm{C}_{2} \mathrm{H}_{4}$ permeance. The $\mathrm{C}_{2} \mathrm{H}_{4} / \mathrm{C}_{2} \mathrm{H}_{6}$ selectivity is varied from $3,10,30,100,300$ to 1000 while 6 different $\mathrm{C}_{2} \mathrm{H}_{4}$ permeances are used ranging from $2.8 \cdot 10^{-6}$ to $1.7 \cdot 10^{-5} \mathrm{~mol} /\left(\mathrm{m}^{2} \mathrm{~s} \mathrm{kPa}\right)$. In a later stage, when membrane feed and permeate pressures and membrane surface areas are varied and optimized, simulations with higher $\mathrm{C}_{2} \mathrm{H}_{4}$ permeances become relevant and economically interesting.

Table 2.3. Fixed parameters for distillation base case and hybrid membrane-distillation set-up in parallel, 1,500 and 2,500 series configuration.

\begin{tabular}{lcccccc}
\hline Configuration & $\begin{array}{c}\mathrm{n}_{\mathrm{F}} \\
(\mathrm{kmol} / \mathrm{hr})\end{array}$ & $\begin{array}{c}\mathrm{P}_{\text {membrane feed }} \\
(\mathrm{kPa})\end{array}$ & $\begin{array}{c}\mathrm{P}_{\text {retentate }} \\
(\mathrm{kPa})\end{array}$ & $\begin{array}{c}\mathrm{P}_{\text {permeate }} \\
(\mathrm{kPa})\end{array}$ & $\begin{array}{c}\mathrm{n}_{\mathrm{F}} \text { to membrane } \\
(\mathrm{kmol} / \mathrm{hr})\end{array}$ & $\mathrm{A}_{\mathrm{m}}\left(\mathrm{m}^{2}\right)$ \\
\hline Base case & 2,500 & $\mathrm{~N} / \mathrm{A}$ & $\mathrm{N} / \mathrm{A}$ & $\mathrm{N} / \mathrm{A}$ & $\mathrm{N} / \mathrm{A}$ & $\mathrm{N} / \mathrm{A}$ \\
Parallel & 2,500 & 2,000 & 2,000 & 400 & 1,500 & 15,000 \\
1,500 series & 2,500 & 2,000 & 2,000 & 400 & 1,500 & 15,000 \\
2,500 series & 2,500 & 2,000 & 2,000 & 400 & 2,500 & 15,000 \\
\hline
\end{tabular}

\subsubsection{Economic calculations and optimization procedure}

To assess the necessary membrane permeances and selectivities, an economical evaluation is performed as well. The total annualized costs (TAC) of the hybrid membrane-distillation process are compared to the TAC of the base case distillation. The total savings per year $(\% / y)$ that can be obtained by retrofitting an existing distillation plant into a hybrid membrane-distillation plant are calculated by Equation 2.6:

Total savings $=\frac{T A C_{D i s}-T A C_{H y b}}{T A C_{D i s}} 100 \%$

Equation 2.6

where $\mathrm{TAC}_{\mathrm{Dis}}$ and $\mathrm{TAC}_{\mathrm{Hyb}}$ are the total annualized costs of the base case distillation plant and the hybrid membrane-distillation plant respectively. The TAC are the summation of the operating expenditures (OPEX) (\$/y), and the annualized capital expenditures $\left(\mathrm{CAPEX} \mathrm{annu}_{\mathrm{a}}\right)$ (\$/y) as defined by Equation 2.7: 
$T A C=C A P E X_{a n n u}+O P E X$

Equation 2.7

Since this evaluation focusses on the retrofit of an existing installation, the CAPEX annu for $\mathrm{TAC}_{\text {Dis }}$ is set at $0 \$ / \mathrm{y}$. The $\mathrm{CAPEX}_{\mathrm{annu}}$ for the $\mathrm{TAC}_{\mathrm{Hyb}}$ is calculated using Equation 2.8:

$C A P E X_{a n n u}=\frac{4.0 \sum(P C E)}{10}+\frac{100 A_{m}}{5}$

Equation 2.8

where $A_{m}$ is the membrane surface area $\left(\mathrm{m}^{2}\right)$ and PCE $(\$)$ the purchase cost of each major equipment item, which is calculated according to the factorial method of cost estimation as described by Coulson and Richardson`s Chemical Engineering.[43]

$\log (P C E)=K_{1}+K_{2} \log (S)+K_{3}[\log (S)]^{2}$

Equation 2.9

where $S$ is the capacity or size parameter of the equipment and $K_{1}, K_{2}$ and $K_{3}$ are values taken from Turton et al. [31] as summarized in Table 2.4. Each equipment item has an assumed life expectancy of 10 years while the membrane unit has a life expectancy of 5 years. Each PCE is multiplied by 4.0 to account for cost factors for the retrofit investment such as equipment erection, piping, instrumentation, electrical, buildings and process, design and engineering, contractor`s fee and contingencies.[43] The membrane costs of $\$ 100 / \mathrm{m}^{2}$ includes the complete installation of a membrane unit. The costs are based on the average price level in 2010.[44] 
Table 2.4. Calculation parameters for small and large compressors and heat exchangers.[31]

\begin{tabular}{ccccccc}
\hline Equipment & $\mathrm{K}_{1}$ & $\mathrm{~K}_{2}$ & $\mathrm{~K}_{3}$ & unit & Min. & Max. \\
\hline Compressor (small) & 5.0355 & -1.8002 & 0.8253 & $\mathrm{~kW}$ & 18 & 950 \\
Compressor (large & 2.2897 & 1.3604 & -0.1027 & $\mathrm{~kW}$ & 450 & 3000 \\
Heat exchanger & 4.327 & -0.3030 & 0.1634 & $\mathrm{~m}^{2}$ & 10 & 1000 \\
\hline
\end{tabular}

The OPEX are based on the duties for various utilities and their corresponding prices as given in Table 2.2, and are defined by Equation 2.10 assuming a total operating time of 8000 hours annually [43]:

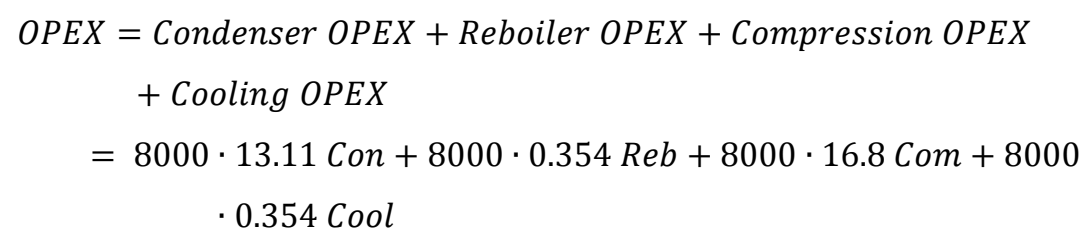

Equation 2.10

where Con, Reb, Com and Cool are the condenser, reboiler, compressor and cooling duties per hour $(\mathrm{GJ} / \mathrm{hr})$, respectively. The ratio of the CAPEX to the additional profit gained by the retrofitted hybrid membrane-distillation process gives the return on investment in years (ROI) [43]:

$R O I=\frac{C A P E X}{\Delta T A C}=\frac{4 \sum(P C E)+100 A_{m}}{T A C_{D i s}-T A C_{H y b}}$

Equation 2.11

To compare the different configurations and limit the number of simulations, the optimization procedure is such that the total savings (Equation 6) are maximized by varying only the $\mathrm{C}_{2} \mathrm{H}_{4} / \mathrm{C}_{2} \mathrm{H}_{6}$ selectivity $(\alpha)$, the $\mathrm{C}_{2} \mathrm{H}_{4}$ permeance $\left(\mathrm{Q}_{\mathrm{f}}\right)$ of the membrane unit and the stage numbers of the feed, side draw, retentate and permeate $\left(\# N_{F, S, R, P}\right)$ : 


$$
\begin{gathered}
\text { Max }(\text { Total Savings }) \\
\text { (Total Savings, CAPEX, OPEX, } \left.x_{p}\right)=f\left(Q_{f}, \alpha, \# N_{F, S, R, P}\right) \\
2.8 \cdot 10^{-6} \leq \mathrm{Q}_{\mathrm{f}} \leq 1.7 \cdot 10^{-5} \mathrm{~mol} /\left(\mathrm{m}^{2} \mathrm{~s} \mathrm{kPa}\right) \\
3 \leq \alpha \leq 1000 \\
0 \leq \# \mathrm{~N}_{\mathrm{F}, \mathrm{S}, \mathrm{R}, \mathrm{P}} \leq 75
\end{gathered}
$$

Equation 2.12 is used to determine to optimal configuration as discussed in section 2.3.2 and 2.3.3. Once this configuration is found, it will be further optimized by Equation 2.13:

$$
\begin{gathered}
\text { Max }(\text { Total Savings }) \\
\text { (Total Savings, CAPEX, OPEX, } \left.x_{p}, R O I\right)=f\left(Q_{f}, \alpha, \# N_{F, S, R, P}, A_{m}, p_{P}\right) \\
2.8 \cdot 10^{-6} \leq \mathrm{Q}_{\mathrm{f}} \leq 2.8 \cdot 10^{-5} \mathrm{~mol} /\left(\mathrm{m}^{2} \mathrm{~s} \mathrm{kPa}\right) \\
30 \leq \alpha \leq 300 \\
0 \leq \# \mathrm{~N}_{\mathrm{F}, \mathrm{S}, \mathrm{R}, \mathrm{P}} \leq 75 \\
1.0 \cdot 10^{3} \leq \mathrm{A}_{\mathrm{m}} \leq 1.0 \cdot 10^{5} \mathrm{~m}^{2} \\
100 \leq \mathrm{p}_{\mathrm{P}} \leq 2,050 \mathrm{kPa}
\end{gathered}
$$

This optimization procedure is discussed in section 2.3.4 and 2.3.5. The complete optimization procedure can be displayed in a flowchart as shown in Scheme 2.1: 
$\S 2.3 .2-2.3 .3 \quad \S 2.3 .4-2.3 .5$

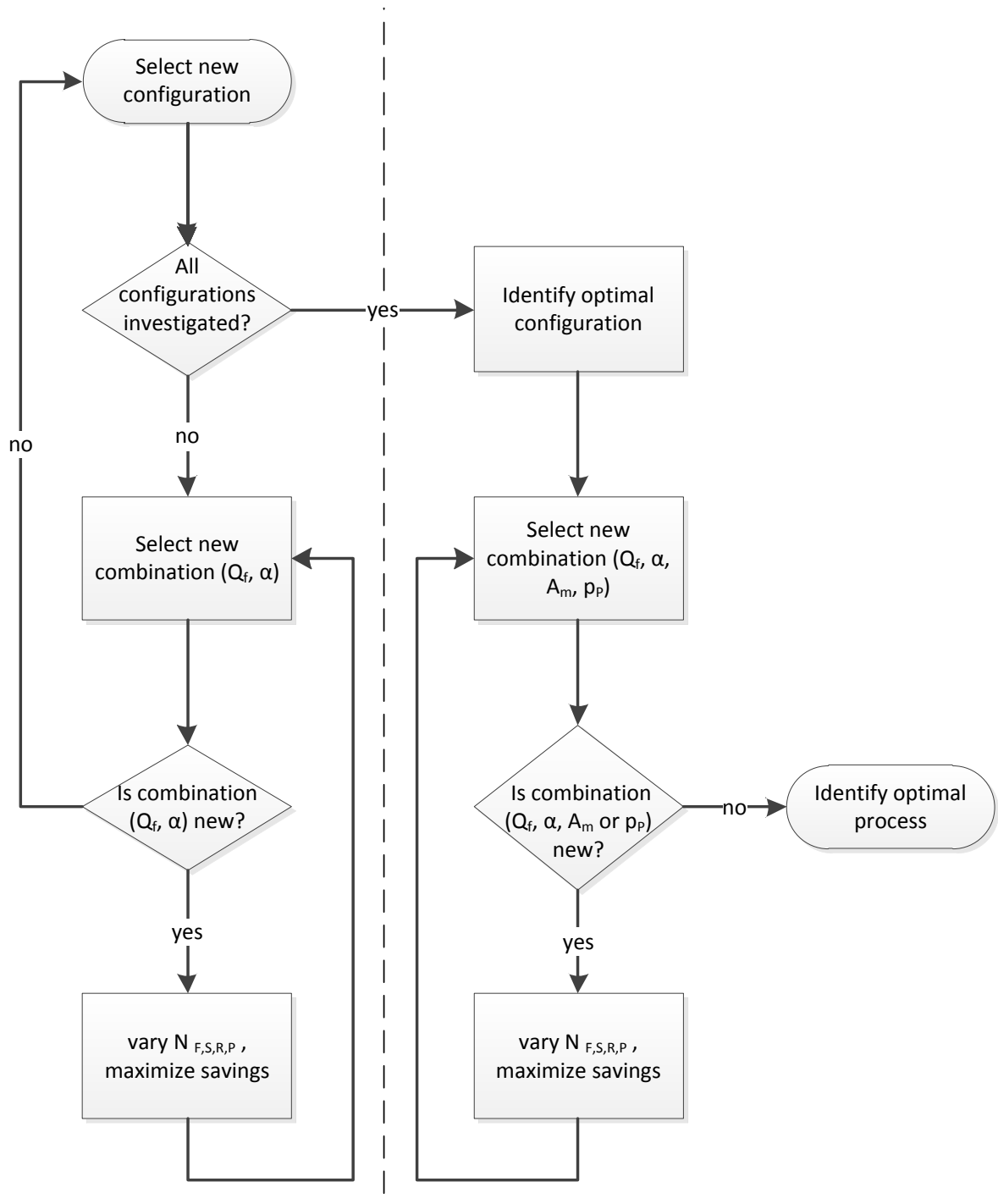

Scheme 2.1. Optimization flow chart to identify optimum configuration, membrane properties and process conditions. 


\subsection{Results \& Discussion}

\subsubsection{Base case distillation unit}

The UniSim model for the distillation base case used is shown in Figure 2.5. The number of stages, temperature, pressure, molar flow and molar $\mathrm{C}_{2} \mathrm{H}_{4}$ composition of the feed was fixed, while for the product streams the molar $\mathrm{C}_{2} \mathrm{H}_{4}$ composition was fixed. The stage number of the feed entry was optimized by trial and error such that the reflux ratio could be calculated and the condenser and reboiler duties could be minimized. Table 2.5 shows these optimized condenser and reboiler duties, together with their corresponding annual operating costs based on Table 2.2 for a total operating time of $8000 \mathrm{hrs}$.

Table 2.5. Duties and annual costs for the condenser and reboiler for the distillation base case.

\begin{tabular}{ccc}
\hline & Duty $(\mathrm{GJ} / \mathrm{hr})$ & Costs $(\mathrm{M} \$ / \mathrm{y})$ \\
\hline Condenser & 88 & 9.2 \\
Reboiler & 63 & 0.2 \\
Total & 151 & 9.4 \\
\hline
\end{tabular}

Although the duties of both the condenser and the reboiler are in the same order of magnitude, there is a large discrepancy between the two in terms of annual operating costs. The condenser makes up for $98 \%$ of the total operating costs due to the requirement of expensive refrigerant, while the reboiler can be operated using inexpensive residual heat. It can be expected that the installation of a membrane unit will have the most beneficial effect when the condenser duty can be lowered. 


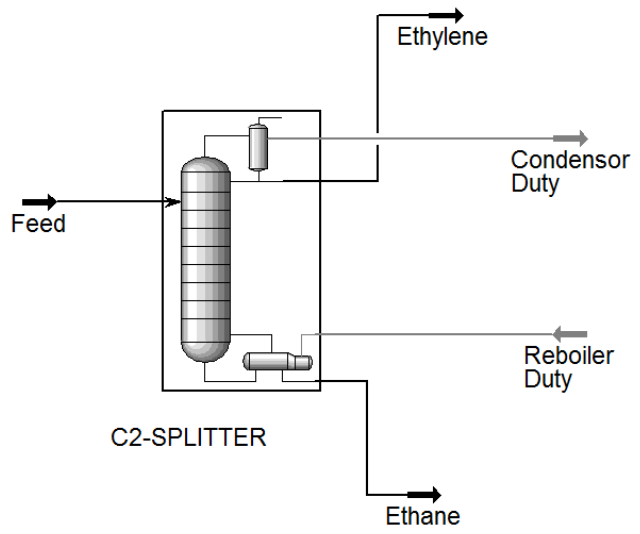

\begin{tabular}{|c|c|c|c|c|c|}
\hline \multicolumn{3}{|c|}{ Feed } & \multicolumn{3}{|c|}{ Condensor Duty } \\
\hline Temperature & -18.00 & C & \begin{tabular}{l|l} 
Heat Flow \\
\end{tabular} & $8.794 \mathrm{e}+007$ & $\mathrm{~kJ} / \mathrm{h}$ \\
\hline Pressure & 2000 & $\mathrm{kPa}$ & \multicolumn{3}{|c|}{ Reboiler Duty } \\
\hline Molar Flow & 2500 & kgmole/h & \begin{tabular}{l|l} 
Heat Flow & \\
\end{tabular} & $6.342 e+007$ & $\mathrm{~kJ} / \mathrm{h}$ \\
\hline Comp Mole Frac (Ethylene) & 0.8000 & & \multicolumn{3}{|c|}{ C2-SPLITTER } \\
\hline \multicolumn{3}{|c|}{ Ethylene } & Reflux Ratio & \begin{tabular}{l|l} 
& 3.733
\end{tabular} & \\
\hline Temperature & -31.07 & C & Number of Trays & 75.00 & \\
\hline Pressure & 1900 & $\mathrm{kPa}$ & & & \\
\hline Molar Flow & 1996 & kgmole/h & & & \\
\hline Comp Mole Frac (Ethylene) & 0.9995 & & & & \\
\hline \multicolumn{3}{|c|}{ Ethane } & & & \\
\hline Temperature & -8.040 & C & & & \\
\hline Pressure & 2000 & $\mathrm{kPa}$ & & & \\
\hline Molar Flow & 504.0 & kgmole/h & & & \\
\hline Comp Mole Frac (Ethylene) & 0.0100 & & & & \\
\hline
\end{tabular}

Figure 2.5. Optimized results of the distillation base case. Stage number of feed is 54 . Trays are set at $100 \%$ efficiency.

\subsubsection{Parallel hybrid configuration}

The implementation of a membrane unit in a parallel configuration, as shown in Figure 2.3, has significant effects on the condenser, reboiler, compressor and cooling duties. Figure 2.6 shows a typical configuration in UniSim of the $1,500 \mathrm{kmol} / \mathrm{hr}$ parallel configuration with a membrane permeance of $0.83 \cdot 10^{-5} \mathrm{~mol} /\left(\mathrm{m}^{2} \mathrm{kPa}\right)$ and a selectivity of $100.1,500 \mathrm{kmol} / \mathrm{hr}$ was fed to the membrane unit taken from stage 53, according to the optimization procedure shown in Equation 12. The $\mathrm{C}_{2} \mathrm{H}_{4}$ permeance and $\mathrm{C}_{2} \mathrm{H}_{4} / \mathrm{C}_{2} \mathrm{H}_{6}$ selectivity were systematically varied to see the effect of the retrofit on the condenser, reboiler, compression and cooling OPEX, calculated using Equation 2.10 and shown in Figure 2.7a-d respectively. Figure 2.7e and 2.7f show the effect on the annualized CAPEX, calculated using Equation 2.8, and total savings, calculated using Equation 2.6, as function of the $\mathrm{C}_{2} \mathrm{H}_{4}$ permeance for various $\mathrm{C}_{2} \mathrm{H}_{4} / \mathrm{C}_{2} \mathrm{H}_{6}$ selectivities, respectively. 


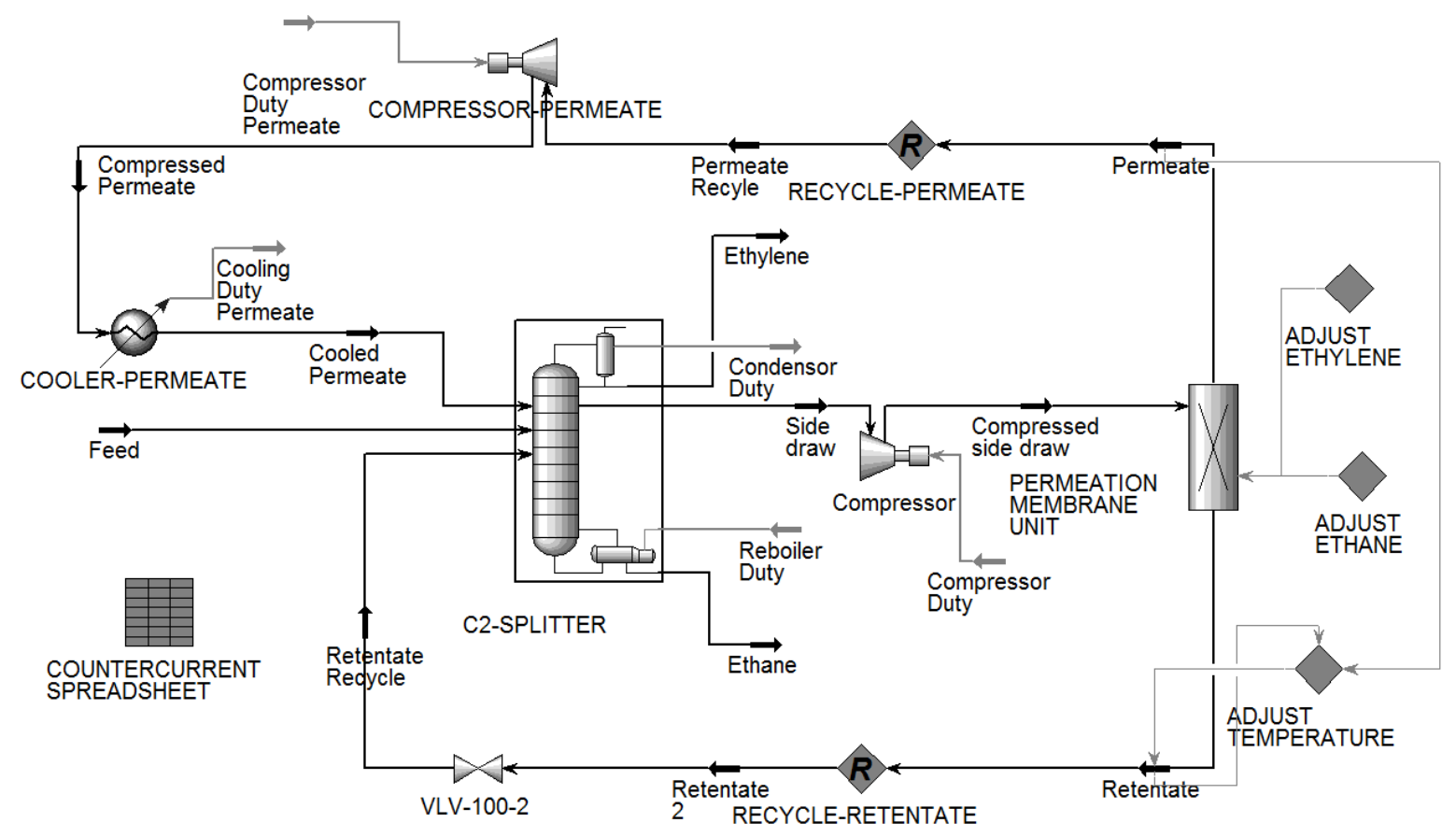

\begin{tabular}{|c|c|c|c|c|c|c|}
\hline \multicolumn{3}{|c|}{ Feed } & \multicolumn{4}{|c|}{ Condensor Duty } \\
\hline Temperature & -18.00 & C & Heat Flow & \multicolumn{2}{|c|}{$7.798 \mathrm{e}+007$} & $\mathrm{~kJ} / \mathrm{h}$ \\
\hline Pressure & 2000 & $\mathrm{kPa}$ & \multicolumn{4}{|c|}{ Reboiler Duty } \\
\hline Molar Flow & 2500 & $\mathrm{kgmole} / \mathrm{h}$ & Heat Flow & \multicolumn{2}{|c|}{$5.266 \mathrm{e}+007$} & $\mathrm{~kJ} / \mathrm{h}$ \\
\hline Comp Mole Frac (Ethylene) & 0.8000 & & \multicolumn{4}{|c|}{ Compressor Duty Permeate } \\
\hline \multicolumn{3}{|c|}{ Ethylene } & Heat Flow & \multicolumn{2}{|c|}{$2.520 \mathrm{e}+006$} & $\mathrm{~kJ} / \mathrm{h}$ \\
\hline Temperature & -31.07 & $\mathrm{C}$ & \multicolumn{4}{|c|}{ Compressor Duty } \\
\hline $\begin{array}{l}\text { Pressure } \\
\text { Molar Flow }\end{array}$ & $\begin{array}{l}1900 \\
1996\end{array}$ & $\begin{array}{l}\mathrm{kPa} \\
\text { kamole/h }\end{array}$ & Heat Flow & \multicolumn{2}{|c|}{$4.590 \mathrm{e}+004$} & $\mathrm{~kJ} / \mathrm{h}$ \\
\hline Comp Mole Frac (Ethylene) & 0.9995 & & \multicolumn{4}{|c|}{ Cooling Duty Permeate } \\
\hline \multicolumn{3}{|c|}{ Ethane } & Heat Flow & & $4 e+006$ & $\mathrm{~kJ} / \mathrm{h}$ \\
\hline Temperature & -8.040 & $\mathrm{C}$ & \multicolumn{4}{|c|}{ C2-SPLITTER } \\
\hline Pressure & 2000 & $\mathrm{kPa}$ & Reflux Ratic & & 3.197 & \\
\hline Molar Flow & 504.0 & kgmole/h & \multicolumn{2}{|c|}{ Number of Trays } & 75.00 & \\
\hline Comp Mole Frac (Ethylene) & 0.0100 & & & & & \\
\hline
\end{tabular}

\begin{tabular}{|c|c|c|}
\hline \multicolumn{3}{|c|}{ Compressed side draw } \\
\hline Temperature & -24.26 & C \\
\hline Pressure & 2000 & $\mathrm{kPa}$ \\
\hline Molar Flow & 1500 & $\mathrm{kgmole} / \mathrm{h}$ \\
\hline Comp Mole Frac (Ethylene) & 0.7980 & \\
\hline \multicolumn{3}{|c|}{ Permeate } \\
\hline Temperature & -23.10 & C \\
\hline Pressure & 400.0 & $\mathrm{kPa}$ \\
\hline Molar Flow & 496.0 & $\mathrm{kgmole} / \mathrm{h}$ \\
\hline Comp Mole Frac (Ethylene) & 0.9955 & \\
\hline \multicolumn{3}{|c|}{ Cooled Permeate } \\
\hline Temperature & 30.00 & C \\
\hline Pressure & 2000 & $\mathrm{kPa}$ \\
\hline Molar Flow & 496.1 & kgmole/h \\
\hline Comp Mole Frac (Ethylene) & 0.9955 & \\
\hline \multicolumn{3}{|c|}{ Retentate Recycle } \\
\hline Temperature & -22.75 & C \\
\hline Pressure & 2000 & $\mathrm{kPa}$ \\
\hline Molar Flow & 1004 & $\mathrm{kgmole} / \mathrm{h}$ \\
\hline Comp Mole Frac (Ethylene) & 0.7004 & \\
\hline
\end{tabular}

Figure 2.6. Optimized results of the parallel hybrid membrane-distillation configuration. $\mathrm{C}_{2} \mathrm{H}_{4}$ permeance through membrane $=0.83 \cdot 10-5 \mathrm{~mol} /(\mathrm{m} 2 \mathrm{~s} \mathrm{kPa})$ and selectivity $=100$. Membrane feed flow $=1,500 \mathrm{kmol} / \mathrm{hr}$. Stage numbers of feed, side draw, cooled permeate and retentate recycle are 53,53,15,57, respectively. Trays are set at $100 \%$ efficiency. 

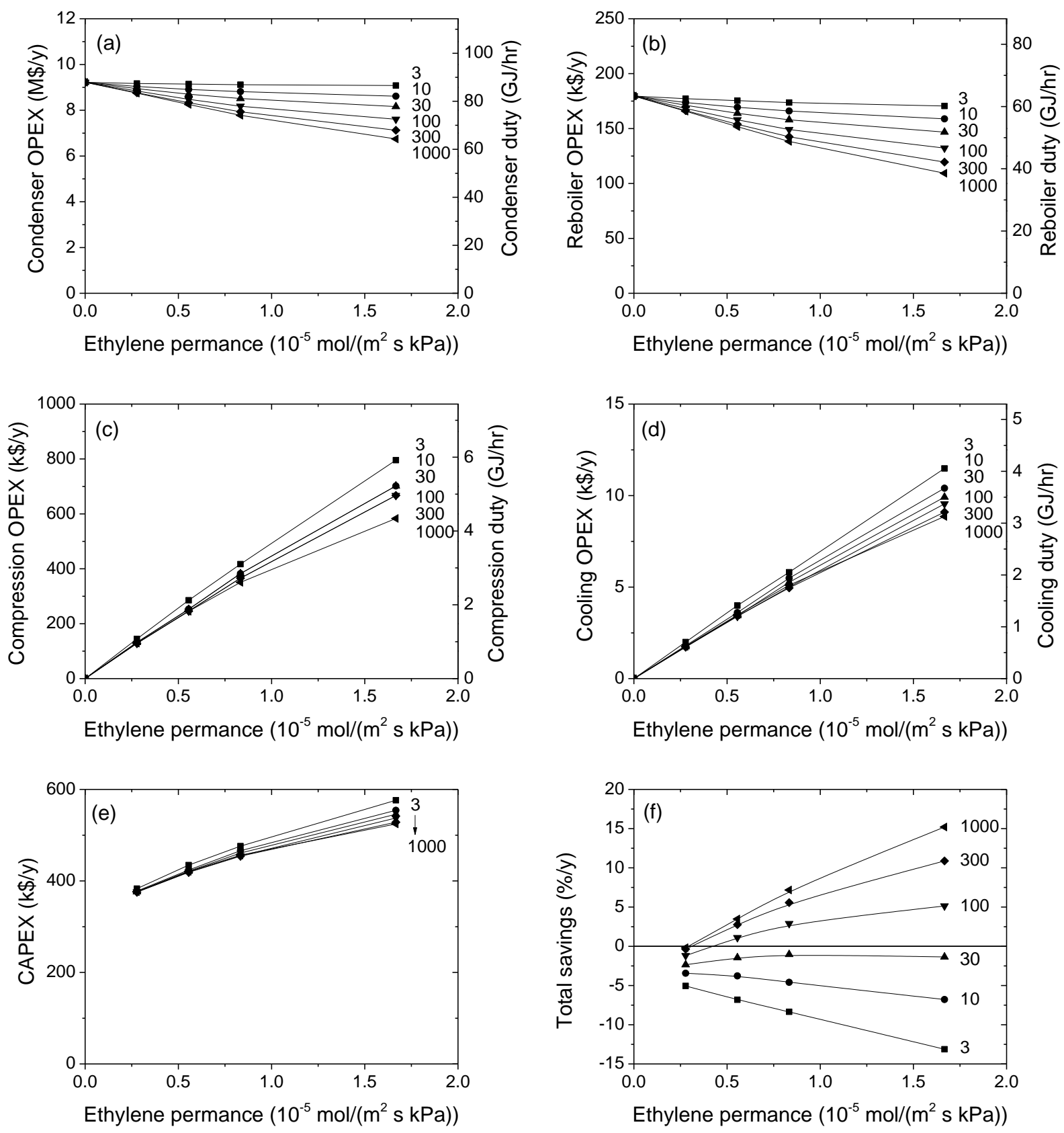

Figure 2.7. OPEX and duty for (a) condenser, (b) reboiler, (c) compressor, (d) cooling and (e) CAPEX capital costs and (f) total savings as function of $\mathrm{C}_{2} \mathrm{H}_{4}$ permeance through the membrane unit for 6 different selectivities in a parallel hybrid membrane-distillation unit with a membrane feed flow of $1,500 \mathrm{kmol} / \mathrm{hr}$. 
Figure 2.7a and 2.7b show that the condenser and reboiler OPEX respectively, decrease with increasing membrane selectivity and $\mathrm{C}_{2} \mathrm{H}_{4}$ permeance. A more selective membrane yields a more pure permeate stream, which can be re-fed higher into the column, thereby reducing the condenser and reboiler duties in the distillation unit. By increasing the $\mathrm{C}_{2} \mathrm{H}_{4}$ permeance, a larger permeate stream is obtained, which also reduces the condenser and reboiler duties in the distillation unit. This effect becomes more pronounced as the selectivity of the membranes increases.

On the other hand, larger permeate streams increase the compressor and cooling requirements because of the larger capacity needed and consequently, the corresponding duties and OPEX as shown in Figure 2.7c and 2.7d. From these figures it is also evident that the selectivity has no significant influence on the compression and cooling OPEX: regardless of composition, the molar flow rate of the permeate, which depends on the $\mathrm{C}_{2} \mathrm{H}_{4}$ permeance, determines the annual compression and cooling operating costs.

The annualized CAPEX as shown in Figure 2.7e also increase with increasing $\mathrm{C}_{2} \mathrm{H}_{4}$ permeance for analogous reasons as described for Figure 2.7c and 2.7d. Larger molar permeate flows require larger capacities of the equipment and therefore larger capital costs, regardless of stream composition.

When the OPEX between Figures 2.7a - 2.7d are compared, it can be seen that the condenser in Figure 2.7a contributes for over $90 \%$ to the total OPEX. The largest effect of a high selective $(\alpha=1000)$ and permeable membrane unit $\left(1.67 \cdot 10^{-5} \mathrm{~mol} /\left(\mathrm{m}^{2} \mathrm{~Pa}\right)\right)$ is observed by a reduction in the condenser operating costs of $2.5 \mathrm{M} \$(27 \%)$.

A hybrid membrane-distillation process in parallel configuration can have a maximum net annual saving of up to $15 \%$, as shown in Figure 2.7f, given a very selective and permeable membrane. It also shows that a selectivity of 100 and a permeance of $0.4 \cdot 10^{-5} \mathrm{~mol} /\left(\mathrm{m}^{2} \mathrm{~s}\right.$ $\mathrm{kPa}$ ) is necessary to be economical viable.

However, it must be noted that several process conditions such as membrane feed and permeate pressure and the membrane surface area have not yet been optimized in these calculations. The membrane properties required to obtained these savings are far higher than the ones obtained by Caballero.[10] This is mainly due to the lower $\mathrm{C}_{2} \mathrm{H}_{4}$ purity required in their end specification (99.5\%), which enhances the impact of the membrane unit since lower selectivities are necessary to meet the end specifications. Also, Caballero et al. took $80 \%$ of 
the feed flow as side draw from the distillation column, while in this study it was limited to $20 \%$ to reduce hydrodynamic disturbances inside the distillation column. Still, it will be interesting to see the advantage of this parallel configuration in comparison to the series configuration.

\subsubsection{Series hybrid configuration}

\subsubsection{1,500 $\mathrm{kmol} / \mathrm{hr}$ series configuration}

In the series configuration, the membrane unit is positioned in front of the distillation column as is shown in the UniSim model in Figure 8. Although this configuration has less flexibility in terms of selecting the optimum composition as membrane feed, it has the advantage that retrofitting an existing distillation column will be easier and less expensive since no sidedraw is taken from the column.

To have a fair comparison between the parallel and series configurations, the first series configuration was simulated with a limited feed flow to the membrane of $1,500 \mathrm{kmol} / \mathrm{hr}$. The remaining $1,000 \mathrm{kmol} / \mathrm{hr}$ was fed to the distillation column directly. Maximization of the total savings was done according to Equation 2.12. Logically, the annualized compressing and cooling OPEX as well as the annual CAPEX of a retrofit, do not significantly differ from the parallel configuration. The magnitude of the permeate stream decreases slightly with increasing membrane selectivity because less $\mathrm{C}_{2} \mathrm{H}_{6}$ permeates through the membrane. However as this is also the case for the parallel configuration, there is no considerable difference in compression and cooling OPEX between these two configurations. 


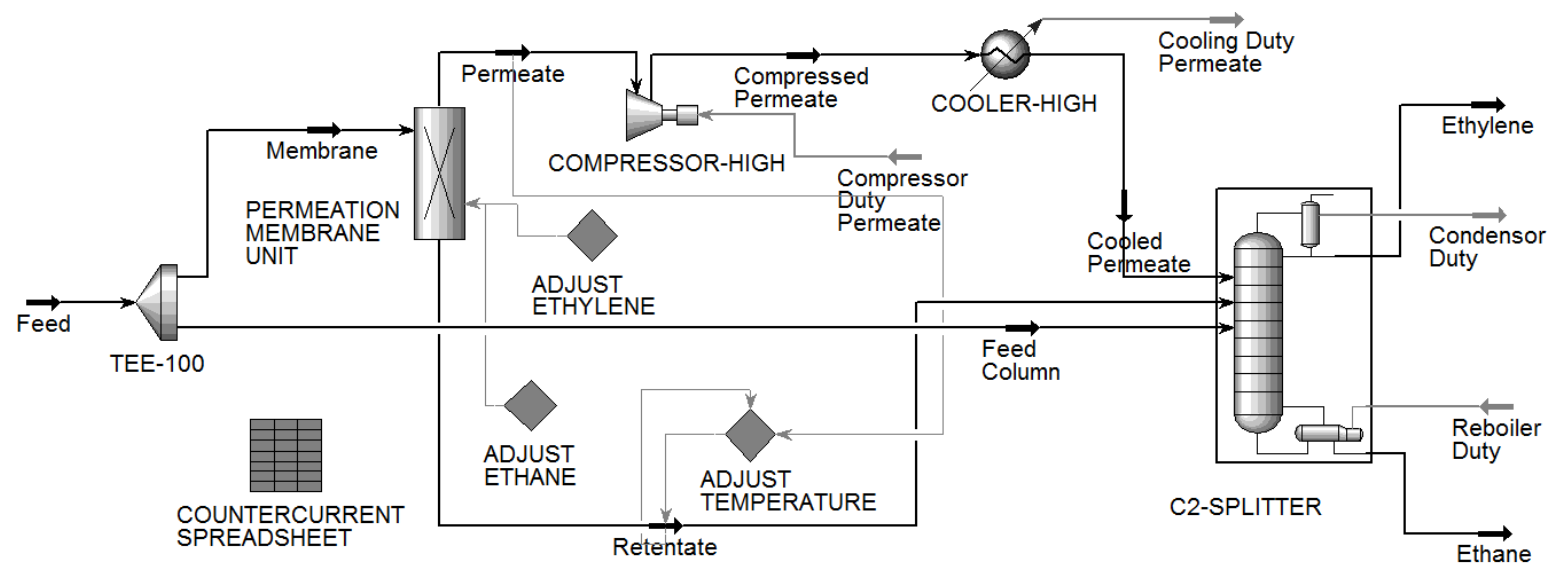

\begin{tabular}{|l|r|l|}
\hline \multicolumn{3}{|c|}{ Feed } \\
\hline Temperature & -18.00 & $\mathrm{C}$ \\
\hline Pressure & 2000 & $\mathrm{kPa}$ \\
\hline Molar Flow & 2500 & $\mathrm{kgmole} / \mathrm{h}$ \\
\hline Comp Mole Frac (Ethylene) & 0.8000 & \\
\hline \hline \multicolumn{3}{|c|}{ Ethylene } \\
\hline Temperature & -31.07 & $\mathrm{C}$ \\
\hline Pressure & 1900 & $\mathrm{kPa}$ \\
\hline Molar Flow & 1996 & $\mathrm{kgmole} / \mathrm{h}$ \\
\hline Comp Mole Frac (Ethylene) & 0.9995 & \\
\hline \hline \multicolumn{3}{|c|}{} \\
\hline Temperature & -8.040 & $\mathrm{C}$ \\
\hline Pressure & 2000 & $\mathrm{kPa}$ \\
\hline Molar Flow & 504.0 & $\mathrm{kgmole} / \mathrm{h}$ \\
\hline Comp Mole Frac (Ethylene) & 0.0100 & \\
\hline
\end{tabular}

\begin{tabular}{|l|l|l|}
\hline \multicolumn{3}{|c|}{ Condensor Duty } \\
\hline Heat Flow & $7.783 \mathrm{e}+007$ & $\mathrm{~kJ} / \mathrm{h}$ \\
\hline \hline \multicolumn{3}{|c|}{ Reboiler Duty } \\
\hline Heat Flow & $5.257 \mathrm{e}+007$ & $\mathrm{~kJ} / \mathrm{h}$ \\
\hline \hline \multicolumn{3}{|c|}{ Compressor Duty Permeate } \\
\hline Heat Flow & $2.543 \mathrm{e}+006$ & $\mathrm{~kJ} / \mathrm{h}$ \\
\hline \hline \multicolumn{3}{|c|}{ Cooling Duty Permeate } \\
\hline Heat Flow & $1.799 \mathrm{e}+006$ & $\mathrm{~kJ} / \mathrm{h}$ \\
\hline \hline \multicolumn{3}{|c|}{ C2-SPLITTER } \\
\hline Number of Trays & 75.00 & \\
\hline Reflux Ratio & 3.189 & \\
\hline
\end{tabular}

\begin{tabular}{|c|c|c|}
\hline \multicolumn{3}{|c|}{ Permeate } \\
\hline Temperature & -21.95 & C \\
\hline Pressure & 400.0 & $\mathrm{kPa}$ \\
\hline Molar Flow & 498.0 & $\mathrm{kgmole} / \mathrm{h}$ \\
\hline Comp Mole Frac (Ethylene) & 0.9956 & \\
\hline \multicolumn{3}{|c|}{ Compressed Permeate } \\
\hline Temperature & 100.2 & C \\
\hline Pressure & 2050 & $\mathrm{kPa}$ \\
\hline Molar Flow & 498.0 & kgmole/h \\
\hline Comp Mole Frac (Ethylene) & 0.9956 & \\
\hline \multicolumn{3}{|c|}{ Cooled Permeate } \\
\hline Temperature & 30.00 & C \\
\hline Pressure & 2000 & $\mathrm{kPa}$ \\
\hline Molar Flow & 498.0 & $\mathrm{kgmole} / \mathrm{h}$ \\
\hline Comp Mole Frac (Ethylene) & 0.9956 & \\
\hline \multicolumn{3}{|c|}{ Retentate } \\
\hline Temperature & -22.70 & C \\
\hline Pressure & 2000 & $\mathrm{kPa}$ \\
\hline Molar Flow & 1002 & kgmole/h \\
\hline Comp Mole Frac (Ethylene) & 0.7028 & \\
\hline
\end{tabular}

Figure 2.8. Optimized results of the $1,500 \mathrm{kmol} / \mathrm{hr}$ series hybrid membrane-distillation configuration. $\mathrm{C}_{2} \mathrm{H}_{4}$ permeance through membrane $=0.83 \cdot 10^{-5} \mathrm{~mol} /\left(\mathrm{m}^{2} \mathrm{~s} \mathrm{kPa}\right)$ and selectivity $=100$. Membrane feed flow $=1,500 \mathrm{kmol} / \mathrm{hr}$. Stage numbers of column feed, cooled permeate and retentate recycle $=52,16,57$, respectively. Trays are set at $100 \%$ efficiency.

Apart from one additional compressor to compress the side draw from the distillation column to $2,000 \mathrm{kPa}$, necessary to for the membrane feed, the same equipment is used in both configurations, which leads to comparable annualized CAPEX as well. The stage number of the permeate, retentate and column feed streams show no significant difference between the series and parallel configuration as can be seen in Figure 2.9a. This results in similar molar 
$\mathrm{C}_{2} \mathrm{H}_{4}$ fractions in all streams and therefore, no significant differences are observed in the condenser and reboiler duties.

Summarizing the above, the $1,500 \mathrm{kmol} / \mathrm{hr}$ series configuration can obtain similar savings as the $1,500 \mathrm{kmol} / \mathrm{hr}$ parallel configuration as is shown in Figure $2.9 \mathrm{~b}$ as would be expected since the composition of the side draw proved to be the same as the composition of the membrane feed in the series configuration.

However, the main advantage of the series configuration is that the membrane feed flow is not limited to $1,500 \mathrm{kmol} / \mathrm{hr}$ by hydrodynamic constraints, as is the case in the parallel configuration. Therefore, the next series of simulations is performed with a membrane feed flow of 2,500 kmol/hr and no direct feed flow to the distillation column.
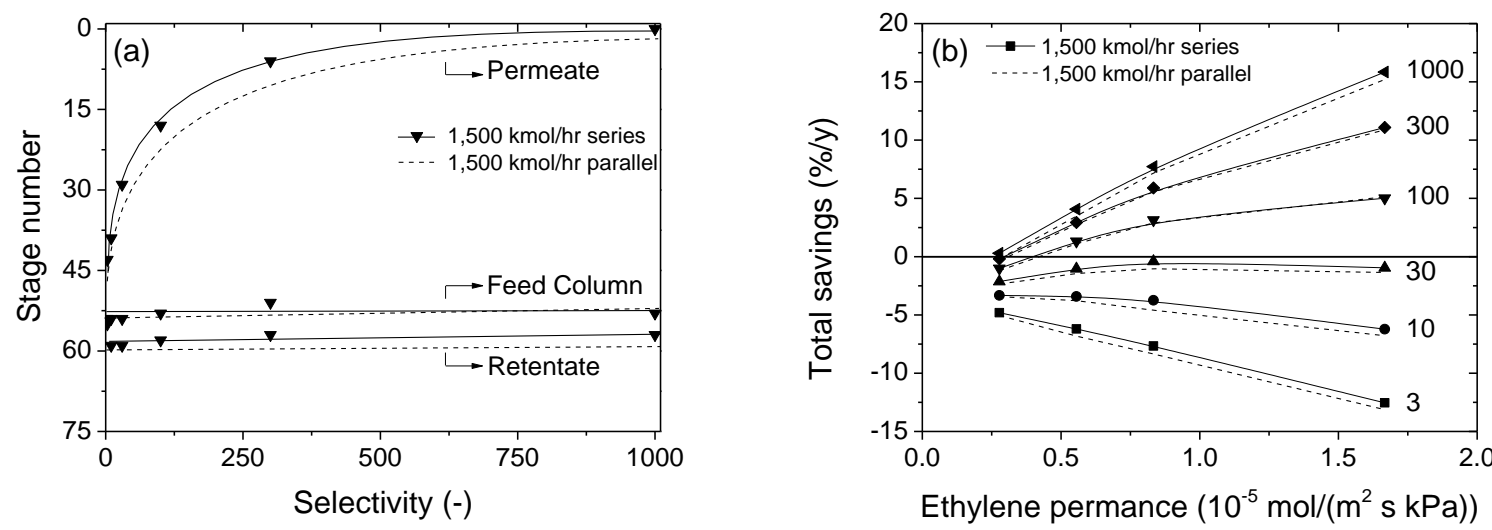

Figure 2.9. Comparison between $1,500 \mathrm{kmol} / \mathrm{hr}$ series and parallel configuration: (a) Stage number inlet in distillation column of permeate, column feed and retentate stream as function of the membrane selectivity (membrane permeance $=0.83 \cdot 10^{-5} \mathrm{~mol} /\left(\mathrm{m}^{2} \mathrm{~s} \mathrm{kPa}\right)$ ) and (b) total savings as function of $\mathrm{C}_{2} \mathrm{H}_{4}$ permeance through the membrane for 6 different selectivities.

\subsubsection{2,500 $\mathrm{kmol} / \mathrm{hr}$ series configuration}

Since the $1,500 \mathrm{kmol} / \mathrm{hr}$ series configuration already showed that the implementation of a membrane unit can reduce the energy requirements and thus reduce the total annual costs, increasing the total flow to the membrane unit to $2,500 \mathrm{kmol} / \mathrm{hr}$ can be even more beneficial. Figure 2.10 shows a typical UniSim setup with a membrane feed flow of 2,500 kmol/hr and a membrane permeance of $\left.0.83 \cdot 10^{-5} \mathrm{~mol} /\left(\mathrm{m}^{2} \mathrm{~s} \mathrm{kPa}\right)\right)$ and a selectivity of 100 . By removing 
the membrane feed flow restrictions, the condenser and reboiler duties are further reduced, compared to the $1,500 \mathrm{kmol} / \mathrm{hr}$ series configurations.

The reduction in condenser OPEX and duty as function of the $\mathrm{C}_{2} \mathrm{H}_{4}$ permeance for various membrane selectivities is shown in Figure 2.11a. The condenser OPEX decrease with increasing $\mathrm{C}_{2} \mathrm{H}_{4}$ permeance and increasing $\mathrm{C}_{2} \mathrm{H}_{4} / \mathrm{C}_{2} \mathrm{H}_{6}$ selectivity, respectively. However, when the membrane selectivity is increased to 1000 , the reductions in condenser and reboiler duties are less substantial. High selective membranes $(\alpha=1000)$ produce a permeate with a molar $\mathrm{C}_{2} \mathrm{H}_{4}$ fraction above the product specifications of 0.9995 , as can be seen in Figure 2.11b. At all other selectivities, a higher membrane feed flow produces a more $\mathrm{C}_{2} \mathrm{H}_{4}$ rich permeate, responsible for the reduced condenser and reboiler OPEX, compared to the 1,500 $\mathrm{kmol} / \mathrm{hr}$ series configuration. Consequently, the annual total savings as function of the $\mathrm{C}_{2} \mathrm{H}_{4}$ permeance are increased as well, compared to the $1,500 \mathrm{kmol} / \mathrm{hr}$ series configurations, as is shown in Figure 2.11c. 


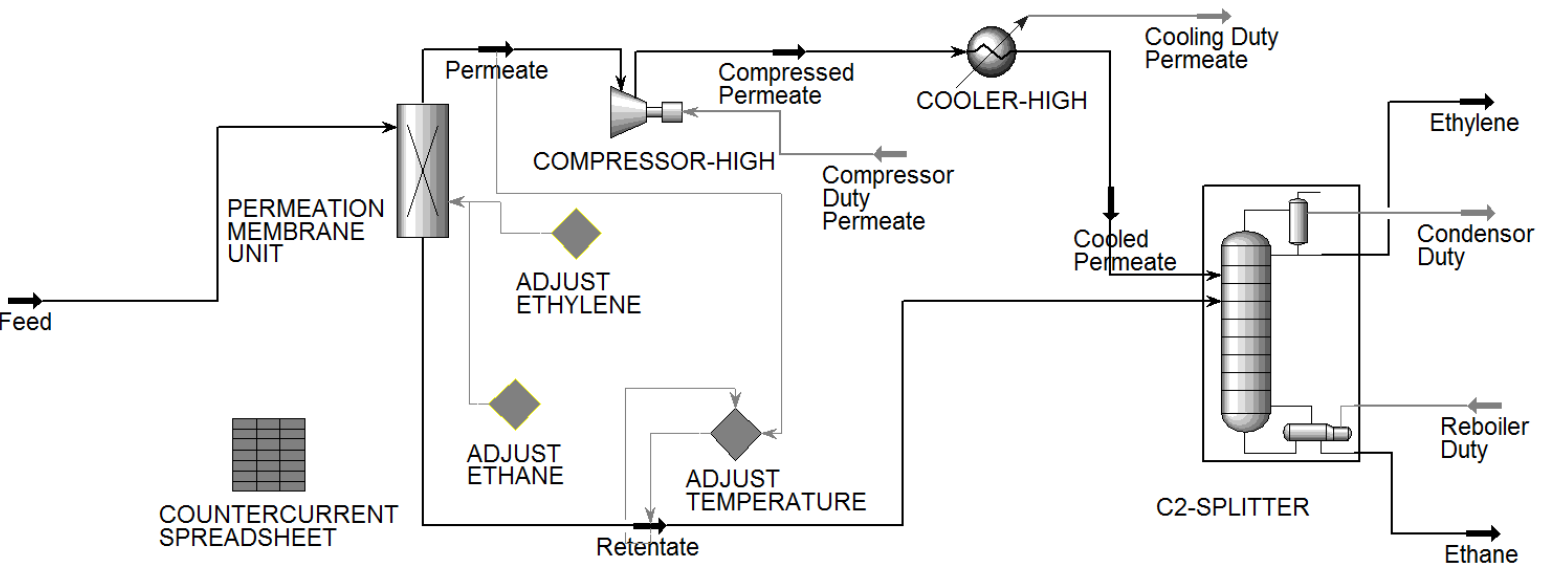

\begin{tabular}{|l|r|l|}
\hline \multicolumn{3}{|c|}{ Feed } \\
\hline Temperature & -18.00 & $\mathrm{C}$ \\
\hline Pressure & 2000 & $\mathrm{kPa}$ \\
\hline Molar Flow & 2500 & $\mathrm{kgmole} / \mathrm{h}$ \\
\hline Comp Mole Frac (Ethylene) & 0.8000 & \\
\hline \hline \multicolumn{3}{|c|}{ Ethylene } \\
\hline Temperature & -31.07 & $\mathrm{C}$ \\
\hline Pressure & 1900 & $\mathrm{kPa}$ \\
\hline Molar Flow & 1996 & $\mathrm{kgmole} / \mathrm{h}$ \\
\hline Comp Mole Frac (Ethylene) & 0.9995 & \\
\hline \hline \multicolumn{3}{|}{ Ethane } \\
\hline Temperature & -8.040 & $\mathrm{C}$ \\
\hline Pressure & 2000 & $\mathrm{kPa}$ \\
\hline Molar Flow & 504.0 & $\mathrm{kgmole} / \mathrm{h}$ \\
\hline Comp Mole Frac (Ethylene) & 0.0100 & \\
\hline
\end{tabular}

\begin{tabular}{|l|l|l|}
\hline \multicolumn{3}{|c|}{ Condensor Duty } \\
\hline Heat Flow & $7.770 \mathrm{e}+007$ & $\mathrm{~kJ} / \mathrm{h}$ \\
\hline \hline \multicolumn{3}{|c|}{ Reboiler Duty } \\
\hline Heat Flow & $5.240 \mathrm{e}+007$ & $\mathrm{~kJ} / \mathrm{h}$ \\
\hline \hline Compressor Duty Permeate \\
\hline Heat Flow & $2.650 \mathrm{e}+006$ & $\mathrm{~kJ} / \mathrm{h}$ \\
\hline \hline \multicolumn{3}{|c|}{ Cooling Duty Permeate } \\
\hline Heat Flow & $1.869 \mathrm{e}+006$ & $\mathrm{~kJ} / \mathrm{h}$ \\
\hline \hline \multicolumn{3}{|c|}{ C2-SPLITTER } \\
\hline Number of Trays & 75.00 & \\
\hline Reflux Ratio & 3.182 & \\
\hline
\end{tabular}

\begin{tabular}{|l|r|l|}
\hline \multicolumn{3}{|c|}{ Permeate } \\
\hline Temperature & -22.17 & $\mathrm{C}$ \\
\hline Pressure & 400.0 & $\mathrm{kPa}$ \\
\hline Molar Flow & 519.4 & $\mathrm{kgmole} / \mathrm{h}$ \\
\hline Comp Mole Frac (Ethylene) & 0.9961 & \\
\hline \hline \multicolumn{3}{|c|}{ Cooled Permeate } \\
\hline Temperature & 30.00 & $\mathrm{C}$ \\
\hline Pressure & 2000 & $\mathrm{kPa}$ \\
\hline Molar Flow & 519.4 & $\mathrm{kgmole} / \mathrm{h}$ \\
\hline Comp Mole Frac (Ethylene) & 0.9961 & \\
\hline \hline \multicolumn{3}{|c|}{} \\
\hline Temperature & -22.30 & $\mathrm{C}$ \\
\hline Pressure & 2000 & $\mathrm{kPa}$ \\
\hline Molar Flow & 1981 & $\mathrm{kgmole} / \mathrm{h}$ \\
\hline Comp Mole Frac (Ethylene) & 0.7486 & \\
\hline
\end{tabular}

Figure 2.10. Optimized results of the $2,500 \mathrm{kmol} / \mathrm{hr}$ series hybrid membrane-distillation configuration. $\mathrm{C}_{2} \mathrm{H}_{4}$ permeance $=0.83 \cdot 10^{-5} \mathrm{~mol} /\left(\mathrm{m}^{2} \mathrm{~s} \mathrm{kPa}\right)$, selectivity $=100$ and membrane feed flow $=2,500 \mathrm{kmol} / \mathrm{hr}$. Stage numbers of column feed, cooled permeate and retentate recycle $=53,14,56$, respectively. Trays are set at $100 \%$ efficiency. 

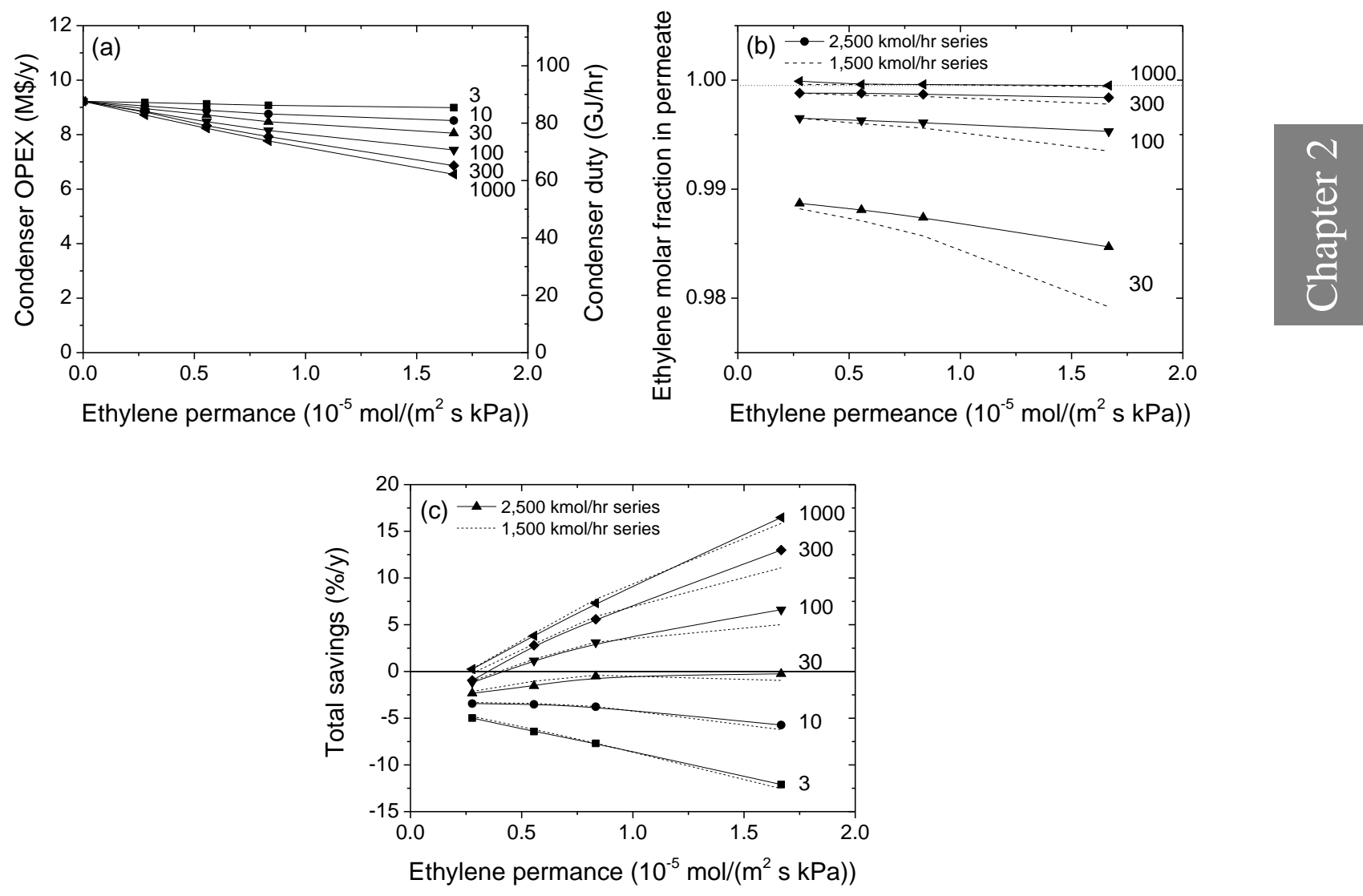

Figure 2.11:(a) Condensor OPEX and duty and (b) $\mathrm{C}_{2} \mathrm{H}_{4}$ molar fraction in permeate and (c) total savings as function of $\mathrm{C}_{2} \mathrm{H}_{4}$ permeance through the membrane for different selectivities in a $1,500 \mathrm{kmol} / \mathrm{hr}$ and $2,500 \mathrm{kmol} / \mathrm{hr}$ series hybrid membrane-distillation unit.

Figure $2.11 \mathrm{c}$ shows that the $2,500 \mathrm{kmol} / \mathrm{hr}$ series configuration outperforms the 1,500 $\mathrm{kmol} / \mathrm{hr}$ series configuration in the total obtainable savings, especially at higher $\mathrm{C}_{2} \mathrm{H}_{4}$ permeances and selectivities. At a relatively low permeance of only $0.4 \cdot 10^{-5} \mathrm{~mol} /\left(\mathrm{m}^{2} \mathrm{~s} \mathrm{kPa}\right)$, a selectivity of 100 is required to break even, which is comparable to the $1,500 \mathrm{kmol} / \mathrm{hr}$ series and parallel configurations. However, the advantage of the $2,500 \mathrm{kmol} / \mathrm{hr}$ series configurations becomes visible at higher $\mathrm{C}_{2} \mathrm{H}_{4}$ permeances where it constantly out performs the $1,500 \mathrm{kmol} / \mathrm{hr}$ series configurations. At selectivities higher than 30 and permeances of 1.7 $\cdot 10^{-5} \mathrm{~mol} /\left(\mathrm{m}^{2} \mathrm{~s} \mathrm{kPa}\right)$, the $2,500 \mathrm{kmol} / \mathrm{hr}$ series configuration yields roughly 2 percentage points more savings compared to the $1,500 \mathrm{kmol} / \mathrm{hr}$ series configuration due to a significantly lower condenser duty, caused by a higher $\mathrm{C}_{2} \mathrm{H}_{4}$ fraction in the permeate stream (See Figure $2.11 b$ ). The maximum total savings of up to $16 \%$ can be obtained by directing the complete feed through a membrane unit with an $\mathrm{C}_{2} \mathrm{H}_{4}$ permeance of $1.7 \cdot 10^{-5} \mathrm{kmol} / \mathrm{hr}$ and a selectivity 
of 1000. Still, this configuration does not include process optimizations such as the feed and permeate pressure and membrane area, which will be discussed in the next section.

Within the boundaries of this study, the $2,500 \mathrm{kmol} / \mathrm{hr}$ series configuration outperformed the $1,500 \mathrm{kmol} / \mathrm{hr}$ series and parallel configuration. At equal membrane feed flows, no significant difference between the series and parallel configuration was found. The magnitude of the membrane feed flow determined the most profitable configuration. The parallel configuration was limited at $1,500 \mathrm{kmol} / \mathrm{hr}$, as this study only considered a retrofit of an existing plant. A parallel configuration with a vapor sidedraw up to $2,500 \mathrm{kmol} / \mathrm{hr}$ will not perform significantly different from the series configuration. However, it is likely that the parallel configuration will outperform the other configurations investigated in this study, if more than the column feed flow $(2,500 \mathrm{kmol} / \mathrm{hr})$ is fed to the membrane module.

\subsubsection{Optimal process conditions}

Additional savings can be obtained by optimizing the process conditions. The most logical optimization is that of the membrane surface area. With a membrane price of $\$ 100 / \mathrm{m}^{2}$ and an expected life time of 5 years, the membrane CAPEX are a significant contribution to the total CAPEX as is shown in Table 2.6.

Table 2.6. Typical example of annualized CAPEX for $2,500 \mathrm{kmol} / \mathrm{hr}$ series configuration as shown in Figure 2.10. $\mathrm{C}_{2} \mathrm{H}_{4}$ permeance $=2.8 \cdot 10^{-6} \mathrm{~mol} /\left(\mathrm{m}^{2} \mathrm{~s} \mathrm{kPa}\right)$ and selectivity $=100$.

CAPEX $(\mathrm{k} \$ / \mathrm{y}) \quad$ Percentage $(\%)$

\begin{tabular}{lcc} 
Membrane unit & 300 & 81 \\
Compressor permeate & 52 & 14 \\
Heat exchanger permeate & 17 & 5 \\
Total & 369 & 100 \\
\hline
\end{tabular}

Since high permeable membranes require less membrane area to process the total feed flow of 2,500 kmol/hr, significant savings can be obtained by increasing the membrane permeance. Also, low permeable but high selective membranes may profit from increasing the membrane surface area since the permeate streams in those cases are close to or meet the 
product specifications and could therefore reduce the condenser and reboiler duties considerable. This would imply that increasing the membrane area beyond $15,000 \mathrm{~m}^{2}$ can be feasible if the condenser and reboiler duties are significantly reduced.

Finally, the optimization of the membrane feed and permeate pressure will be investigated. Changing these pressures not only changes the membrane performance due to altered driving forces, it can also reduce or even eliminate the need for compression of the permeate. Since the evaluation of the different configurations showed that the $1,500 \mathrm{kmol} / \mathrm{hr}$ parallel and series configuration are clearly outperformed by the $2,500 \mathrm{kmol} / \mathrm{hr}$ series configuration, only the latter configuration is optimized. Only selectivities of 30,100 and 300 are regarded since stable membranes with a selectivity beyond 300 are not likely to be developed in the near future. Membranes with a selectivity of $<30$ are also not considered since Figure 2.7f, 2.9b and $2.11 \mathrm{c}$ already showed that these selectivities are too low, despite their permeance, to recover the operating costs and will therefore always cause net losses.

\subsubsection{Feed pressure}

Increasing the pressure of the membrane feed has only a limited effect on the total energy savings (not shown in Figure). The benefit of having a higher driving force by increasing the feed pressure is mainly counterbalanced by the increased compression costs. However, there is a more practical reason for increasing the membrane feed pressure to the critical pressure of $4,850 \mathrm{kPa}$ : by increasing the pressure, additional heat will be fed to the membrane feed stream, which increases the temperature from $-18{ }^{\circ} \mathrm{C}$ to $49^{\circ} \mathrm{C}$. This will be beneficial for the membrane performance since high performing glassy polymers mainly depend on diffusion for permeation and separation, which is enhanced at elevated temperatures.[42] As consequence of increasing the membrane feed pressure and consequently, the retentate feed pressure to $4,850 \mathrm{kPa}$, the retentate stream needs a valve installed to reduce the pressure again to 2,000 $\mathrm{kPa}$ before entering the distillation column. The expansion of the retentate stream will cool it simultaneously, avoiding the installation of an additional heat exchanger.

\subsubsection{Permeate pressure and membrane surface area}

After increasing the membrane feed pressure to $4,850 \mathrm{kPa}$, the permeate pressure and membrane surface area are the two remaining parameters that need to be optimized. Lower 
permeate pressures result in increased driving forces and thus in an improved membrane performance. However, this comes at the expense of the need for compressing the permeate stream to 2,050 kPa before entering the distillation column again. In addition, compression of the permeate stream elevates the temperature beyond $30{ }^{\circ} \mathrm{C}$, which results in the need for cooling. Fortunately, this can be done with inexpensive cooling water, while reductions in temperature below $30{ }^{\circ} \mathrm{C}$ will be at the expense of the condenser.

The permeate pressure was varied between 100 and 2,050 $\mathrm{kPa}$ and optimization was performed as shown in Equation 2.13. Increasing the permeate pressure beyond 2,050 kPa proved to be inefficient due to the need for depressurization of the permeate stream before introduction into the distillation column again. Since both the permeate pressure and the membrane area are varied independently, the optimum $\mathrm{C}_{2} \mathrm{H}_{4}$ permeance could be even higher than $1.7 \cdot 10^{-5} \mathrm{~mol} /\left(\mathrm{m}^{2} \mathrm{~s} \mathrm{kPa}\right)$ as used in previous simulations, according to Equation 2.3. Typical results for the total savings (calculated using Equation 2.6) of a membrane installation with a selectivity of 300 and two different permeances of $2.8 \cdot 10^{-6}$ and $2.8 \cdot 10^{-5}$ $\mathrm{mol} /\left(\mathrm{m}^{2} \mathrm{~s} \mathrm{kPa}\right)$ as a function of the membrane area are shown for various permeate pressures in Figure 2.12a and b, respectively.
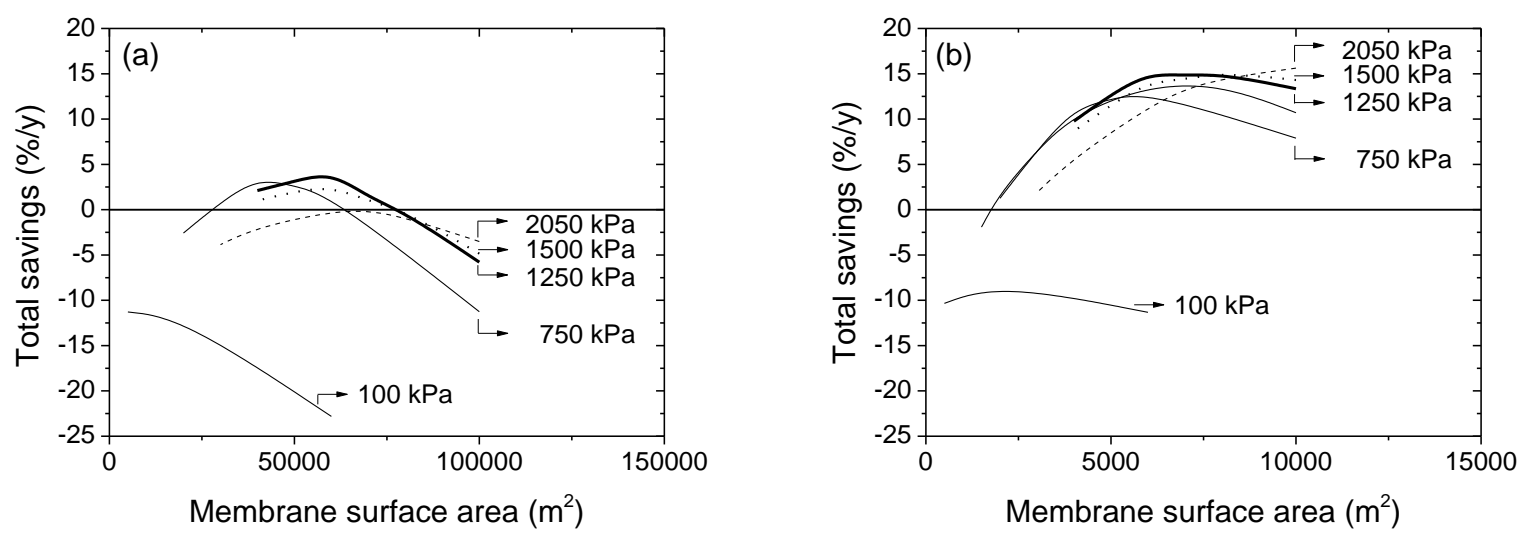

Figure 2.12. Total savings as function of membrane surface area for various permeate pressures for a membrane selectivity of 300 and a permeance of (a) $2.8 \cdot 10^{-6} \mathrm{~mol} /\left(\mathrm{m}^{2} \mathrm{~s} \mathrm{kPa}\right)$ and (b) $2.8 \cdot 10^{-5} \mathrm{~mol} /\left(\mathrm{m}^{2} \mathrm{~s} \mathrm{kPa}\right)$. Membrane feed pressure $=4,850 \mathrm{kPa}$. Membrane feed flow $=2,500 \mathrm{kmol} / \mathrm{hr}$. 
Figure 2.12a shows a quadratic relationship between the total savings and membrane surface area at any given permeate pressure and $\mathrm{C}_{2} \mathrm{H}_{4}$ permeance. When small membrane surface areas are installed only a low permeate flow is produced. Consequently, the condenser and reboiler duties are not adequately reduced to account for the total investment costs, resulting in a net loss. On the other hand, large membrane areas produce a large permeate flow, resulting in significantly reduced condenser and reboiler duties, but at the expense of enormous investment costs of which $90 \%$ ( $2 \mathrm{M} \$ / \mathrm{y}$ for $100.000 \mathrm{~m}^{2}$ ) is the acquisition of membrane units.

The optimum membrane surface area varies as a function of permeate pressure. At low permeate pressures of $100 \mathrm{kPa}$, the large driving force over the membrane produces significant reductions in the condenser and reboiler duties, but this is counterbalanced by the need for expensive compressors to compress the permeate stream to $2,050 \mathrm{kPa}$, resulting in low overall net savings. On the other hand, a permeate pressure of 2,050 kPa does not require additional compression of the permeate stream, but has reduced membrane driving forces and thus, only limited reduced condenser and reboiler duties. These factors result in an optimum permeate pressure and membrane area for any given selectivity and permeance.

According to Equation 2.3, the need for large membrane surface areas reduces, when the membrane permeance increases. This would reduce the membrane investment costs and therefore allows for significantly higher savings. To investigate this, the permeance was further increased to $2.8 \cdot 10^{-5} \mathrm{~mol} /\left(\mathrm{m}^{2} \mathrm{~s} \mathrm{kPa}\right)$, shown in Figure $2.12 \mathrm{~b}$. As can be seen in Figure $2.12 \mathrm{~b}$, the same quadratic relationship exists between the total savings and the membrane surface area at various permeate pressures when the permeance is increased tenfold. However, the optimum membrane surface area is reduced as the result of a higher permeance (different scales at both x-axis), since $Q \cdot A=$ constant according to Equation 2.3. In addition to this, the optimum permeate pressure increases to the limit of $2,050 \mathrm{kPa}$ with increasing permeance. Since the need for larger membrane area is decreased with increasing permeance, the total membrane costs are significantly reduced. As a result, the compression of the permeate stream has a larger contribution to the overall investment costs and thus, it is beneficial to have a permeate pressure similar to the pressure in the distillation column. The reduction in membrane surface area leads to significantly lower membrane costs, which consequently result in higher total savings up to $16 \%$. For comparison, this amount of savings required a membrane selectivity of 1000 before optimization (Figure 2.11c), compared to 300 now. 


\subsubsection{Optimal membrane properties, sensitivity analysis and return on investment}

Now that all process parameters are optimized, the total savings as function of $\mathrm{C}_{2} \mathrm{H}_{4}$ permeance for membrane selectivities of 30, 100 and 300 can be calculated and these are shown in Figure 2.13, together with their corresponding return on investment calculated using Equation 2.11. The optimized membrane feed pressure is $4,850 \mathrm{kPa}$, just below the critical pressure, in all cases, while the optimal permeate pressure varies from $1,250 \mathrm{kPa}$ for an $\mathrm{C}_{2} \mathrm{H}_{4}$ permeance of $2.8 \cdot 10^{-6} \mathrm{~mol} /\left(\mathrm{m}^{2} \mathrm{~s} \mathrm{kPa}\right)$ to $2,050 \mathrm{kPa}$ for an $\mathrm{C}_{2} \mathrm{H}_{4}$ permeance of $2.8 \cdot 10^{-5}$ $\mathrm{mol} /\left(\mathrm{m}^{2} \mathrm{~s} \mathrm{kPa}\right)$. The corresponding optimal membrane areas vary at low $\mathrm{C}_{2} \mathrm{H}_{4}$ permeances of $2.8 \cdot 10^{-6} \mathrm{~mol} /\left(\mathrm{m}^{2} \mathrm{~s} \mathrm{kPa}\right)$ from $20,000 \mathrm{~m}^{2}$, to $40,000 \mathrm{~m}^{2}$ and $60,000 \mathrm{~m}^{2}$ for membrane selectivities of 30, 100 and 300, respectively (areas not shown in Figure 2.13). When the $\mathrm{C}_{2} \mathrm{H}_{4}$ permeance increases to $2.8 \cdot 10^{-5} \mathrm{~mol} /\left(\mathrm{m}^{2} \mathrm{~s} \mathrm{kPa}\right)$, the optimal membrane areas vary from $8,000 \mathrm{~m}^{2}$ to $10,000 \mathrm{~m}^{2}$ and $10,000 \mathrm{~m}^{2}$ ( $\pm 10 \%$ ) for membrane selectivities of 30,100 and 300, respectively (areas not shown in Figure 2.13b).
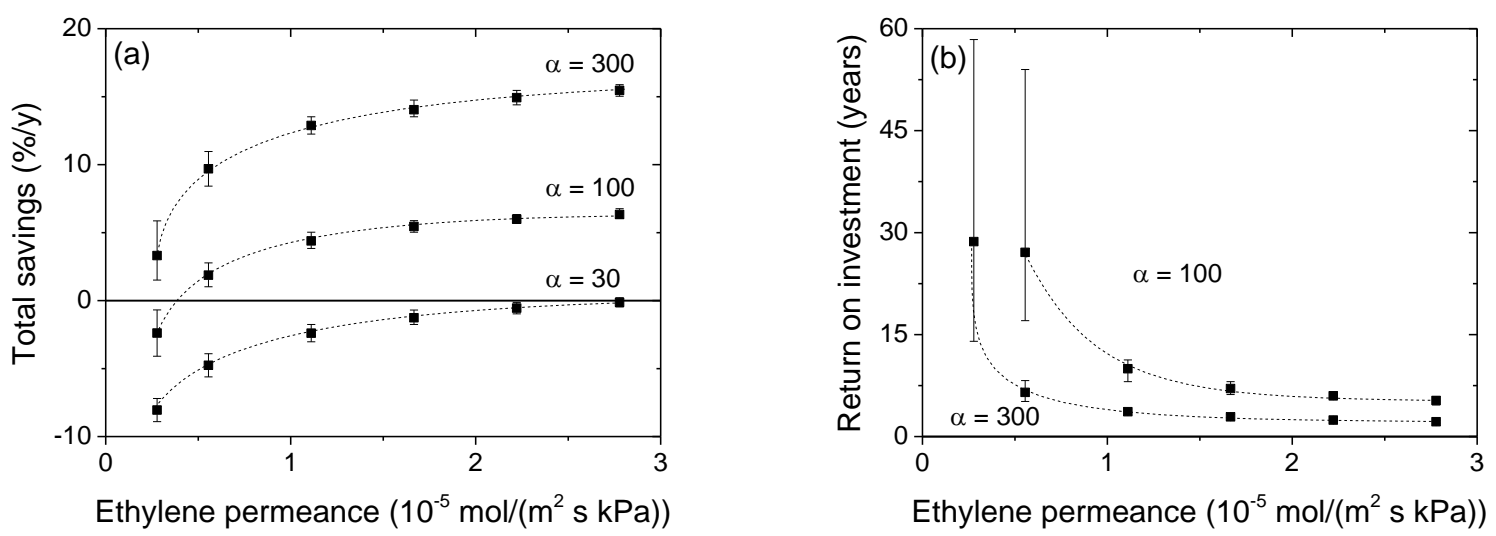

Figure 2.13. (a) Total savings and (b) return on investment as function of $\mathrm{C}_{2} \mathrm{H}_{4}$ permeance for membranes with a selectivity of 30,100 and 300. Error bars represent $\pm 20 \%$ of the membrane costs.

Figure $2.13 \mathrm{a}$ shows that the total savings of membranes with a selectivity of $\geq 300$ increase with increasing permeance and that these are profitable along the entire investigated permeance range. The highest possible saving that can be obtained is $16 \%$. When the membrane selectivity is reduced to 100 , a minimum permeance of $0.4 \cdot 10^{-5} \mathrm{~mol} /\left(\mathrm{m}^{2} \mathrm{~s} \mathrm{kPa}\right)$ is required to have no net loss. From this point onwards, the total net savings increase with 
increasing permeance up to a total of $6 \%$. Lastly, a membrane selectivity of 30 requires a minimum permeance of $2.7 \cdot 10^{-5} \mathrm{~mol} /\left(\mathrm{m}^{2} \mathrm{~s} \mathrm{kPa}\right)$ to have positive net savings.

For all investigated selectivities, the increase in $\mathrm{C}_{2} \mathrm{H}_{4}$ permeance becomes less significant for the total savings once a permeance of $1 \cdot 10^{-5} \mathrm{~mol} /\left(\mathrm{m}^{2} \mathrm{~s} \mathrm{kPa}\right)$ is obtained. At low $\mathrm{C}_{2} \mathrm{H}_{4}$ permeances, large membrane areas are required, which makes the membrane investment costs a significant factor as discussed earlier. By increasing the $\mathrm{C}_{2} \mathrm{H}_{4}$ permeance, the membrane surface area required and hence, the membrane investment costs, are significantly reduced. This effect diminishes at higher $\mathrm{C}_{2} \mathrm{H}_{4}$ permeances, since the contribution of the membrane investment costs to the total investment costs reduces. Motelica et al. reported that a similar selectivity of 60 combined with an $\mathrm{C}_{2} \mathrm{H}_{4}$ permeance of approximately $1 \cdot 10^{-4}$ $\mathrm{mol} /\left(\mathrm{m}^{2} \mathrm{~s} \mathrm{kPa}\right)$ is required to obtain net savings.[13] Their required permeance is an order of magnitude higher than the one found in this study, which is the result of their methodology: they fixed the $\mathrm{C}_{2} \mathrm{H}_{6}$ permeance and as such did not investigate the effect of the $\mathrm{C}_{2} \mathrm{H}_{4}$ permeance on cost reduction independent of the membrane selectivity.

A sensitivity analysis was performed by changing the price per $\mathrm{m}^{2}$ membrane area with \pm 20\%. The results are presented as error bars in Figure 2.13a and show a total variation of 1.7 percentage points for membranes with a permeance of $2.8 \cdot 10^{-6} \mathrm{~mol} /\left(\mathrm{m}^{2} \mathrm{~s} \mathrm{kPa}\right)$ and a selectivity of 30 . As the selectivity of the membrane increases to 100 and 300 , the total variation also increases, to 3.4 percentage points and 4.3 percentage points, respectively. High selective, but low permeable membranes can still significantly reduce the total annual costs given a large enough surface area $\left(\approx 50,000 \mathrm{~m}^{2}\right)$. However, the total membrane CAPEX with such large areas, is very sensitive towards fluctuations in membrane costs and hence, the total annual savings. When the $\mathrm{C}_{2} \mathrm{H}_{4}$ permeance of the membranes increases by a factor of 10 to $2.8 \cdot 10^{-5} \mathrm{~mol} /\left(\mathrm{m}^{2} \mathrm{~s} \mathrm{kPa}\right)$, the total variation in the total savings is reduced to below 1 percentage point for any selectivity. According to Equation 2.3, the $\mathrm{C}_{2} \mathrm{H}_{4}$ permeance is inversely proportional to the membrane area, which makes the total annual savings for membranes with a high $\mathrm{C}_{2} \mathrm{H}_{4}$ permeance, and thus a low membrane area, less sensitive towards price fluctuations.

The total annual savings that can be obtained are directly related to the ROI for the installation of a membrane unit. Figure $2.13 \mathrm{~b}$ shows the ROI for the membranes with a selectivity of 100 and 300 as function of the $\mathrm{C}_{2} \mathrm{H}_{4}$ permeance for a membrane price of $\$ 100 \pm$ $20 \%$. The return on investment shows an inverse relationship with the $\mathrm{C}_{2} \mathrm{H}_{4}$ permeance and 
decreases with increasing permeance. A return of investment of $\leq 5$ years is only possible with permeances of $2.5 \cdot 10^{-5} \mathrm{~mol} /\left(\mathrm{m}^{2} \mathrm{~s} \mathrm{kPa}\right)$ for membranes with a selectivity of 100 . Once the membrane selectivity is increased to 300 , a minimum permeance of only $0.8 \cdot 10^{-5}$ $\mathrm{mol} /\left(\mathrm{m}^{2} \mathrm{~s} \mathrm{kPa}\right)$ is required to obtain a ROI less than 5 years. Since the total annual savings are quite sensitive towards the price $/ \mathrm{m}^{2}$ for membranes with a low permeance, as can be seen in Figure 2.13a, the ROI varies significantly as well. When the $\mathrm{C}_{2} \mathrm{H}_{4}$ permeance is increased beyond 1.0 and $0.5 \cdot 10^{-5} \mathrm{~mol} /\left(\mathrm{m}^{2} \mathrm{~s} \mathrm{kPa}\right)$ for membranes with a selectivity of 100 and 300 respectively, the fluctuations in ROI are reduced to 2-6 months.

Given the selectivity required $(\geq 30$ ), it will be challenging from a practical point of view to reach this value, since currently commercially available polymeric membranes do not possess the necessary selectivity yet.[17] Facilitated transport membranes have reported $\mathrm{C}_{2} \mathrm{H}_{4} / \mathrm{C}_{2} \mathrm{H}_{6}$ selectivities of over 100, but this class of membranes suffers from long term stability issues, carrier poisoning and leaching.[25, 27] In addition, facilitated transport membranes often require water vapor to facilitate the transport, [24, 45-47] which is not present in this case. Room temperature ionic liquid (RTIL) membranes with the addition of Ag (I) salts show a more stabilized performance regarding both selectivities and permeabilities.[28, 48-50] Kim et al. [28] showed that composite polyester membranes impregnated with zwitterionic RTIL with addition of $\mathrm{AgNO}_{3}$ had a stable $\mathrm{C}_{2} \mathrm{H}_{4}$ permeance and $\mathrm{C}_{2} \mathrm{H}_{4} / \mathrm{C}_{2} \mathrm{H}_{6}$ selectivity of $8.5 \cdot 10^{-6}$ $\mathrm{cm}^{3} /\left(\mathrm{cm}^{2} \mathrm{~s} \mathrm{cmHg}\right)\left(=2.8 \cdot 10^{-6} \mathrm{~mol} /\left(\mathrm{m}^{2} \mathrm{~s} \mathrm{kPa}\right)\right.$ and 120 , respectively, for up to 50 hours. However, this class of membranes is operated around atmospheric feed and permeate pressures, which makes their applicability unsuitable. Addition of Metal-OrganicFrameworks (MOFs) to a polymer matrix has shown promising effects towards increasing permeabilities and selectivities of various gas pairs e.g. $\mathrm{CO}_{2} / \mathrm{CH}_{4}$ and $\mathrm{CO}_{2} / \mathrm{N}_{2}$ [39], propylene/propane [21] and $\mathrm{C}_{2} \mathrm{H}_{4} / \mathrm{C}_{2} \mathrm{H}_{6}$. $[19,20]$ Still, the currently obtained selectivities are too low, which mandates research towards the synthesis of more selective MOFs.

The required permeances found in this study to break even are also quite high compared to reported permeabilities found in literature.[25] $\mathrm{An}_{2} \mathrm{H}_{4}$ permeance of $1.0 \cdot 10^{-5} \mathrm{~mol} /\left(\mathrm{m}^{2} \mathrm{~s}\right.$ $\mathrm{kPa}$ ) equals 30 Barrer assuming a membrane thickness of $1 \mu \mathrm{m}$. However, the permeance can also be increased by reducing the membrane thickness. Although it is still quite a challenge to produce thinner membranes, many efforts are done to get large areas of defect free thin membranes with e.g. interfacial polymerization [51] or Layer-by-Layer (LbL) membrane fabrication.[52, 53] Leväsalmi managed to produce between 6.5-300 $\AA$ thin polymer films by 
alternating LbL deposition, which possessed excellent gas permeation properties.[53] It is expected that the required permeance will be a realistic aspect to achieve in the future. 


\subsection{Conclusions}

A hybrid membrane-distillation plant has been successfully modeled. Three different configurations (parallel, series 1,500 kmol/hr and series 2,500 kmol/hr) have been evaluated in terms of possible total annual savings, by varying the $\mathrm{C}_{2} \mathrm{H}_{4}$ permeance and $\mathrm{C}_{2} \mathrm{H}_{4} / \mathrm{C}_{2} \mathrm{H}_{6}$ selectivity of the membrane unit. The most promising configuration proved to be the 2,500 $\mathrm{kmol} / \mathrm{hr}$ series configuration due to the highest possible flow to the membrane unit. This configuration was further optimized by altering the membrane feed and permeate pressure and the membrane surface area.

The highest total savings of $16 \%\left(\alpha=300\right.$, permeance $\left.=2.8 \cdot 10^{-5} \mathrm{~mol} /\left(\mathrm{m}^{2} \mathrm{~s} \mathrm{kPa}\right)\right)$ can be obtained with the $2,500 \mathrm{kmol} / \mathrm{hr}$ series configuration. A minimum $\mathrm{C}_{2} \mathrm{H}_{4} / \mathrm{C}_{2} \mathrm{H}_{6}$ selectivity of 30 is necessary to gain positive savings and these increase with increasing selectivity up to 300 , after which diminishing returns will play a significant role due to enriching the permeate beyond $\mathrm{C}_{2} \mathrm{H}_{4}$ purity specifications of $99.95 \%$. The required $\mathrm{C}_{2} \mathrm{H}_{4}$ permeance to break-even is $2.8 \cdot 10^{-5} \mathrm{~mol} /\left(\mathrm{m}^{2} \mathrm{~s} \mathrm{kPa}\right), 4.2 \cdot 10^{-6} \mathrm{~mol} /\left(\mathrm{m}^{2} \mathrm{~s} \mathrm{kPa}\right)$ and $2.0 \cdot 10^{-6} \mathrm{~mol} /\left(\mathrm{m}^{2} \mathrm{~s} \mathrm{kPa}\right)$ by extrapolation for membranes with a selectivity of 30, 100 and 300, respectively. Once membranes with $\mathrm{C}_{2} \mathrm{H}_{4}$ permeances of $1 \cdot 10^{-5} \mathrm{~mol} /\left(\mathrm{m}^{2} \mathrm{~s} \mathrm{kPa}\right)$ are obtained, it is advised that the focus shifts towards increasing the selectivity to maximize the total savings.

It is not only favorable to compress the membrane feed pressure to $4,850 \mathrm{kPa}$ to assure the highest possible driving force over the membrane, but also to increase the membrane feed stream temperature to $49^{\circ} \mathrm{C}$, which allows for realistic membrane process conditions. The optimum permeate pressure approaches $2,050 \mathrm{kPa}$ with increasing $\mathrm{C}_{2} \mathrm{H}_{4}$ permeance so the permeate can re-enter the distillation column without the need for compression or expansion. The optimum membrane surface area was calculated for the given process conditions and varies between $8,000-60,000 \mathrm{~m}^{2}$.

\section{Acknowledgements}

This project is financially supported by AgentschapNL. The authors would like to thank ECN, Dow and SolSep for the fruitful discussions. 


\section{Nomenclature}

$\begin{array}{ll}\mathrm{A} & =\text { area }\left(\mathrm{m}^{2}\right) \\ \text { CAPEX } & =\text { capital expenditures }(\$ / \mathrm{y}) \\ \text { Com } & =\text { compression } \\ \text { Con } & =\text { condensor } \\ \text { Cool } & =\text { cooling } \\ \text { EOS } & =\text { equation of state } \\ \text { LbL } & =\text { Layer-by-Layer } \\ \text { MOF } & =\text { metal-organic framework } \\ \mathrm{n} & =\text { flux }(\mathrm{kmol} / \mathrm{hr}) \\ \mathrm{N} & =\text { number of stages or } 100 \% \text { efficient trays } \\ \text { OPEX } & =\text { operating expenditures }(\$ / \mathrm{y}) \\ \mathrm{p} & =\text { partial pressure }(\mathrm{kPa}) \\ \mathrm{P} & =\text { pressure }(\mathrm{kPa}) \\ \mathrm{PCE} & =\text { purchase cost of equipment }(\$) \\ \mathrm{PR} & =\text { Peng Robinson } \\ \mathrm{Q} & =\text { permeance }\left(\text { mol } /\left(\mathrm{m}^{2} \mathrm{~s} \mathrm{kPa}\right)\right) \\ \mathrm{R} & =\text { reflux ratio } \\ \mathrm{Reb} & =\text { reboiler } \\ \mathrm{ROI} & =\text { return on investment }(\mathrm{y}) \\ \mathrm{S} & =\text { capacity or size parameter of equipment } \\ \mathrm{SRK} & =\text { Soave-Redlich-Kwong } \\ \mathrm{T} & =\text { temperature }\left({ }^{\circ} \mathrm{C}\right) \\ \mathrm{TAC} & =\text { total annualized costs }(\$ / \mathrm{y}) \\ \mathrm{X} & =\text { molar } \mathrm{C}_{2} \mathrm{H}_{4} \text { fraction } \\ \mathrm{y} & =\text { year }\end{array}$

Greek

$\alpha$

$=$ selectivity

$\theta \quad=$ stage-cut

\begin{tabular}{|c|c|}
\hline $\begin{array}{l}\text { Subscript } \\
\text { annu }\end{array}$ & $=$ annualized \\
\hline $\mathrm{B}$ & $=$ bottom \\
\hline $\mathrm{D}$ & $=$ distillate \\
\hline Dis & $=$ distillation base case \\
\hline $\mathrm{f}$ & $=$ fast \\
\hline $\mathrm{F}$ & $=$ feed \\
\hline Hyb & $=$ hybrid membrane-distillation \\
\hline $\operatorname{lm}$ & $=$ logarithmic mean \\
\hline $\mathrm{m}$ & $=$ membrane \\
\hline $\min$ & $=$ minimum \\
\hline $\mathrm{P}$ & $=$ permeate \\
\hline $\mathrm{R}$ & $=$ retentate \\
\hline S & $=$ slow \\
\hline
\end{tabular}




\section{Bibliography}

1. Eldridge, R.B., Olefin/paraffin separation technology: A review. Industrial and Engineering Chemistry Research, 1993. 32(10): p. 2208-2212.

2. Humphrey, J.L., Separation processes: Playing a critical role. Journal Name: Chemical Engineering Progress; Journal Volume: 91; Journal Issue: 10; Other Information: PBD: Oct 1995, 1995: p. Medium: X; Size: pp. 31-41.

3. $232^{\text {nd }}$ ACS National Meeting, San Francisco, Sept. 10-14. Chemical and Engineering News 2006. 84(34): p. 59-236.

4. Pressly, T.G. and K.M. Ng, A Break-Even Analysis of Distillation-Membrane Hybrids. AIChE Journal, 1998. 44(1): p. 93-105.

5. Moganti, S., R.D. Noble, and C.A. Koval, Analysis of a membrane/distillation column hybrid process. Journal of Membrane Science, 1994. 93(1): p. 31-44.

6. Stephan, W., R.D. Noble, and C.A. Koval, Design methodology for a membrane/distillation column hybrid process. Journal of Membrane Science, 1995. 99(3): p. 259-272.

7. Kreis, P. and A. Górak, Process analysis of hybrid separation processes: Combination of distillation and pervaporation. Chemical Engineering Research and Design, 2006. 84(7 A): p. 595-600.

8. Pettersen, T. and K.M. Lien, Design of hybrid distillation and vapor permeation processes. Journal of Membrane Science, 1995. 102(1-3): p. 21-30.

9. Fahmy, A., D. Mewes, and K. Ebert, Design methodology for the optimization of membrane separation properties for hybrid vapor permeation-distillation processes. Separation Science and Technology, 2001. 36(15): p. 3287-3304.

10. Caballero, J.A., et al., Design of Hybrid Distillation-Vapor Membrane Separation Systems. Industrial \& Engineering Chemistry Research, 2009. 48(20): p. 9151-9162.

11. Kookos, I.K., Optimal design of membrane/distillation column hybrid processes. Industrial and Engineering Chemistry Research, 2003. 42(8): p. 1731-1738.

12. Pettersen, T., et al., Design of combined membrane and distillation processes. Separations Technology, 1996. 6(3): p. 175-187.

13. Motelica, A., et al., Membrane retrofit option for paraffin/olefin separation-a technoeconomic evaluation. Industrial and Engineering Chemistry Research, 2012. 51(19): p. 6977-6986.

14. Barrer, R.M. and E.K. Rideal, Permeation, diffusion and solution of gases in organic polymers. Transactions of the Faraday Society, 1939. 35: p. 628-643.

15. Yampolskii, Y., I. Pinnau, and B.D. Freeman, Materials Science of Membranes2007, Chichester: John Wiley \& Sons Ltd.

16. Staudt-Bickel, C. and W.J. Koros, Olefin/paraffin gas separations with 6FDA-based polyimide membranes. Journal of Membrane Science, 2000. 170(2): p. 205-214.

17. Rungta, M., L. Xu, and W.J. Koros, Carbon molecular sieve dense film membranes derived from Matrimid $\AA$ for ethylenelethane separation. Carbon, 2012. 50(4): p. 1488-1502.

18. Xu, L., M. Rungta, and W.J. Koros, Matrimid ${ }^{\circledR}$ derived carbon molecular sieve hollow fiber membranes for ethylene/ethane separation. Journal of Membrane Science, 2011. 380(1-2): p. 138-147.

19. Ploegmakers, J., S. Japip, and K. Nijmeijer, Mixed matrix membranes containing MOFs for ethylenelethane separation Part A: Membrane preparation and characterization. Journal of Membrane Science, 2013. 428: p. 445-453.

20. Ploegmakers, J., S. Japip, and K. Nijmeijer, Mixed matrix membranes containing MOFs for ethylene/ethane separation-Part B: Effect of Cu3BTC2 on membrane transport properties. Journal of Membrane Science, 2013. 428: p. 331-340. 
21. Zhang, C., et al., High performance ZIF-8/6FDA-DAM mixed matrix membrane for propylene/propane separations. Journal of Membrane Science, 2012. 389: p. 34-42.

22. Tanh Jeazet, H.B., C. Staudt, and C. Janiak, Metal-organic frameworks in mixedmatrix membranes for gas separation. Dalton Transactions, 2012. 41(46): p. 1399114212.

23. Morisato, A., et al., Transport properties of PA12-PTMO/AgBF $\langle$ sub $>4</ s u b>$ solid polymer electrolyte membranes for olefin/paraffin separation. Desalination, 2002. 145(1-3): p. 347-351.

24. Müller, J. and K.V. Peinemann, Development of facilitated transport membranes for the separation of olefins from gas streams. Desalination, 2002. 145(1-3): p. 339-345.

25. Pinnau, I. and L.G. Toy, Solid polymer electrolyte composite membranes for olefin/paraffin separation. Journal of Membrane Science, 2001. 184(1): p. 39-48.

26. Teramoto, M., et al., Ethylenelethane separation by facilitated transport membrane accompanied by permeation of aqueous silver nitrate solution. Separation and Purification Technology, 2002. 28(2): p. 117-124.

27. Hamouda, S.B., et al., Facilitated transport of ethylene in poly (amide 12-block tetramethylenoxide) copolymer/AgBF $<$ sub $>4</$ sub $>$ membranes containing silver (I) and copper (I) ions as carriers. Journal of Applied Sciences, 2008. 8(7): p. 13101314.

28. Kim, H.S., et al., Multi-functional zwitterionic compounds as new membrane materials for separating olefin-paraffin mixtures. Green Chemistry, 2007. 9(6): p. 599-604.

29. Benali, M. and B. Aydin, Ethanelethylene and propane/propylene separation in hybrid membrane distillation systems: Optimization and economic analysis. Separation and Purification Technology, 2010. 73(3): p. 377-390.

30. Zimmermann, $\mathrm{H}$. and R. Walzl, in Ullmann's Encyclopedia of Industrial Chemistry2000, Wiley-VCH Verlag GmbH \& Co. KGaA.

31. Turton, R., et al., Analysis, Synthesis and Design of Chemical Processes - Second Edition2003: Prentice HAll INternational Series.

32. Soave, G., Equilibrium constants from a modified Redlich-Kwong equation of state. Chemical Engineering Science, 1972. 27(6): p. 1197-1203.

33. Peng, D.Y. and D.B. Robinson, A new two-constant equation of state. Industrial and Engineering Chemistry Fundamentals, 1976. 15(1): p. 59-64.

34. Ayotte-Sauvé, E., M. Sorin, and F. Rheault, Energy Requirement of a Distillation/Membrane Parallel Hybrid: A Thermodynamic Approach. Industrial \& Engineering Chemistry Research, 2010. 49(5): p. 2295-2305.

35. Davis, R.A., Simple Gas Permeation and Pervaporation Membrane Unit Operation Models for Process Simulators. Chemical Engineering \& Technology, 2002. 25(7): p. 717-722.

36. Chen, J.J.J., Comments on improvements on a replacement for the logarithmic mean. Chemical Engineering Science, 1987. 42(10): p. 2488-2489.

37. Fletcher, R. and C.M. Reeves, Function minimization by conjugate gradients. The Computer Journal, 1964. 7(2): p. 149-154.

38. McCandless, F.P., Separation of binary mixtures of $\mathrm{CO}$ and $\mathrm{H} 2$ by permeation through polymeric films. Industrial and Engineering Chemistry: Process and Design Development, 1972. 11(4): p. 470-478.

39. Basu, S., A. Cano-Odena, and I.F.J. Vankelecom, MOF-containing mixed-matrix membranes for CO2/CH4 and CO2/N2 binary gas mixture separations. Separation and Purification Technology, 2011. 81(1): p. 31-40. 
40. Schultz, J. and K.V. Peinemann, Membranes for separation of higher hydrocarbons from methane. Journal of Membrane Science, 1996. 110(1): p. 37-45.

41. Singh, A., B.D. Freeman, and I. Pinnau, Pure and mixed gas acetone/nitrogen permeation properties of polydimethylsiloxane [PDMS]. Journal of Polymer Science, Part B: Polymer Physics, 1998. 36(2): p. 289-301.

42. Ghosal, K. and B.D. Freeman, Gas separation using polymer membranes: An overview. Polymers for Advanced Technologies, 1994. 5(11): p. 673-697.

43. Sinnott, R.K. and G. Towler, Coulson \& Richardson Chemical Engineering Design: Chemical Engineering. 5th ed. Vol. 6. 2009: Elsevier.

44. Freriks, A., DACE price booklet. 28 ed2011, Amsterdam: Reed Business.

45. Eriksen, O.I., E. Aksnes, and I.M. Dahl, Facilitated transport of ethene through Nafion membranes. Part I. Water swollen membranes. Journal of Membrane Science, 1993. 85(1): p. 89-97.

46. Eriksen, O.I., E. Aksnes, and I.M. Dahl, Facilitated transport of ethene through Nafion membranes. Part II. Glycerine treated, water swollen membranes. Journal of Membrane Science, 1993. 85(1): p. 99-106.

47. Hong, S.U., J.Y. Kim, and Y.S. Kang, Effect of water on the facilitated transport of olefins through solid polymer electrolyte membranes. Journal of Membrane Science, 2001. 181(2): p. 289-293.

48. Teramoto, M., et al., Separation of ethylene from ethane by supported liquid membranes containing silver nitrate as a carrier. Journal of Chemical Engineering of Japan, 1986. 19(5): p. 419-424.

49. Kang, S.W., K. Char, and Y.S. Kang, Novel application of partially positively charged silver nanoparticles for facilitated transport in olefin/paraffin separation membranes. Chemistry of Materials, 2008. 20(4): p. 1308-1311.

50. Kim, H.S., et al., Separation of olefin/paraffin mixtures using zwitterionic silver complexes as transport carriers. Chemistry - A European Journal, 2007. 13(9): p. 2655-2660.

51. Morgan, P.W., Condensation polymers by Interfacial and Solution Methods. Polymer Series, 1965. 10: p. 19-64.

52. Krasemann, L. and B. Tieke, Selective ion transport across self-assembled alternating multilayers of cationic and anionic polyelectrolytes. Langmuir, 2000. 16(2): p. 287290.

53. Leväsalmi, J.M. and T.J. McCarthy, Poly(4-methyl-1-pentene)-supported polyelectrolyte multilayer films: Preparation and gas permeability. Macromolecules, 1997. 30(6): p. 1752-1757. 
Chapter 2. 


\section{Chapter 3}

\section{Penetrant induced sorption and swelling phenomena in thin PPO films resolved by spectroscopic ellipsometry}

This chapter is in preparation to be published as:

J. Ploegmakers, Penetrant induced sorption and swelling phenomena in thin PPO films resolved by spectroscopic ellipsometry 


\section{Abstract}

Swelling and sorption in thin PPO films of $\mathrm{C}_{2} \mathrm{H}_{4}$ and $\mathrm{C}_{2} \mathrm{H}_{6}$ was investigated with spectroscopic ellipsometry and compared to that of $\mathrm{CO}_{2}$ and $\mathrm{N}_{2} \cdot \mathrm{C}_{2} \mathrm{H}_{4}$ showed similar swelling as $\mathrm{CO}_{2}$, while $\mathrm{C}_{2} \mathrm{H}_{6}$ showed with $4 \%$ the highest swelling at 30 bar. Cumulative secondary relaxations were more pronounced in $\mathrm{C}_{2} \mathrm{H}_{4}$ and $\mathrm{C}_{2} \mathrm{H}_{6}$ as compared to $\mathrm{CO}_{2}$, which could have severe consequences for the membrane performance. Penetrant concentrations in thin PPO films were calculated using an optical model that included pressure dependent refractive indices and densities of penetrants in the gas phase. Next to Fickian swelling, nonFickian relaxations and hysteresis between pressurization-depressurization runs was observed for $\mathrm{CO}_{2}, \mathrm{C}_{2} \mathrm{H}_{4}$ and $\mathrm{C}_{2} \mathrm{H}_{6}$, while only Fickian behavior was observed for $\mathrm{N}_{2}$. Lower concentrations in thin films were found as compared to bulk films. Finally, based on the results, partial molar volumes of all penetrants were estimated and a concentration dependency was found for $\mathrm{CO}_{2}, \mathrm{C}_{2} \mathrm{H}_{4}$ and $\mathrm{C}_{2} \mathrm{H}_{6}$, in contrast to the solution-diffusion model for gas permeation assuming constant partial molar volumes. 


\subsection{Introduction}

Gas transport through dense glassy membranes depends on several parameters, such as sorption and diffusion coefficients, the nature of the permeating component, the membrane chemistry and its fabrication and history [1,2]. Additionally, penetrant induced plasticization, which often occurs in glassy polymers, complicates this even further [3, 4]. Furthermore, most studies are performed on bulk, flat sheet membranes $(10-100 \mu \mathrm{m})$, while membranes used for commercial applications are usually asymmetric integrally skinned membranes with a selective layer of less than $1 \mu \mathrm{m}$. Decreasing the membrane thickness has an immediate effect on the total flux through the membranes and consequently, the capital costs [5]. Therefore, it is expected that membranes will become increasingly thinner. However, several studies show that thin films show different behavior from bulk films in several areas [6-8], but especially for $\mathrm{CO}_{2}$.

A great effort to investigate the difference between bulk and thin films has been done by the group of Paul. They showed that the aging rate of thin glassy PS, PPO and Matrimid films is significantly faster than for the corresponding bulk films [9]. Consequently, the $\mathrm{N}_{2}, \mathrm{O}_{2}$ and $\mathrm{CH}_{4}$ permeability of thin films as the result of this accelerated physical aging, declined faster when compared to bulk films. The effect of $\mathrm{CO}_{2}$ on aging rate, permeability, selectivity and plasticization phenomena has been extensively studied as well [8, 10-14]. Exposure to $\mathrm{CO}_{2}$ decreases the membrane selectivity, even for the separation of non-plasticizing gases such as $\mathrm{O}_{2} / \mathrm{N}_{2}$ [10]. $\mathrm{CO}_{2}$ swells the polymer film, thereby increasing not only its own permeability, but also the permeability of the slower permeating components, resulting in a decreased selectivity. $\mathrm{CO}_{2}$ induced plasticization was found to be dependent on membrane thickness, aging time, $\mathrm{CO}_{2}$ pressure, exposure time and prior history of the membrane [8]. Especially thin films showed enhanced plasticization and physical aging effects. This shows the importance of understanding the influence of plasticizing gases like $\mathrm{CO}_{2}$, especially in thin films.

Analysis of swelling phenomena in thin polymer films is often performed by spectroscopic ellipsometry [7, 15-17]. This non-destructive optical method allows for in-situ determination of both thickness and refractive index. These two parameters can be used to calculate concentrations of penetrants in a polymer matrix. Sirard et al. used this method to estimate the mass fraction of $\mathrm{CO}_{2}$ in PDMS at elevated pressures [15]. Subsequently, this method has been used by several others, but in all cases, several assumptions were made like pressure independence of the molar refractivity and the density, as well as the assumption that the 
refractive index and density of $\mathrm{CO}_{2}$ in the polymer matrix is that of $\mathrm{CO}_{2}$ in a liquid/super critical state $[6,7,17]$.

Besides $\mathrm{CO}_{2}$, membrane based separation of $\mathrm{C}_{2} \mathrm{H}_{4}$ from $\mathrm{C}_{2} \mathrm{H}_{6}$ is a very significant separation [18-21]. Olefin/paraffin separation is one of the most important separations in the petrochemical industry and the development of membranes that can accomplish this separation is far from trivial. Yet to the best of the authors` knowledge, no studies exist on thin polymer film swelling and plasticization phenomena when exposed to $\mathrm{C}_{2} \mathrm{H}_{4}$ and $\mathrm{C}_{2} \mathrm{H}_{6}$ atmospheres. Since the Lennard Jones (LJ) diameter and the Van der Waals volume of $\mathrm{C}_{2} \mathrm{H}_{4}$ and $\mathrm{C}_{2} \mathrm{H}_{6}$ surpasses those of $\mathrm{CO}_{2}$, while their critical temperatures are comparable (Table 3.1), it can be expected that the sorption induced swelling of polymers when exposed to these gases is significant.

Table 3.1. General properties of $\mathrm{N}_{2}, \mathrm{CO}_{2}, \mathrm{C}_{2} \mathrm{H}_{4}$ and $\mathrm{C}_{2} \mathrm{H}_{6}$.

\begin{tabular}{lcccc}
\hline Gas & $\begin{array}{c}\text { Molecular mass } \\
(\mathrm{g} / \mathrm{mol})\end{array}$ & $\begin{array}{c}\text { LJ diameter } \\
\mathrm{d}_{\mathrm{LJ}}(\AA)[22]\end{array}$ & $\begin{array}{c}\text { Van der Waals volume } \\
\left(\mathrm{cm}^{3} / \mathrm{mol}\right)[23]\end{array}$ & $\begin{array}{c}\text { Critical temperature } \\
\mathrm{T}_{\mathrm{c}}(\mathrm{K})\end{array}$ \\
\hline $\mathrm{N}_{2}$ & 28.01 & 3.798 & 38.7 & 126.2 \\
$\mathrm{CO}_{2}$ & 44.01 & 3.941 & 42.9 & 304.2 \\
$\mathrm{C}_{2} \mathrm{H}_{4}$ & 28.05 & 4.163 & 58.2 & 282.5 \\
$\mathrm{C}_{2} \mathrm{H}_{6}$ & 30.07 & 4.443 & 65.1 & 305.3 \\
\hline
\end{tabular}

This chapter aims to systematically investigate the sorption and swelling phenomena for several penetrants in thin PPO films. First, swelling of thin PPO films by four different penetrants is investigated. $\mathrm{N}_{2}$ is taken as control, because of its inert nature. On the other hand, $\mathrm{CO}_{2}$ is a known plasticizer and therefore used for comparison. Subsequently, $\mathrm{C}_{2} \mathrm{H}_{4}$ and $\mathrm{C}_{2} \mathrm{H}_{6}$ induced swelling in thin PPO films is investigated and compared to that of $\mathrm{CO}_{2}$ and $\mathrm{N}_{2}$. Non-equilibrium hysteresis as the result of penetrant sorption is investigated. Finally, the penetrant induced sorption in thin films, taking pressure dependency into account, is compared to sorption in bulk PPO films. In addition, the partial molar volume of the penetrants in thin PPO films is evaluated. 


\subsection{Theory}

\subsubsection{Ellipsometry}

Spectroscopic ellipsometry is an indirect, non-destruction optical method that can be used to determine the thickness and optical properties of thin supported layers. A sample is illuminated with polarized light, after which the polarization state of the reflected light is analyzed by a detector. The parameters psi $(\Psi)\left({ }^{\circ}\right)$ and delta $(\triangle)\left({ }^{\circ}\right)$ are used to describe the changes in the reflectivity ( $r$ ) of the in plane (p) and out of plane (s) polarization state:

$$
\rho=\frac{r_{p}}{r_{s}}=\tan (\Psi) e^{i \Delta}
$$

Psi describes changes in the amplitude ratio of the $\mathrm{p}$ - and s- polarized waves, while delta describes changes in the phase difference. For more information about the principles of ellipsometry, the reader is referred to [25]. Changes in psi and delta at various wavelengths can be interpreted by means of an optical model. This optical model describes the sample as a multilayer system in which each layer can be independently modeled. For dielectric materials, the refractive index (n) can be described by the Cauchy equation:

$$
n=A+\frac{B}{\lambda^{2}}+\frac{C}{\lambda^{4}}+\cdots
$$

where $\lambda$ is the wavelength of the light in $\mathrm{nm}$ and $\mathrm{A}, \mathrm{B}$ and $\mathrm{C}$ are constants.

Upon sorption of a penetrant in a transparent polymer film, the change in refractive index can be related directly to the concentration of the penetrant in the film. The refractive index of a pure component is related to its molecular mass, density and refractivity by the LorentzLorenz equation (also known as the Clausius-Mosotti equation): 


$$
\frac{n^{2}-1}{n^{2}+2}=\frac{A_{j}}{M_{w j}} \rho_{j}
$$

where $n(-)$ is the refractive index of the swollen film, $A_{j}$ is the molar refractivity of component $\mathrm{j}\left(\mathrm{m}^{3} / \mathrm{mol}\right), \mathrm{M}_{\mathrm{wj}}$ is the molecular mass of component $\mathrm{j}(\mathrm{kg} / \mathrm{mol})$ and $\rho_{\mathrm{j}}$ is the density of component $\mathrm{j}\left(\mathrm{kg} / \mathrm{cm}^{3}\right)$. The mass based concentration of the penetrant inside the polymer can then to a certain extend be estimated by applying the Lorentz-Lorenz mixing rule:

$$
\frac{n^{2}-1}{n^{2}+2}=\frac{A_{\text {penetrant }}}{M_{w \text { penetrant }}} C_{\text {penetrant }}+\frac{A_{P P O}}{M_{w P P O}} C_{P P O}
$$

where $A_{\text {penetrant }}$ and $A_{P P O}$ are the molar refractivities $\left(\mathrm{m}^{3} / \mathrm{mol}\right), M_{w}$ penetrant and $M_{w}$ PPO the molecular mass $(\mathrm{kg} / \mathrm{mol})$ and $\mathrm{C}_{\text {penetrant }}$ and $\mathrm{C}_{\mathrm{PPO}}$ the mass based concentrations $\left(\mathrm{kg} / \mathrm{cm}^{3}\right)$ of the sorbed penetrant and the polymer PPO, respectively.

The pure component data for PPO can be determined experimentally at vacuum using Equation 3.3. The mass based concentration of swollen PPO $\left(\mathrm{C}_{\mathrm{PPO}}\right)\left(\mathrm{kg} / \mathrm{m}^{3}\right)$ can be calculated as:

$$
C_{P P O}=\rho_{P P O} \frac{h_{0}}{h}
$$

where $\mathrm{h}_{0}$ is the initial thickness (nm) of the polymer film at vacuum and $\mathrm{h}$ is the film thickness $(\mathrm{nm})$ of the swollen PPO film as determined from experimental spectroscopic ellipsometry data. 


\subsubsection{Dual-mode sorption}

Gas sorption in glassy polymeric membranes can be described by the dual-mode sorption model, which assumes two different sorption mechanisms to take place simultaneously, namely sorption directly proportional to the pressure following Henry`s law, and Langmuir sorption, which relies on a hole-filling mechanism [26]. The gas concentration inside the membrane $(\mathrm{C})\left(\mathrm{kg} / \mathrm{m}^{3}\right)$ can be described by Equation 3.6:

$$
C=k_{d} \cdot p+\frac{C_{H}^{\prime} \cdot b \cdot p}{1+b \cdot p}
$$

where $\mathrm{k}_{\mathrm{d}}$ is Henry`s constant $\left(\mathrm{kg} /\left(\mathrm{m}^{3}\right.\right.$ bar $\left.)\right)$, $\mathrm{p}$ the pressure (bar), $\mathrm{C}_{\mathrm{H}}{ }_{\mathrm{H}}$ the Langmuir capacity constant $\left(\mathrm{kg} / \mathrm{m}^{3}\right)$ and $\mathrm{b}$ the Langmuir affinity constant (1/bar). 


\subsection{Experimental}

\subsubsection{Materials and sample preparation}

Poly(2,6-dimethyl-phenylene oxide) PPO (Ultra High $\mathrm{M}_{\mathrm{w}}$ ) was obtained from Parker while $\mathrm{CHCl}_{3}$ was obtained from Merck KGaA. Si substrates were obtained in-house. $\mathrm{N}_{2}$ (3.0) was supplied by Linde, while $\mathrm{CO}_{2}$ (4.6), $\mathrm{C}_{2} \mathrm{H}_{4}$ (3.5) and $\mathrm{C}_{2} \mathrm{H}_{6}$ (2.5) were supplied by Praxair. All chemicals were used without further purification.

A $1 \%(\mathrm{w} / \mathrm{w} \%)$ PPO solution in $\mathrm{CHCl}_{3}$ was prepared and a thin polymer film was spincoated on a 15 x $15 \mathrm{~mm} \mathrm{Si}$ wafer at $2500 \mathrm{rpm}$ for 1 minute under $\mathrm{N}_{2}$ atmosphere. Thin PPO films between 100-150 nm were prepared this way. The spincoated samples were put in a $35{ }^{\circ} \mathrm{C}$ vacuum oven for at least 48 hours. Prior to installation in the ellipsometer, the sample was thermally annealed at $230{ }^{\circ} \mathrm{C}$ in a WTC Binder oven under $\mathrm{N}_{2}$ atmosphere for 2 hours.

To determine the sorption in bulk PPO, a $13 \%$ (w/w\%) PPO solution in $\mathrm{CHCl}_{3}$ was prepared. The solution was cast on a glass plate in a $\mathrm{N}_{2}$ box using a $0.47 \mathrm{~mm}$ casting knife at room temperature. After drying for 24 hours, the PPO film was removed from the glass plate by immersion in MilliQ water. Afterwards, the detached film was dried at $60{ }^{\circ} \mathrm{C}$ in a WTC Binder oven under $\mathrm{N}_{2}$ atmosphere overnight. The thickness of the PPO films was measured to be approximately $30 \mu \mathrm{m}$. Prior to placement in the magnetic suspension balance (MSB), the PPO film was thermally annealed at $230{ }^{\circ} \mathrm{C}$ under $\mathrm{N}_{2}$ atmosphere for 2 hours.

\subsubsection{Spectroscopic ellipsometry procedure}

The described procedure was used for all individual samples. Each experiment was performed with a newly prepared sample. The annealed PPO sample was put in a custom made high pressure cell for an Alpha-SE Spectroscopic Ellipsometer as described elsewhere [27]. The samples were degassed overnight by a rotary vacuum pump at $35.0{ }^{\circ} \mathrm{C}$. Each experiment consisted of two consecutive cycles where each cycle consisted of a step-wise pressurization run, followed by a step-wise depressurization run. During a pressurization run, subsequent pressure jumps were applied of $0,1,2,3,4,6,8,12,16,20,25$ and 30 bar. Each pressure step lasted for 90 minutes where the initial 5 minutes were used for temperature and pressure equilibration, while the remaining 85 minutes at constant pressure and temperature were used for determination of the film thickness and optical constants. The depressurization run followed a similar protocol with depressurization steps from 30 to 0 bar. After the first 
cycle was completed, the sample was kept at vacuum overnight prior to the second cycle. The second cycle consisted of a pressurization and depressurization run with pressure steps identical as described for the first cycle.

\subsubsection{Modeling of spectroscopic ellipsometry data}

To model the spectroscopic ellipsometry data, a multilayer model was made, shown in Figure 3.1, using CompleteEase 4.64 software. Optical constants for the $\mathrm{Si}$ wafer and $\mathrm{SiO}_{2}$ were taken from literature [28]. The native $\mathrm{SiO}_{2}$ layer was measured to be $2.0 \mathrm{~nm}$ on bare $\mathrm{Si}$ substrates. The PPO film was modeled using a Cauchy equation according to Equation 2. Since this equation is only valid for transparent films and PPO is known for absorption $<500$ $\mathrm{nm}$, a wavelength range between 500-900 nm was selected [7]. The thickness and A and B parameters were fitted, while $\mathrm{C}$ was found not to be significant.

Refractive indices of the pure penetrants at various pressures were interpolated using data from literature [29-31]. Table 3.2 shows the interpolated refractive indices for $\mathrm{N}_{2}, \mathrm{CO}_{2}, \mathrm{C}_{2} \mathrm{H}_{4}$, and $\mathrm{C}_{2} \mathrm{H}_{6}$ for various pressures. In addition, depolarization due to thickness inhomogeneity was fitted. Finally, birefringence was taken into account by calibration of a Si wafer with a thermal $\mathrm{SiO}_{2}$ layer of $76 \mathrm{~nm}$ and $\mathrm{He}$ at various pressures up to 30 bar.

Sorption isotherms were calculated using Equations 3.2-3.5. Refractive indices were varied as function of pressure using Table 3.2. Densities of the pure penetrants as function of pressure at $35{ }^{\circ} \mathrm{C}$ were taken from NIST . The pressure dependency of the refractive index and density implicitly implies that the sorbed penetrant remains in the gas phase. 


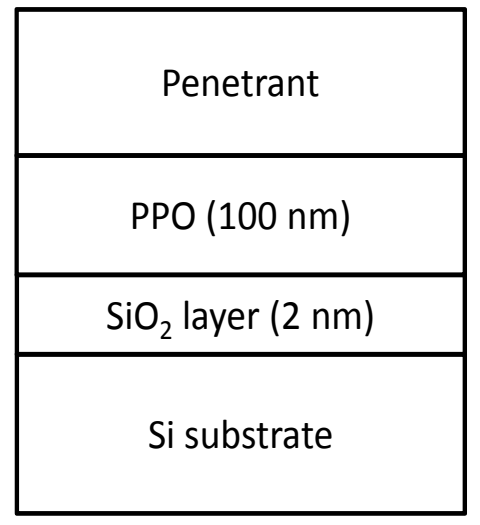

Figure 3.1. Schematic drawing of the optical model used.

Table 3.2. Refractive indices of $\mathrm{N}_{2}$ [31], $\mathrm{CO}_{2}$ [30], $\mathrm{C}_{2} \mathrm{H}_{4}$ [29] and $\mathrm{C}_{2} \mathrm{H}_{6}$ [30] up to 30 bar.

\begin{tabular}{ccccc}
\hline \multirow{2}{*}{ Pressure (bar) } & \multicolumn{3}{c}{$\mathrm{n}(-)$} \\
\cline { 2 - 4 } & $\mathrm{N}_{2}$ & $\mathrm{CO}_{2}$ & $\mathrm{C}_{2} \mathrm{H}_{4}$ & $\mathrm{C}_{2} \mathrm{H}_{6}$ \\
\hline 1 & 1.0000 & 1.0000 & 1.0000 & 1.0000 \\
2 & 1.0003 & 1.0004 & 1.0006 & 1.0005 \\
3 & 1.0006 & 1.0008 & 1.0013 & 1.0010 \\
4 & 1.0008 & 1.0012 & 1.0019 & 1.0016 \\
6 & 1.0011 & 1.0016 & 1.0026 & 1.0022 \\
8 & 1.0017 & 1.0025 & 1.0039 & 1.0035 \\
12 & 1.0022 & 1.0034 & 1.0054 & 1.0048 \\
16 & 1.0033 & 1.0052 & 1.0085 & 1.0079 \\
20 & 1.0044 & 1.0072 & 1.0120 & 1.0114 \\
25 & 1.0055 & 1.0093 & 1.0157 & 1.0154 \\
30 & 1.0069 & 1.0121 & 1.0208 & 1.0209 \\
\hline & 1.0083 & 1.0151 & 1.0264 & 1.0271 \\
\hline
\end{tabular}




\subsubsection{Qualification and quantification of contributions to swelling}

To investigate the swelling of thin PPO films under influence of various pressures, pressurization and depressurization experiments were performed with four different gases, i.e. $\mathrm{N}_{2}, \mathrm{CO}_{2}, \mathrm{C}_{2} \mathrm{H}_{4}$ and $\mathrm{C}_{2} \mathrm{H}_{6}$. To investigate the effect of hysteresis of the polymer film, a second pressurization and depressurization cycle is performed. A typical example of the raw data obtained from one cycle is shown in Figure 3.2.

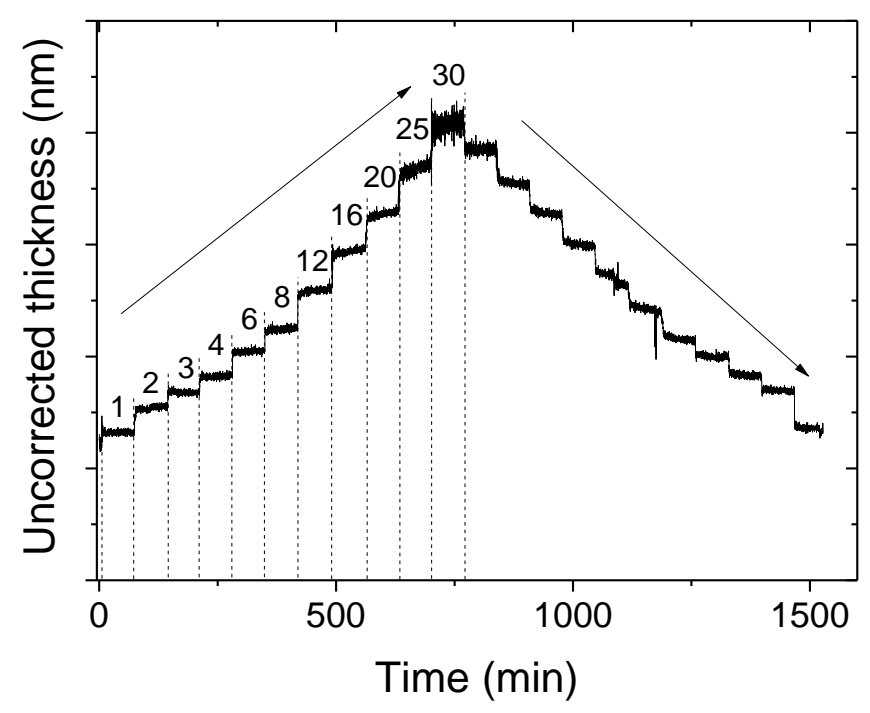

Figure 3.2. First pressurization and depressurization cycle of PPO under $\mathrm{CO}_{2}$ atmosphere.

Figure 3.2 is a typical example of the thickness of the PPO film as a function of time, at various pressures for one pressurization and depressurization cycle and uncorrected for birefringence and ambient refractive index. It can be seen that at the beginning of each pressurization step, there is a significant increase in the film thickness observed. The change in pressure allows for instantaneous Fickian sorption of gas in the polymer film followed by continues swelling over time. A more detailed analysis of these phenomena can be seen in Figure 3.3. 


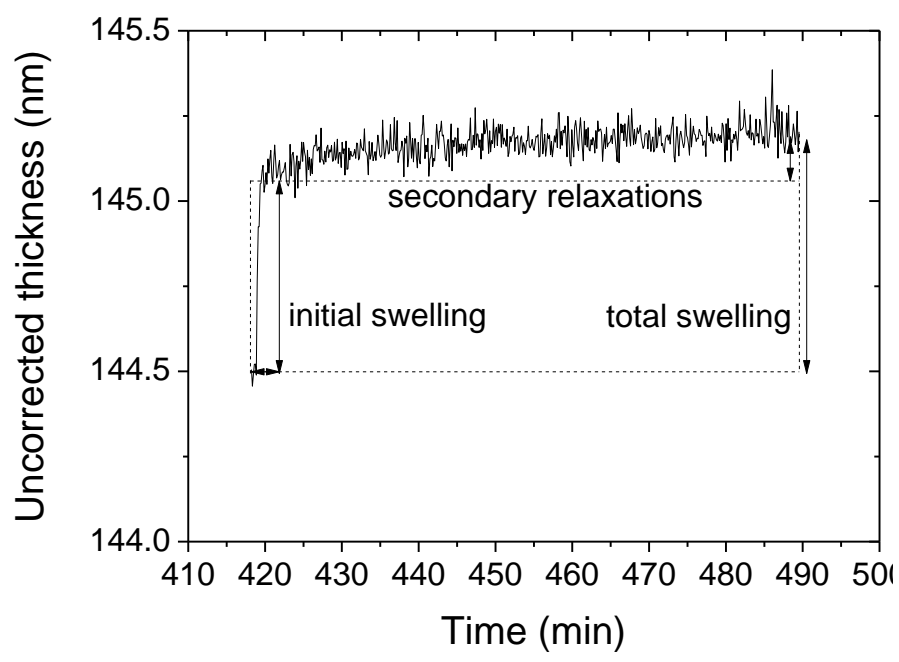

Figure 3.3. Analysis of one pressurization step of the PPO film under $\mathrm{CO}_{2}$ atmosphere.

Figure 3.3 shows an immediate increase in thickness of the PPO film upon pressurization. It should be noted that this immediate response of the polymer is limited only to the pressure increment imposed on the thin film, as opposed to diffusion of gas in the film. The amount of swelling that occurs within the first 5 minutes $(\mathrm{t}=5)$ of the experiments is defined as the initial swelling, caused by Fickian sorption. A time window of 5 minutes is taken to account for equilibration of the pressure by the pump and temperature. The initial swelling is then corrected for the thickness of the film at the beginning of the experiment $(\mathrm{t}=0, \mathrm{P}=0)$ to allow a fair comparison between samples. By cumulative addition of the initial swelling at all pressure steps, the cumulative initial swelling (\%) can be calculated by:

Cumulative initial swelling $(\%)=\sum_{x=1}^{30} \frac{h_{t=5, P x}-h_{t=90, P x-d P}}{h_{0}} * 100 \%$

where the $\mathrm{h}_{\mathrm{t}=5}, \mathrm{Px}$, is the film thickness $(\mathrm{nm})$ after 5 minutes of the beginning of a pressurization step, $\mathrm{h}_{\mathrm{t}=90}$, Px-dP is the film thickness $(\mathrm{nm})$ after 90 minutes of the previous pressurization step, $\mathrm{h}_{\mathrm{P} 0}$ is the film thickness $(\mathrm{nm})$ at the beginning of the first pressurization step at vacuum.

The swelling that occurs in the remaining 85 minutes of the pressure step is the result of nonFickian sorption, or secondary relaxations, which take place at a much slower time scale [32]. 
These secondary relaxations are quantified by the slope of the film thickness as function of the time $\left(\frac{\Delta h}{\Delta t}\right)$, corrected for the initial thickness of the membranes. By cumulative addition of these secondary relaxations, the cumulative secondary relaxation can be calculated:

$$
\begin{aligned}
& \text { Cumulative secondary relaxations (\%) } \\
& \qquad=\sum_{x=1}^{30} \frac{h_{t=90, P=x}-h_{t=5, P=x}}{h_{0}} * 100 \%
\end{aligned}
$$

where $\mathrm{h}_{\mathrm{t}=90, \mathrm{P}=\mathrm{x}}$, is the film thickness $(\mathrm{nm})$ after 90 minutes of the beginning of a pressurization step.

Secondary relaxations are a measure for how far the polymer is away from equilibrium conditions with its surrounding atmosphere. High secondary relaxations indicate that the polymer film is far from equilibrium. However, it must be noted that literature exist about a plasticization pressure, or more specifically, a specific threshold value of dilation that is required before any non-Fickian secondary relaxations can occur [32]. Therefore, we do not always expect to see the occurrence of these secondary relaxations as opposed to the initial Fickian swelling even though the polymer is in a non-equilibrium state.

The total swelling of the polymer film at a specific pressurization step as the result of both initial fast Fickian swelling and the following slow non-Fickian swelling combined is given by Equation 3.9.

$$
\text { Total swelling }(\%)=\frac{h_{t=90, P=x}-h_{0}}{h_{0}} * 100 \%
$$

\subsubsection{Gravitmetric sorption measurement}

A magnetic suspension balance (MSB) (Rubotherm) was used to determine the concentration of $\mathrm{N}_{2}, \mathrm{CO}_{2}, \mathrm{C}_{2} \mathrm{H}_{4}$ and $\mathrm{C}_{2} \mathrm{H}_{6}$ in PPO up to 30 bar in bulk PPO films. A minimum of $25 \mathrm{mg}$ was used as sample. Before each sorption run, the sample was degassed at $35 \pm 0.5^{\circ} \mathrm{C}$ for at least 
24 hrs. A sorption run consisted of a stepwise increase in pressure for $24 \mathrm{hrs}$. All measurements were performed at a constant temperature of $35^{\circ} \mathrm{C} \pm 0.5^{\circ} \mathrm{C}$. The mass uptake of the sample $\left(\mathrm{m}_{\mathrm{t}}\right)(\mathrm{g})$ was calculated according to Equation 3.10:

$$
m_{t}=w_{t}-\left(w_{O}-V_{t} \cdot \rho_{g a s}\right)
$$

where $\mathrm{w}_{0}$ is the weight of the sample at zero sorption $(\mathrm{g}), \mathrm{V}_{\mathrm{t}}$ the volume of the sample at time $\mathrm{t}\left(\mathrm{cm}^{3}\right)$ and $\rho_{\text {gas }}$ is the density of the gas $\left(\mathrm{g} / \mathrm{cm}^{3}\right)$. The recorded weight $\left(\mathrm{w}_{\mathrm{t}}\right)(\mathrm{g})$ was corrected for buoyancy according to the Archimedes principle.

The concentration of gas in the sample was calculated from the mass uptake $\left(\mathrm{m}_{\mathrm{t}}\right)(\mathrm{g})$, the volume of the sample (calculated from the density of the sample $\left(\rho_{\text {poly }}\right)\left(\mathrm{g} / \mathrm{cm}^{3}\right)$ as determined using a Micromeritics AccuPyc II 1340 pycnometer at $26.0^{\circ} \mathrm{C} \pm 0.8^{\circ} \mathrm{C}$ and the weight of the sample at vacuum $\left.\left(\mathrm{w}_{0}\right)(\mathrm{g})\right)$, the molar volume $\left(\mathrm{V}_{\mathrm{m}}\right)\left(\mathrm{cm}^{3} / \mathrm{mol}\right)$ and the molecular weight of the gas $\left(\mathrm{M}_{\mathrm{w}}\right)(\mathrm{g} / \mathrm{mol})$ as shown in Equation 3.11. The molar volume of the gas was calculated using the Van der Waals equation of state.

$$
C=\frac{m_{t} \cdot V_{m} \cdot \rho_{p o l y}}{M_{w} \cdot w_{0}}
$$




\subsection{Results and discussion}

The results and discussion will be divided into three different parts. Initially, the first pressurization-depressurization cycle will be discussed. The focus of this part lies on differences in sorption induced swelling by the various penetrants, as well as the occurrence of non-equilibrium hysteresis during the desorption. The next part focusses on the second pressurization-depressurization cycle, where the focus lies on the differences observed between the first and the second cycle. Finally, a comparison between sorption in thin films as observed with spectroscopic ellipsometry and sorption in bulk films using gravimetric sorption is made.

\subsubsection{First pressurization-depressurization cycle}

\subsubsection{Effect of penetrant pressurization on psi oscillations}

Sorption of a gaseous penetrant in polymeric films occurs upon pressurization. The sorbed gas swells the polymeric film and simultaneously changes the effective refractive index of the film, resulting in a shift of the psi oscillation. Typical changes of the psi oscillation in thin PPO films due to sorption, are shown in Figure 3.4 for all investigated penetrants.

Figure 3.4a shows that for $\mathrm{N}_{2}$ both curves for 0 and 30 bar coincide. A clear shift in the maximum of psi, upon pressurization of the sample with $\mathrm{N}_{2}$ is not visible. This is due to the combination of $\mathrm{N}_{2}$ being a poor condensable gas (Table 3.1), and a the relatively low increase in refractive index of $\mathrm{N}_{2}$ at 30 bar, compared to the other gases. The psi oscillation change becomes more pronounced when high refractive index penetrants sorb into the polymer matrix at high concentrations and induce high swelling degrees, such as $\mathrm{C}_{2} \mathrm{H}_{6}$, as shown in Figure 3.4d. By fitting the parameters of the optical model, as described in section 3.3.3, the thickness and refractive index of the samples at various pressures can be independently obtained. The refractive indices of the films shown in Figure 4a-d were found to be 1.599, $1.569,1.595,1.584$, respectively. 


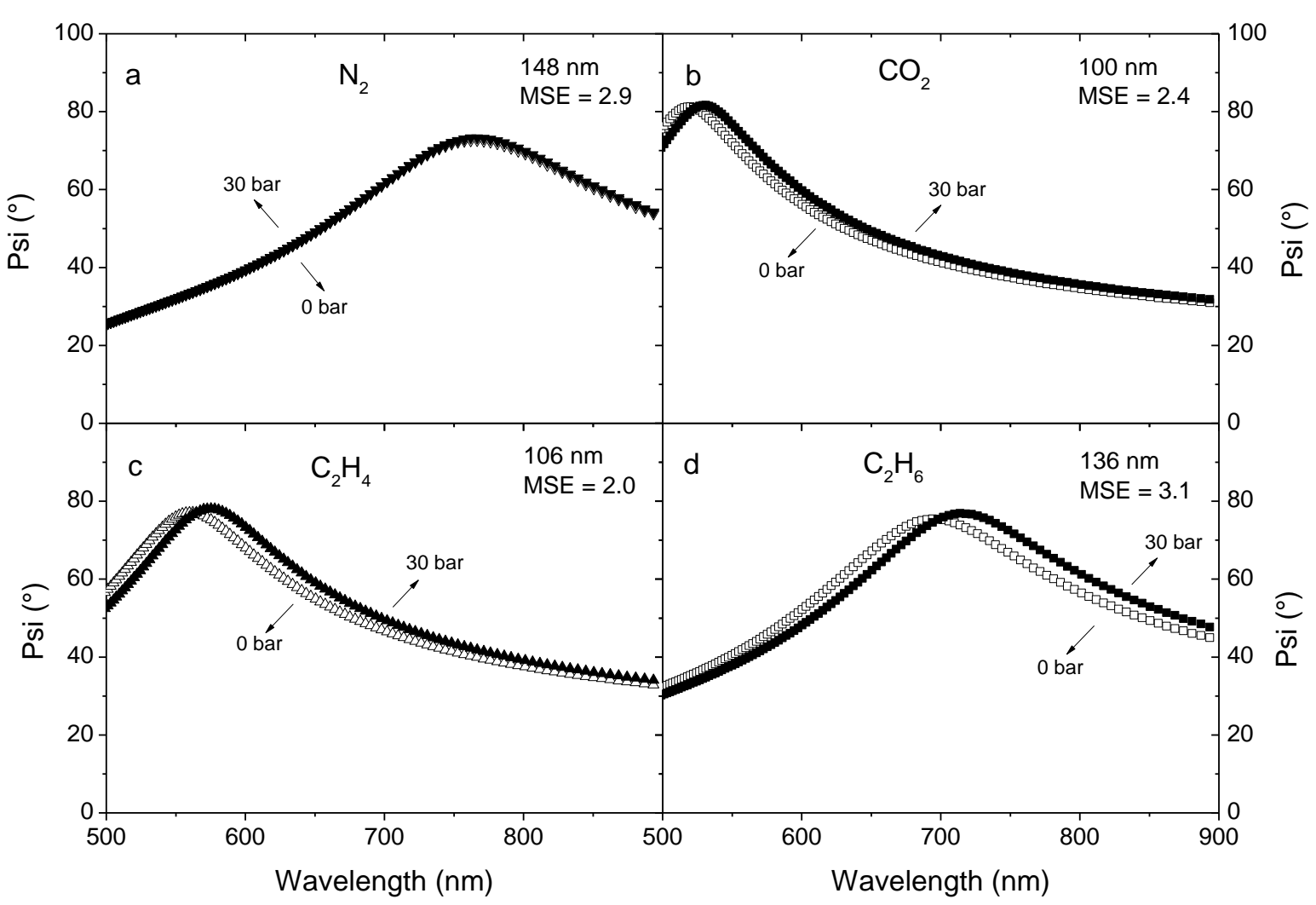

Figure 3.4. Typical changes in psi upon pressurization from 0 bar (open symbols) to 30 bar (closed symbols) for (a) $\mathrm{N}_{2}$, (b) $\mathrm{CO}_{2}$, (c) $\mathrm{C}_{2} \mathrm{H}_{4}$ and (d) $\mathrm{C}_{2} \mathrm{H}_{6}$ in thin PPO films.

The mean square error (MSE) was below 5 for all samples over the entire investigated pressure range, which was considered to be a good fit. The precision of the swelling was below $0.4 \%$ at 30 bar. The MSE could be further reduced by including the angle offset and anisotropy as fit parameters. However as the model already produced a low MSE, it was decided to limit the number of parameters as much as possible.

\subsubsection{Cumulative initial swelling}

Investigation of Fickian sorption in thin PPO films for all investigated gases is performed by examining the initial swelling of the film at the start of each pressurization step. Figure 3.5, calculated using Equation 7, shows the cumulative initial swelling as function of pressure for (a) $\mathrm{N}_{2}$, (b) $\mathrm{CO}_{2}$, (c) $\mathrm{C}_{2} \mathrm{H}_{4}$ and (d) $\mathrm{C}_{2} \mathrm{H}_{6}$ during the first pressurization-depressurization cycle. 
Figure 3.5a shows that $\mathrm{N}_{2}$ swells PPO for only $0.4 \%$ at 30 bar, which is the least of all investigated gases. On the other hand, $\mathrm{CO}_{2}, \mathrm{C}_{2} \mathrm{H}_{4}$ and $\mathrm{C}_{2} \mathrm{H}_{6}$ show a significantly higher amount of swelling. This is attributed to a combination of a larger LJ diameter of these penetrants, a higher Van der Waals volume, and a higher critical temperature of the penetrants. It is somewhat unexpected that $\mathrm{CO}_{2}$ and $\mathrm{C}_{2} \mathrm{H}_{4}$ induce similar amounts of initial swelling, since the $\mathrm{LJ}$ diameter of $\mathrm{CO}_{2}$ is smaller than that of $\mathrm{C}_{2} \mathrm{H}_{4}$, as shown in Table 3.1, and their critical temperatures are comparable. Also, the Van der Waals volume of $\mathrm{CO}_{2}$ is much lower than that of $\mathrm{C}_{2} \mathrm{H}_{4}$. This implies that the amount of $\mathrm{CO}_{2}$ dissolved in PPO is much higher compared to $\mathrm{C}_{2} \mathrm{H}_{4}$, to compensate for the lower $\mathrm{LJ}$ diameter and Van der Waals volume of $\mathrm{CO}_{2}$ and yet cause similar swelling degrees. The reason for this higher $\mathrm{CO}_{2}$ concentration is most probably the presence of flexible, polar ether linkages in the polymer that increase the $\mathrm{CO}_{2}$ solubility compared to that of $\mathrm{C}_{2} \mathrm{H}_{4}$ [33].

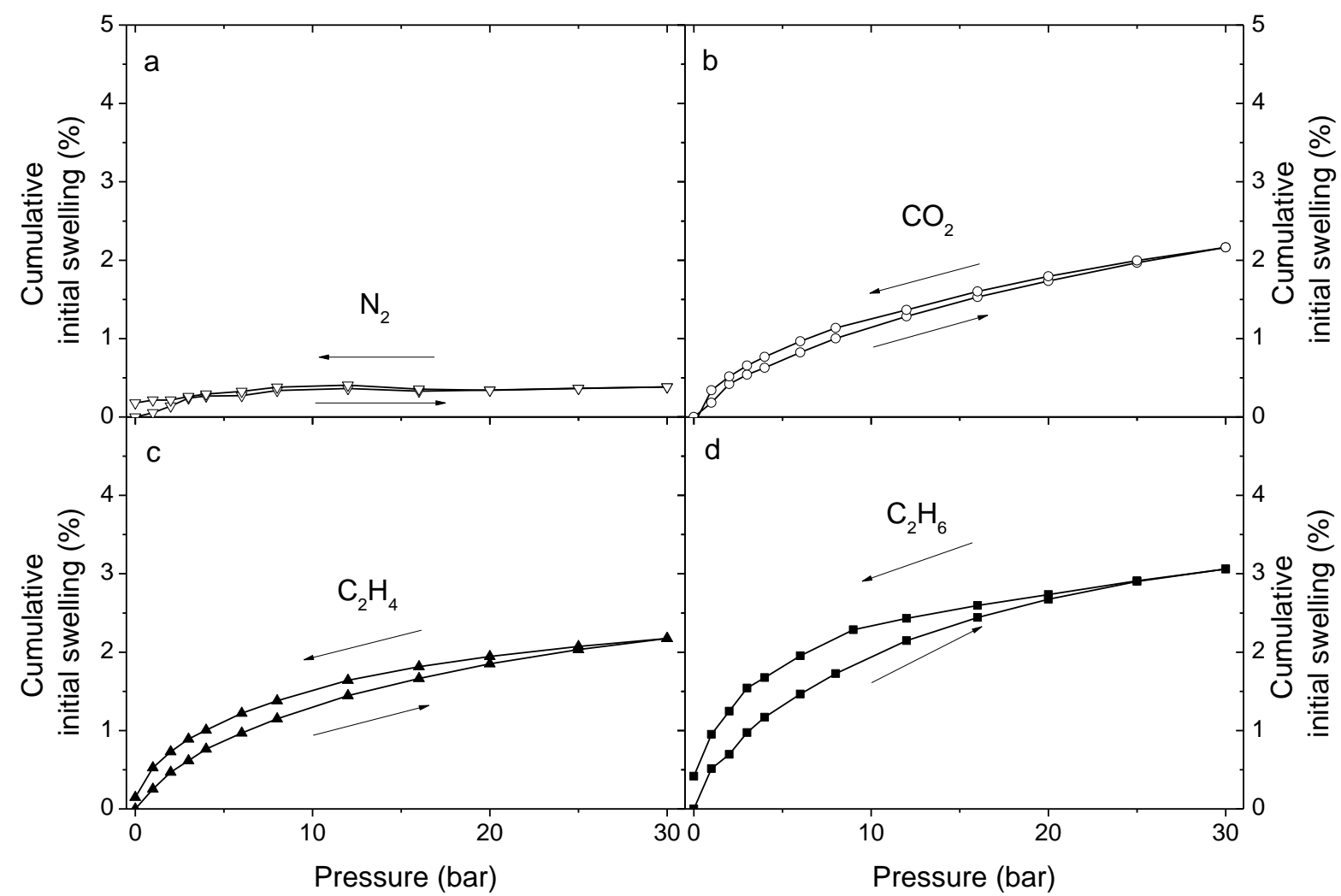

Figure 3.5. Cumulative initial swelling of the first pressurization-depressurization cycle as function of pressure for (a) $\mathrm{N}_{2}$, (b) $\mathrm{CO}_{2}$, (c) $\mathrm{C}_{2} \mathrm{H}_{4}$ and (d) $\mathrm{C}_{2} \mathrm{H}_{6}$ in thin PPO films. 
Figure 3.5 shows that for all gases at low pressures, the cumulative initial swelling increases rapidly but levels of when the pressure increases further. This concave shape is similar to sorption isotherms following the dual-mode sorption model, in which the solubility coefficient of gas in a glassy polymer decreases with increasing feed pressure. Logically, at high pressures, there is a linear relation between the swelling and the concentration of gas inside a polymer film as a result of Henry sorption. However, at low pressures, Langmuir sorption contributes to a significant amount to the total sorption. Since Langmuir sorption assumes the filling of excessive free volume sites in between the polymer phase, swelling induced by Langmuir sorption is not trivial [34]. Yet a significantly higher initial swelling is observed at low pressures, especially for $\mathrm{CO}_{2}, \mathrm{C}_{2} \mathrm{H}_{4}$ and $\mathrm{C}_{2} \mathrm{H}_{6}$. A similar observation was made by Wessling et al. and they stated that every sorbed molecule into a polymer film contributes to the swelling, regardless of the sorption mechanism [35]. Also here, it can be assumed that both Henry and Langmuir sorption contribute to the swelling of the polymer.

Depressurization steps remove gas residing inside the polymer matrix, allowing it to shrink. This can be observed for all gases over the entire investigated pressure range. Figure 5a shows that out of the four gases investigated, $\mathrm{N}_{2}$ shows no significant difference between pressurization and depressurization of a PPO film. The inert nature of $\mathrm{N}_{2}$ has only very limited interactions with the PPO matrix and sorbs poorly due to its low critical temperature. As a result, the $\mathrm{N}_{2}$ induced swelling is fairly reversible and does not induce non-equilibrium hysteresis.

On the other hand, $\mathrm{CO}_{2}, \mathrm{C}_{2} \mathrm{H}_{4}$ and $\mathrm{C}_{2} \mathrm{H}_{6}$, shown in Figure 3.5b-d, respectively, reveal very different behavior. During the depressurization from 30 to 20 bar, the cumulative initial swelling is similar as it was during pressurization from 20 to 30 bar. However, the nonequilibrium hysteresis increases as the pressure is further decreased, with the largest difference around 6-8 bar. Berends interpret this non-equilibrium hysterises as filling of newly created free volume sites during sorption and the collaps of free volume sites during desorption, which takes place on a much longer time scale [36]. Although the differences of the maximum non-equilibrium hysterises between $\mathrm{CO}_{2}, \mathrm{C}_{2} \mathrm{H}_{4}$ and $\mathrm{C}_{2} \mathrm{H}_{6}$ are similar within the experimental error, there could be a relation with the LJ diameter or Van der Waals volume. Molecules with a lower LJ diameter and Van der Waals volume like $\mathrm{CO}_{2}$, could introduce smaller free volume sites as opposed to larger molecules like $\mathrm{C}_{2} \mathrm{H}_{6}$. 
When the pressure is further decreased, the difference becomes smaller again as the result of the increasingly larger difference between the gas concentration of the ambient and inside the polymer matrix. This increase in the driving force results in a larger quantity of gas being removed at lower pressures and thus to a reduction in the non-equilibrium hysteresis.

\subsubsection{Cumulative secondary relaxations}

The amount of swelling that occurs between 5-90 minutes of each pressurization step is considered to be the result of non-Fickian sorption. The cumulative secondary relaxations as function of pressure are shown in Figure 3.6 for each of the investigated gases for the first pressurization-depressurization cycle and calculated according to Equation 3.8. For clarity, Figure $6 \mathrm{~b}-\mathrm{d}$ have been divided into two regions, which will be individually discussed.

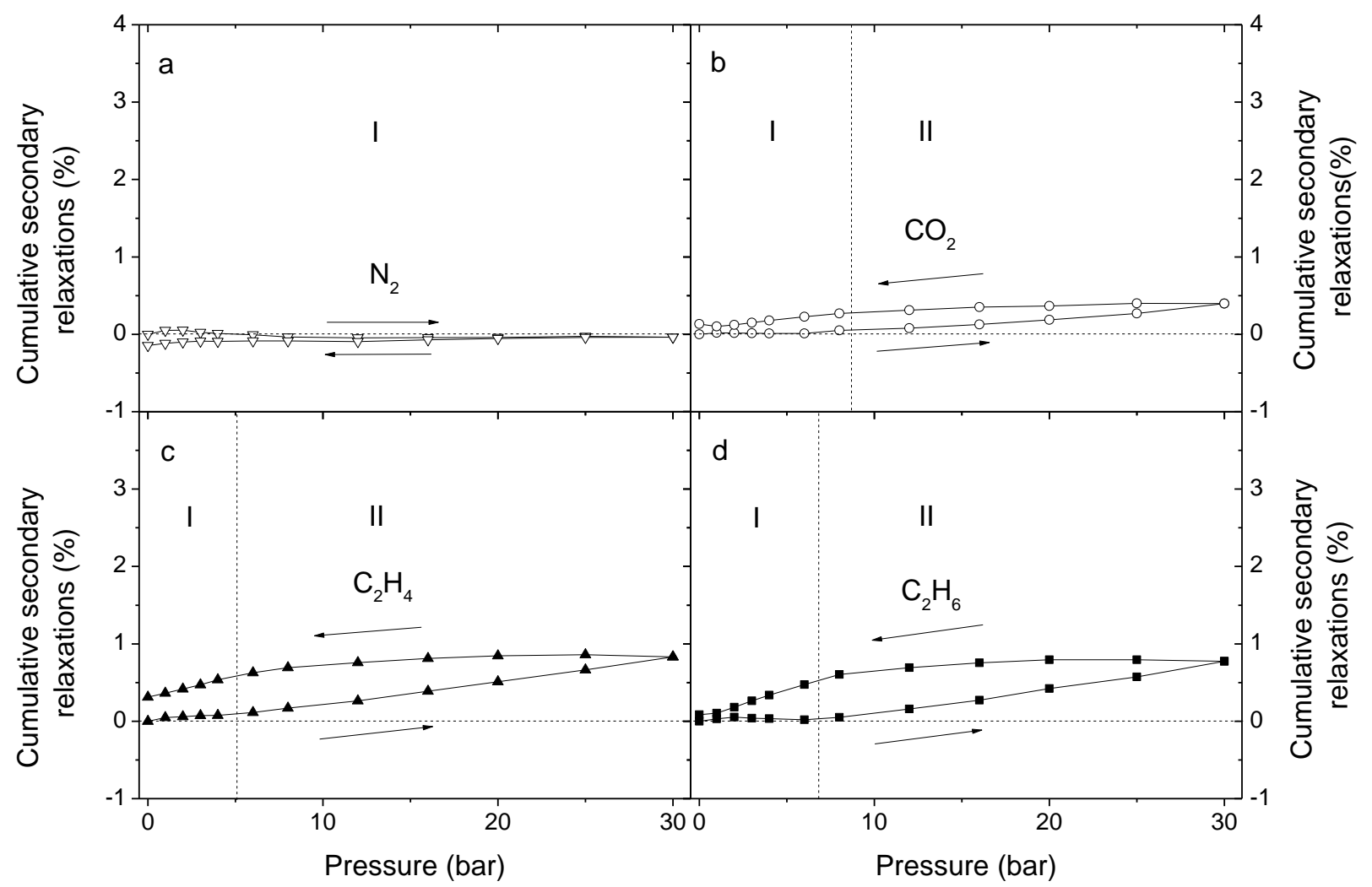

Figure 3.6. Cumulative secondary relaxations of the first pressurization-depressurization cycle as function of pressure for (a) $\mathrm{N}_{2}$, (b) $\mathrm{CO}_{2}$, (c) $\mathrm{C}_{2} \mathrm{H}_{4}$ and (d) $\mathrm{C}_{2} \mathrm{H}_{6}$ in thin PPO films. 
Region I in Figure 3.6, is marked by the absence of secondary relaxations during pressurization. Although there is still a significant amount of initial Fickian swelling in this pressure range as was shown in Figure 3.5, non-Fickian swelling does not occur yet. A thorough investigation of sorption induced relaxations in glassy polymers was performed by Visser et al., who showed that a certain threshold of polymer dilation was required to induce non-Fickian sorption kinetics [32]. In region I, the concentration of sorbed penetrant is still too low to surpass this threshold. Small, low sorbing gases like $\mathrm{N}_{2}$, do not even surpass the threshold during this experiment, resulting in the absence of secondary relaxations over the entire pressure range.

Region II indicates the occurrence of secondary relaxations during pressurization as the result of non-Fickian sorption. The concentration where the transition to Region II occurs is indicated based on extrapolation of the last four data points, which represent the highest concentration of penetrant. The concentration of $\mathrm{CO}_{2}, \mathrm{C}_{2} \mathrm{H}_{4}$ and $\mathrm{C}_{2} \mathrm{H}_{6}$ inside the PPO film in this region has reached a certain threshold value after which secondary relaxations occur. When the film is exposed to higher pressures, the secondary relaxations increase as the pressure increases. This increase is the result of an increasingly larger difference in equilibrium between the concentration of gas inside and outside the PPO film. The glassy state of the polymer prevents such equilibrium to take place, as opposed to a polymer in the rubbery state. Furthermore, it can be seen that the cumulative secondary relaxations caused by $\mathrm{C}_{2} \mathrm{H}_{4}$ and $\mathrm{C}_{2} \mathrm{H}_{6}$ are similar, but slightly higher than for $\mathrm{CO}_{2}$. This differs from the maximum cumulative initial swelling due to Fickian sorption as shown in Figure 3.5, where $\mathrm{CO}_{2}$ and $\mathrm{C}_{2} \mathrm{H}_{4}$ showed similar swelling while $\mathrm{C}_{2} \mathrm{H}_{6}$ showed somewhat higher values. This could be an indication that the Van der Waals volume of the sorbed penetrants is a dominant parameter for the magnitude of these secondary relaxations. This is turn would imply that plasticization phenomena in case of $\mathrm{C}_{2} \mathrm{H}_{4}$ and $\mathrm{C}_{2} \mathrm{H}_{6}$ are even more severe than in case of $\mathrm{CO}_{2}$.

During the depressurization run, Figure 3.6a shows that the cumulative secondary relaxations for $\mathrm{N}_{2}$ are still at $0 \%$ along the entire investigated pressure range. Since also no cumulative secondary relaxations where observed during the first pressurization of the sample, this reversible behavior is expected. Upon depressurization from 30-25 bar, a minor increase in the cumulative secondary relaxations is still observed for $\mathrm{C}_{2} \mathrm{H}_{4}$ and $\mathrm{C}_{2} \mathrm{H}_{6}$, while none are observed for $\mathrm{CO}_{2}$. It is proposed that there is still no equilibrium state between the $\mathrm{C}_{2} \mathrm{H}_{4}$ and $\mathrm{C}_{2} \mathrm{H}_{6}$ concentration outside and inside the membrane even though the pressure has been reduced. Upon further reduction of the pressure, the membrane initially shrinks, as is shown 
in Figure 3.6c and 3.6d, but continues to swell in time. For $\mathrm{CO}_{2}$ it is suggested, that there is a close to equilibrium state between the $\mathrm{CO}_{2}$ concentration outside and inside the membrane at 25 bar, which removes the driving force for secondary relaxations.

When the pressure is further reduced, the cumulative secondary relaxations decrease for $\mathrm{CO}_{2}, \mathrm{C}_{2} \mathrm{H}_{4}$ and $\mathrm{C}_{2} \mathrm{H}_{6}$, which indicates a consolidation of the polymer chains. The maximum in non-equilibrium hysteresis coincides with the transition between Region I and Region II. The maximum in non-equilibrium is smaller for $\mathrm{CO}_{2}$ than it is for $\mathrm{C}_{2} \mathrm{H}_{4}$ and $\mathrm{C}_{2} \mathrm{H}_{6}$, which is attributed to the differences in the LJ diameter and the Van der Waals volume. It is suggested that the smaller $\mathrm{CO}_{2}$ can more easily be removed from the polymer matrix as opposed to $\mathrm{C}_{2} \mathrm{H}_{4}$ and $\mathrm{C}_{2} \mathrm{H}_{6}$, which are much larger and remain in the polymer matrix until the pressure is further decreased, resulting in larger non-equilibrium hysteresis. When the pressure is further decreased and the transition into Region I is made, the non-equilibrium hysteresis decreases. However, although eventually vacuum is applied, a slight non-equilibrium hysteresis remains in case of $\mathrm{CO}_{2}, \mathrm{C}_{2} \mathrm{H}_{4}$ and $\mathrm{C}_{2} \mathrm{H}_{6}$, which indicates that not all newly introduced Langmuir sites due to sorption, have yet collapsed.

\subsubsection{Total swelling}

The total swelling of the PPO film at the end of each pressurization step for the first pressurization-depressurization cycle was calculated according to Equation 3.9. Logically, the total swelling is a summation of the cumulative initial swelling and cumulative secondary relaxations as discussed earlier. The total swelling for the first pressurization-depressurization cycle is shown in Figure 7 as function of the pressure for all investigated gases. 


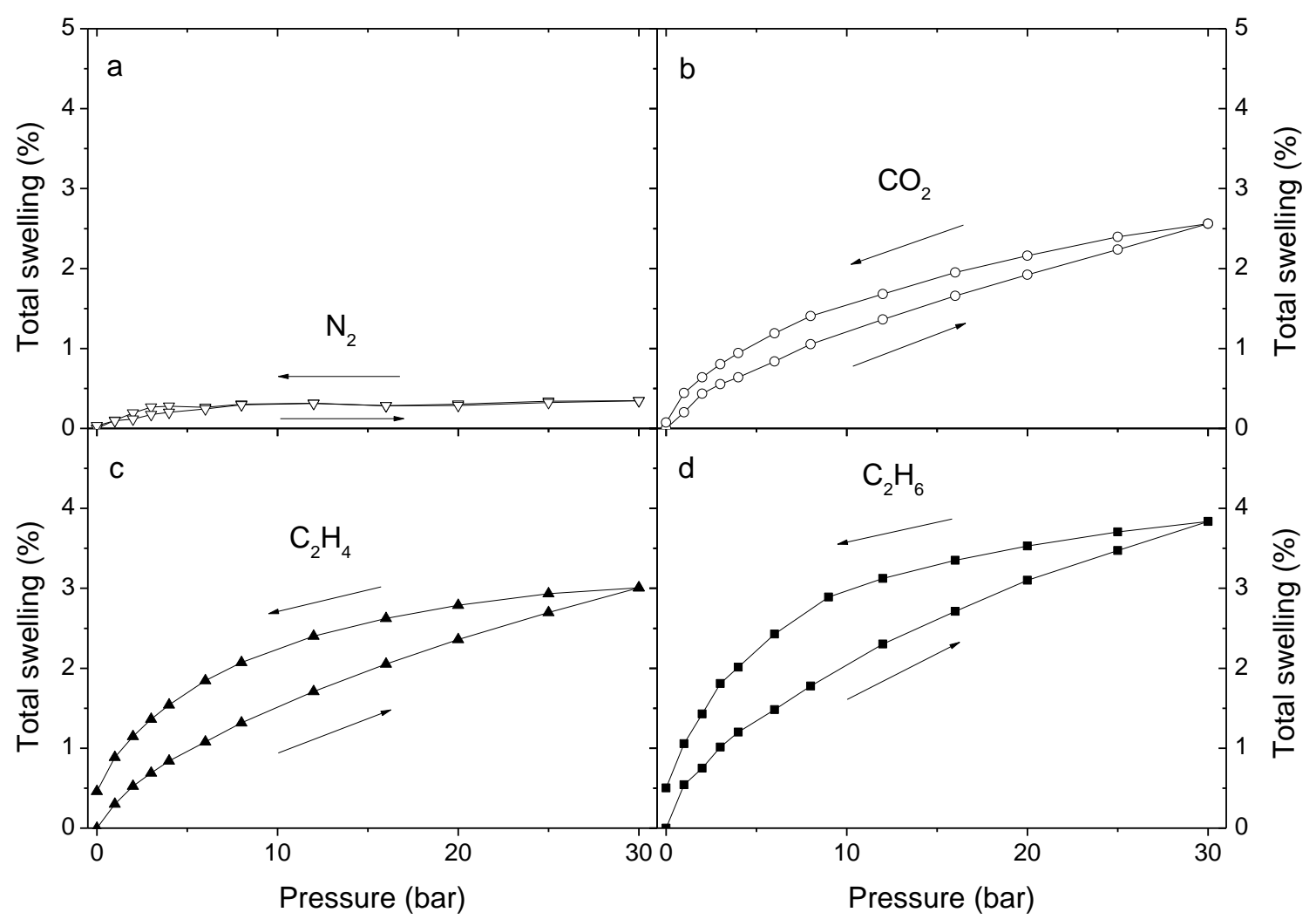

Figure 3.7. Cumulative secondary relaxations of the first pressurization-depressurization cycle as function of pressure for (a) $\mathrm{N}_{2}$, (b) $\mathrm{CO}_{2}$, (c) $\mathrm{C}_{2} \mathrm{H}_{4}$ and (d) $\mathrm{C}_{2} \mathrm{H}_{6}$ in thin PPO films.

As shown in Figure 3.7, the highest total swelling of the PPO film at 30 bar is caused by ethane, followed by ethylene with and $\mathrm{CO}_{2}$, while $\mathrm{N}_{2}$ caused the least amount of swelling. The total swelling of $\mathrm{N}_{2}$, as shown in Figure 3.7a, showed no non-equilibrium hysteresis between sorption and desorption. As was shown before in Figure 3.5a and Figure 3.6a, the cumulative initial swelling and secondary relaxations, respectively, showed no difference between pressurization or depressurization. Consequently, the total swelling as the result of $\mathrm{N}_{2}$ sorption is completely reversible.

In case of $\mathrm{CO}_{2}, \mathrm{C}_{2} \mathrm{H}_{4}$ and $\mathrm{C}_{2} \mathrm{H}_{6}$, shown in Figure 3.7b-d, respectively, the total swelling is higher during depressurization than it was at the same pressure during the pressurization run. This difference in swelling is attributed to the non-equilibrium state of the polymer. As shown before in Figure 3.6, the secondary relaxations are highly dependent on the distance 
from equilibrium, since even positive secondary relaxations are observed during a depressurization step.

\subsubsection{Second pressurization-depressurization cycle}

After completion of the first pressurizations-depressurization cycle, a second cycle was performed to investigate hysteresis effects of the polymer swelling as a consequence of conditioning. No significant difference was found in the cumulative initial swelling and the cumulative secondary relaxations between the first and the second pressurizationdepressurization cycle. Therefore, also the total swelling did not show no a significant difference when the first and the second pressurization-depressurization cycles are compared (Figure 3.8).

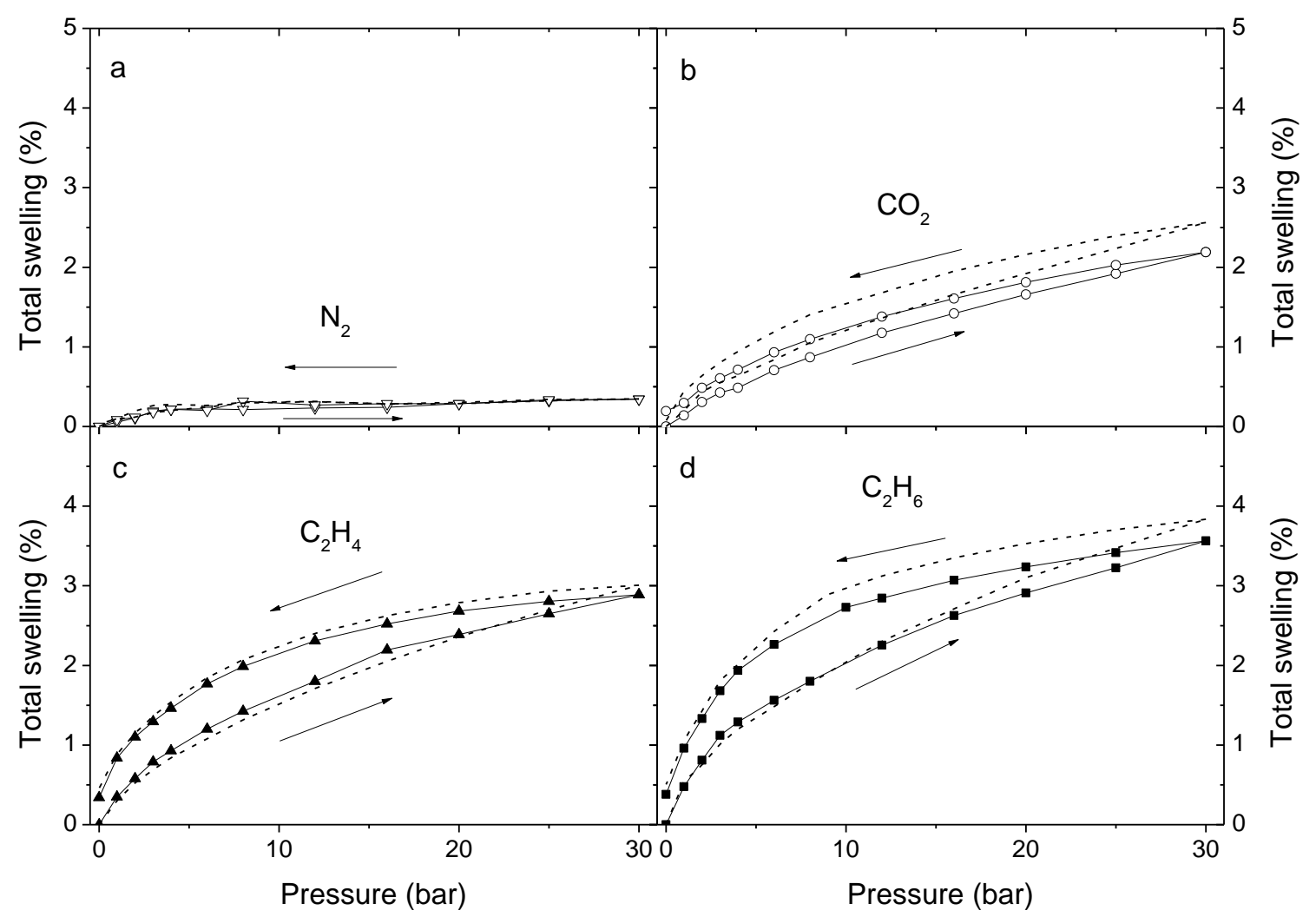

Figure 3.8. Total swelling during the second pressurization-depressurization cycle for (a) $\mathrm{N}_{2}$, (b) $\mathrm{CO}_{2}$, (c) $\mathrm{C}_{2} \mathrm{H}_{4}$ and (d) $\mathrm{C}_{2} \mathrm{H}_{6}$ in thin PPO films. Dashed lines (- -) represent the result from the first pressurization-depressurization cycle as shown in Figure 3.7. 
Although we do not observe a significant difference between the first and the second cycle, many studies report about accelerated physical again in thin polymer films, which decreases the swelling degree, as well as gas sorption and permeability [7, 10, 12, 14]. On the other hand, Horn et al. showed that short-term exposure of thin glassy polymer films to $\mathrm{CO}_{2}$ leads to an increase in permeability up to $20 \%$ [13]. This increase in permeability can directly be related to an increase in swelling, opposite to the effect of physical aging. The balance between physical aging reducing the film thickness, and short term exposure to plasticizing gases increasing the thickness, prevented significant differences in the total swelling to occur between the first and second pressurization-depressurization cycles.

\subsubsection{Penetrant sorption in thin PPO films}

\subsubsection{Comparison of thin and bulk PPO films}

Membranes become increasingly thinner to enhance the permeance. However, several reports showed that thin polymer films exhibit different properties as compared to bulk films, such as physical aging, permeability and gas sorption [8-14]. Gas concentrations in bulk PPO film obtained by gravimetric sorption were calculated using Equations 3.10 and 3.11. The gas concentration in thin PPO films at various pressures was approximated as well, based on ellipsometric spectroscopy data using Equations 3.2-3.5. As discussed in the introduction, a pressure dependency of the penetrant refractive index and density was used during the modeling and calculations of each pressurization step, as opposed to the method used by Sirard et al. [15]. Concentration isotherms were constructed for both thin and bulk PPO films by fitting the data according to the dual-mode sorption model as shown in Equation 3.6, after which the Langmuir and Henry sorption parameters were obtained. The $\mathrm{N}_{2}$ Langmuir parameters were found to be correlated. For that reason, $\mathrm{N}_{2}$ data was fitted using Henry`s law instead of the dual-mode sorption model. The results are shown in Figure 3.9. For comparison, thin film isotherms using Sirard`s method are also included. The Henry and Langmuir fit parameters are shown in Table 3.3. 
Table 3.3. Henry $\mathrm{k}_{\mathrm{d}}\left(\mathrm{kg} /\left(\mathrm{m}^{3}\right.\right.$ bar $\left.)\right)$ and Langmuir $\mathrm{C}_{\mathrm{H}}\left(\mathrm{kg} / \mathrm{m}^{3}\right)$ and $\mathrm{b}(1 / \mathrm{bar})$ parameters for thin and bulk films, based on ellipsometry and MSB experiments, respectively.

Thin films

\begin{tabular}{|c|c|c|c|c|c|c|c|c|c|c|c|c|}
\hline & \multicolumn{4}{|c|}{ This study } & \multicolumn{4}{|c|}{ Sirard`s method [15] } & \multirow[b]{2}{*}{$\mathrm{N}_{2}$} & \multirow[b]{2}{*}{$\mathrm{CO}_{2}$} & \multirow[b]{2}{*}{$\mathrm{C}_{2} \mathrm{H}_{4}$} & \multirow[b]{2}{*}{$\mathrm{C}_{2} \mathrm{H}_{6}$} \\
\hline & $\mathrm{N}_{2}$ & $\mathrm{CO}_{2}$ & $\mathrm{C}_{2} \mathrm{H}_{4}$ & $\mathrm{C}_{2} \mathrm{H}_{6}$ & $\mathrm{~N}_{2}$ & $\mathrm{CO}_{2}$ & $\mathrm{C}_{2} \mathrm{H}_{4}$ & $\mathrm{C}_{2} \mathrm{H}_{6}$ & & & & \\
\hline $\mathrm{k}_{\mathrm{d}}$ & 0.50 & 0.88 & 0.49 & 0.58 & 0.45 & 1.09 & 0.72 & 0.85 & 0.57 & 0.60 & 0.71 & 0.73 \\
\hline $\mathrm{C}_{\mathrm{H}}^{\prime}$ & - & 49.7 & 24.7 & 26.6 & - & 47.2 & 22.2 & 22.1 & - & 80.7 & 28.4 & 28.3 \\
\hline b & - & 0.23 & 0.45 & 0.67 & - & 0.24 & 0.47 & 0.69 & - & 0.13 & 0.37 & 0.44 \\
\hline
\end{tabular}

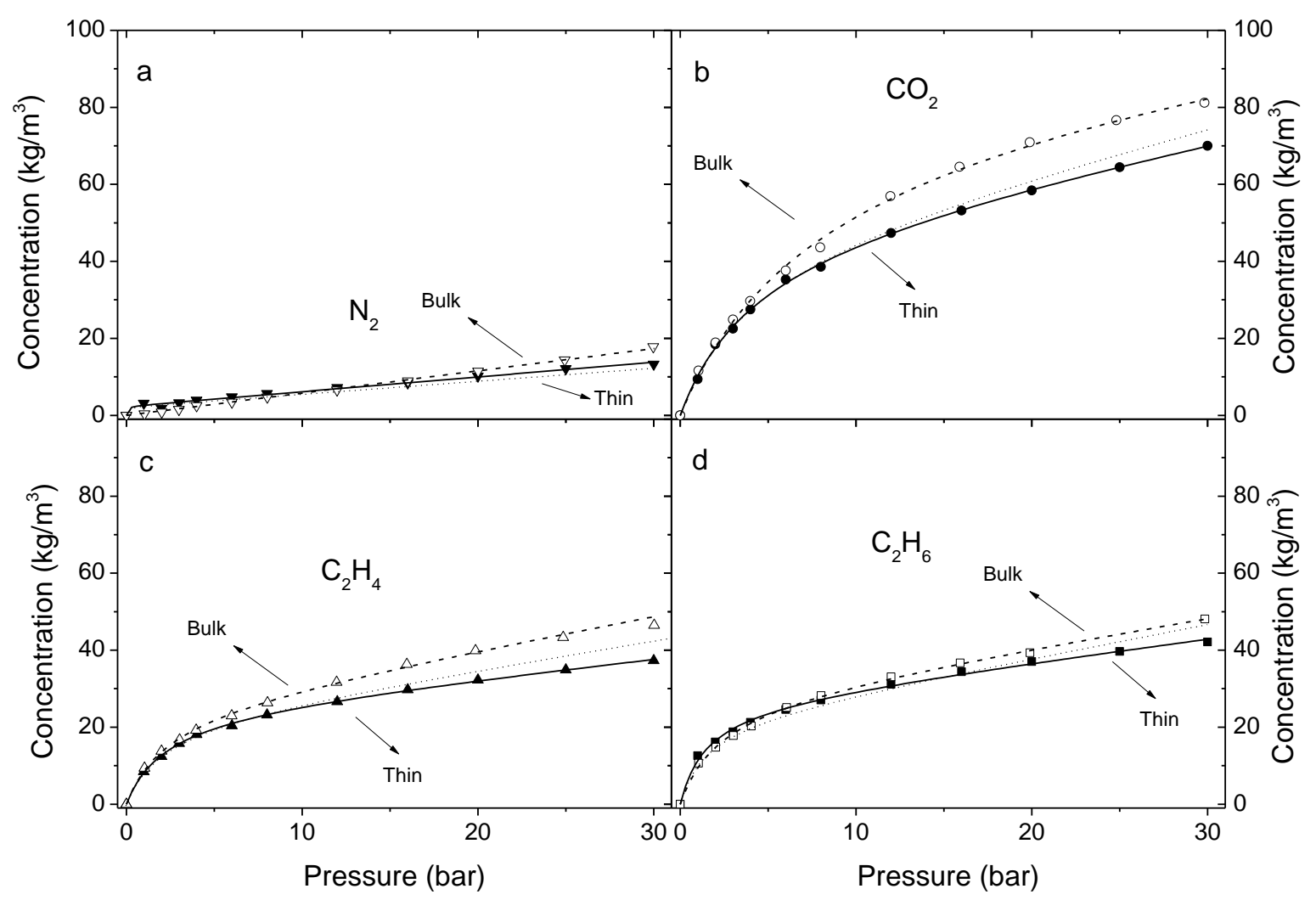

Figure 3.9. Concentration as function of pressure for (a) $\mathrm{N}_{2}$, (b) $\mathrm{CO}_{2}$, (c) $\mathrm{C}_{2} \mathrm{H}_{4}$ and (d) $\mathrm{C}_{2} \mathrm{H}_{6}$ in PPO films. Open and closed symbols represent the calculated concentrations in PPO for bulk and thin films, respectively. Dashed (- -) and solid lines (-) represent the fitted isotherm for bulk and thin films, respectively. Dotted lines $(\cdot \cdot)$ represents the isotherm based on Sirard`s method. 
Figure 3.9a shows that a good similarity is obtained for the $\mathrm{N}_{2}$ concentration in thin films and bulk films. This is also represented by the similar $\mathrm{k}_{\mathrm{d}}$ values as shown in Table 3.3. Since $\mathrm{N}_{2}$ has a low critical temperature, it sorbs poorly in the PPO film, resulting in low concentrations. This complicated the observation of thickness dependent effects, since the significance of the measurement error increases. On the other hand, $\mathrm{CO}_{2}$, and $\mathrm{C}_{2} \mathrm{H}_{4}$ show a significant difference in the concentration between thin and bulk films, especially at higher pressures. Figures $3.9 \mathrm{~b}$ and $\mathrm{c}$ show significantly higher concentrations of $\mathrm{CO}_{2}$, and $\mathrm{C}_{2} \mathrm{H}_{4}$, respectively, in bulk films as compared to thin films. In addition, $\mathrm{CO}_{2}$ concentrations in PPO are significantly higher than $\mathrm{C}_{2} \mathrm{H}_{4}$ and $\mathrm{C}_{2} \mathrm{H}_{6}$ concentrations, as was already predicted based on the similar cumulative initial swelling caused by these penetrants, as shown in Figure 3.5. There seems to be no difference in $\mathrm{C}_{2} \mathrm{H}_{6}$ induced sorption between thin and bulk films.

The difference in sorption between thin and bulk films is also reflected in the fitted Langmuir and Henry parameters as shown in Table 3.3. The $\mathrm{C}_{\mathrm{H}}^{\prime}$ parameter for $\mathrm{CO}_{2}$ is significantly lower for the thin film as compared to the bulk film. This can directly be related to the accelerated physical aging that occurs in thin films, resulting in increased densification due to loss of excessive free volume and leading to reduced permeabilities and increased selectivities and agrees well with other thin film $\mathrm{CO}_{2}$ studies [10, 12, 17, 37]. The reduction of the $\mathrm{C}_{\mathrm{H}}^{\prime}$ parameters in thin films seems less pronounced for $\mathrm{C}_{2} \mathrm{H}_{4}$ and $\mathrm{C}_{2} \mathrm{H}_{6}$. Possibly, the lower Langmuir sorption of $\mathrm{C}_{2} \mathrm{H}_{4}$ and $\mathrm{C}_{2} \mathrm{H}_{6}$ in bulk films, as compared to $\mathrm{CO}_{2}$, makes differences between thin and bulk film less pronounced. The $\mathrm{k}_{\mathrm{d}}$ values for $\mathrm{CO}_{2}, \mathrm{C}_{2} \mathrm{H}_{4}$ and $\mathrm{C}_{2} \mathrm{H}_{6}$ also show thickness dependency when pressure dependency of the refractive index and density is taken into account, possibly also the result of accelerated physical aging. For both $\mathrm{C}_{2} \mathrm{H}_{4}$ and $\mathrm{C}_{2} \mathrm{H}_{6}$, the $\mathrm{k}_{\mathrm{d}}$ values are reduced for thin films. The $\mathrm{k}_{\mathrm{d}}$ value of 0.88 for $\mathrm{CO}_{2}$ in thin films was larger as compared to the bulk $\mathrm{k}_{\mathrm{d}}$ value of 0.60 . However, due to the high bulk $\mathrm{C}_{\mathrm{H}}$ value of 80.7 , the error in the bulk $\mathrm{k}_{\mathrm{d}}$ value is significantly higher as well.

Thickness dependent sorption has been reported before. Simons et al. [6] reported a thickness dependency of the $\mathrm{C}_{\mathrm{H}}$ parameter, which was related to loss of non-equilibrium excess free volume due to accelerated ageing in thin films. Yet no thickness dependency of the $k_{d}$ parameter was observed. This could be the result of investigating relatively thick films (2 $\mu \mathrm{m})$ and the absence of including pressure dependent refractive indices and densities during modeling and concentration calculations. Wind et al. reported also a decrease in the $\mathrm{C}_{\mathrm{H}}$ parameter [17]. During this study, also $\mathrm{k}_{\mathrm{d}}$ parameters were reported and although differences between bulk and thin films were observed, no clear correlation or cause could be found. 
However, Wind primarily focused on the effect of annealing temperature and also pointed out that assumptions in their optical model like the constant refractivity might be an oversimplification. In a later study, Horn et al. showed the irreproducibility of $\mathrm{CO}_{2}$ sorption isotherms for Matrimid found in literature [7]. Additionally, they found a thickness dependency of all dual-mode sorption parameters for $\mathrm{CO}_{2}$ in polystyrene (PS), polysulfone (PSF), PPO and Matrimid. The difference in $\mathrm{CO}_{2}$ concentration between thin and thick films that they reported for PPO was similar to what is reported in this study.

The introduction of accounting for pressure dependency of the refractive indices and densities of the penetrants in Equations 3.3 and 3.4 results in a slight reduction of the calculated gas concentration as compared to Sirard`s method where this is not taken in to account. The calculated molar refractivity increases slightly with increasing pressure. Sirard assumed a condensed, liquefied state of the penetrant with a corresponding refractive index and density, whereas the present method assumes the penetrant sorbed in a gaseous state. Including the pressure dependent density is also in agreement with densities calculated from gravimetric sorption measurements. This is also in line with the solution-diffusion model and the absence of any partial molar volume corrections, because no liquid phase is in contact with the membrane [1, 38]. This justifies the assumption that penetrants remain in a gaseous state inside the polymer matrix.

\subsubsection{Partial molar volume in thin PPO films}

Since both the concentration and the isotropic swelling were experimentally determined with spectroscopic ellipsometry, the partial molar volume, $v_{\text {penetrant }}\left(\mathrm{cm}^{3} / \mathrm{mol}\right)$, of the penetrants inside the polymer matrix at $35^{\circ} \mathrm{C}$ can be estimated $[6,7]$ to a certain extent by:

$$
v_{\text {penetrant }}=22400 \frac{\delta \frac{\Delta h}{h_{0}}}{\delta \text { Concentration }}
$$

When the sorption induced polymer swelling is plotted as a function of the penetrant concentration inside the film (shown in Figure 3.10), Equation 3.12 assumes that the derivative at any point equals the partial molar volume at that specific point. As the sorption 
for especially $\mathrm{N}_{2}$ is low, the error in the measurements is quite significant. As such the partial molar volume for $\mathrm{N}_{2}$ in PPO cannot be estimated. In principle, for $\mathrm{N}_{2}$ the penetrant induced swelling is linearly proportional to the concentration of $\mathrm{N}_{2}$ as Henry sorption is the major sorption mechanism: Every sorbed molecule swells the membrane equally.

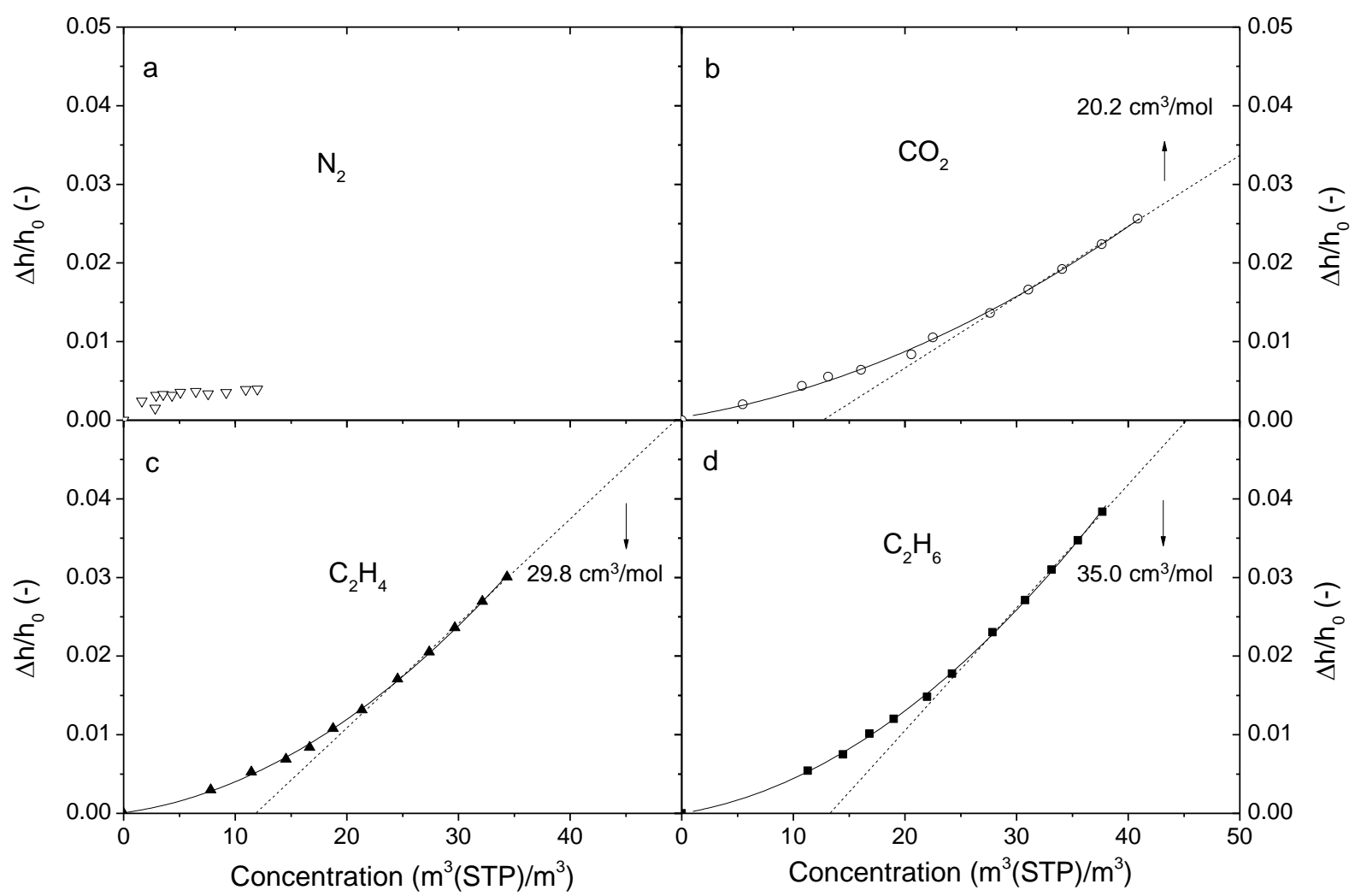

Figure 3.10. Swelling as function of concentration for (a) $\mathrm{N}_{2}$, (b) $\mathrm{CO}_{2}$, (c) $\mathrm{C}_{2} \mathrm{H}_{4}$ and (d) $\mathrm{C}_{2} \mathrm{H}_{6}$ in thin PPO films. Solid line is fitted with $a^{2}+b x+c$, while the dashed line is fitted with $a x+b$. Only the last 5 data points are used for the linear fit of $\mathrm{CO}_{2}, \mathrm{C}_{2} \mathrm{H}_{4}$ and $\mathrm{C}_{2} \mathrm{H}_{6}$.

Figures 3.10b-d show the sorption induced swelling as function of the sorbed concentration of $\mathrm{CO}_{2}, \mathrm{C}_{2} \mathrm{H}_{4}$ and $\mathrm{C}_{2} \mathrm{H}_{6}$, respectively. Table 3.4 shows the partial molar volume for the different gases as obtained from the linear fit using Equation 3.12 for only the last 5 data points in Figure 3.10. Contrary to $\mathrm{N}_{2}$, a clear deviation from a linear relation is visible for all three other penetrants. However, fitting the investigated concentration range with a quadratic relation yields excellent correlations with an $\mathrm{r}^{2}$ of $0.998,0.999$ and 0.999 for $\mathrm{CO}_{2}, \mathrm{C}_{2} \mathrm{H}_{4}$ and 
$\mathrm{C}_{2} \mathrm{H}_{6}$, respectively. This implies that the partial molar volume of the penetrants is dependent on the concentration. This is in contrast to the solution-diffusion model that assumes a constant partial molar volume of the penetrant when dissolved in the polymer matrix, as if it was a liquid [1].

Table 3.4. Estimated partial molar volume of $\mathrm{CO}_{2}, \mathrm{C}_{2} \mathrm{H}_{4}$ and $\mathrm{C}_{2} \mathrm{H}_{6}$ in PPO.

\begin{tabular}{cccc}
\hline & $\mathrm{CO}_{2}$ & $\mathrm{C}_{2} \mathrm{H}_{4}$ & $\mathrm{C}_{2} \mathrm{H}_{6}$ \\
$v_{\text {penetrant }}\left(\mathrm{cm}^{3} / \mathrm{mol}\right)$ & 20.2 & 29.8 & 35.0 \\
\hline
\end{tabular}

Figure 3.10 shows that at concentrations beyond $25 \mathrm{~m}^{3}(\mathrm{STP}) / \mathrm{m}^{3}$, there appears to be a linear relation between penetrant concentration and swelling for $\mathrm{CO}_{2}, \mathrm{C}_{2} \mathrm{H}_{4}$ and $\mathrm{C}_{2} \mathrm{H}_{6}$, which is the result of Henry sorption being the dominating sorption mechanism. The partial molar volumes in this concentration range increase with increasing LJ diameter and Van der Waals volume of the penetrant, as shown in Table 3.1.

The calculated partial molar volumes of all investigated gases are approximately 20-30 $\mathrm{cm}^{3} /$ mol smaller than their corresponding Van der Waals volumes. This reduction in calculated partial molar volume is in agreement with Wessling et al. [39] and Fleming et al., [40] who also showed that the partial molar volumes of gaseous penetrants were lower as compared to their partial molar volumes in the liquid state. The calculated partial molar volume of $\mathrm{CO}_{2}$ corresponds well with the results from Horn et al. using the same method [7]. Not surprisingly, the partial molar volumes of $\mathrm{C}_{2} \mathrm{H}_{4}$ and $\mathrm{C}_{2} \mathrm{H}_{6}$ are estimated to be somewhat larger than that of $\mathrm{CO}_{2}$, which correlates well with their larger $\mathrm{LJ}$ diameter and Van der Waals volume.

It must be noted that the reported concentrations and partial molar volumes as obtained by spectroscopic ellipsometry, are estimations. Apart from errors due to the indirectly obtained (modeled) thickness and refractive index, Equations 3.3 and 3.4 require the molar refractivity of PPO ( $\left.\mathrm{A}_{\mathrm{PPO}}\right)$. $\mathrm{A}_{\mathrm{PPO}}$ depends on the refractive index and the density of the pure PPO film. The refractive index can be obtained from the modeled data, but the density is usually taken from literature (bulk) data, as it cannot be independently obtained from ellipsometry measurements. The introduced uncertainty only allows for estimation of the penetrant concentrations and consequently, the penetrants partial molar volume. In addition, the pump 
used to control the pressure inside the cell has an accuracy of \pm 0.1 bar, which indicates that especially at low pressures ( $<5$ bar) a significant measurement error is present. However, duplicate measurements showed deviations in the total swelling smaller than $0.5 \%$ at higher pressures. Additionally, at the molecular level, differences at the microdomain organisation may be present, which can introduce a certain discrepancy. E.g. Wall et al. showed that spincoated PPO films inherit a larger spread of the refractive index among several samples, due to solvent effects [41]. While interpreting the data, this has been taken into account. As such, the data show clear trends and significant differences for the different gases and the work gives valuable insight in the behavior of $\mathrm{C}_{2} \mathrm{H}_{4}$ and $\mathrm{C}_{2} \mathrm{H}_{6}$ sorption at high pressure in a polymer PPO matrix, which is of relevance for membrane separations using increasingly thinner selective membrane layers.

These results show that the assumption of penetrants in the gaseous state with pressure dependent densities and refractive indices is equally, if not more, justified than the assumption of penetrants in a liquid/supercritical state. Variable partial molar volume as function of pressure, as is observed for $\mathrm{CO}_{2}, \mathrm{C}_{2} \mathrm{H}_{4}$ and $\mathrm{C}_{2} \mathrm{H}_{6}$, has been observed before for bulk films [42] and thin films [6,7]. Wijmans elaborated on the effect of variable partial molar volumes on penetrant fluxes in the solution-diffusion model [38]. Significant deviations between calculated and realized fluxes can occur when the partial molar volume of the penetrant differs significantly from the partial molar volume in the liquid phase, as is the case in e.g. high pressure reverse osmosis processes. However, in the case of gas separation applications, this molar volume difference is usually low, as was also found in this study. Since the maximum pressure for these applications usually does not exceed 50 bar, Wijmans showed that in such cases correction factors to the solution-diffusion model are less critical. 


\subsection{Conclusions}

$\mathrm{N}_{2}, \mathrm{CO}_{2}, \mathrm{C}_{2} \mathrm{H}_{4}$ and $\mathrm{C}_{2} \mathrm{H}_{6}$ induced swelling of thin $100 \mathrm{~nm}$ PPO films has been investigated with spectroscopic ellipsometry, using an optical model, which included pressure dependency of the refractive indices and density of the penetrants in a gaseous state. $\mathrm{C}_{2} \mathrm{H}_{4}$ swells PPO similar to $\mathrm{CO}_{2}$, while $\mathrm{C}_{2} \mathrm{H}_{6}$ swells the PPO film slightly more due to a combination of reasonable sorption and larger LJ diameter and Van der Waals volume. It was found that a certain threshold of sorbed penetrant was required to induce secondary relaxations. $\mathrm{C}_{2} \mathrm{H}_{4}$ and $\mathrm{C}_{2} \mathrm{H}_{6}$ induced secondary relaxations were equal or larger as compared to $\mathrm{CO}_{2}$. Repeating the pressurization-depressurization cycle on the same sample did not lead to significant differences in swelling. Penetrant concentrations in thin films were estimated and compared to bulk films. Lower concentrations were found for $\mathrm{CO}_{2}$ and $\mathrm{C}_{2} \mathrm{H}_{4}$ in thin PPO films as compared to bulk films due to accelerated physical aging. However, these seem to be absent for $\mathrm{C}_{2} \mathrm{H}_{6}$. Subsequently, partial molar volumes of all four penetrants were approximated. The partial molar volumes of $\mathrm{CO}_{2}, \mathrm{C}_{2} \mathrm{H}_{4}$ and $\mathrm{C}_{2} \mathrm{H}_{6}$ were found to be concentration dependent, and lower compared to their liquid state. This indicates that the solution-diffusion model might be an oversimplification, as it assumes constant partial molar volumes and the assumption of gaseous penetrants can at least equally be justified.

\section{Acknowledgements}

This project is financially supported by AgentschapNL. The authors would like to thank ECN, Dow and SolSep for the fruitful discussions. 


\section{Bibliography}

1. Wijmans, J.G. and R.W. Baker, The solution-diffusion model: A review. Journal of Membrane Science, 1995. 107(1-2): p. 1-21.

2. Robeson, L.M., Correlation of separation factor versus permeability for polymeric membranes. Journal of Membrane Science, 1991. 62(2): p. 165-185.

3. Bos, A., et al., CO2-induced plasticization phenomena in glassy polymers. Journal of Membrane Science, 1999. 155(1): p. 67-78.

4. Minelli, M. and G.C. Sarti, Permeability and diffusivity of CO2 in glassy polymers with and without plasticization. Journal of Membrane Science, 2013. 435(0): p. 176185.

5. Ploegmakers, J., et al., Economic evaluation of membrane potential for ethylenelethane separation in a retrofitted hybrid membrane-distillation plant using Unisim Design. Industrial and Engineering Chemistry Research, 2013. 52(19): p. 6524-6539.

6. Simons, K., et al., CO2 sorption and transport behavior of ODPA-based polyetherimide polymer films. Polymer, 2010. 51(17): p. 3907-3917.

7. Horn, N.R. and D.R. Paul, Carbon dioxide sorption and plasticization of thin glassy polymer films tracked by optical methods. Macromolecules, 2012. 45(6): p. 28202834.

8. Horn, N.R. and D.R. Paul, Carbon dioxide plasticization and conditioning effects in thick vs. thin glassy polymer films. Polymer, 2011. 52(7): p. 1619-1627.

9. Huang, Y. and D.R. Paul, Effect of film thickness on the gas-permeation characteristics of glassy polymer membranes. Industrial and Engineering Chemistry Research, 2007. 46(8): p. 2342-2347.

10. Kim, J.H., W.J. Koros, and D.R. Paul, Effects of CO2 exposure and physical aging on the gas permeability of thin 6FDA-based polyimide membranes: Part 1. Without crosslinking. Journal of Membrane Science, 2006. 282(1-2): p. 21-31.

11. Kim, J.H., W.J. Koros, and D.R. Paul, Effects of CO2 exposure and physical aging on the gas permeability of thin 6FDA-based polyimide membranes: Part 2. with crosslinking. Journal of Membrane Science, 2006. 282(1-2): p. 32-43.

12. Xia, J., et al., Aging and carbon dioxide plasticization of thin polyetherimide films. Polymer, 2012. 53(10): p. 2099-2108.

13. Horn, N.R. and D.R. Paul, Carbon dioxide plasticization of thin glassy polymer films. Polymer, 2011. 52(24): p. 5587-5594.

14. Cui, L., et al., Responses of 6FDA-based polyimide thin membranes to CO2 exposure and physical aging as monitored by gas permeability. Polymer, 2011. 52(24): p. 5528-5537.

15. Sirard, S.M., P.F. Green, and K.P. Johnston, Spectroscopic ellipsometry investigation of the swelling of poly(dimethylsiloxane) thin films with high pressure carbon dioxide. Journal of Physical Chemistry B, 2001. 105(4): p. 766-772.

16. Wind, J.D., et al., Relaxation dynamics of CO2 diffusion, sorption, and polymer swelling for plasticized polyimide membranes. Macromolecules, 2003. 36(17): p. 6442-6448.

17. Wind, J.D., et al., Carbon dioxide-induced plasticization of polyimide membranes: Pseudo-equilibrium relationships of diffusion, sorption, and swelling. Macromolecules, 2003. 36(17): p. 6433-6441.

18. Ploegmakers, J., et al., Economic evaluation of membrane properties for ethylenelethane separation in a retrofitted hybrid membrane-distillation plant. (submitted). 2013. 
19. Benali, M. and B. Aydin, Ethane/ethylene and propane/propylene separation in hybrid membrane distillation systems: Optimization and economic analysis. Separation and Purification Technology, 2010. 73(3): p. 377-390.

20. Kookos, I.K., Optimal design of membrane/distillation column hybrid processes. Industrial and Engineering Chemistry Research, 2003. 42(8): p. 1731-1738.

21. Motelica, A., et al., Membrane retrofit option for paraffin/olefin separation-a technoeconomic evaluation. Industrial and Engineering Chemistry Research, 2012. 51(19): p. 6977-6986.

22. Poling, B.E., J.M. Prausnitz, and J.P. O'Connell, The Properties of Gases and Liquids. Fifth ed2000, New York: McGraw-Hill.

23. Reid, R.C., J.M. Prausnitz, and B.E. Poling, The Properties of Gases and Liquids. Fourth ed1987, New York: McGraw-Hill.

24. NIST Chemistry WebBook. Available from: http://webbook.nist.gov/chemistry/.

25. Tompkins, H.G., A User`s Guide to Ellipsometry2006, Mineola, N.Y.: Dover Publications.

26. Koros, W.J., A.H. Chan, and D.R. Paul, Sorption and transport of various gases in polycarbonate. Journal of Membrane Science, 1977. 2(0): p. 165-190.

27. Ogieglo, W., et al., n-Hexane induced swelling of thin PDMS films under nonequilibrium nanofiltration permeation conditions, resolved by spectroscopic ellipsometry. Journal of Membrane Science, 2013. 431(0): p. 233-243.

28. Herzinger, C.M., et al., Ellipsometric determination of optical constants for silicon and thermally grown silicon dioxide via a multi-sample, multi-wavelength, multiangle investigation. Journal of Applied Physics, 1998. 83(6): p. 3323-3336.

29. Michels, A., A. Botzen, and S.R. De Groot, Refractive index and Lorentz-Lorenz function of ethylene up to 2300 atmospheres at $25^{\circ} \mathrm{C}$ and $100^{\circ} \mathrm{C}$. Physica, 1947. 13(67): p. 343-348.

30. Besserer, G.J. and D.B. Robinson, Refractive indices of ethane, carbon dioxide, and isobutane. Journal of Chemical and Engineering Data, 1973. 18(2): p. 137-140.

31. Xiao, G.Z., et al., Monitoring changes in the refractive index of gases by means of a fiber optic Fabry-Perot interferometer sensor. Sensors and Actuators A: Physical, 2005. 118(2): p. 177-182.

32. Visser, T. and M. Wessling, When do sorption-induced relaxations in glassy polymers set in? Macromolecules, 2007. 40(14): p. 4992-5000.

33. Puleo, A.C., N. Muruganandam, and D.R. Paul, Gas sorption and transport in substituted polystyrenes. Journal of Polymer Science Part B: Polymer Physics, 1989. 27(11): p. 2385-2406.

34. Michaels, A.S., W.R. Vieth, and J.A. Barrie, Solution of gases in polyethylene terephthalate. Journal of Applied Physics, 1963. 34(1): p. 1-12.

35. Wessling, M., et al., Plasticization of gas separation membranes. Gas Separation \& Purification, 1991. 5(4): p. 222-228.

36. Berens, A.R., Effects of sample history, time, and temperature on the sorption of monomer vapor by PVC. Journal of Macromolecular Science, Part B, 1977. 14(4): p. 483-498.

37. McCaig, M.S., D.R. Paul, and J.W. Barlow, Effect of film thickness on the changes in gas permeability of a glassy polyarylate due to physical agingPart II. Mathematical model. Polymer, 2000. 41(2): p. 639-648.

38. Wijmans, J.G., The role of permeant molar volume in the solution-diffusion model transport equations. Journal of Membrane Science, 2004. 237(1-2): p. 39-50.

39. Wessling, M., et al., Transport of gases through polymeric membranes. Makromolekulare Chemie. Macromolecular Symposia, 1993. 70-71(1): p. 379-396. 
40. Fleming, G.K. and W.J. Koros, Dilation of polymers by sorption of carbon dioxide at elevated pressures. 1. Silicone rubber and unconditioned polycarbonate. Macromolecules, 1986. 19(8): p. 2285-2291.

41. Wall, J.F., et al., Spectroscopic Ellipsometry and Atomic Force Microscopy of Polyphenylene Oxide Films. Journal of The Electrochemical Society, 1994. 141(1): p. 306-310.

42. Böhning, M. and J. Springer, Sorptive dilation and relaxational processes in glassy polymer/gas systems-I. Poly(sulfone) and poly(ether sulfone). Polymer, 1998. 39(21): p. 5183-5195. 
Chapter 3. 


\section{Chapter 4}

\section{Thin polymer film behavior for gas separation membrane applications}

This chapter is in preparation to be published as:

J.Ploegmakers, Thin polymer film behavior for gas separation membrane applications 


\section{Abstract}

$\mathrm{N}_{2}, \mathrm{CO}_{2}, \mathrm{C}_{2} \mathrm{H}_{4}$ and $\mathrm{C}_{2} \mathrm{H}_{6}$ induced swelling was investigated in thin PPO, PDMS, P84 and SPPO films with spectroscopic ellipsometry. The rubbery PDMS showed typical rubbery behavior with solely Henry sorption and the absence of non-Fickian secondary relaxation upon pressurization by the investigated gases. The glassy PPO, P84 and SPPO films showed dual-mode like swelling and the presence of non-Fickian secondary relaxation. Penetrant polymer swelling is more pronounced when favorable dipole-quadrupole or Van der Waals interactions can be formed between $\mathrm{CO}_{2}$ and $\mathrm{SO}_{3} \mathrm{H}$, and $\mathrm{C}_{2} \mathrm{H}_{6}$ and PDMS, respectively. Penetrant concentrations in thin films were determined using an optical model with pressure dependent densities and refractive indices of the penetrants. Partial molar volumes of the penetrants in all thin polymer films were subsequently approximated. The partial molar volume of the penetrants was found to be concentration dependent, as opposed to the usually applied solution-diffusion model. Finally, the $\mathrm{C}_{2} \mathrm{H}_{6}$ concentration in thin and bulk PPO, PDMS, P84 and SPPO films was compared. The difference between both concentrations appeared to be less pronounced than is the case for $\mathrm{CO}_{2}$. 


\subsection{Introduction}

Gas separation membranes become increasingly thinner to increase the flux, thus reducing the total membrane area required and consequently the capital costs [1]. Currently, gas separation applications use spiral wound modules or integrally skinned hollow fibers. To decrease the membrane thickness further, also alternative techniques like layer-by-layer (LbL) coatings or interfacial polymerization (IP) are being investigated [2-4]. This should lead to a substantial decrease in membrane thickness with selective layers of $100 \mathrm{~nm}$ or lower. Yet it is unclear if the membranes properties of such thin films are similar to those of bulk films $(>10 \mu \mathrm{m})$ [5-8], which are often used to characterize polymers for subsequent membrane preparation.

Spectroscopic ellipsometry is an often-used tool to investigate swelling and relaxation phenomena in thin polymer films [5-7, 9-11]. In Chapter 3, it was concluded that sorption of $\mathrm{CO}_{2}$ in thin poly(2,6-dimethyl-phenylene oxide) PPO films $(\sim 100 \mathrm{~nm})$ is reduced compared to that in bulk PPO films [12]. However, this effect seemed less pronounced for $\mathrm{C}_{2} \mathrm{H}_{6}$ that showed significantly lower Langmuir sorption. Additionally, the estimated partial molar volume of these penetrants in PPO showed to be pressure dependent at lower pressures $(<10$ bar), where Langmuir sorption still contributed a significant part to the total sorption. Pressure dependent partial molar volumes in gas separation are inconsistent with the traditional view of the solution-diffusion model, where a penetrant is assumed to possess a partial molar volume equal to that in its liquid state [13]. Although Wijmans showed that the effect of this on the gas flux calculations can be ignored, it suggests that the assumption of penetrants being sorbed in the polymer matrix as a liquid does not necessarily hold, and the assumption of a gaseous state can be equally justified [14].

Although the investigation of PPO was relevant because of its commercial applications in e.g. $\mathrm{O}_{2} / \mathrm{N}_{2}$ separations, many other interesting polymers exist whose potential for commercial gas separation applications are also recognized. Additionally it allows examining the differences between thin and bulk film as the result of Langmuir sorption in more detail. Membranes made from polyimides [15], sulfonated polymers [16-19] and poly(dimethylsiloxane) (PDMS) [20-22] are also widely used in commercial applications. Yet all these mentioned polymers have significantly different physical properties. PPO, polyimide and sulfonated polymer based membranes are usually operated below their glass transition temperature $\left(\mathrm{T}_{\mathrm{g}}\right)$, unlike PDMS that is operated above its $T_{\mathrm{g}}$. The rubbery state of PDMS also excludes Langmuir sorption to take place. Oppositely, the excess free volume in the glassy polymers 
enables additional Langmuir sorption besides Henry sorption, which gives insight in thickness depending sorption effects. In addition, PPO and PDMS based membranes are apolar due to the large amount of carbon and silicon present in the polymer backbone. Contrary to this, polyimides contain a significant amount of polar $\mathrm{N}=\mathrm{O}$ groups, while sulfonated polymers contain very polar $\mathrm{SO}_{3} \mathrm{H}$ groups allowing polar interactions with penetrants. Horn et al. found higher $\mathrm{CO}_{2}$ concentrations in thin polyimide Matrimid films than in PPO films [6]. Additionally, they observed a relation between $\mathrm{CO}_{2}$ sorption capacity and polymer $\mathrm{T}_{\mathrm{g}}$. Fu et al. [23] and Jia et al. [24] showed that sulfonation of PPO changed the polymeric backbone, as the addition of $\mathrm{SO}_{3} \mathrm{H}$ groups changes the hydrophilicity and therefore the polymer-penetrant interactions. Consequently, the permeability of the polar $\mathrm{H}_{2} \mathrm{O}$ molecules was greatly enhanced.

Gas separation membranes are used in a variety of applications. Membranes are applied for $\mathrm{CO}_{2}$ capture and $\mathrm{CO}_{2} / \mathrm{N}_{2}$ separations [25-29], but also show potential for olefin/paraffin separation [1, 30, 31]. However, these gases have quite different physical properties and as such, exhibit different interactions with polymer membranes. The molecular mass, LenardJones (LJ) diameter, Van der Waals constant and critical temperature $\left(\mathrm{T}_{\mathrm{c}}\right)$ of $\mathrm{N}_{2}, \mathrm{CO}_{2}, \mathrm{C}_{2} \mathrm{H}_{4}$ and $\mathrm{C}_{2} \mathrm{H}_{6}$ are shown in Table 4.1. Two important differences among these molecules can be distinguished. First, there is a significant size difference among these molecules with $\mathrm{N}_{2}$ having the smallest LJ diameter and Van der Waals constant, which become increasingly larger for $\mathrm{CO}_{2}, \mathrm{C}_{2} \mathrm{H}_{4}$ and $\mathrm{C}_{2} \mathrm{H}_{6}$, respectively. Especially the Van der Waals volumes show a large difference of $15.3 \mathrm{~cm}^{3}$ between $\mathrm{N}_{2}$ and $\mathrm{CO}_{2}$ on one hand and $\mathrm{C}_{2} \mathrm{H}_{4}$ and $\mathrm{C}_{2} \mathrm{H}_{6}$ on the other hand. This indicates that if these penetrants would sorb into a polymer film in equal concentrations, a significantly higher swelling is expected for $\mathrm{C}_{2} \mathrm{H}_{4}$ and $\mathrm{C}_{2} \mathrm{H}_{6}$ as opposed to $\mathrm{N}_{2}$ and $\mathrm{CO}_{2}$. Second, $\mathrm{N}_{2}$ has a significantly lower $\mathrm{T}_{\mathrm{c}}$ as compared to $\mathrm{CO}_{2}, \mathrm{C}_{2} \mathrm{H}_{4}$ and $\mathrm{C}_{2} \mathrm{H}_{6}$. Therefore, it is assumed that $\mathrm{CO}_{2}, \mathrm{C}_{2} \mathrm{H}_{4}$ and $\mathrm{C}_{2} \mathrm{H}_{6}$ sorb in much higher concentrations than $\mathrm{N}_{2}$. Lastly, although being a neutral net molecule, $\mathrm{CO}_{2}$ has polar $\mathrm{C}=\mathrm{O}$ bonds, which can be responsible for sorption to polar groups in a polymer via dipole-quadrupole interactions [32]. Contrary to $\mathrm{CO}_{2}, \mathrm{C}_{2} \mathrm{H}_{6}$ is a saturated hydrocarbon and only capable of Van der Waals interactions. $\mathrm{C}_{2} \mathrm{H}_{4}$ and $\mathrm{N}_{2}$ also lack polar bonds, but do have $\pi$-bonds capable of interactions with other $\pi$-bonds. 
Table 4.1. General properties of $\mathrm{N}_{2}, \mathrm{CO}_{2}, \mathrm{C}_{2} \mathrm{H}_{4}$ and $\mathrm{C}_{2} \mathrm{H}_{6}$.

\begin{tabular}{lcccc}
\hline Gas & $\begin{array}{c}\text { Molecular mass } \\
(\mathrm{g} / \mathrm{mol})\end{array}$ & $\begin{array}{c}\text { LJ diameter } \\
\mathrm{d}_{\mathrm{LJ}}(\AA)[33]\end{array}$ & $\begin{array}{c}\text { Van der Waals volume } \\
\left(\mathrm{cm}^{3} / \mathrm{mol}\right)\end{array}$ & $\begin{array}{c}\text { Critical temperature } \\
\mathrm{T}_{\mathrm{c}}(\mathrm{K})[35]\end{array}$ \\
\hline $\mathrm{N}_{2}$ & 28.01 & 3.798 & 38.7 & 126.2 \\
$\mathrm{CO}_{2}$ & 44.01 & 3.941 & 42.9 & 304.2 \\
$\mathrm{C}_{2} \mathrm{H}_{4}$ & 28.05 & 4.163 & 58.2 & 282.5 \\
$\mathrm{C}_{2} \mathrm{H}_{6}$ & 30.07 & 4.443 & 65.1 & 305.3 \\
\hline
\end{tabular}

This chapter investigates $\mathrm{N}_{2}, \mathrm{CO}_{2}, \mathrm{C}_{2} \mathrm{H}_{4}$ and $\mathrm{C}_{2} \mathrm{H}_{6}$ induced swelling and sorption phenomena in PPO, PDMS, P84 and sulfonated PPO (SPPO) thin films. It explains observed changes in swelling and sorption based on differences in physical parameters of the penetrants (i.e. LJdiameter and Van der Waals volume, polarity and $\mathrm{T}_{\mathrm{c}}$ ) and the polymers (i.e. $\mathrm{T}_{\mathrm{g}}$ and polarity or functional groups). In addition, differences in $\mathrm{C}_{2} \mathrm{H}_{6}$ concentration in thin films and bulk PDMS, P84, SPPO and PPO are investigated, as the previous chapter showed indications that differences between bulk and thin film sorption are less pronounced when Langmuir sorption is not a significant contributor to the total sorption. Finally, with this obtained information, partial molar volumes of the selected penetrants were estimated for all investigated films. 


\subsection{Theory}

\subsubsection{Spectroscopic ellipsometry}

Spectroscopic ellipsometry is an optical, non-destructive technique that can be used to indirectly determine the thickness and refractive index of a thin, supported layer. After illumination of the sample with a beam of polarized light, the polarization change of the reflected beam is analyzed by a detector. The change in the in plane (p) and out of plane (s) polarization state can be expressed as a function of psi $(\Psi)\left(^{\circ}\right)$ and delta $(\triangle)\left(^{\circ}\right)$ according to Equation 4.1:

$$
\rho=\frac{r_{p}}{r_{s}}=\tan (\Psi) e^{i \Delta}
$$

The psi parameter describes how the amplitude ratio changes of the $\mathrm{p}$ - and s- polarized waves, while the delta parameter describes changes in the phase difference. The reader is referred to [35] for more information about ellipsometry. By means of an optical model, the changes in psi and delta at various wavelengths can be interpreted. In the optical model, the sample is described as a multilayer system in which each layer can be independently modeled. As most polymer layers are dielectric materials, the Cauchy equation can be used to describe them [5]:

$$
n=A+\frac{B}{\lambda^{2}}+\frac{C}{\lambda^{4}}+\cdots
$$

where $\lambda$ is the wavelength of the light in $\mathrm{nm}$ and $\mathrm{A}, \mathrm{B}$ and $\mathrm{C}$ are constants. The refractive index of a single component layer depends on its molecular mass, density and refractivity according to the Lorentz-Lorenz equation [36]: 


$$
\frac{n^{2}-1}{n^{2}+2}=\frac{A_{j}}{M_{w j}} \rho_{j}
$$

where $n(-)$ is the refractive index of the swollen film, $A_{j}$ is the molar refractivity of component $\mathrm{j}\left(\mathrm{m}^{3} / \mathrm{mol}\right), \mathbf{M}_{\mathrm{wj}}$ is the molecular mass of component $\mathrm{j}(\mathrm{kg} / \mathrm{mol})$ and $\rho_{\mathrm{j}}$ is the density of component $\mathrm{j}\left(\mathrm{kg} / \mathrm{cm}^{3}\right)$. When sorption of a penetrant in a transparent polymer film occurs, the penetrant concentration in the film can be directly related to the change in refractive index. The mass based concentration of this sorbed penetrant can be approximated by applying the Lorentz-Lorenz mixing rule [10]:

$$
\frac{n^{2}-1}{n^{2}+2}=\frac{A_{\text {penetrant }}}{M_{w \text { penetrant }}} C_{\text {penetrant }}+\frac{A_{\text {polymer }}}{M_{w \text { polymer }}} C_{\text {polymer }}
$$

where $A_{\text {penetrant }}$ and $A_{\text {polymer }}$ are the molar refractivities $\left(\mathrm{m}^{3} / \mathrm{mol}\right), \mathbf{M}_{\mathrm{w} \text { penetrant }}$ and $\mathbf{M}_{\mathrm{w} \text { polymer }}$ the molecular mass $(\mathrm{kg} / \mathrm{mol})$ and $\mathrm{C}_{\text {penetrant }}$ and $\mathrm{C}_{\text {polymer }}$ the mass based concentrations $\left(\mathrm{kg} / \mathrm{cm}^{3}\right)$ of the sorbed penetrant and the polymer, respectively. By using Equation 4.3, $\mathrm{A}_{\text {polymer }}$ and $\mathrm{M}_{\mathrm{w}}$ polymer can be experimentally determined, while $\mathrm{C}_{\text {polymer }}$ can be calculated by Equation 4.5:

$$
C_{\text {polymer }}=\rho_{\text {polymer }} \frac{h_{0}}{h}
$$

where $\mathrm{h}_{0}$ is the initial thickness $(\mathrm{nm})$ of the polymer film at vacuum and $\mathrm{h}$ is the film thickness $(\mathrm{nm})$ of the swollen polymer film as determined from experimental spectroscopic ellipsometry data. 


\subsubsection{Sorption}

\subsubsection{Sorption in rubbery polymers}

The equilibrium concentration of low condensable gases in a polymer $(\mathrm{C})\left(\mathrm{cm}^{3}(\mathrm{STP}) / \mathrm{cm}^{3}\right)$ is usually described by Henry`s law as a function of feed pressure (p) (bar) [37]:

$$
C=k_{D} \cdot p
$$

where $\mathrm{k}_{\mathrm{D}}$ is the Henry`s law parameter $\left(\mathrm{cm}^{3}(\mathrm{STP}) / \mathrm{cm}^{3}\right.$ bar). However, for more condensable gases like small organic vapors in a cross-linked rubbery polymer, Flory-Rehner`s equation is better suited [38]:

$$
\begin{aligned}
\ln a=\ln \frac{p}{p_{\text {sat }}} & =\ln \varphi_{2}+\left(1-\varphi_{2}\right)+\chi\left(1-\varphi_{2}\right)^{2}+V_{2}\left(\frac{v_{e}}{V_{0}}\right) \\
\cdot & {\left[\left(1-\varphi_{2}\right)^{1 / 3}-\left(\frac{1-\varphi_{2}}{2}\right)\right] }
\end{aligned}
$$

where $\ln (\mathrm{a})$ is the natural $\log$ penetrant activity in the vapor phase (-), p the pressure (bar), $\mathrm{p}_{\mathrm{sat}}$ the saturation vapor pressure (bar), $\chi$ the Flory-Huggins interaction parameter, $V_{2}$ the penetrant molecular volume $\left(\mathrm{cm}^{3} / \mathrm{mol}\right), v_{\mathrm{e}} / \mathrm{V}_{0}$ the effective number of crosslinks per unit volume of penetrant free polymer $\left(\mathrm{mol} / \mathrm{m}^{3}\right)$ and $\varphi_{2}$ the volume fraction of the penetrant in the polymer (-), which can be calculated according to Equation 4.8:

$$
\varphi_{2}=\frac{1}{1+\frac{22414}{C \cdot v_{\text {penetrant }}}}
$$

where $v_{\text {penetrant }}$ is the penetrant partial molar volume $\left(\mathrm{cm}^{3} / \mathrm{mol}\right)$ and $\mathrm{C}$ the equilibrium gas concentration $\left(\mathrm{cm}^{3}(\mathrm{STP}) / \mathrm{cm}^{3}\right)$. 


\subsubsection{Sorption in glassy polymers}

The dual-mode sorption model can be used to describe gas sorption in glassy polymers. The model assumes two independent sorption mechanisms to take place simultaneously, i.e. Henry sorption, following Henry`s law where sorption is linearly related to the feed pressure, and Langmuir sorption, which relies on a hole-filling mechanism [39]. Equation 4.9 describes the gas concentration inside the membrane $(\mathrm{C})\left(\mathrm{kg} / \mathrm{m}^{3}\right)$ as function of pressure (p) (bar):

$$
C=k_{d} \cdot p+\frac{C_{H}^{\prime} \cdot b \cdot p}{1+b \cdot p}
$$

where $\mathrm{k}_{\mathrm{d}}$ is Henry`s constant $\left(\mathrm{kg} /\left(\mathrm{m}^{3}\right.\right.$ bar $\left.)\right), \mathrm{C}_{\mathrm{H}}$ the Langmuir capacity constant $\left(\mathrm{kg} / \mathrm{m}^{3}\right)$ and b the Langmuir affinity constant (1/bar), which can be obtained by curve fitting methodologies. 


\subsection{Experimental}

\subsubsection{Materials}

Poly(2,6-dimethyl-phenylene oxide) PPO (Ultra High $\mathrm{M}_{\mathrm{w}}$ ) was obtained from Parker. Lenzing P84 polyimide (325 mesh, STD) was supplied by HP Polymer GmbH, Austria. SYLGARD $^{\circledR} 184$ Silicone elastomer and curing agent were obtained from Dow Corning. 99\% n-hexane, chloroform (analytical grade) and methanol were supplied by Merck KGaA, Darmstadt, while N-methyl-2-pyrrolidinone (NMP, 99\% extra pure) was supplied by Acros Organics, Belgium. Trimethylsilyl chlorosulfonate was obtained from Sigma-Aldrich. Si substrates were obtained in-house. $\mathrm{N}_{2}$ (3.0) was supplied by Linde, while $\mathrm{CO}_{2}$ (4.6), $\mathrm{C}_{2} \mathrm{H}_{4}$ (3.5) and $\mathrm{C}_{2} \mathrm{H}_{6}$ (2.5) were supplied by Praxair. All chemicals were used without further purification.

\subsubsection{PPO sulfonation}

Modification of PPO was done with trimethylsilyl chlorosulfonate (TMSCS) as sulfonating agent (Figure 4.1) [40]. Via the substitution of the trimethylsilyl sulfonic ester, the hydrophobic character of the polymer backbone is retained during sulfonation. This allows for a homogenous sulfonation in chloroform [41]. For a typical sulfonation reaction, 20 grams of dried PPO was dissolved in $300 \mathrm{ml}$ chloroform under a nitrogen atmosphere at room temperature. To this, $31.45 \mathrm{~g}$ TMSCS $(0.167 \mathrm{~mol})$ dissolved in $50 \mathrm{ml}$ of chloroform was added drop wise within 15 minutes, while continuously stirring the mixture at $500 \mathrm{rpm}$. After 12 hours, $200 \mathrm{ml}$ of methanol were added and the mixture was allowed to stir for 2 hours. The methanol quenched any residual TMSCS and yielded sulfonated PPO by cleavage of the trimethylsilyl group. The formed precipitate was washed 5 times with methanol and dried in a vacuum oven at $30{ }^{\circ} \mathrm{C}$ until further usage for at least 1 week. The sulfonation degree was determined by ${ }^{1} \mathrm{H}-\mathrm{NMR}$ analysis and was $20 \%$. 


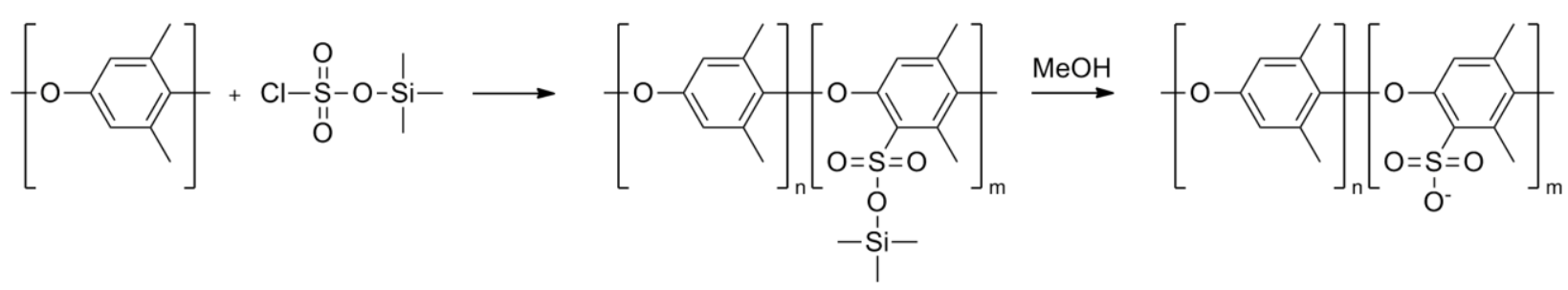

Figure 4.1. Reaction scheme of PPO sulfonation.

\subsubsection{Film preparation}

\subsubsection{Bulk film preparation}

Polymer solutions were made by dissolving 12-14 w\% of P84 and SPPO in NMP. The solutions were cast using a $0.47 \mathrm{~mm}$ casting knife on a glass plate in a nitrogen box and the films were dried for at least 72 hours at room temperature. Films were immersed in MilliQ water to remove them from the glass plate. Afterwards, the films were dried in a WTC Binder oven at $60{ }^{\circ} \mathrm{C}$ under $\mathrm{N}_{2}$ atmosphere overnight. PDMS films were prepared by thorough mixing SYLGARD ${ }^{\circledR} 184$ silicone elastomer with the curing agent in a ratio of 10:1. Afterwards, a film was prepared by casting the mixture with a $0.2 \mathrm{~mm}$ casting knife on a Teflon plate and subsequently placing it in to a WTC Binder oven at $60{ }^{\circ} \mathrm{C}$ under $\mathrm{N}_{2}$ atmosphere for 24 hours. PPO films were prepared as described in chapter 5, by dissolving 13 w\% PPO in $\mathrm{CHCl}_{3}$, after which the same protocol was followed as for the other bulk films. The thickness of the films was determined using an IP65 Coolant Proof digital Micrometer from Mitutoyo and found to be $30 \mu \mathrm{m}, 73 \mu \mathrm{m}, 46 \mu \mathrm{m}$ and $320 \mu \mathrm{m}$ for the PPO, SPPO, P84 and PDMS films, respectively.

\subsubsection{Thin film preparation}

1-3 w\% polymer solutions were made by diluting the P84, PDMS and SPPO solutions as described in the section 3.2.1 with NMP, n-hexane and NMP, respectively. Thin films were prepared by spin coating these solutions on a $15 \times 15 \mathrm{~mm} \mathrm{Si}$ wafer at $2500 \mathrm{rpm}$ for 1 minute under $\mathrm{N}_{2}$ atmosphere. This way, thin supported films between 78-101 nm were prepared and subsequently placed in a vacuum oven at $30{ }^{\circ} \mathrm{C}$ for at least 48 hours. Thin PPO films were prepared as described in chapter 5, by dissolving $1 \mathrm{w} \%$ PPO in $\mathrm{CHCl}_{3}$, after which the same protocol was followed as for the other thin films. All films were placed in the spectroscopic ellipsometry cell $72 \mathrm{hrs}$ after spin coating. 


\subsubsection{Thermal stability analysis}

Thermal stability of bulk P84, PDMS, PPO and SPPO films was investigated by thermogravimetrical analysis (TGA) (Perkin Elmer TGA 4000). At least $5 \mathrm{mg}$ of each film was placed in an alumina cup. After initially being held at $30{ }^{\circ} \mathrm{C}$ for 1 minute, the samples were heated up to $900{ }^{\circ} \mathrm{C}$ under $\mathrm{N}_{2}$ of $20 \mathrm{~mL} /$ minute, at a heating rate of $20{ }^{\circ} \mathrm{C} /$ minute. Afterwards, the atmosphere was switched from $\mathrm{N}_{2}$ to air to burn any remaining sample.

\subsubsection{Differential scanning calorimetry}

The glass transition temperature $\left(\mathrm{T}_{\mathrm{g}}\right)$ of the bulk films was determined by differential scanning calorimetry (DSC) using a Perkin Elmer DSC 8000. At least $3 \mathrm{mg}$ of the P84, PPO and SPPO bulk film sample was placed in an aluminum sample holder. As the PDMS film was crosslinked, it was not possible to determine its $\mathrm{T}_{\mathrm{g}}$. The temperature scan program for P84, PPO and SPPO is shown in Table 4.2. The third scan was used to determine the $\mathrm{T}_{\mathrm{g}}$, which was defined as the midpoint of the heat capacity transition. Since a heating rate of 40 ${ }^{\circ} \mathrm{C} /$ minute did not yield conclusive results for $\mathrm{P} 84$, a heating rate of $50{ }^{\circ} \mathrm{C} /$ minute, was chosen in these cases.

Table 4.2. DSC program for P84, PPO and SPPO.

\begin{tabular}{lccc}
\hline & P84 & PPO & SPPO \\
\hline Initial temp $\left({ }^{\circ} \mathrm{C}\right)$ & 35 & 30 & 30 \\
Hold time (minutes & 1 & 1 & 1 \\
Heating rate $\left({ }^{\circ} \mathrm{C} /\right.$ minute $)$ & 50 & 40 & 40 \\
Max temp $\left({ }^{\circ} \mathrm{C}\right)$ & 400 & 250 & 250 \\
$\begin{array}{l}\text { Cooling rate } \\
\left({ }^{\circ} \mathrm{C} / \text { minute }\right)\end{array}$ & -20 & -40 & -50 \\
End temp $\left({ }^{\circ} \mathrm{C}\right)$ & 35 & 30 & 30 \\
Hold time $($ minutes $)$ & 2 & 2 & 2 \\
\hline
\end{tabular}




\subsubsection{Gravimetric sorption measurements}

$\mathrm{C}_{2} \mathrm{H}_{6}$ sorption isotherms up to 30 bar were created by performing gravimetric sorption measurements with a minimum of $25 \mathrm{mg}$ bulk P84, PDMS, PPO and SPPO films with a magnetic suspension balance (MSB) (Rubotherm). Before each sorption run, the sample was thoroughly degassed in-situ for at least 24 hours. Afterwards, a sorption run was performed, which consisted of a stepwise pressurization. For P84, PPO and SPPO, each individual pressure was maintained for 24 hours while PDMS was held at equal pressure for a minimum of 3 hours. All measurements we performed at $35.3{ }^{\circ} \mathrm{C} \pm 0.4{ }^{\circ} \mathrm{C}$. The mass uptake of the sample $\left(\mathrm{m}_{\mathrm{t}}\right)$ was calculated according to Equation 4.10:

$$
m_{t}=w_{t}-\left(w_{0}-V_{t} \cdot \rho_{g a s}\right)
$$

where $\mathrm{w}_{0}$ is the weight of the sample $(\mathrm{g})$ at zero sorption, $\mathrm{V}_{\mathrm{t}}$ is the volume $\left(\mathrm{cm}^{3}\right)$ of the sample at time $\mathrm{t}(\mathrm{s})$ and $\rho_{\mathrm{gas}}$ is the density of the gas $\left(\mathrm{g} / \mathrm{cm}^{3}\right)$. The recorded weight $\left(\mathrm{w}_{\mathrm{t}}\right)(\mathrm{g})$ was corrected for buoyancy according to the Archimedes principle. $V_{t}$ was calculated from the mass of the sample and the density. A Micromeritics Accupyc II 1340 pycnometer was used to determine the density of the bulk polymer films at $25.2{ }^{\circ} \mathrm{C} \pm 0.9{ }^{\circ} \mathrm{C}$. As subsequent measurements are performed at $35{ }^{\circ} \mathrm{C}$, this introduces an error of approximately $0.2 \%$ assuming a polymer thermal expansion coefficient of $200 \cdot 10^{-6}\left({ }^{\circ} \mathrm{C}^{-1}\right)[42]$.

The concentration (C) $(\mathrm{g} / \mathrm{g})$ of $\mathrm{C}_{2} \mathrm{H}_{6}$ was subsequently calculated according to Equation 4.11:

$$
C=\frac{m_{t} \cdot V_{m} \cdot \rho_{\text {poly }}}{M_{w} \cdot w_{0}}
$$

where $V_{m}$ is the molar volume of the gas $\left(\mathrm{cm}^{3} / \mathrm{mol}\right), \rho_{\text {poly }}$ the density of the polymer $\left(\mathrm{g} / \mathrm{cm}^{3}\right)$ and $\mathrm{M}_{\mathrm{w}}$ the molecular mass $(\mathrm{g} / \mathrm{mol})$. 


\subsubsection{Spectroscopic Ellipsometry}

\subsubsection{Method}

The protocol for the thin films spectroscopic ellipsometry experiments was identical to the one used in a previous study [12], where each experiment was performed with a newly prepared sample. Each experiment was performance once since duplicate measurements of PPO showed that the repeatability was high and deviations in duplicates were around $0.5 \%$ only, as reported in the previous chapter. After removal from the vacuum oven, the spin coated PDMS, P84, PPO and SPPO samples were placed in a custom made high pressure cell for an Alpha-SE Spectroscopic Ellipsometer as described elsewhere [9]. The samples were constantly held at $35{ }^{\circ} \mathrm{C}$ and degassed overnight by a rotary vacuum pump. Each experiment contained one step-wise pressurization run, followed by one step-wise depressurization run. Pressurization and depressurization experiments were performed with four different penetrants, i.e. $\mathrm{N}_{2}, \mathrm{CO}_{2}, \mathrm{C}_{2} \mathrm{H}_{4}$ and $\mathrm{C}_{2} \mathrm{H}_{6}$. During the pressurization run, subsequent pressure steps were applied of $0,1,2,3,4,6,8,12,16,20,25$ and 30 bar, where each pressure step lasted for 90 minutes. The initial 5 minutes of each pressure step were used for temperature and pressure equilibration, while the remaining 85 minutes were used at constant pressure and temperature $\left(35^{\circ} \mathrm{C}\right)$ to determine changes in film thickness and optical constants. The depressurization run followed an analogous protocol with varying pressures from 30 to 0 bar.

\subsubsection{Optical Model}

CompleteEase 4.64 software was used to create a multilayer optical model used to interpret the ellipsometry data. Figure 4.2 schematically presents this model. Optical constant for the Si wafer and $\mathrm{SiO}_{2}$ were obtained from literature [43]. 


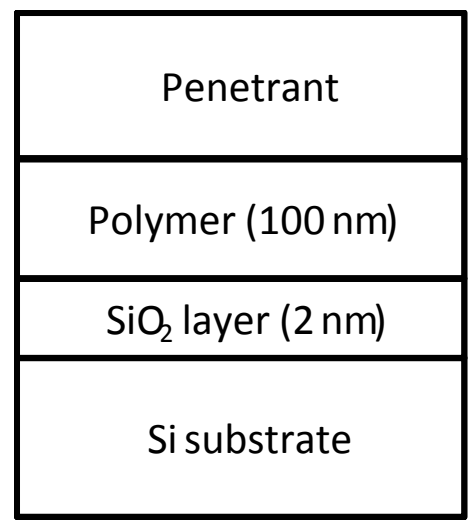

Figure 4.2. Schematic drawing of the optical multilayer model.

The thickness of the native $\mathrm{SiO}_{2}$ layer was found to be $2 \mathrm{~nm}$. The modeled wavelength ranges were adjusted for each polymer to maximize the amount of modeled data in the transparent region, as the Cauchy equation (Equation 4.2) is only valid for these regions. The selected wavelength ranges were $380-900 \mathrm{~nm}, 450-900 \mathrm{~nm}, 500-900 \mathrm{~nm}$ and 420-900 nm for PDMS, P84, PPO and SPPO, respectively. It should be noted that each wavelength range contained at least 1 psi oscillation to accurately determine the thickness and refractive index. Besides the thickness and the refractive index, the Cauchy parameters A and B, as well as depolarization due to thickness inhomogeneity was fitted. The refractive indices of the pure penetrants were adjusted during the modeling of each pressure step according to Table 4.3. For penetrant concentration calculations, pressure dependent densities at $35{ }^{\circ} \mathrm{C}$ were taken from NIST[[35]. The pressure dependent refractive indices and densities implicitly imply that sorbed penetrants are present in a gaseous phase as opposed to a (supercritical) liquid [10]. Finally, sorption isotherms were calculated using Equations 4.3-4.5. 
Table 4.3. Refractive indices of $\mathrm{N}_{2}$ [44], $\mathrm{CO}_{2}$ [45], $\mathrm{C}_{2} \mathrm{H}_{4}$ [46] and $\mathrm{C}_{2} \mathrm{H}_{6}$ [45] up to 30 bar.

\begin{tabular}{ccccc}
\hline \multirow{2}{*}{ Pressure (bar) } & \multicolumn{5}{c}{$\mathrm{n} \mathrm{(-)}$} \\
\cline { 2 - 5 } $\mathrm{N}_{2}$ & $\mathrm{CO}_{2}$ & $\mathrm{C}_{2} \mathrm{H}_{4}$ & $\mathrm{C}_{2} \mathrm{H}_{6}$ \\
\hline 1 & 1.0000 & 1.0000 & 1.0000 & 1.0000 \\
2 & 1.0003 & 1.0004 & 1.0006 & 1.0005 \\
3 & 1.0006 & 1.0008 & 1.0013 & 1.0010 \\
4 & 1.0008 & 1.0012 & 1.0019 & 1.0016 \\
6 & 1.0011 & 1.0016 & 1.0026 & 1.0022 \\
8 & 1.0017 & 1.0025 & 1.0039 & 1.0035 \\
12 & 1.0022 & 1.0034 & 1.0054 & 1.0048 \\
16 & 1.0033 & 1.0052 & 1.0085 & 1.0079 \\
20 & 1.0044 & 1.0072 & 1.0120 & 1.0114 \\
25 & 1.0055 & 1.0093 & 1.0157 & 1.0154 \\
30 & 1.0069 & 1.0121 & 1.0208 & 1.0209 \\
\hline
\end{tabular}

\subsubsection{Qualification and quantification of modeled ellipsometric data.}

The effect of pressurization and depressurization with $\mathrm{N}_{2}, \mathrm{CO}_{2}, \mathrm{C}_{2} \mathrm{H}_{4}$ and $\mathrm{C}_{2} \mathrm{H}_{6}$ were performed on thin PDMS, P84 and SPPO samples. A typical example of the obtained data from such a pressurization-depressurization cycle is shown in Figure 4.3.

Figure 4.3 shows the change in thickness of a thin P84 layer upon stepwise pressurization and depressurization with $\mathrm{C}_{2} \mathrm{H}_{6}$, uncorrected for birefringence and the ambient refractive index. A more detailed explanation of one pressurization step is shown in Figure 4.4. 


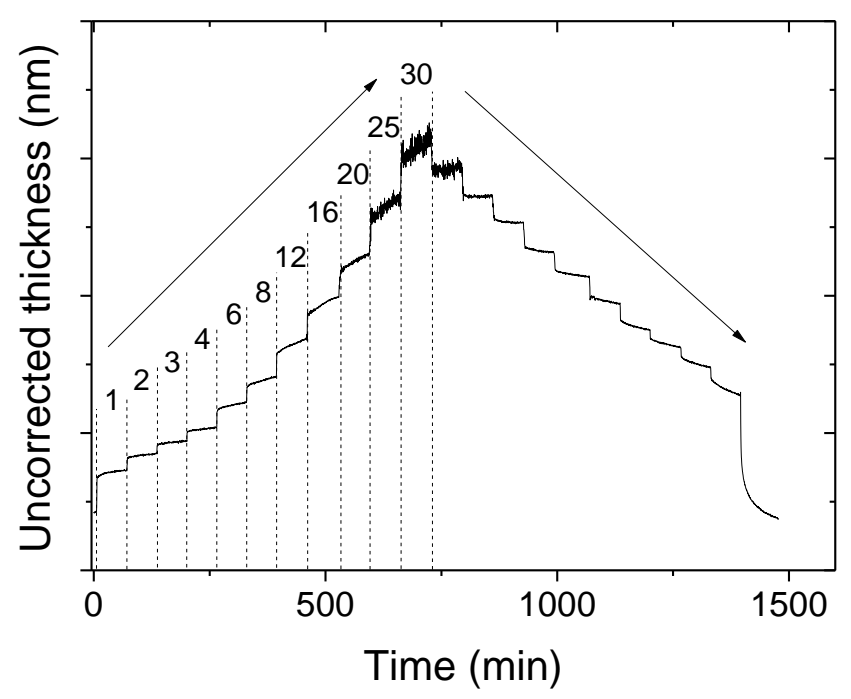

Figure 4.3. Typical example of pressurization and depressurization run from 0 to 30 bar (P84 under $\mathrm{C}_{2} \mathrm{H}_{6}$ atmosphere).

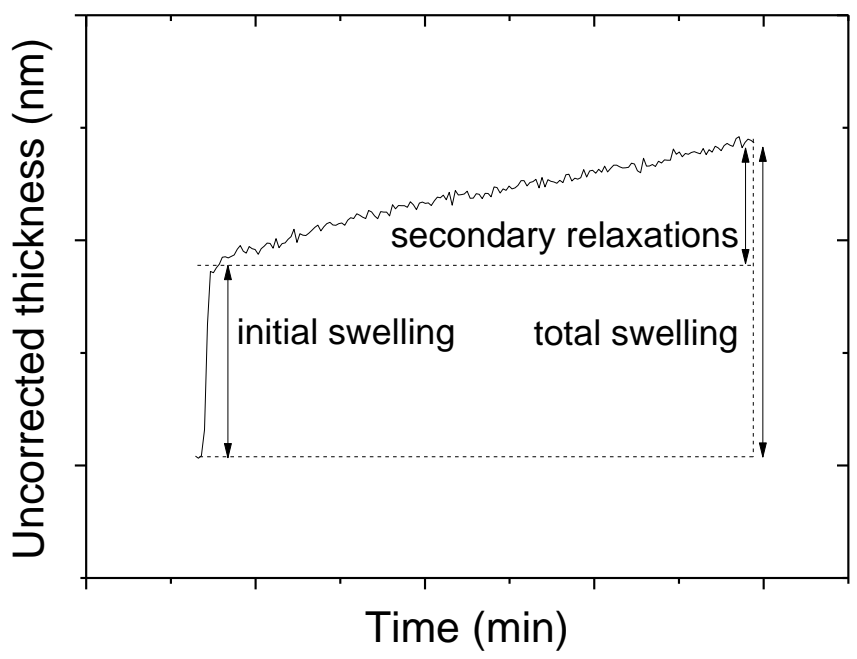

Figure 4.4. Definitions of initial swelling, secondary relaxations and total swelling of one pressurization step (P84 under $\mathrm{C}_{2} \mathrm{H}_{6}$ atmosphere).

Figure 4.4 shows that at the beginning of a pressurization step, the thickness increases rapidly. This is defined as the initial swelling, which is the result of fast Fickian sorption. As an increase in pressure causes small fluctuations in temperature, the initial 5 minutes of the pressure step were used for pressure and temperature equilibration. Although the initial Fickian sorption cannot be measured directly due to these small pressure and temperature 
fluctuations, the total amount of initial Fickian sorption that occurs can be calculated indirectly by subtracting the secondary relaxations from the total swelling. The remaining 85 minutes of the pressure step at constant temperature and pressure were used to investigate thickness changes caused by non-Fickian sorption phenomena, which will be defined as secondary relaxations. The film swelling as the result of these secondary relaxations can be calculated according to Equation 4.12:

$$
\text { Secondary relaxations }(\%)=\frac{h_{t=90, P=x}-h_{t=5, P=x}}{h_{0}} * 100 \%
$$

where $\mathrm{h}_{\mathrm{t}=90, \mathrm{P}=\mathrm{x}}$, is the film thickness $(\mathrm{nm})$ after 90 minutes of the beginning of a pressurization step at pressure $\mathrm{x}, \mathrm{h}_{\mathrm{t}=5, \mathrm{P}=\mathrm{x}}$, is the film thickness $(\mathrm{nm})$ after 5 minutes of the beginning of a pressurization step at pressure $x$ and $h_{0}$ is the film thickness $(n m)$ at the beginning of the first pressurization step at vacuum. From the summation of all secondary relaxation contributions of all individual pressure steps, the cumulative secondary relaxations can be calculated, which is the amount of swelling at any given pressure solely from contributions of the secondary relaxations:

Cumulative secondary relaxations $(\%)=\sum_{x=1}^{30} \frac{h_{t=90, P=x}-h_{t=5, P=x}}{h_{0}} * 100 \%$

Logically, the total swelling that occurred at 90 minutes after the beginning of a pressure step is the summation of the initial swelling and the secondary relaxation. The total swelling of the polymer film at any given pressure can be calculated by:

$$
\text { Total swelling }(\%)=\frac{h_{t=90, P=x}-h_{0}}{h_{0}} * 100 \%
$$


Finally, the contribution of the cumulative secondary relaxations to the total swelling is the ratio of the cumulative secondary relaxations and the total swelling. 


\subsection{Results and discussion}

In this section, we first discuss the general bulk polymer properties (i.e. density, decomposition temperature and glass transition temperature). Afterwards, the thin film characterization is discussed. The focus lies on swelling behavior of thin films and pressure dependence of the partial molar volume of the sorbed penetrants. Finally, differences in gas sorption between bulk and thin films will be evaluated.

As was discussed in the previous chapter, the gas concentration, and consequently, the partial molar volume, can only be approximated. Besides errors in the refractive indices of the samples due to approximations in the optical model, $\mathrm{A}_{\text {polymer }}$ (Equation 4.4) cannot be determined using spectroscopic ellipsometry alone. Additionally, differences at the microdomain level in the polymer film and limitations of the pressure control system $( \pm 0.1$ bar) may introduce an error as well. However, this has been taking into account and the presented data do show clear trends and behavior with significant differences among the different polymers and the different gasses investigated.

\subsubsection{Bulk film characterization}

General bulk polymer film properties were determined by pycnometry, TGA and DSC and are shown in Table 4.4. The membrane density was determined with a pycnometer to accurately obtain the intrinsic density as opposed to the bulk density, which is unsuitable for subsequent calculations using gravimetric sorption techniques. All obtained values correspond well with literature [23, 47, 48].

Table 4.4. Density, decomposition temperature and $\mathrm{T}_{\mathrm{g}}$ of P84, PDMS [32], PPO and SPPO.

\begin{tabular}{lcccc}
\hline & P84 & PDMS & PPO & SPPO \\
\hline Density $\left(\mathrm{g} / \mathrm{cm}^{3}\right)$ & 1.323 & 1.066 & 1.060 & 1.280 \\
Decomposition temperature $\left({ }^{\circ} \mathrm{C}\right)$ & 400 & 320 & 415 & 200 \\
$\mathrm{~T}_{\mathrm{g}}\left({ }^{\circ} \mathrm{C}\right)$ & 341 & $-125[32]$ & 216 & 230 \\
\hline
\end{tabular}


The densities of P84 and SPPO are higher than the densities of PDMS and PPO. The decomposition temperature of all investigated polymers is well above $35{ }^{\circ} \mathrm{C}$. This ensures thermal stability of all polymer films during the spectroscopic ellipsometry experiments. PDMS is reported to have a $\mathrm{T}_{\mathrm{g}}$ of $-125^{\circ} \mathrm{C}$ [32]. and can therefore be considered rubbery during all subsequent experiments. SPPO was found to have a decomposition temperature at $200{ }^{\circ} \mathrm{C}$, which is reported to be the result of desulfonation upon heating [49]. As this desulfonation occurs below the observed $T_{g}$, it suggests that the true $T_{g}$ of SPPO cannot be determined. Consequently, thermal annealing of the SPPO samples is not possible. Similarly, optical inspection of thermally annealed P84 samples at $350{ }^{\circ} \mathrm{C}$ showed a change in color from yellow to brown, indicating some structural change has occurred, although the measured $\mathrm{T}_{\mathrm{g}}$ was below the decomposition temperature. For this reason, it was decided not to thermally anneal the P84 samples prior to any experiments, although thermal treatment of polymer films would erase all prior history of the samples. As this was not possible, all samples were identically prepared and the time between the fabrication and measurement was 72 hours for all samples.

\subsubsection{Thin film behavior}

Since the swelling of polymer films as the result of penetrant penetration can largely influence the permeation behavior of membranes in terms of permeability and selectivity [50], it is important to analyze the individual contributions of the Fickian and non-Fickian swelling towards the total swelling. Polymer swelling or shrinkage can occur as a result of Fickian or non-Fickian sorption or desorption, respectively. The type of sorption depends on various parameters, e.g. penetrant activity [51], penetrant concentration and size [52] and $\mathrm{T}_{\mathrm{g}}$ [53]. The amount of sorption that occurs does not only depend on the sorption type (e.g. Henry sorption, Langmuir sorption) but also on the $T_{c}$ of the penetrant, the temperature and the possibility of polymer-penetrant interactions (e.g. Van der Waals interactions, polar interactions) [54]. In each subsequent section, the results from a previous study with PPO will be briefly discussed [12] for comparison, followed by those of PDMS, P84 and SPPO. Each section will be concluded with a comparison between these four polymers.

\subsubsection{Total swelling}

The total swelling of a polymer film can directly influence the membrane performance in terms of flux and selectivity [50]. Also, non-equilibrium hysteresis effects between the 
pressurization and the depressurization runs yield information on the non-equilibrium state of the penetrant-polymer system. The film thickness of PPO, PDMS, P84 and SPPO at vacuum varied between $100 \mathrm{~nm}-148 \mathrm{~nm}, 90 \mathrm{~nm}-104 \mathrm{~nm}, 79 \mathrm{~nm}-101 \mathrm{~nm}$ and $91 \mathrm{~nm}-100 \mathrm{~nm}$ respectively. The refractive indices varied between $1.569-1.599,1.428-1.443,1.650-$ 1.671 and 1.565 - 1.572 for PPO, PDMS, P84 and SPPO, respectively.

Figure 4.5a, b, c and d show the total swelling of PPO as function of feed pressure for $\mathrm{N}_{2}$, $\mathrm{CO}_{2}, \mathrm{C}_{2} \mathrm{H}_{4}$ and $\mathrm{C}_{2} \mathrm{H}_{6}$, respectively [12]. PPO shows typical dual-mode sorption behavior for all investigated gases. After pressurization, the induced swelling is the lowest for $\mathrm{N}_{2}$ (Figure 4.5a), due to its low $\mathrm{T}_{\mathrm{c}}$. As shown in Figure 4.5b and c, $\mathrm{CO}_{2}$ and $\mathrm{C}_{2} \mathrm{H}_{4}$, respectively, induce a similar amount of swelling. Since $\mathrm{CO}_{2}$ has a substantial smaller Van der Waals volume than $\mathrm{C}_{2} \mathrm{H}_{4}$, it induces similar amounts of swelling. Combined with the occurrence of specific interactions between $\mathrm{CO}_{2}$ and the ether linkages in PPO [55], it suggests that the concentration of $\mathrm{CO}_{2}$ in PPO is higher than that of $\mathrm{C}_{2} \mathrm{H}_{4}$. 


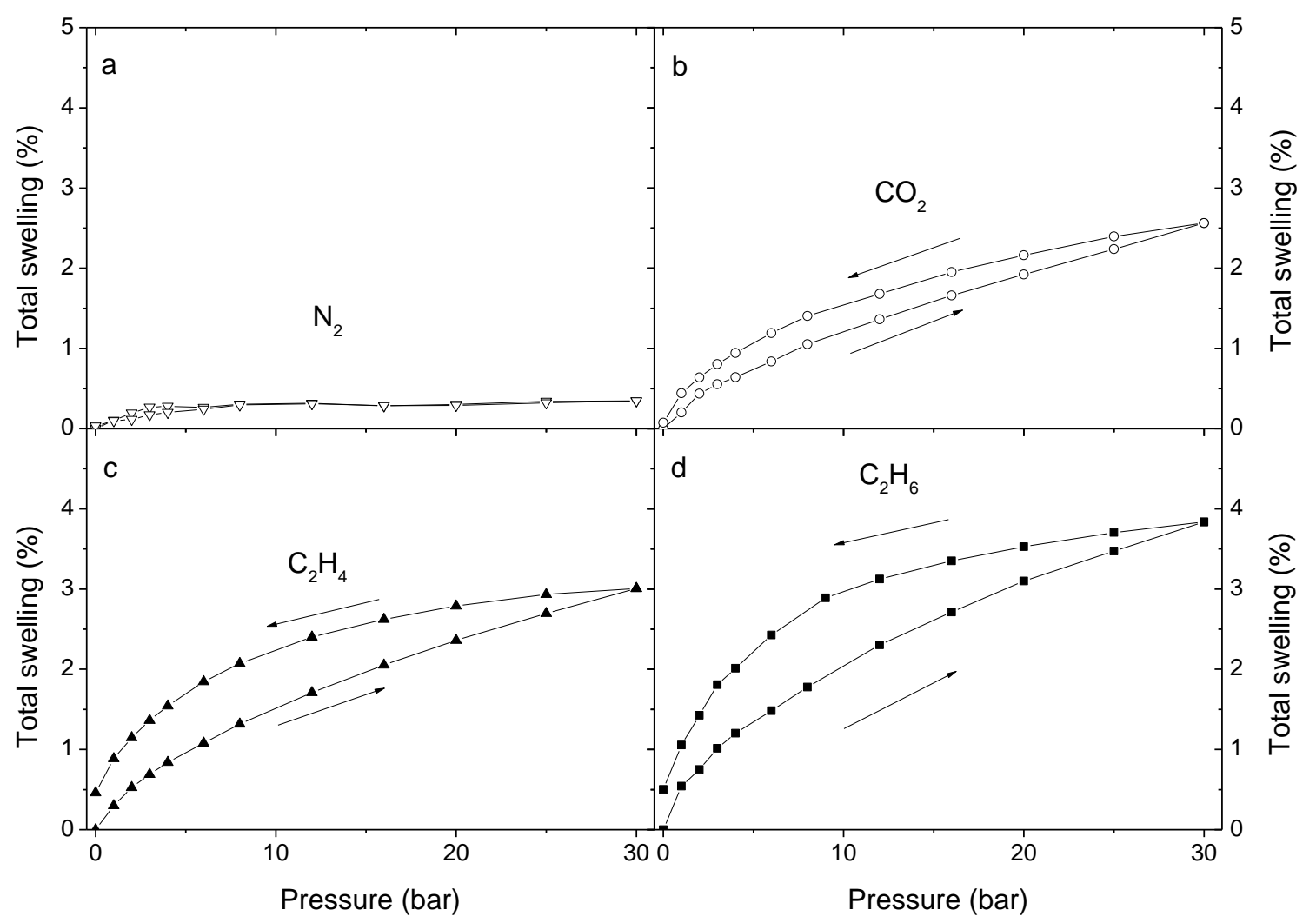

Figure 4.5. Total swelling during one pressurization-depressurization cycle of PPO as function of (a) $\mathrm{N}_{2}$, (b) $\mathrm{CO}_{2}$, (c) $\mathrm{C}_{2} \mathrm{H}_{4}$ and (d) $\mathrm{C}_{2} \mathrm{H}_{6}$ pressure [12].

The amount of $\mathrm{C}_{2} \mathrm{H}_{6}$ induced swelling in PPO is, within the accuracy of the measurement, the highest of all investigated gases, as is shown in Figure 4.5d. The higher LJ-diameter and Van der Waals volume of $\mathrm{C}_{2} \mathrm{H}_{6}$ causes a higher amount of swelling as compared to $\mathrm{C}_{2} \mathrm{H}_{4}$, although their concentrations in PPO at 30 bar are almost equal [12]. During the depressurization run, non-equilibrium hysteresis occurs for $\mathrm{CO}_{2}, \mathrm{C}_{2} \mathrm{H}_{4}$ and $\mathrm{C}_{2} \mathrm{H}_{6}$ as shown in Figures $4.5 \mathrm{~b}$, c and d, respectively. This non-equilibrium hysteresis is the result of collapsing Langmuir sites that occur on significantly longer time scales [56].

Figure 4.6 shows the total swelling of PDMS as function of (a) $\mathrm{N}_{2}$, (b) $\mathrm{CO}_{2}$, (c) $\mathrm{C}_{2} \mathrm{H}_{4}$ and (d) $\mathrm{C}_{2} \mathrm{H}_{6}$ pressure. As expected, Figure 4.6a shows low swelling for $\mathrm{N}_{2}$ as the result of low $\mathrm{N}_{2}$ sorption. The low critical temperature and small Van der Waals volume of the gas and the lack of possible interactions between the penetrant and the polymer are responsible for this 
low amount of swelling. On the other hand, as is shown in Figure 4.6b-d, $\mathrm{CO}_{2}, \mathrm{C}_{2} \mathrm{H}_{4}$ and $\mathrm{C}_{2} \mathrm{H}_{6}$ swell PDMS significantly more.

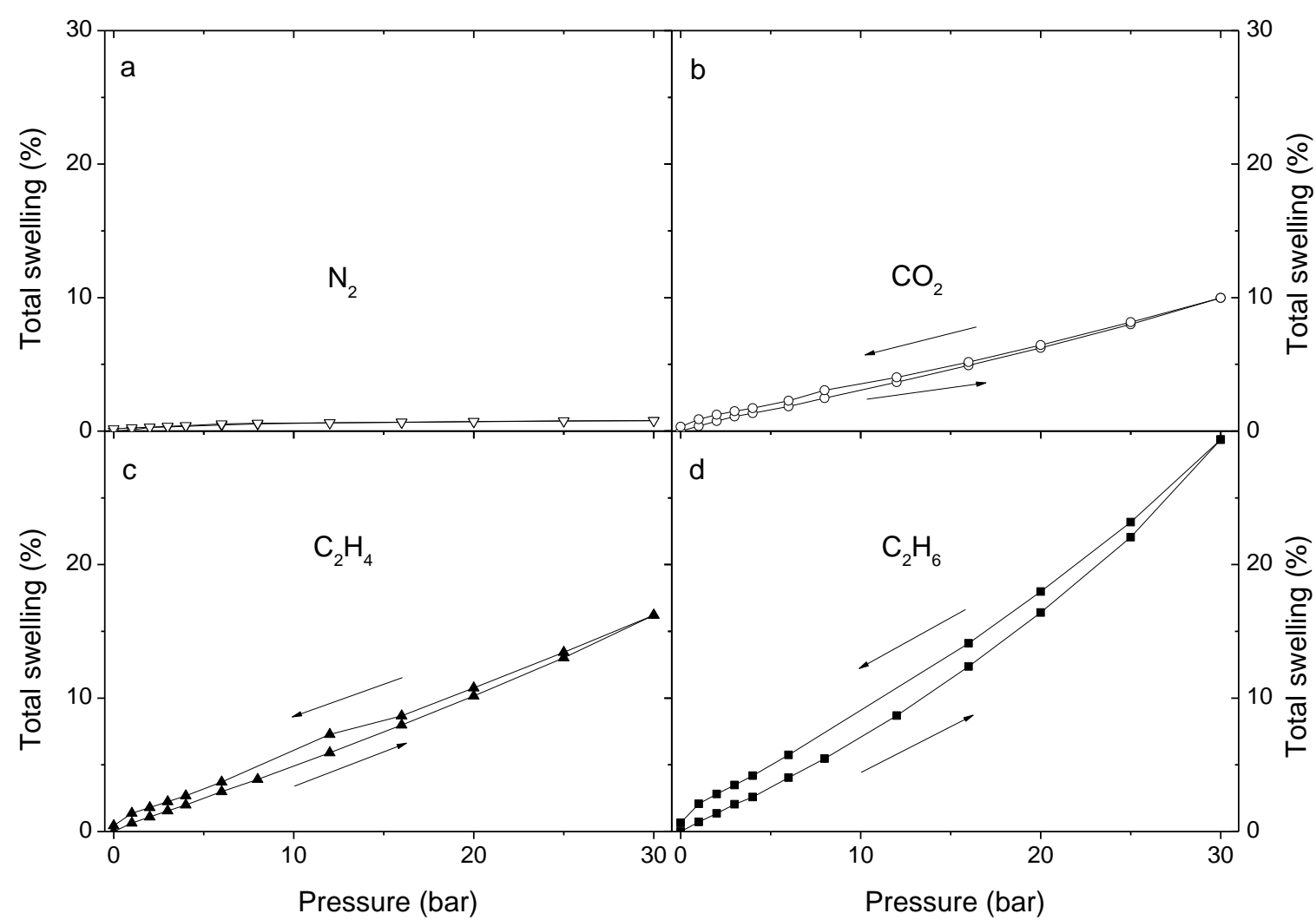

Figure 4.6. Total swelling during one pressurization-depressurization cycle of PDMS as function of (a) $\mathrm{N}_{2}$, (b) $\mathrm{CO}_{2}$, (c) $\mathrm{C}_{2} \mathrm{H}_{4}$ and (d) $\mathrm{C}_{2} \mathrm{H}_{6}$ pressure.

The total swelling induced by $\mathrm{CO}_{2}$ is linearly related to the $\mathrm{CO}_{2}$ pressure as can be seen in Figure 4.6b. This indicates that Henry sorption is the only sorption mechanism, as is expected for rubbery materials. During desorption, no non-equilibrium hysteresis between the pressurization and the depressurization run can be observed. This is also the result of the rubbery state of the polymer, which enables quick polymer chain reconfiguration to a new equilibrium state. Similar behavior can be observed for $\mathrm{C}_{2} \mathrm{H}_{4}$ as shown in Figure 4.6c: The total swelling is almost proportional to the feed pressure according to Henry`s law and no significant non-equilibrium hysteresis is observed. $\mathrm{C}_{2} \mathrm{H}_{4}$ does swell PDMS more than $\mathrm{CO}_{2}$ because of the larger LJ diameter and Van der Waals volume of $\mathrm{C}_{2} \mathrm{H}_{4}$ (Table 4.1), and 
because of favorable Van der Waals interactions between the apolar PDMS and apolar $\mathrm{C}_{2} \mathrm{H}_{4}$. When PDMS is exposed to $\mathrm{C}_{2} \mathrm{H}_{6}$, slightly different behavior can be observed. Figure 4.6d shows not only that $\mathrm{C}_{2} \mathrm{H}_{6}$ swells the layer almost two times more than compared to $\mathrm{C}_{2} \mathrm{H}_{4}$ at 30 bar, but it also shows a stronger non-linear relationship between swelling and feed pressure. This is the result of high concentrations of sorbed penetrants in the polymer matrix and can be well described by the Flory-Rehner theory (Equation 4.7). The apolar nature of paraffins allows for significant Van der Waals interactions with the apolar PDMS, leading to high solubility coefficients. Only a slight non-equilibrium hysteresis is visible between the pressurization and depressurization run, which could be the result of the extensive polymer swelling, which can be confirmed by the absence of secondary relaxations.

As opposed to sorption in rubbery polymers that can be described by Henry`s law and the Flory-Rehner theory, sorption in glassy polymers can be described by the dual-mode sorption model. This different sorption mechanism shows different swelling behavior of glassy polymers, as glassy polymers are unable to quickly accommodate to the shift in equilibrium conditions upon penetrant sorption. Figure 4.7 shows the total swelling of the glassy polymer $\mathrm{P} 84$ as function of (a) N2, (b) $\mathrm{CO} 2$, (c) $\mathrm{C} 2 \mathrm{H} 4$ and (d) $\mathrm{C} 2 \mathrm{H} 6$ pressure for one pressurizationdepressurization cycle. 


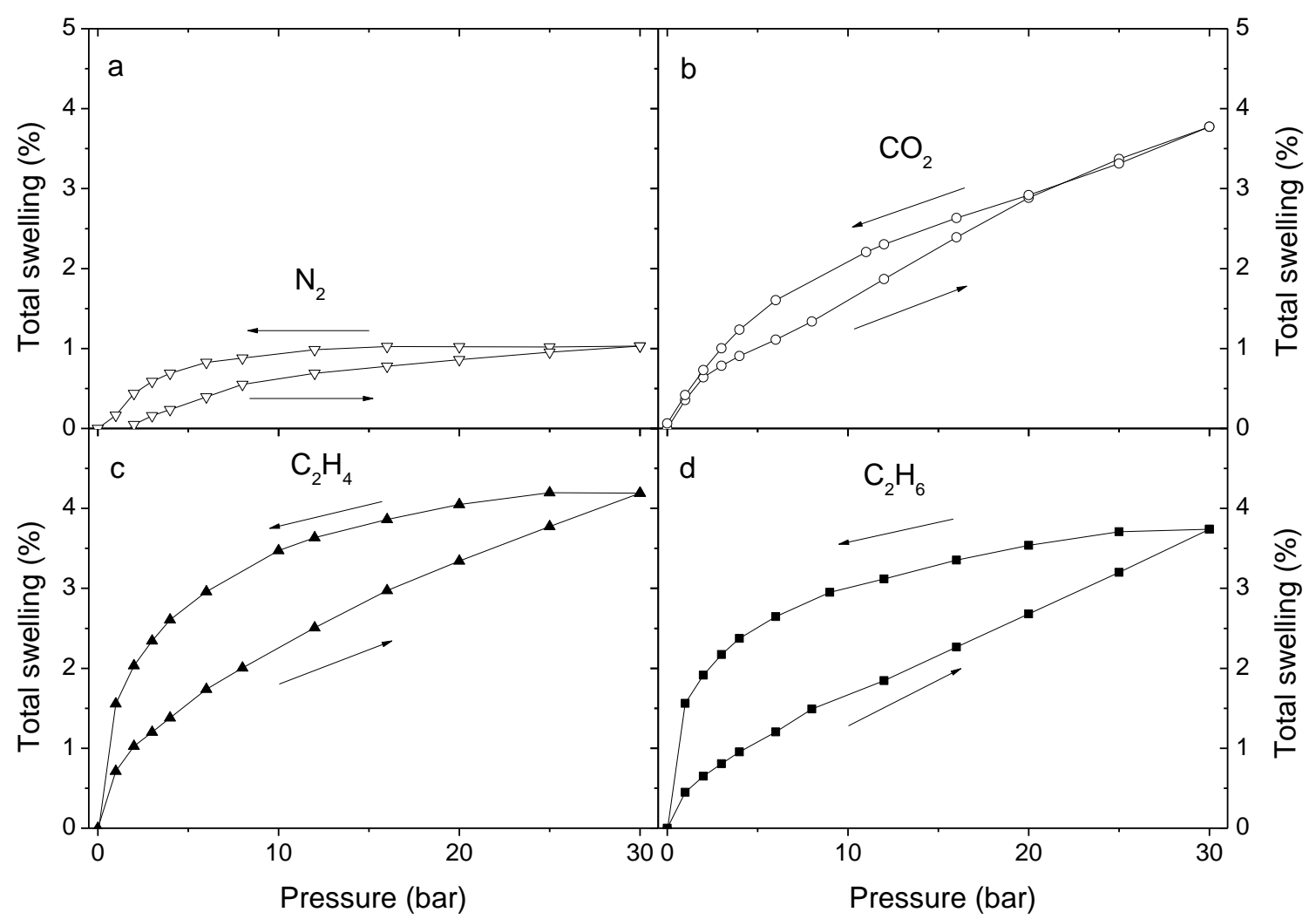

Figure 4.7. Total swelling during one pressurization-depressurization cycle of P84 as function of (a) $\mathrm{N}_{2}$, (b) $\mathrm{CO}_{2}$, (c) $\mathrm{C}_{2} \mathrm{H}_{4}$ and (d) $\mathrm{C}_{2} \mathrm{H}_{6}$ pressure.

Apart from $\mathrm{N}_{2}$, all other penetrants cause significantly lower swelling of the P84 layer as compared to the PDMS layer. The strong glassy state of P84 restricts polymer chain rotation and inhibits the polymer matrix to achieve an equilibrium situation [57]. Consequently, nonequilibrium hysteresis occurs between pressurization and depressurization for all investigated penetrants. Figure 4.7 a shows that even a low soluble gas like $\mathrm{N}_{2}$ can cause this nonequilibrium hysteresis to a little extent. Upon depressurization under $\mathrm{N}_{2}$, the total swelling remains fairly constant up to 4 bar, after which the total swelling quickly decreases as the result of collapsing Langmuir sorption sites.

$\mathrm{CO}_{2}, \mathrm{C}_{2} \mathrm{H}_{4}$ and $\mathrm{C}_{2} \mathrm{H}_{6}$ swell the P84 matrix equally as shown in Figures $4.7 \mathrm{~b}, 4.7 \mathrm{c}$ and $4.7 \mathrm{~d}$, respectively. However, a significant difference occurs during the depressurization run where the non-equilibrium is especially visible for $\mathrm{C}_{2} \mathrm{H}_{4}$ and $\mathrm{C}_{2} \mathrm{H}_{6}$ as opposed to $\mathrm{CO}_{2}$. This is most 
likely the result of the significant larger Van der Waals volume of $\mathrm{C}_{2} \mathrm{H}_{4}$ and $\mathrm{C}_{2} \mathrm{H}_{6}$, stretching the polymer matrix during the pressurization run. During the depressurization run desorption occurs. However, the strong glassy state of P84 prevents rapid accommodation to the new equilibrium and consequently, the polymer is 'frozen', despite a lower concentration of penetrant being present in the matrix. When the pressure is reduced to 2 bar, the P84 films exposed to $\mathrm{C}_{2} \mathrm{H}_{4}$ and $\mathrm{C}_{2} \mathrm{H}_{6}$ are still swollen to approximately half of the maximum total swelling that occurred at 30 bar feed pressure. Further reduction of the pressure leads to a rapid decrease in thickness due to collapse of the Langmuir sites.

Figure 4.8 shows the total swelling of SPPO as function of (a) $\mathrm{N}_{2}$, (b) $\mathrm{CO}_{2}$, (c) $\mathrm{C}_{2} \mathrm{H}_{4}$ and (d) $\mathrm{C}_{2} \mathrm{H}_{6}$ pressure for one pressurization-depressurization cycle.

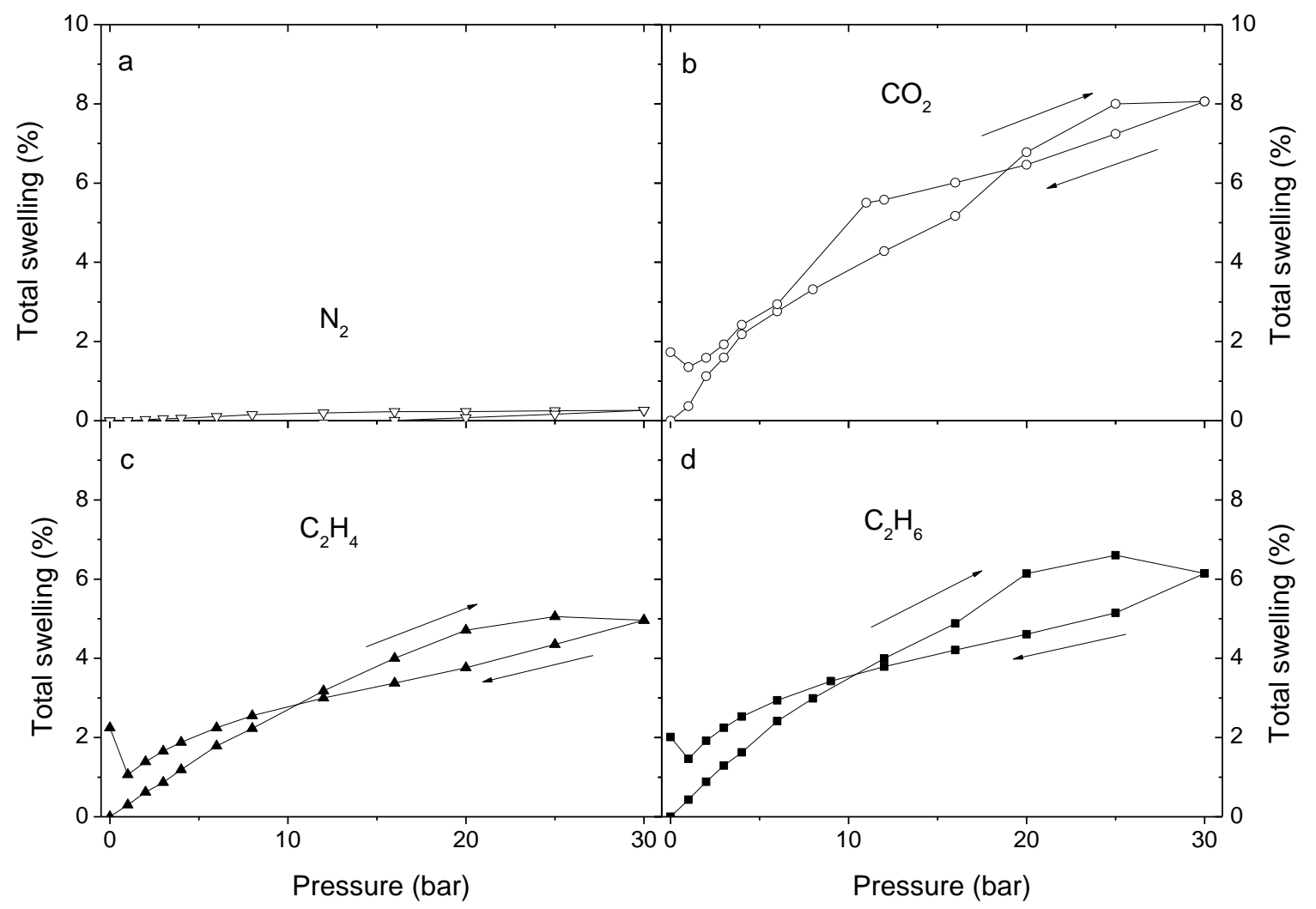

Figure 4.8. Total swelling during one pressurization-depressurization cycle of SPPO as function of (a) $\mathrm{N}_{2}$, (b) $\mathrm{CO}_{2}$, (c) $\mathrm{C}_{2} \mathrm{H}_{4}$ and (d) $\mathrm{C}_{2} \mathrm{H}_{6}$ pressure. 
When the SPPO film is exposed to $\mathrm{N}_{2}$, hardly any swelling can be observed as was also the case for the previously investigated polymers. The low critical temperature causes only a low concentration of $\mathrm{N}_{2}$ to sorb into the SPPO matrix, which in turn, because of its small LJ diameter and low Van der Waals volume, has very limited effect on the total swelling.

Contrary to $\mathrm{N}_{2}$, exposure of SPPO to $\mathrm{CO}_{2}, \mathrm{C}_{2} \mathrm{H}_{4}$ and $\mathrm{C}_{2} \mathrm{H}_{6}$ has significantly different effects as shown in Figures $4.8 \mathrm{~b}, 4.8 \mathrm{c}$ and $4.8 \mathrm{~d}$, respectively. Sorption of these three penetrants causes a substantial higher swelling, which we believe can be attributed to the introduction of bulky $\mathrm{SO}_{3} \mathrm{H}$ groups [42]. The polar nature of these $\mathrm{SO}_{3} \mathrm{H}$ groups enables interactions with $\mathrm{CO}_{2}$, resulting in substantial more $\mathrm{CO}_{2}$ induced swelling as compared to $\mathrm{C}_{2} \mathrm{H}_{4}$ and $\mathrm{C}_{2} \mathrm{H}_{6}[51$, 58]. Consequently, this suggests that the concentration of $\mathrm{CO}_{2}$ in SPPO is significantly higher than the concentration of $\mathrm{C}_{2} \mathrm{H}_{4}$ and $\mathrm{C}_{2} \mathrm{H}_{6}$.

When the total swelling of all investigated penetrants in PPO, PDMS, P84 and SPPO, as shown in Figures 4.5, 4.6, 4.7 and 4.8, respectively, is compared, a clear distinction can be made between the rubbery PDMS on one side, and the glassy PPO, P84 and SPPO polymers on the other side. Whereas low sorbing gases like $\mathrm{N}_{2}$ induce almost no swelling in any of the investigated polymer, gases with a higher critical temperature such as $\mathrm{CO}_{2}, \mathrm{C}_{2} \mathrm{H}_{4}$ and $\mathrm{C}_{2} \mathrm{H}_{6}$, induce significantly higher polymer swelling in the rubbery PDMS.

PPO (Figure 4.5) and P84 (Figure 4.7) show typical glassy behavior where the swelling isotherms follow a dual-mode like curve. In addition, non-equilibrium hysteresis occurs in PPO and P84 for $\mathrm{CO}_{2}, \mathrm{C}_{2} \mathrm{H}_{4}$ and $\mathrm{C}_{2} \mathrm{H}_{6}$ during desorption. However, in SPPO, the total swelling is lower during the depressurization run as it was during the pressurization run. Although Figure 4.8 alone cannot explain the exact mechanisms taking place, it is clear that typical glassy phenomena are either absent or take place at different timescales in SPPO as compared to PPO and P84. Investigation of the secondary relaxations provides more conclusive evidence on this.

A significantly higher $\mathrm{CO}_{2}$ induced swelling is observed for SPPO as compared to PPO, as shown in Figure 4.5 and 4.8, respectively. Although the $\mathrm{C}_{2} \mathrm{H}_{4}$ and $\mathrm{C}_{2} \mathrm{H}_{6}$ induced swelling in SPPO is also more pronounced as compared to PPO, it is not as significant as for $\mathrm{CO}_{2}$. The maximum $\mathrm{CO}_{2}$ induced swelling is highly dependent on the presence of polar groups in the polymer matrix, as is the case for P84 and PPO containing $\mathrm{C}=\mathrm{N}$ and ether groups, respectively. However, the $\mathrm{CO}_{2}$ induced total swelling is even significantly higher in SPPO, where $20 \%$ of the PPO backbone contained a highly polar $\mathrm{SO}_{3} \mathrm{H}$ group. 


\subsubsection{Secondary relaxations}

Secondary relaxations yield information about the non-equilibrium state of the polymer. When the concentration of penetrant inside the polymer differs from the concentration outside the polymer, a driving force for transport is created leading to sorption or desorption. When the penetrant concentration outside the polymer changes quickly and the polymer matrix is not able to respond quickly enough, Fick`s law of diffusion is no longer obeyed and non-Fickian (de)sorption takes place. Differences in behavior are expected between rubbery polymers with a flexible polymer matrix and the glassy polymers with only limited chain mobility and free volume. Figure 4.9 shows the cumulative secondary relaxations, calculated with Equation 4.12, as function of pressure for PDMS. For comparison, the cumulative secondary relaxations of PPO are also displayed [12].

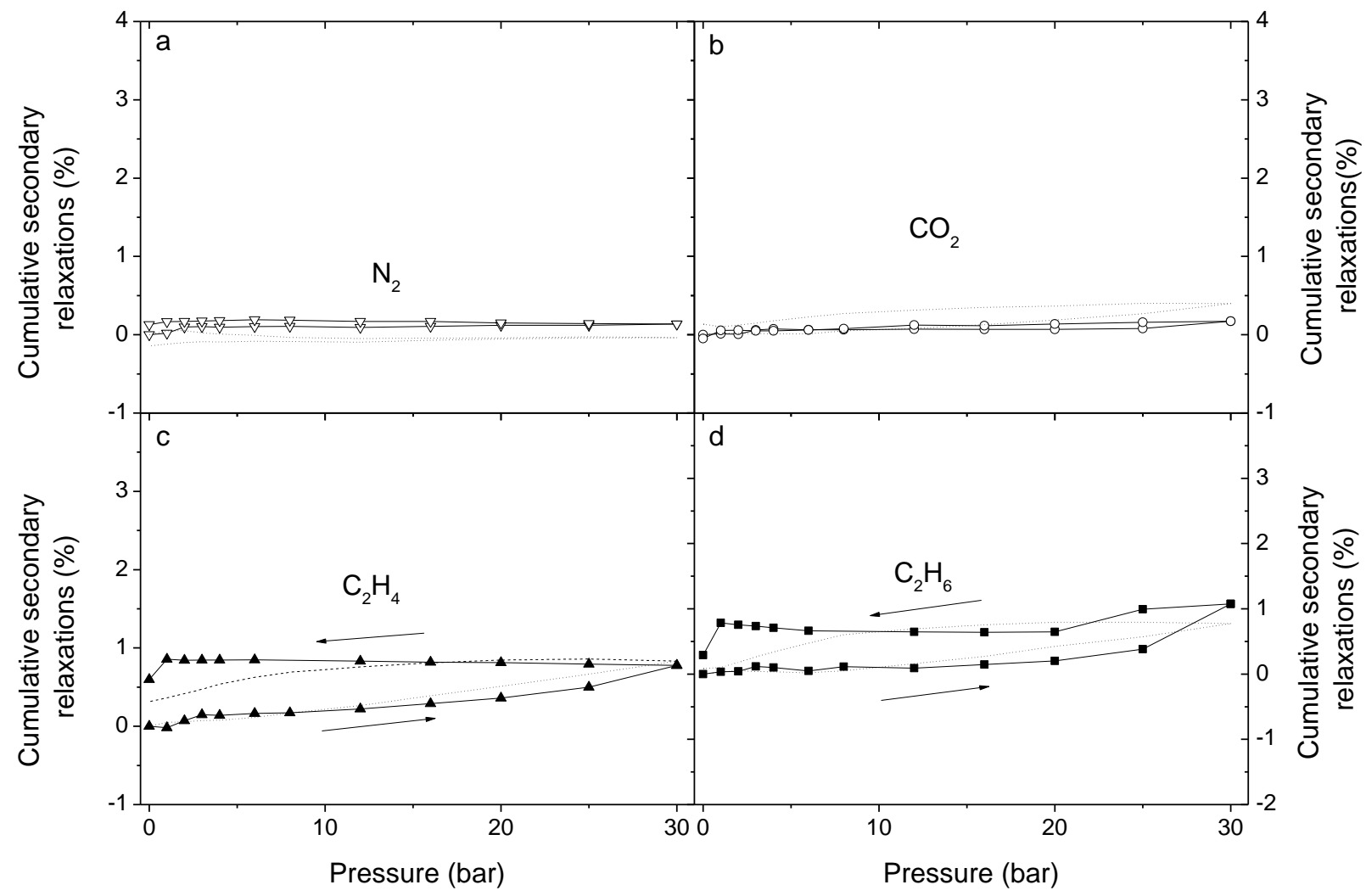

Figure 4.9. Cumulative secondary relaxations induced by (a) $\mathrm{N}_{2}$, (b) $\mathrm{CO}_{2}$, (c) $\mathrm{C}_{2} \mathrm{H}_{4}$ and (d) $\mathrm{C}_{2} \mathrm{H}_{6}$ as function of pressure for PDMS (solid line) and PPO (dotted line [12]). 
Figure 4.9a shows no significant $\mathrm{N}_{2}$ induced secondary relaxations over the entire investigated pressure range for PDMS, nor for PPO. This was expected as $\mathrm{N}_{2}$ has a low LJ diameter and Van der Waals volume and has a low condensability. Similarly to $\mathrm{N}_{2}$, also $\mathrm{CO}_{2}$ does not induce significant secondary relaxation in PDMS. Yet contrary to $\mathrm{N}_{2}, \mathrm{CO}_{2}$ does cause significant swelling in PDMS as was shown in Figure 4.6b. The rubbery state of the PDMS allows equilibrium to take place between the concentration of penetrant inside and outside the matrix. When the cumulative secondary relaxations of $\mathrm{C}_{2} \mathrm{H}_{4}$ and $\mathrm{C}_{2} \mathrm{H}_{6}$, shown in Figures $4.9 \mathrm{c}$ and $4.9 \mathrm{~d}$, are compared to those of PPO, the amount of cumulative secondary relaxations appears to be very similar. However, it should be taken in to account that $\mathrm{C}_{2} \mathrm{H}_{4}$ and $\mathrm{C}_{2} \mathrm{H}_{6}$ cause a significantly higher swelling of the PDMS layer (Figure 4.6c and 4.6d). To put this in perspective, Figure 4.10 shows the relative contribution of the cumulative secondary relaxations to the total swelling of PPO as function of pressure for $\mathrm{CO}_{2}, \mathrm{C}_{2} \mathrm{H}_{4}$ and $\mathrm{C}_{2} \mathrm{H}_{6}$.

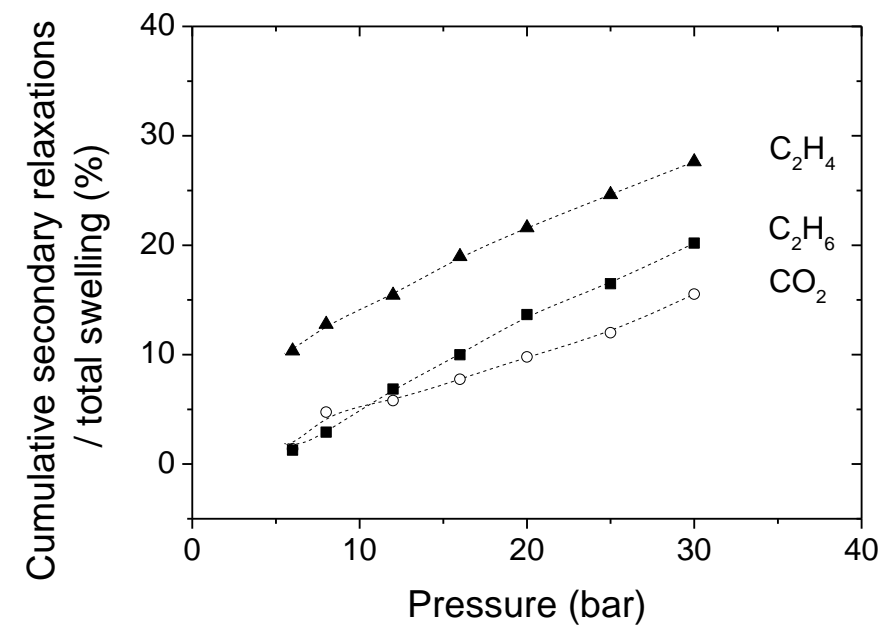

Figure 4.10. Relative contribution of the cumulative secondary relaxations to the total swelling induced by $\mathrm{CO}_{2}, \mathrm{C}_{2} \mathrm{H}_{4}$ and $\mathrm{C}_{2} \mathrm{H}_{6}$ as function of pressure for PPO.

As the $\mathrm{N}_{2}$ induced swelling and that of $\mathrm{CO}_{2}, \mathrm{C}_{2} \mathrm{H}_{4}$ and $\mathrm{C}_{2} \mathrm{H}_{6}$ at lower pressures $(<5$ bar $)$ in PPO is very low over the entire investigated pressure range, no significant result can be obtained about the contribution of the cumulative secondary relaxations to the total swelling. Figure 4.10 show that the contribution of the cumulative secondary relaxations in PPO seems 
to increase with increasing pressure. As the pressure increases, an increasingly higher part of the total swelling is caused by the cumulative secondary relaxations within the experimental uncertainty. The contribution of the cumulative secondary relaxations is the lowest for $\mathrm{CO}_{2}$ and the highest for $\mathrm{C}_{2} \mathrm{H}_{4}$ at 30 bar. The non-equilibrium state of the glassy PPO increases as the polymer matrix has insufficient time during one pressure step to accommodate and achieve equilibrium.

Figure 4.11 shows the contribution of the cumulative secondary relaxations to the total swelling as function of the pressure in PDMS for $\mathrm{CO}_{2}, \mathrm{C}_{2} \mathrm{H}_{4}$ and $\mathrm{C}_{2} \mathrm{H}_{6}$.

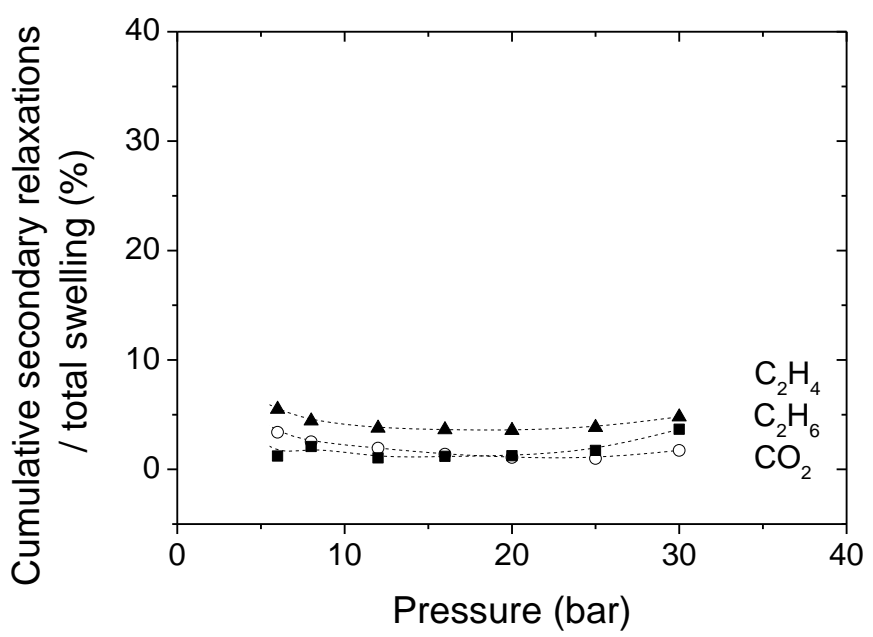

Figure 4.11. Relative contribution of the cumulative secondary relaxations to the total swelling induced by $\mathrm{CO}_{2}, \mathrm{C}_{2} \mathrm{H}_{4}$ and $\mathrm{C}_{2} \mathrm{H}_{6}$ as function of pressure for PDMS.

For $\mathrm{N}_{2}$, the contribution of the cumulative secondary relaxations to the total swelling fluctuates strongly, as the total induced $\mathrm{N}_{2}$ swelling in PDMS is close to zero (Figure 4.6a), which makes the result for $\mathrm{N}_{2}$ insignificant. Similarly, because of the low amounts of swelling that have occurred up to pressures of 5 bar the results shown in Figure 4.11 for $\mathrm{CO}_{2}$, $\mathrm{C}_{2} \mathrm{H}_{4}$ and $\mathrm{C}_{2} \mathrm{H}_{6}$ are also insignificant. For PDMS at higher pressures, the contribution of the cumulative secondary relaxations is limited to less than $5 \%$ of the total swelling only. As the pressure increases, the rubbery PDMS reaches equilibrium almost instantaneously with the increased concentration of penetrant in the ambient, resulting in the absence of secondary relaxations. 
The relative contributions of the cumulative secondary relaxation to the total swelling for the glassy polymer P84, as function of the $\mathrm{CO}_{2}, \mathrm{C}_{2} \mathrm{H}_{4}$ and $\mathrm{C}_{2} \mathrm{H}_{6}$ pressure are shown in Figure 4.12. Similar to PPO and PDMS, the total $\mathrm{N}_{2}$ induced swelling in P84 is too low to make the contribution of the cumulative secondary relaxations significant, as is the case for $\mathrm{CO}_{2}, \mathrm{C}_{2} \mathrm{H}_{4}$ and $\mathrm{C}_{2} \mathrm{H}_{6}$ at pressures below 5 bar. For $\mathrm{C}_{2} \mathrm{H}_{4}$ and $\mathrm{C}_{2} \mathrm{H}_{6}$, the contribution of the cumulative secondary relaxations to the total swelling in P84 is very pronounced, reaching a value up to approximately $35 \%$ for $\mathrm{C}_{2} \mathrm{H}_{6}$ at 30 bar. $\mathrm{CO}_{2}$ induced secondary relaxations contribute significantly less to the total swelling of P84. However, as shown in Figure 4.7, the total induced swelling is similar for $\mathrm{CO}_{2}, \mathrm{C}_{2} \mathrm{H}_{4}$ and $\mathrm{C}_{2} \mathrm{H}_{6}$, indicating that the majority of the $\mathrm{CO}_{2}$ induced swelling is caused by the initial Fickian swelling.

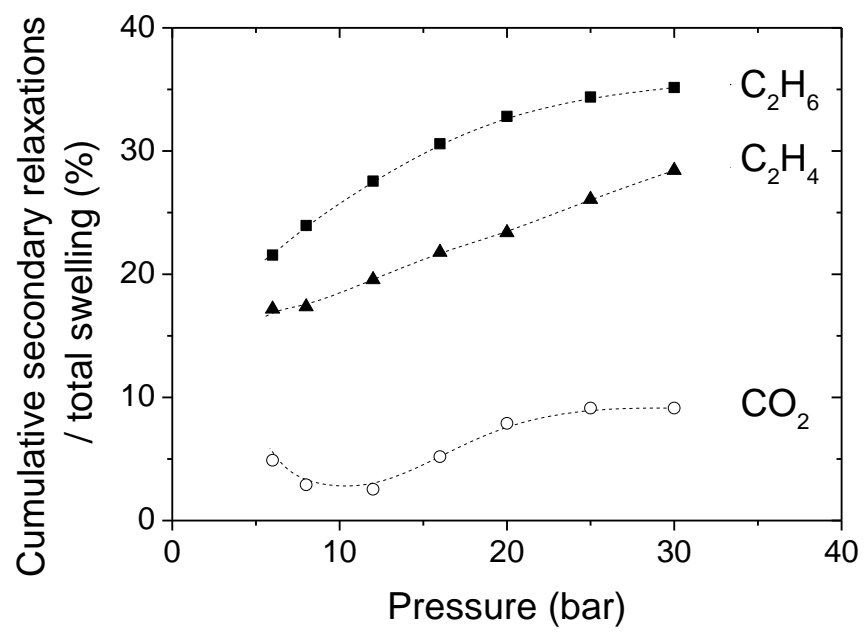

Figure 4.12. Relative contribution of the cumulative secondary relaxations to the total swelling induced by (a) $\mathrm{N}_{2}$, (b) $\mathrm{CO}_{2}$, (c) $\mathrm{C}_{2} \mathrm{H}_{4}$ and (d) $\mathrm{C}_{2} \mathrm{H}_{6}$ as function of pressure for P84.

Finally, the addition of a sulfon group to the PPO polymer backbone changes its properties drastically, as shown in Figure 4.13. 


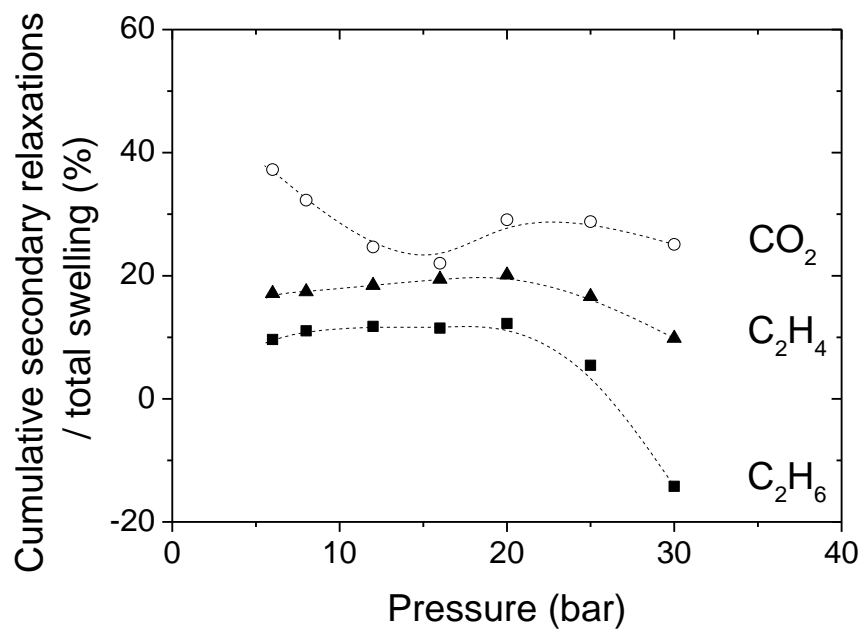

Figure 4.13. Relative contribution of the cumulative secondary relaxations to the total swelling induced by (a) $\mathrm{CO}_{2}$, (b) $\mathrm{C}_{2} \mathrm{H}_{4}$ and (c) $\mathrm{C}_{2} \mathrm{H}_{6}$ as function of pressure for SPPO (Note the difference in y-scale when compared to PPO, PDMS and P84 in Figures 4.10, 4.11 and 4.12).

Figure 4.13 shows the relative contributions of the secondary relaxations to the total swelling of $\mathrm{CO}_{2}, \mathrm{C}_{2} \mathrm{H}_{4}$ and $\mathrm{C}_{2} \mathrm{H}_{6}$ in SPPO. Similar to PPO, PDMS and P84, the low $\mathrm{N}_{2}$ induced swelling degree and the low swelling of $\mathrm{CO}_{2}, \mathrm{C}_{2} \mathrm{H}_{4}$ and $\mathrm{C}_{2} \mathrm{H}_{6}$ at pressures below 5 bar in SPPO yield insignificant results. The addition of the sulfon groups gives substantial changes to the polymers relaxation behavior. Besides an increase in the total $\mathrm{CO}_{2}$ induced swelling as compared to $\mathrm{C}_{2} \mathrm{H}_{4}$ and $\mathrm{C}_{2} \mathrm{H}_{6}$, as shown in Figure 4.8, the relative amount of cumulative secondary relaxations increased as well as shown in Figure 4.13. Approximately $30 \%$ of the total $\mathrm{CO}_{2}$ induced swelling is caused by cumulative secondary relaxations. At high pressures, a decline in the contribution of the $\mathrm{CO}_{2}, \mathrm{C}_{2} \mathrm{H}_{4}$ and $\mathrm{C}_{2} \mathrm{H}_{6}$ induced secondary relaxations can be observed. This decline represents a decrease in thickness of the polymer layer over time, even though the pressure was increased from 25 to 30 bar. This decrease in thickness was also shown in Figure 4.8b-d where the total swelling decreased upon pressurization from 25-30 bar.

A similar observation was made by Potreck et al. [51], who investigated $\mathrm{H}_{2} \mathrm{O}$ sorption induced relaxations in sulfonated poly-ether-ether-ketone (SPEEK). They observed with increasing $\mathrm{H}_{2} \mathrm{O}$ activity, a decrease in Fickian sorption, accompanied by a simultaneous 
increase in non-Fickian sorption. The increase in $\mathrm{H}_{2} \mathrm{O}$ activity initially led to only an increase in non-Fickian sorption, while desorption showed mainly Fickian behavior. At even higher $\mathrm{H}_{2} \mathrm{O}$ activities, the desorption also changed from mainly Fickian, to non-Fickian behavior, which had significant effect on e.g. water vapor transport. It is likely that such changes from Fickian to non-Fickian behavior are also observed in Figure 4.8 and Figure 4.13 for $\mathrm{CO}_{2}$, $\mathrm{C}_{2} \mathrm{H}_{4}$ and $\mathrm{C}_{2} \mathrm{H}_{6}$.

\subsubsection{Partial molar volume}

As discussed in $\$ 4.1$, the solution-diffusion model assumes penetrants in a polymer matrix being present in a liquid state with a constant partial molar volume. As both the relative thickness increase (Equation 4.14) and penetrant concentration (Equation 4.3-4.5) inside the matrix were experimentally determined with spectroscopic ellipsometry, to a certain extent, information on the penetrants partial molar volume can be obtained. The relative thickness increase can be presented as function of the penetrant concentration and this is shown in Figure 4.14. In principle, the derivative at any point equals the partial molar volume of the penetrant, $v_{\text {penetrant }}\left(\mathrm{cm}^{3} / \mathrm{mol}\right)$, at that specific point and can be calculated according to Equation 4.15 [5, 6]:

$$
v_{\text {penetrant }}=22400 \frac{\delta \frac{\Delta h}{h_{0}}}{\delta \text { Concentration }}
$$




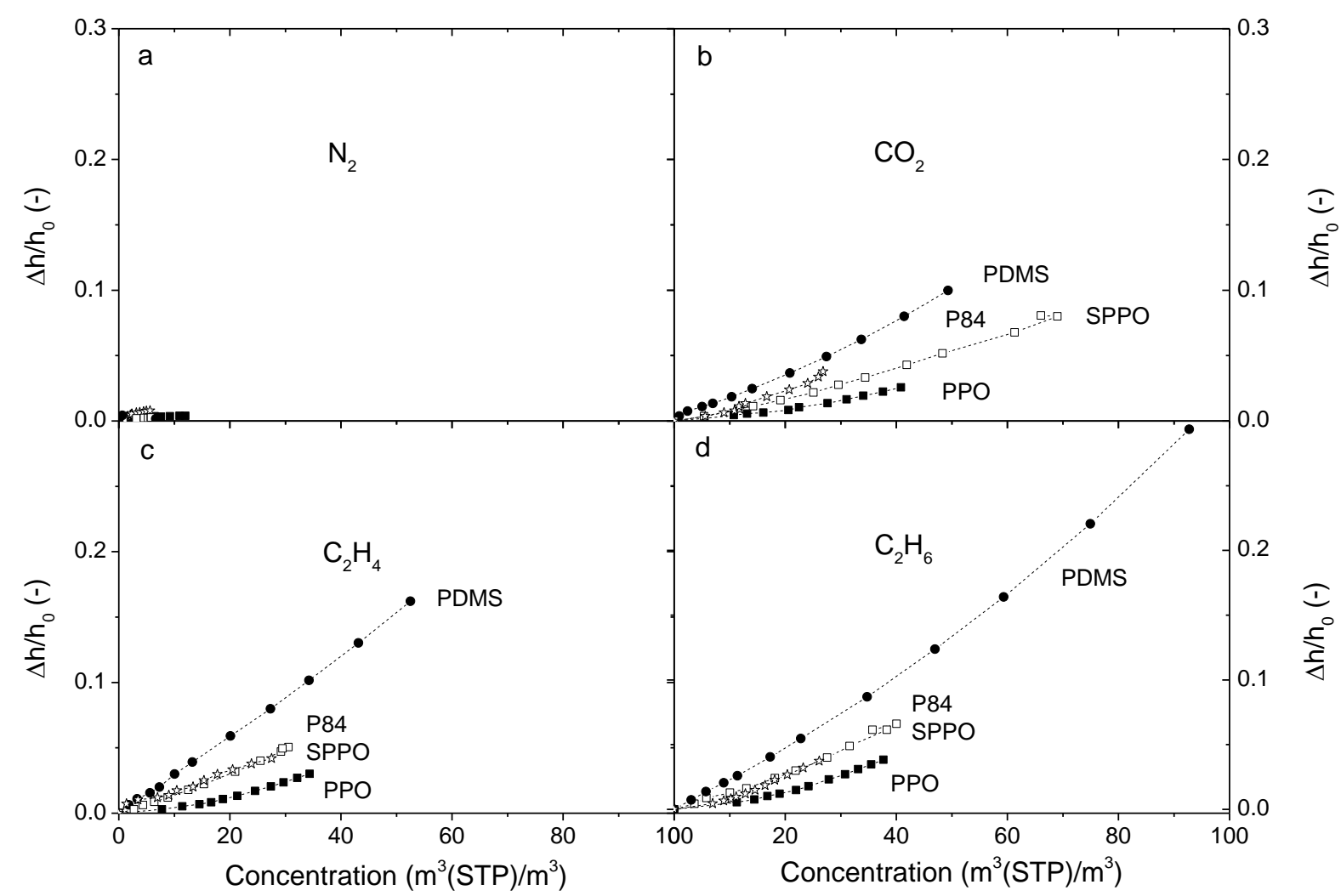

Figure 4.14. Relative thickness increase of PDMS, P84, SPPO and PPO [12], as function of (a) $\mathrm{N}_{2}$, (b) $\mathrm{CO}_{2}$, (c) $\mathrm{C}_{2} \mathrm{H}_{4}$ and (d) $\mathrm{C}_{2} \mathrm{H}_{6}$ concentration.

The low values found for $\mathrm{N}_{2}$, both in terms of concentration and $\Delta \mathrm{h} / \mathrm{h}_{0}$ (Figure $4.14 \mathrm{a}$ ), do not justify a approximation of the partial molar volume nor do these allow a comparison of the four different polymers. The $\mathrm{N}_{2}$ induced swelling is very low and the experimental error in the measurements is too high, due a combination of the small LJ diameter and Van der Waals volume of $\mathrm{N}_{2}$, combined with the low amount of sorbed gas due to its low critical temperature. On the other hand, Figures $4.14 \mathrm{~b}, 4.14 \mathrm{c}$ and $4.14 \mathrm{~d}$ show some trends and differences between the four different polymers when $\mathrm{CO}_{2}, \mathrm{C}_{2} \mathrm{H}_{4}$ or $\mathrm{C}_{2} \mathrm{H}_{6}$ are considered.. For all three gases, the rubbery PDMS swells the most at equal penetrant concentration. The larger chain mobility of the rubbery polymer enables a fast equilibrium when penetrants sorb into the matrix. In addition, the lack of Langmuir sorption assures that all sorbed penetrants swell the PDMS matrix, also at lower pressures. The penetrant induced swelling as function 
of its concentration is equal for both P84 and SPPO, while it is slightly reduced for PPO in the case of $\mathrm{C}_{2} \mathrm{H}_{4}$ and $\mathrm{C}_{2} \mathrm{H}_{6}$.

The results in Figure 4.14b-d also show that low concentrations $\left(<20 \mathrm{~m}^{3}(\mathrm{STP}) / \mathrm{m}^{3}\right)$ of $\mathrm{CO}_{2}$, $\mathrm{C}_{2} \mathrm{H}_{4}$ and $\mathrm{C}_{2} \mathrm{H}_{6}$, respectively swell the glassy PPO, P84 and SPPO films already a significant amount compared to $\mathrm{N}_{2}$, similar to PDMS. This was also shown in Figures 4.5, 4.7, 4.8 where the total swelling in the glassy polymers PPO, P84 and SPPO, respectively, as function of feed pressure showed dual-mode sorption like swelling. This indicates that penetrants sorbed as the result of Langmuir sorption do induce swelling, as was also observed by Wessling et al. using dilation experiments [57]. This contradicts the dual-mode sorption model, where only penetrants sorbed in the matrix contribute to swelling as opposed to molecules sorbed in the excess free volume. Consequently, the average partial molar volume of the penetrants also changes with concentration. To estimate the partial molar volume at the highest concentrations of sorbed penetrants, linear regression was performed using the last five data points in Figure 4.14b-d, which represent the largest amount of penetrant induced swelling in PDMS, PPO, P84 and SPPO at the highest penetrant concentrations. The corresponding approximated partial molar volumes are shown in Table 4.5.

Table 4.5. Partial molar volumes of $\mathrm{CO}_{2}, \mathrm{C}_{2} \mathrm{H}_{4}$ and $\mathrm{C}_{2} \mathrm{H}_{6}$ in PPO, P84, PDMS and SPPO estimated using the experimental data and Equation 4.15 (based on last 5 data points shown in Figure 4.14).

\begin{tabular}{cccc}
\hline \multirow{2}{*}{ Polymer } & \multicolumn{3}{c}{$v_{\text {penetrant }}\left(\mathrm{cm}^{3} / \mathrm{mol}\right)$} \\
\cline { 2 - 4 } & $\mathrm{CO}_{2}$ & $\mathrm{C}_{2} \mathrm{H}_{4}$ & $\mathrm{C}_{2} \mathrm{H}_{6}$ \\
PPO & 20.2 & 29.7 & 35.0 \\
P84 & 39.8 & 30.3 & 42.8 \\
SPPO & 32.1 & 44.5 & 46.7 \\
PDMS & 49.7 & 71.4 & 79.8 \\
\hline
\end{tabular}

Table 4.5 shows that the estimated partial molar volume of $\mathrm{CO}_{2}, \mathrm{C}_{2} \mathrm{H}_{4}$ and $\mathrm{C}_{2} \mathrm{H}_{6}$, respectively, increases with increasing LJ diameter and Van der Waals volume of the gases 
for all investigated polymers. The only exception is the partial molar volume of $\mathrm{CO}_{2}$ in $\mathrm{P} 84$ that is substantially higher than expected, which is caused by the last two data points that show deviations from linearity. The deviation of the data points from linearity as shown in Figure 4.14b-d, indicate the variability of the partial molar volume of the penetrants in glassy polymers. This suggests behavior similar to that of penetrants present in a gaseous state as opposed to a liquid state and has been observed for bulk films $[57,59]$ and thin films $[5,6$, 12]. This suggests that the solution-diffusion model is an over simplification, as pointed out by Wijmans as well [14]. However, Wijmans also indicated that this is very relevant for high pressure reverse osmosis applications, but almost insignificant for gas separation applications, as the difference between the apparent partial molar volume of the penetrant and the partial molar volume of that penetrant in its liquid state is usually small $\left(<30 \mathrm{~cm}^{3} / \mathrm{mol}\right)$ [14].

\subsubsection{Penetrant concentration in thin and bulk films}

As membranes become increasingly thinner, it becomes more important to investigate if the performance of thin membranes is similar to those of bulk films. It has been shown before that thin films show accelerated physical aging, which reduces the FFV, leading to differences in gas permeabilities and sorption [7, 60-64]. In chapter 3, we also showed that this accelerated physical aging in thin films leads to reduced Langmuir sorption for $\mathrm{CO}_{2}$, but this effect appeared to be less pronounced for $\mathrm{C}_{2} \mathrm{H}_{4}$ and $\mathrm{C}_{2} \mathrm{H}_{6}$, as Langmuir sorption in PPO was lower for these gases. Thickness dependent concentration effects can be examined by comparison of the $\mathrm{C}_{2} \mathrm{H}_{6}$ concentrations in all investigated thin films with the concentrations in their corresponding bulk films, as determined by gravimetric sorption using Equations 4.10 and 4.11. The results are summarized in Figure 4.15. Additionally the relation between bulk polymer $\mathrm{T}_{\mathrm{g}}$ and sorption capacity of the bulk films can be investigated.

Based on our results, no distinct relation exists between polymer $\mathrm{T}_{\mathrm{g}}$ and the $\mathrm{C}_{2} \mathrm{H}_{6}$ sorption capacity. P84 has the highest $\mathrm{T}_{\mathrm{g}}$ and the lowest sorption capacity, while PDMS with the lowest $\mathrm{T}_{\mathrm{g}}$ has the highest sorption capacity. This in contrast to the findings of Horn et al. [6]. However, also the data of Horn et al, show some deviations. At the same time also our data exhibit a certain uncertainty and experimental error. Also, sorption of a penetrant in a polymer is a multi parameter complex effect that cannot by definition only be quantified by 
the $\mathrm{Tg}$ (i.e. also e.g. penetrant $\mathrm{T}_{\mathrm{c}}$, Van der Waals volume and possible polymer-penetrant interactions play a role).

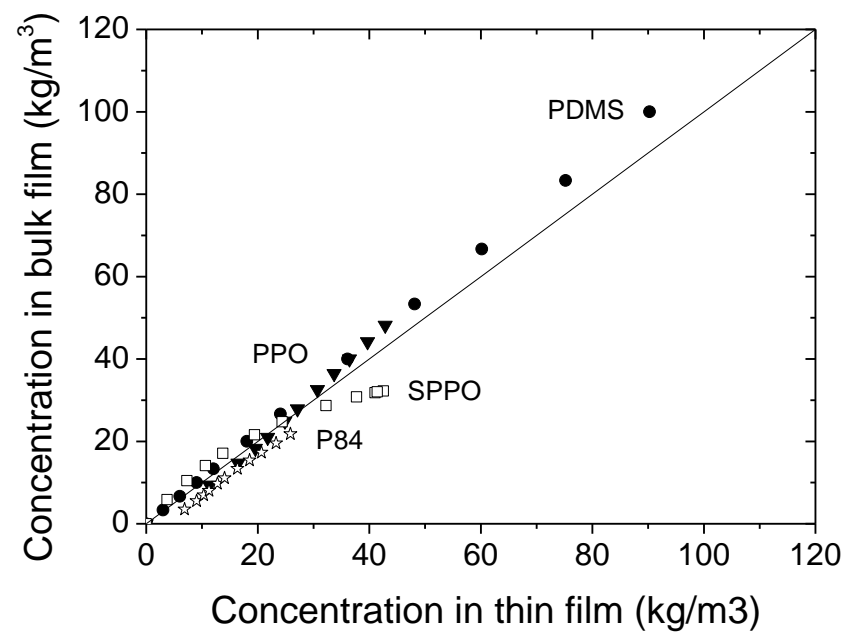

Figure 4.15. $\mathrm{C}_{2} \mathrm{H}_{6}$ concentration in bulk films as function of concentration in thin films for PDMS, P84, SPPO and PPO films.

If a reduction in Langmuir sites due to accelerated physical aging in thin films is indeed responsible for reduced gas concentrations in thin films, it is expected that this behavior will be comparable in all glassy polymers and absent in the rubbery polymer due to the lack of Langmuir sites. As Langmuir sorption of $\mathrm{C}_{2} \mathrm{H}_{6}$ is much lower than that of $\mathrm{CO}_{2}$, it is expected that concentration differences between bulk and thin films are less pronounced as for $\mathrm{C}_{2} \mathrm{H}_{6}$. Figure 4.15, indeed shows that similar $\mathrm{C}_{2} \mathrm{H}_{6}$ concentrations were found in thin and bulk PDMS films due to the absence of Langmuir sites. Additionally, Figure 4.15 shows no consistently lower $\mathrm{C}_{2} \mathrm{H}_{6}$ concentrations in thin glassy polymers as compared to bulk glassy polymers, while we did observe those differences for $\mathrm{CO}_{2}$ in thin and thick PPO films as shown in chapter 3. As shown in Chapter 3, it is hypothesized that this can be related to the fact that accelerated physical aging leads to lower gas concentration in thinner films for gases that show significant Langmuir sorption. However, thickness depending concentration effects seem less pronounced when Langmuir sorption is not as significant. 


\subsection{Conclusions}

The effect of different penetrants, $\mathrm{N}_{2}, \mathrm{CO}_{2}, \mathrm{C}_{2} \mathrm{H}_{4}$ and $\mathrm{C}_{2} \mathrm{H}_{6}$, on the swelling of PPO, PDMS, P84 and SPPO thin films was investigated with spectroscopic ellipsometry. The used optical model included pressure dependent refractive indices of the penetrants, thereby assuming sorbed penetrants in a gaseous state, as opposed to a liquid state. $\mathrm{N}_{2}$ did not show significant swelling of any of the investigated polymers. The rubbery PDMS was found to swell significantly more when exposed to $\mathrm{CO}_{2}, \mathrm{C}_{2} \mathrm{H}_{4}$ and $\mathrm{C}_{2} \mathrm{H}_{6}$ as compared to the glassy polymers PPO and P84. $\mathrm{C}_{2} \mathrm{H}_{6}$ induced swelling was most pronounced in PDMS due to a low $\mathrm{T}_{\mathrm{c}}$ and high Van der Waals volume of $\mathrm{C}_{2} \mathrm{H}_{6}$, and a high number of Van der Waals interactions between $\mathrm{C}_{2} \mathrm{H}_{6}$ and PDMS. In addition, PDMS swelling was almost entirely attributed to Fickian sorption, whereas in the glassy PPO and P84 the non-Fickian sorption contribution to the total swelling increases with increasing pressure. Sulfonation of the PPO backbone (SPPO) led to a significant increase in $\mathrm{CO}_{2}$ induced swelling as compared to PPO, due to polar interactions between the penetrant and the sulfon groups of the polymer. In addition, the sulfon groups drastically changed the sorption mechanism from Fickian to non-Fickian at higher concentrations of penetrant inside the polymer matrix. The partial molar volumes of $\mathrm{CO}_{2}, \mathrm{C}_{2} \mathrm{H}_{4}$, and $\mathrm{C}_{2} \mathrm{H}_{6}$ in all investigated polymers were approximated. Concentration dependent partial molar volumes were found, generally increasing with increasing Van der Waals volume in all polymers. Finally, no thickness dependencies were found between $\mathrm{C}_{2} \mathrm{H}_{6}$ concentrations in bulk films, as measured by gravimetric sorption, and thin films, using spectroscopic ellipsometry. This indicated that thickness dependent concentration effects are less pronounced for gases with low amounts of Langmuir sorption.

\section{Acknowledgements}

This project is financially supported by AgentschapNL. The authors would like to thank ECN, Dow and SolSep for their support. 


\section{Bibliography}

1. Ploegmakers, J., et al., Economic evaluation of membrane potential for ethylene/ethane separation in a retrofitted hybrid membrane-distillation plant using Unisim Design. Industrial and Engineering Chemistry Research, 2013. 52(19): p. 6524-6539.

2. Morgan, P.W., Condensation polymers by Interfacial and Solution Methods. Polymer Series, 1965. 10: p. 19-64.

3. Krasemann, L. and B. Tieke, Selective ion transport across self-assembled alternating multilayers of cationic and anionic polyelectrolytes. Langmuir, 2000. 16(2): p. 287290.

4. Leväsalmi, J.M. and T.J. McCarthy, Poly(4-methyl-1-pentene)-supported polyelectrolyte multilayer films: Preparation and gas permeability. Macromolecules, 1997. 30(6): p. 1752-1757.

5. Simons, K., et al., CO2 sorption and transport behavior of ODPA-based polyetherimide polymer films. Polymer, 2010. 51(17): p. 3907-3917.

6. Horn, N.R. and D.R. Paul, Carbon dioxide sorption and plasticization of thin glassy polymer films tracked by optical methods. Macromolecules, 2012. 45(6): p. 28202834.

7. Horn, N.R. and D.R. Paul, Carbon dioxide plasticization and conditioning effects in thick vs. thin glassy polymer films. Polymer, 2011. 52(7): p. 1619-1627.

8. Pham, J.Q., K.P. Johnston, and P.F. Green, Retrograde Vitrification in CO2/Polystyrene Thin Films. The Journal of Physical Chemistry B, 2004. 108(11): p. 3457-3461.

9. Ogieglo, W., et al., n-Hexane induced swelling of thin PDMS films under nonequilibrium nanofiltration permeation conditions, resolved by spectroscopic ellipsometry. Journal of Membrane Science, 2013. 431(0): p. 233-243.

10. Sirard, S.M., P.F. Green, and K.P. Johnston, Spectroscopic ellipsometry investigation of the swelling of poly(dimethylsiloxane) thin films with high pressure carbon dioxide. Journal of Physical Chemistry B, 2001. 105(4): p. 766-772.

11. Wind, J.D., et al., Carbon dioxide-induced plasticization of polyimide membranes: Pseudo-equilibrium relationships of diffusion, sorption, and swelling. Macromolecules, 2003. 36(17): p. 6433-6441.

12. Ploegmakers, J., J. Grooth de, and K. Nijmeijer, Penetrant induced sorption and swelling phenomena in thin PPO films resolved by spectroscopic ellipsometry. Submitted. 2013.

13. Wijmans, J.G. and R.W. Baker, The solution-diffusion model: A review. Journal of Membrane Science, 1995. 107(1-2): p. 1-21.

14. Wijmans, J.G., The role of permeant molar volume in the solution-diffusion model transport equations. Journal of Membrane Science, 2004. 237(1-2): p. 39-50.

15. Industries, E. http://www.p84.com/product/p84/en/products/membranes-gasseparation/pages/applications.aspx. 2008; Available from: http://www.p84.com/product/p84/en/products/membranes-gasseparation/pages/applications.aspx.

16. Fang, J., et al., Novel sulfonated polyimides as polyelectrolytes for fuel cell application: 1. Synthesis, proton conductivity, and water stability of polyimides from 4,4'-diaminodiphenyl ether-2,2'-disulfonic acid. Macromolecules, 2002. 35(24): p. 9022-9028. 
17. Kreuer, K.D., On the development of proton conducting polymer membranes for hydrogen and methanol fuel cells. Journal of Membrane Science, 2001. 185(1): p. 2939.

18. Nolte, R., et al., Partially sulfonated poly(arylene ether sulfone) - A versatile proton conducting membrane material for modern energy conversion technologies. Journal of Membrane Science, 1993. 83(2): p. 211-220.

19. Xing, P., et al., Synthesis and characterization of sulfonated poly(ether ether ketone) for proton exchange membranes. Journal of Membrane Science, 2004. 229(1-2): p. 95-106.

20. Li, L., et al., Composite PDMS membrane with high flux for the separation of organics from water by pervaporation. Journal of Membrane Science, 2004. 243(1-2): p. 177-187.

21. Mohammadi, T., A. Aroujalian, and A. Bakhshi, Pervaporation of dilute alcoholic mixtures using PDMS membrane. Chemical Engineering Science, 2005. 60(7): p. 1875-1880.

22. Qi, R., et al., Pervaporation separation of alkane/thiophene mixtures with PDMS membrane. Journal of Membrane Science, 2006. 280(1-2): p. 545-552.

23. $\mathrm{Fu}, \mathrm{H}$. and J. Ku, Studies on the sulfonation of poly(phenylene oxide) (PPO) and permeation behavior of gases and water vapor through sulfonated PPO membranes. I. Sulfonation of PPO and characterization of the products. Journal of Applied Polymer Science, 1994. 51(8): p. 1399-1404.

24. Jia, L., et al., Studies on the sulfonation of poly(phenylene oxide) (PPO) and permeation behavior of gases and water vapor through sulfonated PPO membranes. III. Sorption behavior of water vapor in PPO and sulfonated PPO membranes. Journal of Applied Polymer Science, 1994. 52(1): p. 29-37.

25. Aaron, D. and C. Tsouris, Separation of CO2 from flue gas: A review. Separation Science and Technology, 2005. 40(1-3): p. 321-348.

26. D'Alessandro, D.M., B. Smit, and J.R. Long, Carbon dioxide capture: Prospects for new materials. Angewandte Chemie - International Edition, 2010. 49(35): p. 60586082.

27. Figueroa, J.D., et al., Advances in CO2 capture technology-The U.S. Department of Energy's Carbon Sequestration Program. International Journal of Greenhouse Gas Control, 2008. 2(1): p. 9-20.

28. Koros, W.J. and R. Mahajan, Pushing the limits on possibilities for large scale gas separation: Which strategies? Journal of Membrane Science, 2000. 175(2): p. 181196.

29. Yang, H., et al., Progress in carbon dioxide separation and capture: A review. Journal of Environmental Sciences, 2008. 20(1): p. 14-27.

30. Motelica, A., et al., Membrane retrofit option for paraffin/olefin separation-a technoeconomic evaluation. Industrial and Engineering Chemistry Research, 2012. 51(19): p. 6977-6986.

31. Eldridge, R.B., Olefin/paraffin separation technology: A review. Industrial and Engineering Chemistry Research, 1993. 32(10): p. 2208-2212.

32. Ghosal, K., et al., Effect of Basic Substituents on Gas Sorption and Permeation in Polysulfone. Macromolecules, 1996. 29(12): p. 4360-4369.

33. Poling, B.E., J.M. Prausnitz, and J.P. O'Connell, The Properties of Gases and Liquids. Fifth ed2000, New York: McGraw-Hill.

34. NIST Chemistry WebBook. Available from: http://webbook.nist.gov/chemistry/.

35. Tompkins, H.G., A User`s Guide to Ellipsometry2006, Mineola, N.Y.: Dover Publications. 
36. Sirard, S.M., et al., Spectroscopic ellipsometry of grafted poly(dimethylsiloxane) brushes in carbon dioxide. Journal of Supercritical Fluids, 2004. 32(1-3): p. 265-273.

37. Ghosal, K. and B.D. Freeman, Gas separation using polymer membranes: an overview. Polymers for Advanced Technologies, 1994. 5(11): p. 673-697.

38. Flory, P.J., Statistical Mechanics of Swelling of Network Structures. The Journal of Chemical Physics, 1950. 18(1): p. 108-111.

39. Koros, W.J., A.H. Chan, and D.R. Paul, Sorption and transport of various gases in polycarbonate. Journal of Membrane Science, 1977. 2(0): p. 165-190.

40. Bourgeois, P. and R. Calas, Poly(trimethylsilyl)benzenes: Synthese, sulfonation. Journal of Organometallic Chemistry, 1975. 84(2): p. 165-175.

41. Iojoiu, C., et al., Mastering sulfonation of aromatic polysulfones: Crucial for membranes for fuel cell application. Fuel Cells, 2005. 5(3): p. 344-354.

42. Sridhar, S., et al., Modified poly(phenylene oxide) membranes for the separation of carbon dioxide from methane. Journal of Membrane Science, 2006. 280(1-2): p. 202209.

43. Herzinger, C.M., et al., Ellipsometric determination of optical constants for silicon and thermally grown silicon dioxide via a multi-sample, multi-wavelength, multiangle investigation. Journal of Applied Physics, 1998. 83(6): p. 3323-3336.

44. Xiao, G.Z., et al., Monitoring changes in the refractive index of gases by means of a fiber optic Fabry-Perot interferometer sensor. Sensors and Actuators A: Physical, 2005. 118(2): p. 177-182.

45. Besserer, G.J. and D.B. Robinson, Refractive indices of ethane, carbon dioxide, and isobutane. Journal of Chemical and Engineering Data, 1973. 18(2): p. 137-140.

46. Michels, A., A. Botzen, and S.R. De Groot, Refractive index and Lorentz-Lorenz function of ethylene up to 2300 atmospheres at $25^{\circ} \mathrm{C}$ and $100^{\circ} \mathrm{C}$. Physica, 1947. 13(67): p. 343-348.

47. Shen, Y. and A.C. Lua, Structural and transport properties of BTDA-TDI/MDI copolyimide (P84)-silica nanocomposite membranes for gas separation. Chemical Engineering Journal, 2012. 188(0): p. 199-209.

48. Che Pa, N.F., et al., Influence of Polystyrene on PDMS IPNs Blend Membrane Performance. Separation Science and Technology, 2012. 47(4): p. 562-576.

49. Mikhailenko, S.D., et al., Proton conducting membranes based on cross-linked sulfonated poly(ether ether ketone) (SPEEK). Journal of Membrane Science, 2004. 233(1-2): p. 93-99.

50. Staudt-Bickel, C. and W. J. Koros, Improvement of CO2/CH4 separation characteristics of polyimides by chemical crosslinking. Journal of Membrane Science, 1999. 155(1): p. 145-154.

51. Potreck, J., et al., Sorption induced relaxations during water diffusion in S-PEEK. Physical Chemistry Chemical Physics, 2009. 11(2): p. 298-308.

52. Visser, T. and M. Wessling, When do sorption-induced relaxations in glassy polymers set in? Macromolecules, 2007. 40(14): p. 4992-5000.

53. Paul, D.R., Gas Sorption and Transport in Glassy Polymers. Berichte der Bunsengesellschaft für physikalische Chemie, 1979. 83(4): p. 294-302.

54. Stannett, V., The transport of gases in synthetic polymeric membranes. An historic perspective. Journal of Membrane Science, 1978. 3(2-3 4): p. 97-115.

55. Lin, H. and B.D. Freeman, Gas solubility, diffusivity and permeability in poly(ethylene oxide). Journal of Membrane Science, 2004. 239(1): p. 105-117.

56. Berens, A.R., Effects of sample history, time, and temperature on the sorption of monomer vapor by PVC. Journal of Macromolecular Science, Part B, 1977. 14(4): p. 483-498. 
57. Wessling, M., et al., Plasticization of gas separation membranes. Gas Separation \& Purification, 1991. 5(4): p. 222-228.

58. Chen, W.-J. and C.R. Martin, Gas-transport properties of sulfonated polystyrenes. Journal of Membrane Science, 1994. 95(1): p. 51-61.

59. Böhning, M. and J. Springer, Sorptive dilation and relaxational processes in glassy polymer/gas systems-I. Poly(sulfone) and poly(ether sulfone). Polymer, 1998. 39(21): p. 5183-5195.

60. Huang, Y. and D.R. Paul, Effect of film thickness on the gas-permeation characteristics of glassy polymer membranes. Industrial and Engineering Chemistry Research, 2007. 46(8): p. 2342-2347.

61. Kim, J.H., W.J. Koros, and D.R. Paul, Effects of CO2 exposure and physical aging on the gas permeability of thin 6FDA-based polyimide membranes: Part 1. Without crosslinking. Journal of Membrane Science, 2006. 282(1-2): p. 21-31.

62. Xia, J., et al., Aging and carbon dioxide plasticization of thin polyetherimide films. Polymer, 2012. 53(10): p. 2099-2108.

63. Horn, N.R. and D.R. Paul, Carbon dioxide plasticization of thin glassy polymer films. Polymer, 2011. 52(24): p. 5587-5594.

64. Cui, L., et al., Responses of 6FDA-based polyimide thin membranes to CO2 exposure and physical aging as monitored by gas permeability. Polymer, 2011. 52(24): p. 5528-5537. 
Chapter 4.

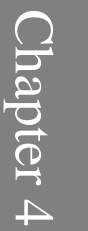




\section{Chapter 5}

\section{Mixed matrix membranes containing MOFs for $\mathrm{C}_{2} \mathrm{H}_{4} / \mathrm{C}_{2} \mathrm{H}_{6}$ separation: Membrane preparation and characetrization}

This chapter has been published as:

J.Ploegmakers, S. Japip and K. Nijmeijer, Mixed matrix membranes containing MOFs for ethylene/ethane separation, part A: Membrane preparation and characterization, Journal of Membrane Science, 2013, 428(1), pp 445-453. 


\section{Abstract}

Mixed matrix membranes (MMMs) containing three different metal organic frameworks (MOFs) $\left(\mathrm{Cu}_{3} \mathrm{BTC}_{2}\right.$, FeBTC and MIL-53 (Al)) as filler in P84 were prepared and characterized in terms of $\mathrm{C}_{2} \mathrm{H}_{4} / \mathrm{C}_{2} \mathrm{H}_{6}$ separating ability. SEM, TGA and DSC suggest the absence of non-selective voids in the $\mathrm{Cu}_{3} \mathrm{BTC}_{2}$ and FeBTC MMMs. Gas permeation experiments confirmed this, and showed an increase in $\mathrm{C}_{2} \mathrm{H}_{4} / \mathrm{C}_{2} \mathrm{H}_{6}$ selectivity of $73 \%$ to a value of 7.1 , while $\mathrm{C}_{2} \mathrm{H}_{4}$ permeability remained constant at $17 \cdot 10^{-18} \mathrm{~mol} \cdot \mathrm{m} /\left(\mathrm{m}^{2} \cdot \mathrm{s} \cdot \mathrm{Pa}\right)$ with addition of $20 \mathrm{w} \% \mathrm{Cu}_{3} \mathrm{BTC}_{2}$. Addition of $20 \mathrm{w} \%$ FeBTC showed a reduced permeability, caused by the formation of a denser intermediate layer, and no significant change in selectivity. Addition of MIL-53 led to increased permeabilities and no change in selectivity, which is probably the result of the formation of non-selective voids or the absence of inherent selectivity of MIL-53. 


\subsection{Introduction}

$\mathrm{C}_{2} \mathrm{H}_{4}$ is the single largest produced chemical and used for the production of important products like low and high-density polyethylene, ethylene oxide, ethylene dichloride and ethylbenzene [1]. Due to their almost similar boiling points, both $\mathrm{C}_{2} \mathrm{H}_{4}$ and $\mathrm{C}_{2} \mathrm{H}_{6}$, culminate in the product stream after the cracking process of naphtha. Since $\mathrm{C}_{2} \mathrm{H}_{6}$ can only be used as feed for the steam-cracker, separation of these components is required. Currently, $\mathrm{C}_{2} \mathrm{H}_{4} / \mathrm{C}_{2} \mathrm{H}_{6}$ separation is carried out by cryogenic distillation at $248 \mathrm{~K}$ and $2.2 \mathrm{MPa}$, consuming large amounts of energy [2]. Yet significant energy reductions of $30 \%$ can be obtained by the use of hybrid membrane-distillation units [3]. However, the best performing membranes reported for the binary $\mathrm{C}_{2} \mathrm{H}_{4} / \mathrm{C}_{2} \mathrm{H}_{6}$ separation, are 6FDA-based polyimide membranes $(\alpha=3.2, \mathrm{P}=$ 0.85 Barrer), but their performance is still too low to be economical viable [4]. Also, the permeability-selectivity tradeoff and the plasticizing nature of these high performing glassy polymers make them less suitable for industrial applications [5-7].

Since both permeability and selectivity need to be improved, much effort is put into overcoming this upper bound. Carbon membranes have shown to possess higher permeabilities and selectivities than their polymeric precursors [8-10]. However, they suffer from poor reproducibility due to marginal changes in the pyrolysis atmosphere and poor mechanical stability [11]. Another approach is facilitated transport membranes (FTMs) which have already been studied for over 30 years [12]. The transport mechanism relies on the reversible interaction between metal-ions and olefins, as described by the Dewar-ChattDuncanson model, in order to selectively enhance the olefin flux through the membrane [13, 14]. Although by using this concept it is possible to obtain both high permeabilities and selectivities, these membranes suffer usually from carrier poisoning, reduction of the complexing agent or leaching and are often not mechanically stable at process conditions [1518]. Additionally, many FTMs need the presence of significant amounts of water vapor in the feed stream to induce facilitated transport, which is usually not present in current olefin/paraffin streams [19-23].

In the last decade, Metal-Organic Frameworks (MOFs) have gathered much interest. MOFs are $1 \mathrm{D}, 2 \mathrm{D}$ or $3 \mathrm{D}$ porous structures consisting of a metal ion coordinated by tunable organic linkers. A comprehensive overview on the possible configurations and implications of MOFs has been given by James [24]. This wide variety of possible structures led to an exponential growth in the number of MOFs synthesized [25]. MOFs possess high sorption capacities and exhibit sorption selectivity between different gasses because of size exclusion and affinity 
effects, which makes them useful for industrial applications like hydrogen and carbon dioxide storage and adsorbers/desorbers [26-30]. These properties make them also interesting as membrane materials [31-33]. Still, MOF membranes, like other inorganic membranes, are expensive to produce and suffer from poor mechanical stability [34].

To overcome these disadvantages, we propose to incorporate MOFs in polymer membranes to create mixed matrix membranes (MMMs) for the separation of $\mathrm{C}_{2} \mathrm{H}_{4}$ and $\mathrm{C}_{2} \mathrm{H}_{6}$, thereby combining the superior gas separation performance of MOFs with cheap and mechanical stable polymers [35-39]. Basu et al. obtained both an increase in carbon dioxide permeance and carbon dioxide/methane selectivity by combining the commercial MOFs $\mathrm{Cu}_{3} \mathrm{BTC}_{2}$, ZIF- 8 and MIL-53 with Matrimid. The effects were less pronounced with addition of ZIF-8 ( $\mathrm{Zn}$ ) and MIL-53 (Al). Also changing to carbon dioxide/nitrogen separation showed less significant improvements [36]. Dai et al. did find a significant increase in carbon dioxide permeance and a $20 \%$ enhanced carbon dioxide/nitrogen selectivity when ZIF-8 was combined with Ultem as polymer matrix [40]. Although the absolute permeance and selectivity values did not surpass the Robeson upper bound because of the intrinsic low permeability of the Ultem material, their work did show that ZIF-8 selectively enhanced the carbon dioxide permeability and that the choice of polymer matrix can be crucial to see any effects. A similar study was performed by Zhang and co-workers, where they mixed ZIF-8 with 6FDA-DAM polyimide for the separation of propylene and propane [41]. They found increased propylene permeabilities and increased propylene/propane selectivities when ZIF-8 was added to the polymer matrix, but did not observe sorption selectivity and saw a much lower diffusion selectivity than expected for the ZIF-8 MOFs, which was attributed to the usage of smaller sized crystals compared to other studies. Nevertheless, the main reason of the enhanced separation was due to increased molecular sieving effects. Since $\mathrm{C}_{2} \mathrm{H}_{4}$ and $\mathrm{C}_{2} \mathrm{H}_{6}$ have smaller dimensions than their $\mathrm{C}_{3}$ counterparts, it is not expected to see significant improvements by using ZIF-8 MMMs for $\mathrm{C}_{2} \mathrm{H}_{4} / \mathrm{C}_{2} \mathrm{H}_{6}$ separation. On the other hand, the MOF $\mathrm{Cu}_{3} \mathrm{BTC}_{2}$ is reported to exhibit solubility selectivity towards olefins over paraffins due to copper(II)-olefin interaction [42, 43].

Considering this, especially the investigation of the effect of $\mathrm{Cu}_{3} \mathrm{BTC}_{2}$ in relation to other MOFs in MMMs on the separation of $\mathrm{C}_{2} \mathrm{H}_{4}$ and $\mathrm{C}_{2} \mathrm{H}_{6}$ is relevant. $\mathrm{Cu}_{3} \mathrm{BTC}_{2}$ can increase the $\mathrm{C}_{2} \mathrm{H}_{4}$ permeability by increasing the solubility and diffusion of $\mathrm{C}_{2} \mathrm{H}_{4}$. Furthermore, addition of $\mathrm{Cu}_{3} \mathrm{BTC}_{2}$ can increase the solubility and diffusion selectivity and therefore the permeability selectivity. For comparison, two other MOFs with different metal ions will be 
investigated as well. Firstly, FeBTC, containing iron(III) ions will be used as a control. In a recent study, it was found that the iron(III) MOF, MIL-100, did not show any selectivity towards propylene over propane, which is expected since iron(III) has less d-electrons than copper(II) and makes bonding to an olefin energetically unfavorable [44]. Therefore, if any increase in permeability selectivity is found, it is expected that this is caused only by an increase in diffusion selectivity as opposed to $\mathrm{Cu}_{3} \mathrm{BTC}_{2}$. Secondly, the MOF MIL-53, containing aluminium(III) ions, will be used to create MMMs. Similar to FeBTC, no $\mathrm{C}_{2} \mathrm{H}_{4}$ MIL-53 interactions are expected, which means that if permeability selectivity is increased due to addition of MIL-53, this has to be attributed to molecular sieving effects increasing the diffusion selectivity.

The commercially available polyimide P84 is chosen as polymer phase because of its low permeability towards gasses, diffusion driven selectivity and plasticization resistant properties [45, 46]. The choice for P84 as polymer phase is important for several reasons: because of its low permeable properties, it enables to easily identify influences of MOFs on the permeability in MMMs. Secondly, P84`s diffusion driven selectivity ensures that MOF induced solubility selectivity changes in MMMs are well observed. Lastly, P84 shows reduced plasticization effects on the permeability and selectivity and therefore allows changes in membrane properties to be assigned to effects caused by the introduction of MOFs dispersed in the polymer matrix such as non-selective voids or new intermediate phases [47, 48].

This chapter will focus on the preparation and characterization of MMMs containing $20 \mathrm{w} \%$ $\mathrm{Cu}_{3} \mathrm{BTC}_{2}$, FeBTC and MIL-53. Characterization will be performed by a multitude of techniques such as SEM, TGA, DSC and gas sorption. Finally the gas separation performance of the prepared MOF-polymer membranes will be evaluated in terms of $\mathrm{C}_{2} \mathrm{H}_{4} / \mathrm{C}_{2} \mathrm{H}_{6}$ separation performance. Not only mixed gas separation experiments will be performed but also both low and high pressure separation behavior of the membranes will be evaluated. As such the effect of the type of MOF and mixed gas pressure on membrane permeability and selectivity will be identified. Chapter 4 will describe a more detailed study on the effect of addition of various $\mathrm{Cu}_{3} \mathrm{BTC}_{2}$ loadings on the permeability, solubility and diffusivity coefficient. 


\subsection{Theory}

\subsubsection{Sorption}

Sorption isotherms provide information on the gas sorption potential of the MOFs. When multiple molecules adsorb on a single site, which often happens in case of metals because of their multiple number of possible ligand sites, the Sips sorption model can be applied and is for a one component system described by Equation 5.1 [49]:

$$
C=\frac{C_{S}^{\prime} \cdot\left(b_{S} \cdot p\right)^{1 / n}}{1+\left(b_{S} \cdot p\right)^{1 / n}}
$$

where C's $(\mathrm{kmol} / \mathrm{g})$ is the Sips capacity constant $(\mathrm{kmol} / \mathrm{g}), \mathrm{b}_{\mathrm{S}}$ is the Sips affinity constant (1/bar), p is the pressure (bar) and $n(-)$ is the sorption intensity, which is the number of molecules adsorbing to a single site. Although Equation 5.1 can be extended into a two component system, it must be stressed that even though single component Sips parameters can be accurately obtained from Equation 5.1, multi-component sorption behavior cannot necessarily be predicted [50]. For this reason, only single gas experiments will be performed.

\subsubsection{Gas permeation}

Gas permeation through a dense membrane takes place according to the well-known solutiondiffusion mechanism [51]:

$$
P_{i}=S_{i} \cdot D_{i}
$$

where the permeability coefficient $P_{i}$ in Barrer $\left(1\right.$ Barrer $=10^{-10} \mathrm{~cm}^{3}(\mathrm{STP}) \mathrm{cm} /\left(\mathrm{cm}^{2} \mathrm{~s} \mathrm{cmHg}\right)=$ $\left.3.34 \cdot 10^{-16} \mathrm{~mol} \mathrm{~m} /\left(\mathrm{m}^{2} \mathrm{~s} \mathrm{~Pa}\right)\right)$ is the product of the solubility coefficient $\left(\mathrm{S}_{\mathrm{i}}\right)\left(\mathrm{cm}^{3}(\mathrm{STP}) /\left(\mathrm{cm}^{3}\right.\right.$ bar) and the diffusion coefficient $\left(\mathrm{D}_{\mathrm{i}}\right)\left(\mathrm{cm}^{2} / \mathrm{s}\right)$ of component $\mathrm{i}$. The selectivity of a gas pair is the ratio of their permeability coefficients: 


$$
\alpha_{i j}=\frac{P_{i}}{P_{j}}=\left(\frac{D_{i}}{D_{j}}\right) \cdot\left(\frac{S_{i}}{S_{j}}\right)
$$

where $D_{i} / D_{j}$ is the diffusion selectivity and $S_{i} / S_{j}$ the solubility selectivity of components $i$ and j respectively. Diffusion coefficients increase with decreasing penetrant size, increasing polymeric fractional free volume, increasing polymer chain flexibility, increasing temperature and decreasing polymer-penetrant interactions [52]. On the other hand, solubility coefficients increase with increasing polymer-penetrant interactions, decreasing temperature and increasing condensability of the penetrant.

\subsubsection{Mixed matrix membranes}

The Maxwell model is often used to quantitatively describe the transport properties of gasses through MMMs. It assumes a uniform distribution of the dispersed phase and no formation of tertiary phases (e.g. non-selective voids or intermediate phases). The permeability of a gas through a MMM $\left(\mathrm{P}_{\text {eff }}\right)$ is given by:

$$
P_{e f f}=P_{c} \frac{P_{d} \cdot 2 P_{c} \cdot 2 \varphi_{d}\left(P_{c}-P_{d}\right)}{P_{d} \cdot 2 P_{c} \cdot \varphi_{d}\left(P_{c}-P_{d}\right)}
$$

where $\mathrm{P}_{c}$ and $\mathrm{P}_{d}$ are the permeabilities $\left(10^{-16} \mathrm{~mol} \mathrm{~m} /\left(\mathrm{m}^{2} \mathrm{~s} \mathrm{~Pa}\right)\right.$ of the continuous (polymer) and dispersed (MOF) phase respectively and $\varphi_{\mathrm{d}}$ is the volume fraction of the dispersed phase. Since it is often not possible to obtain the dispersed phase permeability data directly, the Maxwell model can be used to make accurate predictions by measuring MMMs with various amounts of dispersed phase.

Moore et al. have made a thorough categorization of the possible situations that can occur when particles are placed in a polymer matrix and divided these into six cases [48]. Case 0 is the ideal case in which there is perfect interaction between filler and matrix. The effective permeability will be described by the Maxwell model of Equation 5.4. Case I-III are the 
result when stresses occur during the membrane formation process. Case I arises when a rigidified polymer layer is formed between the bulk polymer and the filler. This is usually accompanied by an increase in $\mathrm{T}_{\mathrm{g}}$ or the presence of a second $\mathrm{T}_{\mathrm{g}}$ at a higher temperature. Case II and III represent the 'sieve-in-a-cage' morphology in which non-selective voids are formed between the polymer and the filler, thereby enhancing the permeability while showing no change in selectivity. Case II can easily be observed by SEM images since the voids are usually large, while Case III shows much smaller nano sized voids. Case IV occurs when impermeable particles or strong sorbents are added to the polymer phase, which hinder the transport of the penetrant. This results in lower permeabilities with unchanged selectivities. Finally, Case V describes the situation, much like Case I, in which there is a layer of reduced permeability around the fillers. 


\subsection{Experimental}

\subsubsection{Materials}

Lenzing P84 polyimide (325 mesh, STD) was supplied by HP Polymer GmbH, Austria. Nmethyl-2-pyrrolidinone (NMP, 99\% extra pure) was supplied by Acros Organics, Belgium. The MOFs copper benzene-1,3,5-tricarboxylate $\left(\mathrm{Cu}_{3} \mathrm{BTC}_{2}\right)$, iron benzene-1,3,5tricarboxylate (FeBTC) and aluminum terephthalate (MIL-53) were obtained from SigmaAldrich as Basolite C300, Basolite F300 and Basolite A100 respectively. The binary gas mixture $\mathrm{C}_{2} \mathrm{H}_{4} / \mathrm{C}_{2} \mathrm{H}_{6}(80 / 20 \pm 0.4 \mathrm{v} / \mathrm{v} \%)$ was supplied by Praxair, the Netherlands. All chemicals were used without further purification.

\subsubsection{Membrane preparation}

\subsubsection{Native P84 membranes}

P84 polyimide powder was dried in a Heraus Instruments Vacutherm vacuum oven at $100{ }^{\circ} \mathrm{C}$ overnight before use. The P84 solution was prepared by mixing 15\% (w/w\%) P84 in NMP as solvent. The solution was stirred at room temperature overnight. Afterwards, the P84 solution was filtered through a $15 \mu \mathrm{m}$ metal filter and degassed using an ultrasound bath for at least 30 minutes. The filtered and degassed solution was cast on a glass plate by using a $0.47 \mathrm{~mm}$ casting knife. The cast membranes were dried at room temperature under nitrogen flow for at least 3 days before they were dried in a WTC Binder oven at $150{ }^{\circ} \mathrm{C}$ with nitrogen flow for 24 hours. Finally, the dried membranes were peeled off from the glass plate and dried in the oven at $60^{\circ} \mathrm{C}$ under nitrogen flow for at least 3 days.

\subsubsection{Mixed matrix membranes}

The MMM casting suspension was prepared by mixing as received MOFs $\left(\mathrm{Cu}_{3} \mathrm{BTC} \mathrm{C}_{2}\right.$, FeBTC or MIL-53) in NMP as solvent. The suspension was stirred for 1 hour and then sonicated using a Branson 5210 ultrasound bath $(40 \mathrm{kHz})$ for 15 minutes. $10 \%$ of the total added amount of dried P84 powder was added to the MOF/NMP suspension and stirred until completely dissolved. Next, the remaining $90 \%$ of P84 powder was added and the mixture was stirred at least overnight. The weight ratio of P84/MOF was kept at 80/20 w/w\%. The suspension was degassed using an ultrasound bath for at least 30 minutes and subsequently cast on a glass plate in a nitrogen box using a $0.47 \mathrm{~mm}$ casting knife. The cast membranes were dried at 
room temperature under nitrogen flow for at least 2 days. The membranes were then transferred into a WTC Binder oven at $150{ }^{\circ} \mathrm{C}$ under nitrogen flow for 24 hours for further drying. The dried membranes were peeled off from the glass plate and dried in the oven at 60 ${ }^{\circ} \mathrm{C}$ under nitrogen flow for at least 3 days.

MMMs with $20 \% \mathrm{Cu}_{3} \mathrm{BTC}_{2}, 20 \%$ FeBTC and 20\% MIL-53 in P84, (w/w\%) were prepared this way and used for further experiments.

All prepared membrane samples were cut into circles $(\varnothing 47 \mathrm{~mm})$. The thickness of the samples was determined using an IP65 Coolant Proof digital Micrometer from Mitutoyo and found to be $46 \mu \mathrm{m} \pm 1$ for the native P84 membranes, $66 \mu \mathrm{m} \pm 3$ for $\mathrm{Cu}_{3} \mathrm{BTC}_{2}$ and FeBTC MMMs and $87 \mu \mathrm{m} \pm 2$ for the MIL-53 MMMs.

\subsubsection{SEM}

Samples for scanning electron microscopy (SEM) were prepared by freezing the prepared membranes in liquid nitrogen and then breaking them to investigate homogeneity of the MOFs throughout the MMMs and compatibility between the MOFs and the polymer phase. The samples were dried in a vacuum oven at $30{ }^{\circ} \mathrm{C}$ overnight and coated with a thin gold layer using a Balzers Union SCD040 sputtering device under argon flow. Images of the cross-sectional membrane area were taken using a JEOL JSM-5600LV Scanning Electron Microscope and Semaphore software.

\subsubsection{XRD}

To determine the crystallinity of the obtained MOFs, X-Ray diffraction (XRD) of $\mathrm{Cu}_{3} \mathrm{BTC}_{2}$, FeBTC and MIL-53 was performed on a Bruker D2 PHASER. Scans were made from 5-50 $2 \theta$ with a step-size of $0.0202^{\circ}$ in 42 minutes.

\subsubsection{TGA}

Investigation of the thermal stability of the MOFs, P84 and MMMs was performed by thermogravimetrical analysis (TGA) on a Perkin Elmer TGA 4000. At least $5 \mathrm{mg}$ of each sample was placed into a small aluminum sample holder. Under a constant nitrogen flow of 
$20 \mathrm{~mL}$ per minute, the sample was heated up to $900{ }^{\circ} \mathrm{C}$ at a heating rate of $20{ }^{\circ} \mathrm{C}$ per minute after initially being held at $30{ }^{\circ} \mathrm{C}$ for 1 minute.

\subsubsection{DSC}

Differential scanning calorimetry (DSC) was performed on a Perkin Elmer DSC 8000 in order to determine the glass transition temperature $\left(\mathrm{T}_{\mathrm{g}}\right)$ of P84 and the MMMs. At least $2 \mathrm{mg}$ of each sample was placed into an aluminum sample holder. The sample was held at $30{ }^{\circ} \mathrm{C}$ for 1 minute before being heated. The P84 membrane was heated to $400{ }^{\circ} \mathrm{C}$, while the MMMs were heated till $350{ }^{\circ} \mathrm{C}$ at a constant heating rate of $100{ }^{\circ} \mathrm{C}$ per minute. Afterwards, the sample was held for 1 minute at the maximum temperature and then cooled down to 30 ${ }^{\circ} \mathrm{C}$ at a cooling rate of $100{ }^{\circ} \mathrm{C}$ per minute. This cycle was repeated three times, and data from the last heating scan were used to determine the $\left(\mathrm{T}_{\mathrm{g}}\right)$, which is defined as the midpoint of the heat capacity transition.

\subsubsection{Gas sorption}

A magnetic suspension balance (MSB) (Rubotherm) was used to perform sorption measurements. Sorption measurements are used to construct sorption isotherms in order to determine capacity and affinity constants for various MOFs according to Equation 5.1. The mass uptake of the sample $\left(\mathrm{m}_{\mathrm{t}}\right)$ was calculated according to Equation 5.5:

$$
m_{t}=w_{t}-\left(w_{0}-V_{t} \cdot \rho_{\text {gas }}\right)
$$

where $\mathrm{w}_{0}$ is the weight of the sample $(\mathrm{g})$ at zero sorption, $\mathrm{V}_{\mathrm{t}}$ is the volume $\left(\mathrm{cm}^{3}\right.$ of the sample at time $\mathrm{t}(\mathrm{s})$ and $\rho_{\mathrm{gas}}$ is the density of the gas $\left(\mathrm{g} / \mathrm{cm}^{3}\right)$. The recorded weight $\left(\mathrm{w}_{\mathrm{t}}(\mathrm{g})\right)$ was corrected for buoyancy according to the Archimedes principle.

Pure gas sorption of $\mathrm{C}_{2} \mathrm{H}_{4}$ and $\mathrm{C}_{2} \mathrm{H}_{6}$ was determined in all samples. The concentration of gas in the sample was calculated from the mass uptake, the volume of the sample (calculated from the density of the sample as determined using a Micromeritics AccuPyc 1330 
pycnometer at $26.0^{\circ} \mathrm{C} \pm 0.8^{\circ} \mathrm{C}$ ), the molar volume and the molecular weight of the gas. The molar volume of the gas was calculated using the Peng-Robinson equation of state.

A minimum of $50 \mathrm{mg}$ was used as sample. Before each sorption run, the sample was degassed at $35{ }^{\circ} \mathrm{C}$. A sorption run consisted of a stepwise increase in pressure until equilibrium was reached. A pseudo-equilibrium was taken if no equilibrium was reached in $24 \mathrm{hr}$. All measurements were performed at a constant temperature of $35{ }^{\circ} \mathrm{C} \pm 0.5{ }^{\circ} \mathrm{C}$. Sorption isotherms were curve fitted using Equation 5.1 for all MOF particles to investigate the potential $\mathrm{C}_{2} \mathrm{H}_{4}$ and $\mathrm{C}_{2} \mathrm{H}_{6}$ sorption capacity.

\subsubsection{Gas permeation}

Gas permeation experiments were performed on native P84 membranes and all MMMs. Permeability measurements were performed by using the constant volume, variable pressure method with vacuum at the permeate side as described elsewhere [53]. Partial pressures higher than 1 bar were replaced by their corresponding fugacities to correct for non-ideal behavior.

Alternating single gas nitrogen and $\mathrm{C}_{2} \mathrm{H}_{4} / \mathrm{C}_{2} \mathrm{H}_{6}$ mixed gas permeation measurements were performed on the same membrane samples. The nitrogen feed pressure was kept constant at 5 bar to investigate plasticization effects. The $\mathrm{C}_{2} \mathrm{H}_{4} / \mathrm{C}_{2} \mathrm{H}_{6}$ feed pressure was increased from 5 bar, to 10 bar and eventually to 15 bar.

In the case of a mixed gas feed, both feed and permeate were analyzed by a Varian 3900GC gas chromatograph using an Alltech Alumina F-1 60/80 packed bed column at $150{ }^{\circ} \mathrm{C}$. Enough permeate was collected to achieve a signal/noise $(\mathrm{S} / \mathrm{N})$ ratio of at least 10 . Mixed gas selectivity was calculated according to Equation 5.6:

$$
\alpha_{i j}=\frac{y_{i} / y_{j}}{x_{i} / x_{j}}
$$

where $y_{j}$ and $x_{j}$ are the downstream and upstream mole fractions of compound $\mathrm{j}$ respectively. 


\subsubsection{Analysis of variance}

Analysis of variance (ANOVA) was used in order to determine if the addition of MOFs to the polymer matrix had a significant effect on the permeability and selectivity of $\mathrm{C}_{2} \mathrm{H}_{6}$ and $\mathrm{C}_{2} \mathrm{H}_{4}$. ANOVA is a powerful statistical method to determine the effect of a controlled source of variation in comparison to the random variation in the obtained results that always occurs in experiments. ANOVA also shows if deviations from the mean are statistically significant. The $\mathrm{F}$ value, which is the ratio of the within-sample mean square and the between sample mean square $(F>1)$, is compared to the critical $F$ value $\left(F_{\text {crit }}\right)$ for the appropriate number of degrees of freedom and a confidence interval of $95 \%$. The null hypothesis is rejected if $\mathrm{F}>$ $\mathrm{F}_{\text {crit. }}$ The null hypothesis is defined as the means of the samples do not differ significantly. 


\subsection{Results and discussion}

\subsubsection{MOF characterization}

\subsubsection{General properties}

The characteristics of the MOFs used in this work are shown in Table 5.1. $\mathrm{Cu}_{3} \mathrm{BTC}_{2}$ has the highest BET surface area, followed by FeBTC and MIL-53, which has the lowest. The average particle size of $\mathrm{Cu}_{3} \mathrm{BTC}_{2}$ is $15.96 \mu \mathrm{m}$, which is approximately half that of MIL-53. No particle size information was provided on FeBTC. Within the experimental error, all MOFs show similar densities of $\sim 1.7 \mathrm{~g} / \mathrm{cm}^{3}$.

Table 5.1. Properties of Cu3BTC2, FeBTC and MIL-53.

\begin{tabular}{lccc}
\hline & $\begin{array}{c}\text { BET surf. area } \\
\left(\mathrm{m}^{2} / \mathrm{g}\right)[54]\end{array}$ & $\begin{array}{c}\text { Particle size (D50) } \\
(\mu \mathrm{m})[54]\end{array}$ & $\begin{array}{c}\text { Density }^{*} \\
\left(\mathrm{~g} / \mathrm{cm}^{3}\right)\end{array}$ \\
\hline $\mathrm{Cu}_{3} \mathrm{BTC}_{2}$ & $1500-2100$ & 15.96 & 1.663 \\
FeBTC & $1300-1600$ & - & 1.677 \\
MIL-53 & $1100-1500$ & 31.55 & 1.642 \\
\hline
\end{tabular}

* Experimentally determined with Micromeritics AccuPyc 1330 pycnometer

The densities of the MOFs are higher than those typical for polymer solutions, which means that during the casting procedure, MOF particles might sediment to the bottom. The densities obtained with pycnometry show large discrepancies with values provided by the manufacturer, caused by a different measurement technique of the manufacturer that does not account for the porosity of the materials. The high D50 value of $31.55 \mu \mathrm{m}$ for MIL-53 might pose a problem for membrane fabrication since large particles require thick films to be completely encapsulated and reduce defects. The high BET surface area for $\mathrm{Cu}_{3} \mathrm{BTC}_{2}$ makes these particles promising for $\mathrm{C}_{2} \mathrm{H}_{4}$ adsorption, which in turn can enhance the gas separation performance in MMMs. 


\subsubsection{SEM}

Figure 5.1 shows SEM images of $\mathrm{Cu}_{3} \mathrm{BTC}_{2}, \mathrm{FeBTC}$ and MIL-53 respectively. $\mathrm{Cu}_{3} \mathrm{BTC}_{2}$ shows particles with a crystalline structure and a diameter between 1 and $15 \mu \mathrm{m}$, which is slightly lower than the D50 value reported in Table 5.1. The particle diameter of FeBTC varies between 3 and $30 \mu \mathrm{m}$. MIL-53 shows large $80 \mu \mathrm{m}$ crystalline particles, which can be expected based on Table 5.1. The large MIL-53 particles can pose a problem during the membrane formation since they are larger than the thickness of typical symmetric dense flat sheet membranes, which can lead to membrane defects. To avoid these problems, the MIL-53 particles were grinded to obtain sub $30 \mu \mathrm{m}$ particles. No clear crystalline structure can be observed for FeBTC like is the case for $\mathrm{Cu}_{3} \mathrm{BTC}_{2}$.

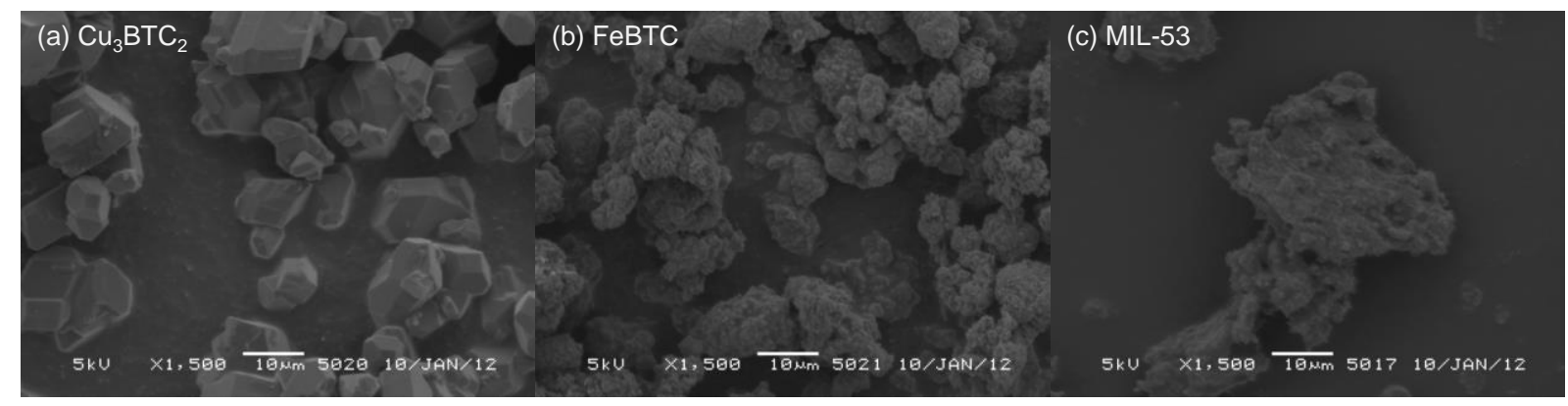

Figure 5.1. SEM images of (a) $\mathrm{Cu}_{3} \mathrm{BTC}_{2}$, (b) FeBTC and (c) MIL-53 respectively.

\subsubsection{XRD}

$\mathrm{XRD}$ measurements were performed to gain further insight on the crystallinity of the MOF particles. Figure 5.2 shows the XRD spectra of $\mathrm{Cu}_{3} \mathrm{BTC}_{2}$, FeBTC and MIL-53. Both $\mathrm{Cu}_{3} \mathrm{BTC}_{2}$ and MIL-53 have a crystalline structure which is in accordance with literature [55]. FeBTC on the other hand, shows an amorphous structure due to the absence of peaks caused by scattering of the X-rays. To the best of the author's knowledge, there are no reports in literature about the effect of the MOF crystallinity in MMMs on gas permeation, 


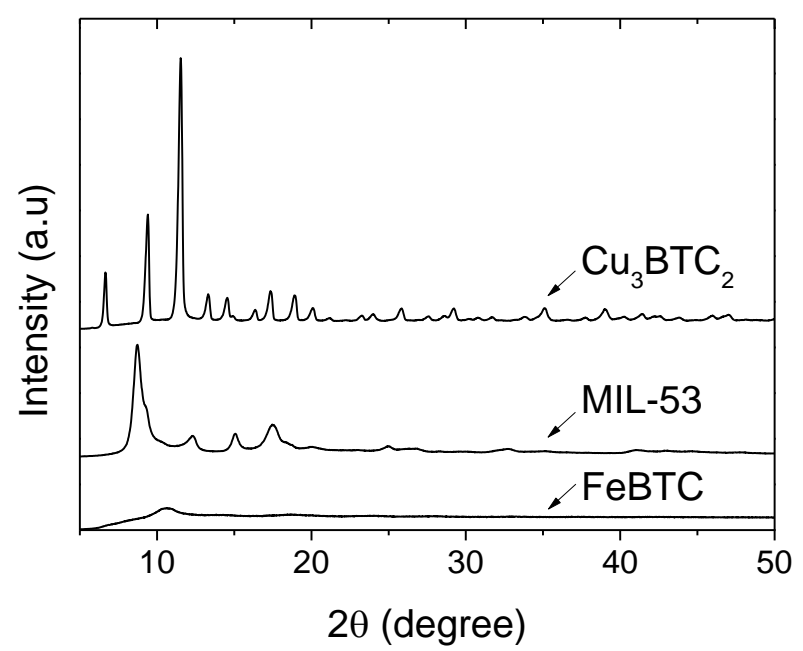

Figure 5.2. XRD of Cu3BTC2, FeBTC and MIL-53.

\subsubsection{TGA}

The thermal stability of all MOFs was investigated by means of TGA and is shown in Figure 5.3. $\mathrm{Cu}_{3} \mathrm{BTC}_{2}$ shows a weight loss of $26 \%$ up to $200{ }^{\circ} \mathrm{C}$, which indicates a loss of hydrated water [55]. When the temperature is increased from $310{ }^{\circ} \mathrm{C}$ to $375{ }^{\circ} \mathrm{C}, \mathrm{Cu}_{3} \mathrm{BTC}_{2}$ loses another $27 \%$ of its initial weight and this marks the start of the degradation process that continues up to the final temperature of $900{ }^{\circ} \mathrm{C}$ where only $32 \%$ of its initial weight is remained.

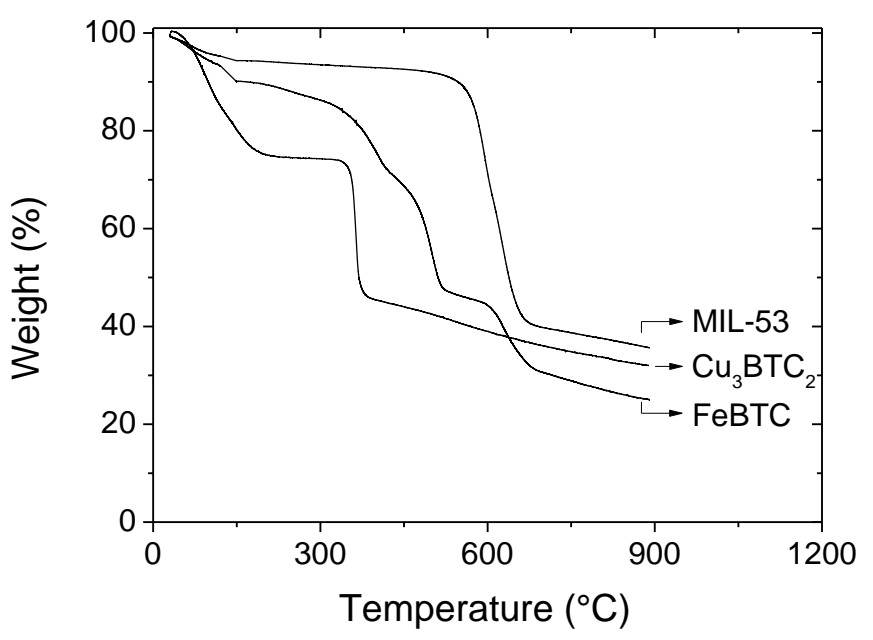

Figure 5.3. TGA of Cu3BTC2, FeBTC and MIL-53 MOFs. 
A weight loss of $10 \%$ is observed for FeBTC up to $200{ }^{\circ} \mathrm{C}$. This can be attributed to a lower amount of hydrated water compared to $\mathrm{Cu}_{3} \mathrm{BTC}_{2}$. From this temperature upwards till the final temperature of $900{ }^{\circ} \mathrm{C}$, the weight decreases continuously with increasing temperature. This weight decrease is caused by the degradation of FeBTC into gaseous products [56]. The largest weight loss is observed between $400{ }^{\circ} \mathrm{C}$ and $500{ }^{\circ} \mathrm{C}$ with a weight loss of $27 \%$.

In contrast to $\mathrm{Cu}_{3} \mathrm{BTC}_{2}$ and $\mathrm{FeBTC}$, MIL-53 only shows a $5 \%$ weight loss when heated to $200{ }^{\circ} \mathrm{C}$. This can be attributed to a low amount of hydrated water and is consistent with literature which reports a low adsorption of water molecules per MOF molecule $(<2)$ [57]. When the temperature is increased to $550{ }^{\circ} \mathrm{C}$, an additional weight loss of only $3 \%$ is visible. This indicates that, up to this temperature, MIL-53 forms almost no gaseous products as a consequence of degradation. A large weight decrease of $40 \%$ is observed when the sample is further heated to $700{ }^{\circ} \mathrm{C}$, indicating that in this temperature range, MIL-53 decomposes into gaseous products.

Given the above, we conclude that $\mathrm{Cu}_{3} \mathrm{BTC}_{2}$, FeBTC and MIL-53 are thermally stable up to 200, 350 and $550{ }^{\circ} \mathrm{C}$ respectively. This is relevant for the preparation of MMMs, since heating the polymer matrix above the $\mathrm{T}_{\mathrm{g}}$ or $\mathrm{T}_{\mathrm{m}}$ can reduce the formation of non-selective voids [48].

\subsubsection{Static gas sorption}

The sorption capacity of polymer membranes can be increased by incorporating MOFs with a higher sorption capacity into the polymer phase. Therefore, the sorption behavior of $\mathrm{C}_{2} \mathrm{H}_{4}$ and $\mathrm{C}_{2} \mathrm{H}_{6}$ in $\mathrm{Cu}_{3} \mathrm{BTC}_{2}$, FeBTC and MIL-53 was investigated and the obtained data were fitted using Equation 5.1. The resulting sorption isotherms and the ideal solubility of the MOFs as function of the feed fugacity are shown in Figure 5.4a and Figure 5.4b respectively. 

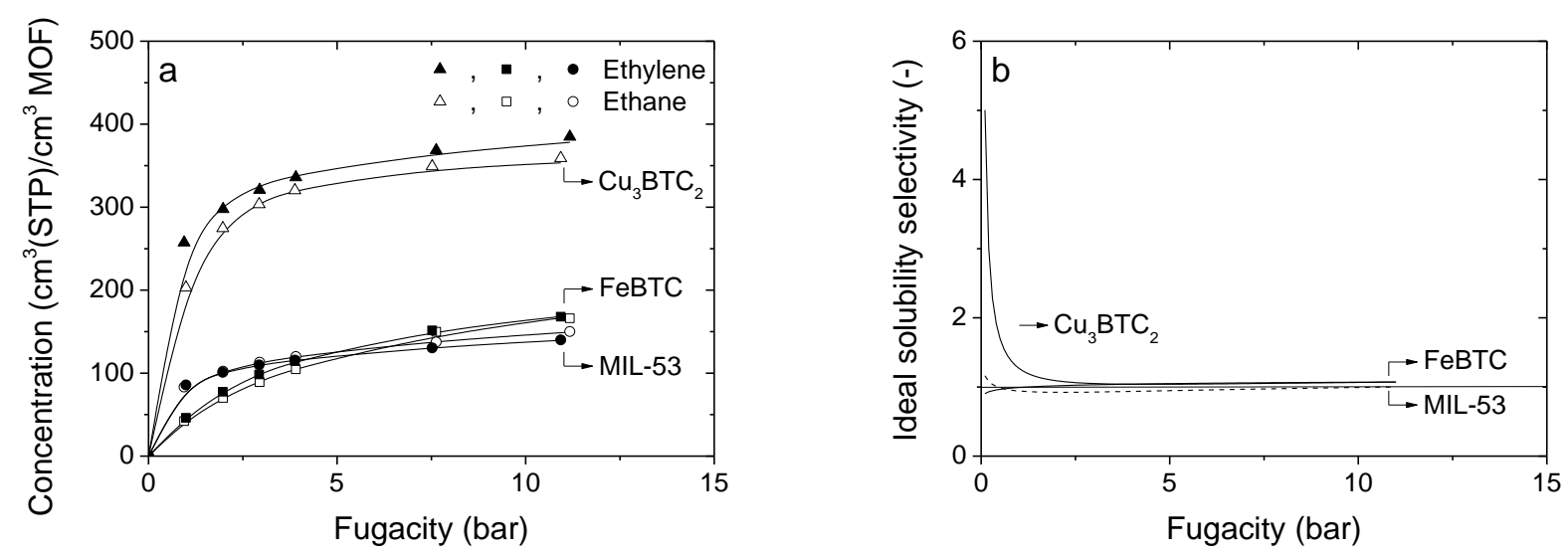

Figure 5.4. (a) Sorption isotherms of $\mathrm{C} 2 \mathrm{H} 4(\boldsymbol{\Delta}, \boldsymbol{\bullet}, \bullet)$ and $\mathrm{C} 2 \mathrm{H} 6(\triangle, \square, \odot)$ in $\mathrm{Cu} 3 \mathrm{BTC} 2$ (triangle), FeBTC (square) and MIL-53 (circle) as function of fugacity. Lines indicate isotherms fitted using the Sips model. (b) Ideal solubility selectivity of Cu3BTC2, FeBTC and MIL-53 as function of fugacity.

Figure 5.4a shows a significant difference in sorption behavior between $\mathrm{Cu}_{3} \mathrm{BTC}_{2}$ on one hand and FeBTC and MIL-53 on the other. $\mathrm{Cu}_{3} \mathrm{BTC}_{2}$ has the highest $\mathrm{C}_{2} \mathrm{H}_{4}$ sorption with a sorption capacity of around $390 \mathrm{~cm}^{3}(\mathrm{STP}) / \mathrm{cm}^{3}$ at 11 bar, which is comparable to values found in literature for carbon dioxide, while FeBTC and MIL-53 have a sorption capacity of only 170 and $150 \mathrm{~cm}^{3}(\mathrm{STP}) / \mathrm{cm}^{3}$ respectively at 11 bar [58]. In order to understand the origin of these differences, the sorption data were fitted using Equation 5.1 and the obtained parameters are shown in Table 5.2. The maximum Sips sorption capacity, C's, of $\mathrm{Cu}_{3} \mathrm{BTC}_{2}$ is twice as high compared to that of FeBTC and MIL-53. The Sips affinity parameter $b_{S}$ for both $\mathrm{C}_{2} \mathrm{H}_{4}$ and $\mathrm{C}_{2} \mathrm{H}_{6}$ in $\mathrm{Cu}_{3} \mathrm{BTC}_{2}$ is roughly 4 to 8 times higher compared to that of FeBTC and MIL-53. As shown in Table 5.1, the BET surface area of $\mathrm{Cu}_{3} \mathrm{BTC}_{2}$ is larger in comparison to that of FeBTC and MIL-53. Given these three properties, $\mathrm{C}_{2} \mathrm{H}_{4}$ and $\mathrm{C}_{2} \mathrm{H}_{6}$ sorption is significantly higher in $\mathrm{Cu}_{3} \mathrm{BTC}_{2}$ as compared to FeBTC and MIL-53, since there is more surface area available in $\mathrm{Cu}_{3} \mathrm{BTC}_{2}$ and there are stronger interactions between the gas molecules and the copper(II) ions. In addition, multiple $\mathrm{C}_{2} \mathrm{H}_{4}$ molecules can adsorb per sorption site as represented by $n>1$. 
Table 5.2. Fit results of the sorption isotherms of $\mathrm{C} 2 \mathrm{H} 4$ and $\mathrm{C} 2 \mathrm{H} 6$ using the Sips model for various MOFs.

\begin{tabular}{|c|c|c|c|c|c|c|c|c|c|}
\hline & \multicolumn{3}{|c|}{$\mathrm{Cu}_{3} \mathrm{BTC}_{2}$} & \multicolumn{3}{|c|}{ FeBTC } & \multicolumn{3}{|c|}{ MIL-53 } \\
\hline & $\mathrm{C}^{\prime}{ }_{\mathrm{s}}$ & $b_{S}$ & $\mathrm{n}$ & $\mathrm{C}^{\prime} \mathrm{s}$ & $b_{S}$ & $\mathrm{n}$ & $\mathrm{C}^{\prime} \mathrm{s}$ & $b_{S}$ & $\mathrm{n}$ \\
\hline $\mathrm{C}_{2} \mathrm{H}_{4}$ & 513 & 1.07 & 2.25 & 263 & 0.17 & 1.09 & 278 & 0.13 & 2.48 \\
\hline $\mathrm{C}_{2} \mathrm{H}_{6}$ & 377 & 1.16 & 0.85 & 223 & 0.27 & 0.97 & 247 & 0.18 & 2.70 \\
\hline
\end{tabular}

Figure $5.4 \mathrm{~b}$ shows that $\mathrm{Cu}_{3} \mathrm{BTC}_{2}$ has the highest ideal sorption selectivity with a maximum of 1.5 at 0.5 bar compared to FeBTC and MIL-53 with an ideal sorption selectivity of 1.0 for both MOFs. The presence of an ideal $\mathrm{C}_{2} \mathrm{H}_{4} / \mathrm{C}_{2} \mathrm{H}_{6}$ sorption selectivity in $\mathrm{Cu}_{3} \mathrm{BTC}_{2}$ can be unexpected at first because the reversible bonds formed between the metal ion and the olefin are based on the donation of d-electrons from the metal ion to the empty $\pi^{*}$-antibonding orbital as explained by the Dewar-Chatt-Duncanson model. Since the copper(II) ions in $\mathrm{Cu}_{3} \mathrm{BTC}_{2}$ only have 9 d-electrons, the interaction between the nucleus of the copper(II) ions and the surrounding electrons is much stronger and donation of d-electrons requires much more energy. Yet olefin/paraffin selectivity in $\mathrm{Cu}_{3} \mathrm{BTC}_{2}$ has been observed by other researchers as well and can be caused by the fact that $25 \%$ of the copper(II) ions-olefin bond strength is caused by $\pi$-donation of electrons from the olefin $\pi$-orbital to the copper(II) ionsorbital [42, 59]. So although the copper(II) ions-olefin complexation is much weaker as compared to the copper(I) ions-olefin complexation, there is still some interaction which causes sorption selectivity between olefins and paraffins and this can be utilized to increase the $\mathrm{C}_{2} \mathrm{H}_{4} / \mathrm{C}_{2} \mathrm{H}_{6}$ selectivity in MMMs. The absence of any ideal sorption selectivity in the case of FeBTC and MIL-53 indicates that if any increase in selectivity is found during gas permeation experiments, this increase is caused by an increase in diffusion selectivity as the result of molecular sieving effects.

\subsubsection{Membrane characterization}

\subsubsection{SEM}

Figure 5.5a, $\mathrm{b}$ and $\mathrm{c}$ show the cross-sectional SEM images of the $20 \mathrm{w} \% \mathrm{Cu}_{3} \mathrm{BTC}_{2}, \mathrm{FeBTC}$ and MIL-53 MMMs respectively. The $20 \mathrm{w} \% \mathrm{Cu}_{3} \mathrm{BTC}_{2}$ and FeBTC MMMs show a good 
adhesion between the P84 and MOFs, in contrast to the $20 \mathrm{w} \%$ MIL-53 MMM, shown in Figure 5.5c, which shows small voids spread across the MIL-53-P84 layer. This might be caused by smaller MIL-53 crystals being removed from the polymer matrix during sample preparation for SEM. Another reason could be that there is an incompatibility between the polymer matrix and the MIL-53 particles, creating large non-selective voids.

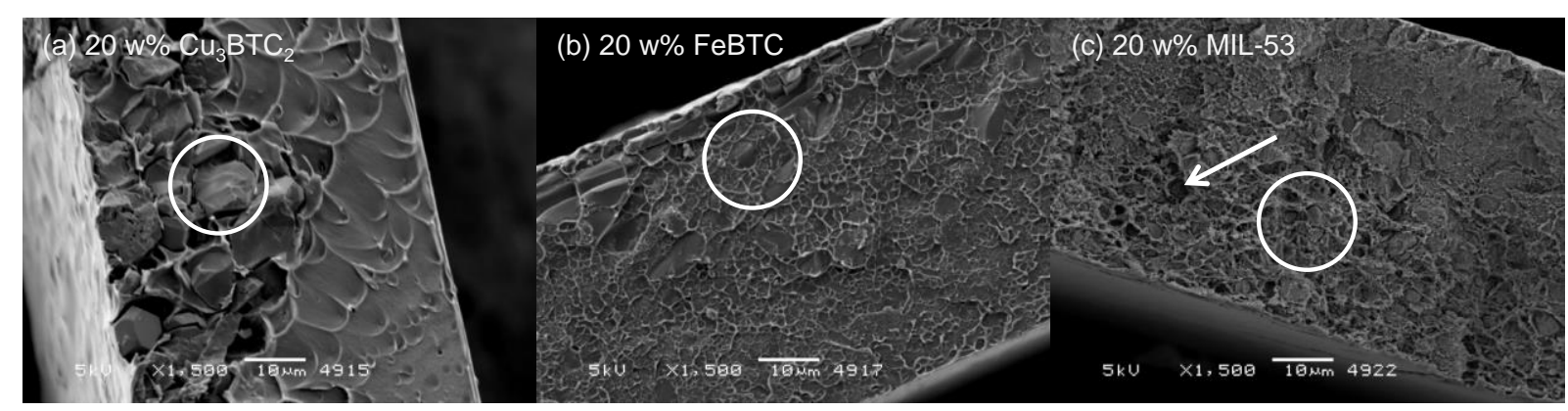

Figure 5.5. SEM images of P84 MMMs with (a) $20 \mathrm{w} \% \mathrm{Cu} 3 \mathrm{BTC} 2$ (b) $20 \mathrm{w} \%$ FeBTC and (c) 20 w\% MIL-53. Particles are indicated by a white circle. An example of a void is indicated by a white arrow.

Apart from the $20 \mathrm{w} \%$ MIL-53 MMM, the avoidance of larger non-selective voids in the MMMs has been accomplished by choosing an appropriate polymer as the matrix in combination with a suitable membrane fabrication process [48]. The combination of polar $\mathrm{Cu}_{3} \mathrm{BTC}_{2}$ and FeBTC MOFs inside a polar P84 membrane allows for polar interactions, thereby improving the polymer-MOF adhesion. Also, the gradual addition of the P84 powder to the MOFs during the membrane fabrication process prevents agglomeration of both the MOF particles and the P84 polymer. Unfortunately, all MMMs showed an asymmetric structure consisting of a P84 and a MMM layer. This is caused by the slow evaporation of NMP, which allows the MOF particles to descend to the glass side of the membrane. Although a more homogenous distribution was initially preferred instead of this asymmetric morphology, it was found that the inhomogeneity had no negative impact on the adhesion between the polymer and the MOF particles and consequently, on the permeability, as will be discussed later. 


\subsubsection{TGA}

Figure 5.6 shows the TGA of native P84 and the P84 MMMs with $20 \mathrm{w} \% \mathrm{Cu}_{3} \mathrm{BTC}_{2}, \mathrm{FeBTC}$ and MIL-53. The native P84 membrane has a weight loss of only $1.2 \%$ when the temperature is increased to $175^{\circ} \mathrm{C}$. This is caused by evaporation of adsorbed solvent. An additional $9.5 \%$ of the weight is lost when the temperature is increased to $400{ }^{\circ} \mathrm{C}$, which marks the start of the degradation process. At the final temperature of $900{ }^{\circ} \mathrm{C}, \mathrm{P} 84$ has lost $46 \%$ of its original weight.

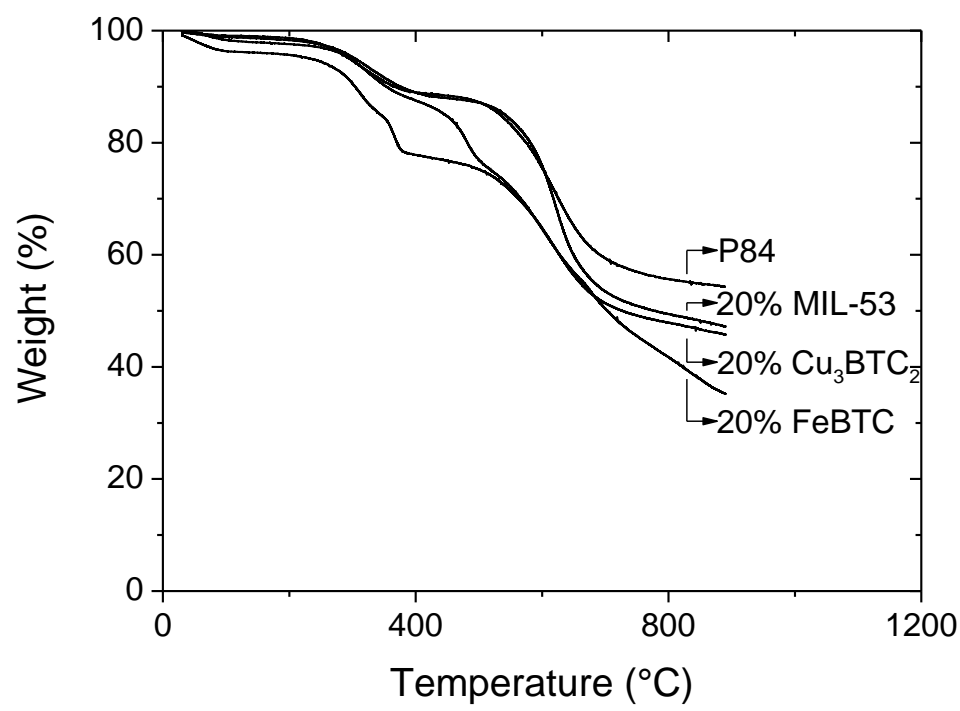

Figure 5.6. TGA of P84 MMMs with $20 \mathrm{w} \% \mathrm{Cu}_{3} \mathrm{BTC}_{2}$, FeBTC and MIL-53.

All MMMs show a thermal stability which is a linear contribution of native P84 and the pure MOFs shown in Figure 5.3; besides the decomposition stages of native P84, an additional decomposition stage appears, which coincides with the decomposition of the pure MOFs. The $20 \mathrm{w} \% \mathrm{Cu}_{3} \mathrm{BTC}_{2} \mathrm{MMM}$ shows a weight loss of $3.2 \%$ when the temperature is increased to $175{ }^{\circ} \mathrm{C}$, which is attributed to the large amount of hydrated water in $\mathrm{Cu}_{3} \mathrm{BTC}_{2}$. The $20 \mathrm{w} \%$ MIL-53 MMM has also similar decomposition stages as the native P84 membrane. Only the second decomposition stage at $600{ }^{\circ} \mathrm{C}$ shows a higher weight loss of $41 \%$ compared to $35 \%$ for the native P84 membrane. This is due to the additional decomposition of MIL-53, which happens at this temperature as can be seen in Figure 5.3. Up to $400{ }^{\circ} \mathrm{C}$, the $20 \mathrm{w} \%$ FeBTC MMM shows similar weight loss compared to the native P84 membrane. When the 
temperature is further increased, the weight loss of the FeBTC MMM starts to increase and deviate from P84 due to degradation of the FeBTC MOF as shown in Figure 5.3. The degradation of the FeBTC MMM continues till the final temperature of $900{ }^{\circ} \mathrm{C}$ when $65 \%$ of its initial weight is lost.

The TGA results presented in Figure 5.6 indicate thermally stable P84 membranes and 20 w\% $\mathrm{Cu}_{3} \mathrm{BTC}_{2}$ and MIL-53 MMMs, up to $350{ }^{\circ} \mathrm{C}$. From this temperature onwards, $\mathrm{Cu}_{3} \mathrm{BTC}_{2}$ starts to decompose. TGA of the pure MOFs, as shown in Figure 5.3, already showed decomposition of FeBTC above $200{ }^{\circ} \mathrm{C}$, which means the $20 \mathrm{w} \%$ FeBTC MMM cannot be heated above this temperature without degradation. These results indicate that if the $\mathrm{T}_{\mathrm{g}}$ of P84 is equal or higher than 200 or $350{ }^{\circ} \mathrm{C}$, at which degradation of the MOFs occurs, it will not be possible to erase the sample history of the $20 \mathrm{w} \%$ FeBTC or $\mathrm{Cu}_{3} \mathrm{BTC}_{2}$ and MIL-53 MMM, respectively. For this reason and to investigate polymer-MOF interactions, DSC measurements are performed, which will be discusses in the next paragraph.

\subsubsection{DSC}

DSC analysis was performed on native P84 and all MMMs to determine the glass transition temperature and to investigate changes in chain flexibility when MOFs are added to the polymer matrix. As shown in Table 5.3, the $\mathrm{T}_{\mathrm{g}}$ of P84 is located at $345{ }^{\circ} \mathrm{C}$. When $20 \mathrm{w} \%$ $\mathrm{Cu}_{3} \mathrm{BTC}_{2}$ is added to the polymer matrix, a decrease in $\mathrm{T}_{\mathrm{g}}$ of $16^{\circ} \mathrm{C}$ to $329{ }^{\circ} \mathrm{C}$ is visible. This decrease in $\mathrm{T}_{\mathrm{g}}$ is caused by disruption of physical crosslinks between the polymer chains due to the introduction of $\mathrm{Cu}_{3} \mathrm{BTC}_{2}$ crystals, which results in the formation of a more flexible intermediate phase between the polymer and the MOF. 
Table 5.3: Tg of native P84 and P84 MMMs with various types of MOFs.

\begin{tabular}{cccc}
\hline Polymer & MOF type added & MOF loading $(\mathrm{w} \%)$ & $\mathrm{T}_{\mathrm{g}}\left({ }^{\circ} \mathrm{C}\right)$ \\
\hline P84 & - & 0 & 345 \\
P84 & $\mathrm{Cu}_{3}$ BTC $_{2}$ & 20 & 329 \\
P84 & MIL-53 & 20 & 344 \\
P84 & FeBTC & 20 & - \\
\hline
\end{tabular}

The P84 MMM with $20 \mathrm{w} \%$ MIL-53 has a $\mathrm{T}_{\mathrm{g}}$ of $344{ }^{\circ} \mathrm{C}$, which is only $1{ }^{\circ} \mathrm{C}$ lower than the $\mathrm{T}_{\mathrm{g}}$ of P84. This reveals that there is neither disruption of polymer chain packing, nor formation of any intermediate phase and can imply that non-selective voids have been formed during the membrane fabrication process. It was not possible to determine the $\mathrm{T}_{\mathrm{g}}$ of the $20 \mathrm{w} \%$ FeBTC MMM because of the decomposition of FeBTC that takes place from $200{ }^{\circ} \mathrm{C}$ and onwards which is far below the $\mathrm{T}_{\mathrm{g}}$ of P84.

Since the $\mathrm{T}_{\mathrm{g}}$ of P84 and the P84 MMMs is equal to their corresponding decomposition temperatures as shown in and Figure 5.6, it is not possible to anneal the membranes and erase their history. In order to obtain comparable results, all membranes were fabricated such that all samples had the same history. Differences in sample history can affect permeabilities and selectivities as the result of physical aging [60].

\subsubsection{Gas permeation measurements}

To investigate the effect of various MOFs (i.e. $\mathrm{Cu}_{3} \mathrm{BTC}_{2}$, FeBTC and MIL-53) in MMMs on the $\mathrm{C}_{2} \mathrm{H}_{4}$ permeability and $\mathrm{C}_{2} \mathrm{H}_{4} / \mathrm{C}_{2} \mathrm{H}_{6}$ selectivity, gas permeation experiments at 5,10 and 15 bar total pressure were performed. Results are summarized in Figure 5.7. 

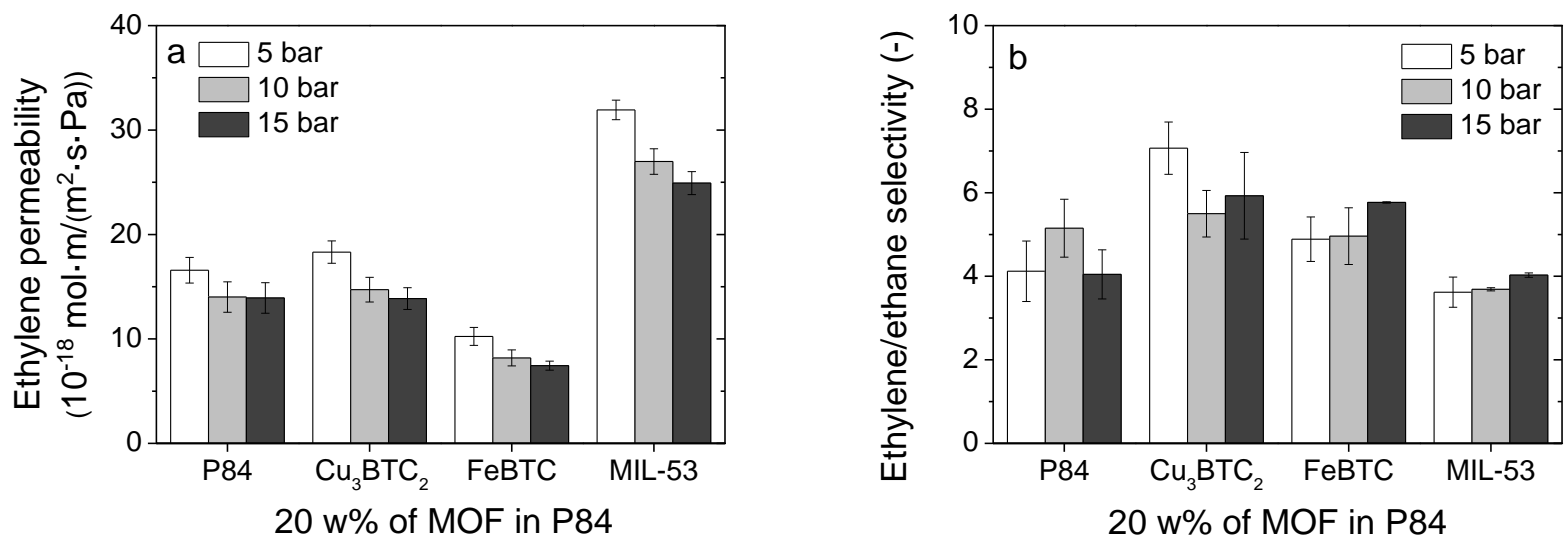

Figure 5.7. Average $\mathrm{C} 2 \mathrm{H} 4$ permeability (a) and $\mathrm{C} 2 \mathrm{H} 4 / \mathrm{C} 2 \mathrm{H} 6$ selectivity (b) $( \pm 2 \sigma)$ of native P84 and $20 \mathrm{w} \%$ Cu3BTC2, FeBTC and MIL-53 MMMs at 5, 10 and 15 bar mixed gas feed pressure.

Figure 5.7a shows the mixed gas $\mathrm{C}_{2} \mathrm{H}_{4}$ permeability for native $\mathrm{P} 84$ and $20 \mathrm{w} \% \mathrm{Cu}_{3} \mathrm{BTC}_{2}$, FeBTC and MIL-53 MMMs at feed pressures ranging from 5 to 15 bar. At 5 bar mixed gas feed pressure, the permeability of the $20 \mathrm{w} \% \mathrm{Cu}_{3} \mathrm{BTC}_{2}$ MMM does not increase significantly compared to the permeability native P84 which is found to be $17 \cdot 10^{-18} \mathrm{~mol} \cdot \mathrm{m} /\left(\mathrm{m}^{2} \cdot \mathrm{s} \cdot \mathrm{Pa}\right)$. This indicates that there are no non-selective voids present in the MMMs as these would increase the permeability. Also, Figure 5.7a shows that there is a reduction in permeability visible to $10 \cdot 10^{-18} \mathrm{~mol} \cdot \mathrm{m} /\left(\mathrm{m}^{2} \cdot \mathrm{s} \cdot \mathrm{Pa}\right)$ for the $20 \mathrm{w} \%$ FeBTC MMM as compared to the native P84 membranes. A reduction in permeability with the introduction of particles to polymer membranes has also been observed by other researchers [47, 61] and was well described by Moore et al. [48] where this phenomenon is classified as Case I or Case V. On the other hand, there is a significant increase in permeability for the $20 \mathrm{w} \%$ MIL-53 MMM to $32 \cdot 10^{-18} \mathrm{~mol} \cdot \mathrm{m} /\left(\mathrm{m}^{2} \cdot \mathrm{s} \cdot \mathrm{Pa}\right)$. There are two possibilities to explain this result. First, the addition of MIL-53 could introduce non-selective voids or Case II behavior. Since it was already shown in Figure 5.3 that MIL-53 adsorbs the least amount of water out of the MOFs investigated, this indicates that MIL-53 is less polar than $\mathrm{Cu}_{3} \mathrm{BTC}_{2}$ and FeBTC and therefore could have a reduced interaction with the polar P84 polymer. Also, some minor voids were observed in the SEM image shown in Figure 5.5c. The second reason could be that both $\mathrm{C}_{2} \mathrm{H}_{4}$ and $\mathrm{C}_{2} \mathrm{H}_{6}$ diffuse through MIL-53 without any interactions, in contrast to $\mathrm{Cu}_{3} \mathrm{BTC}_{2}$. This allows for a higher permeability for the penetrants in the MMM containing MIL-53 and this 
is also supported by the fact that the sorption capacity for both $\mathrm{C}_{2} \mathrm{H}_{4}$ and $\mathrm{C}_{2} \mathrm{H}_{6}$ and the Sips affinity constant in MIL-53 are low as was shown in Table 5.2. An increase in permeability without increase in selectivity has also been reported for $\mathrm{O}_{2} / \mathrm{N}_{2}$ separations using MOF MMMs [62].

When the effect of feed pressure on the $\mathrm{C}_{2} \mathrm{H}_{4}$ permeability of the different MOF containing MMMs is investigated, it can be seen that the permeability decreases in all cases with increasing feed pressure up to 15 bar. This is consistent with the dual-mode behavior in glassy polymers $[63,64]$. In addition, no signs of induced plasticization were observed within the pressure range studied.

Figure 5.7b shows the mixed gas $\mathrm{C}_{2} \mathrm{H}_{4} / \mathrm{C}_{2} \mathrm{H}_{6}$ selectivity for native $\mathrm{P} 84$ and $20 \mathrm{w} \% \mathrm{Cu}_{3} \mathrm{BTC}_{2}$, FeBTC and MIL-53 MMMs at a feed pressure ranging from 5 to 15 bar. At 5 bar mixed gas feed pressure, the $\mathrm{C}_{2} \mathrm{H}_{4} / \mathrm{C}_{2} \mathrm{H}_{6}$ selectivity is almost doubled from 4.1 to 7.1 when $20 \mathrm{w} \%$ $\mathrm{Cu}_{3} \mathrm{BTC}_{2}$ is added to the polymer matrix. The selectivity does not significantly increase at 5 bar feed pressure when $20 \mathrm{w} \%$ FeBTC or MIL-53 is added to the polymer matrix. This is consistent with the sorption data reported in Figure $4 \mathrm{~b}$, which showed that only $\mathrm{Cu}_{3} \mathrm{BTC}_{2}$ provided $\mathrm{C}_{2} \mathrm{H}_{4} / \mathrm{C}_{2} \mathrm{H}_{6}$ sorption selectivity higher than 1.0. Combined with the permeability data shown in Figure 5.7a, addition of FeBTC to the P84 matrix shows either Case I or Case IV behavior. Since it was not possible to determine the $T_{g}$ of these membranes, it is impossible to discriminate between the two. In any case, addition of FeBTC particles does provide neither any additional solubility nor diffusion selectivity. The fact that MIL-53 does not provide an increase in selectivity indicates that there are non-selective voids present or that there is no selective reversible interaction between the $\mathrm{Al}(\mathrm{III})$ ion and the $\mathrm{C}_{2} \mathrm{H}_{4}$ double bond. This lack of interaction is expected since $\mathrm{Al}$ (III) neither has the necessary d-electrons to donate to $\mathrm{C}_{2} \mathrm{H}_{4}$, nor the empty s-orbital required to accept electrons from the $\mathrm{C}_{2} \mathrm{H}_{4} \pi$ orbitals. However it also shows that MIL-53 does not provide any additional diffusion selectivity. Therefore, MMMs containing MIL-53 can either be the result of Case 0 where MIL-53 has no additional selectivity, or the result of Case II in which non-selective voids are responsible for the increase in permeability. 


\subsection{Conclusions}

Native P84 membranes and MMMs with 20 w\% $\mathrm{Cu}_{3} \mathrm{BTC}_{2}$, FeBTC and MIL-53 have been successfully prepared. $\mathrm{C}_{2} \mathrm{H}_{4} / \mathrm{C}_{2} \mathrm{H}_{6}$ selectivity increased up to $73 \%$ from 4.1 to 7.1 when 20 $\mathrm{w} \% \mathrm{Cu}_{3} \mathrm{BTC}_{2}$ was added to the P84 matrix, while the permeability remained constant at 17 . $10^{-18} \mathrm{~mol} \cdot \mathrm{m} /\left(\mathrm{m}^{2} \cdot \mathrm{s} \cdot \mathrm{Pa}\right)$, which confirms, in combination with DSC data, the absence of non-selective voids in the MMMs. Addition of FeBTC MOFs resulted in reduced permeabilities of $10 \cdot 10^{-18} \mathrm{~mol} \cdot \mathrm{m} /\left(\mathrm{m}^{2} \cdot \mathrm{s} \cdot \mathrm{Pa}\right)$ at 5 bar feed pressure with no significant increase in selectivity, indicating the formation of a denser intermediate phase. When MIL-53 MOFs were added to the polymer phase, the permeability increased to $32 \cdot 10^{-18} \mathrm{~mol} \cdot \mathrm{m} /\left(\mathrm{m}^{2}\right.$. $\mathrm{s} \cdot \mathrm{Pa}$ ), while the selectivity remained constant, indicating either the formation of nonselective voids, or the non-selective $\mathrm{C}_{2} \mathrm{H}_{4} / \mathrm{C}_{2} \mathrm{H}_{6}$ properties of MIL-53 as was shown with static sorption experiments. Increasing the feed pressure from 5 to 15 bar resulted in slightly reduced permeabilities for all membranes, which is typical dual-mode behavior in glassy polymers. In addition, plasticization was not observed within the pressure range studied.

\section{Acknowledgements}

This project is financially supported by AgentschapNL. The authors would like to thank ECN, Dow and SolSep for the fruitful discussions and dr. H.H.J.L. Ploegmakers for his help regarding the statistical analysis. 


\section{Bibliography}

[1] $232^{\text {nd }}$ ACS National Meeting, San Francisco, Sept. 10-14, Chemical and Engineering News 84 (2006) 59-236.

[2] Z. Wu, S.S. Han, S.H. Cho, J.N. Kim, K.T. Chue, R.T. Yang, Modification of Resin-Type Adsorbents for Ethane/Ethylene Separation, Industrial and Engineering Chemistry Research, 36 (1997) 2749-2756.

[3] J.A. Caballero, I.E. Grossmann, M. Keyvani, E.S. Lenz, Design of hybrid distillationvapor membrane separation systems, Industrial and Engineering Chemistry Research, 48 (2009) 9151-9162.

[4] C. Staudt-Bickel, W.J. Koros, Olefin/paraffin gas separations with 6FDA-based polyimide membranes, Journal of Membrane Science, 170 (2000) 205-214.

[5] L.M. Robeson, Correlation of separation factor versus permeability for polymeric membranes, Journal of Membrane Science, 62 (1991) 165-185.

[6] L.M. Robeson, The upper bound revisited, Journal of Membrane Science, 320 (2008) 390-400.

[7] C. Staudt-Bickel, W. J. Koros, Improvement of CO2/CH4 separation characteristics of polyimides by chemical crosslinking, Journal of Membrane Science, 155 (1999) 145-154.

[8] J.I. Hayashi, H. Mizuta, M. Yamamoto, K. Kusakabe, S. Morooka, S.H. Suh, Separation of ethane/ethylene and propane/propylene systems with a carbonized BPDA-pp'ODA polyimide membrane, Industrial and Engineering Chemistry Research, 35 (1996) 4176-4181.

[9] M. Yoshino, S. Nakamura, H. Kita, K.I. Okamoto, N. Tanihara, Y. Kusuki, Olefin/paraffin separation performance of carbonized membranes derived from an asymmetric hollow fiber membrane of 6FDA/BPDA-DDBT copolyimide, Journal of Membrane Science, 215 (2003) 169-183.

[10] L. Xu, M. Rungta, W.J. Koros, Matrimid® derived carbon molecular sieve hollow fiber membranes for ethylene/ethane separation, Journal of Membrane Science, 380 (2011) 138147.

[11] M. Kiyono, P.J. Williams, W.J. Koros, Effect of pyrolysis atmosphere on separation performance of carbon molecular sieve membranes, Journal of Membrane Science, 359 (2010) 2-10.

[12] O.H. LeBlanc Jr, W.J. Ward, S.L. Matson, S.G. Kimura, Facilitated transport in ionexchange membranes, Journal of Membrane Science, 6 (1980) 339-343.

[13] M.J.S. Dewar, A review of the pi-complex theory, Bull. Soc. Chim., 18 (1951) 8.

[14] J. Chatt, L.A. Duncanson, Olefin co-ordination compounds. Part III. Infra-red spectra and structure: Attempted preparation of acetylene complexes, Journal of the Chemical Society (Resumed), (1953) 2939-2947.

[15] S.B. Hamouda, Q.T. Nguyen, D. Langevin, S. Roudesli, Facilitated transport of ethylene in poly (amide 12-block tetramethylenoxide) copolymer/AgBF $<$ sub $>4</$ sub $>$ membranes containing silver (I) and copper (I) ions as carriers, Journal of Applied Sciences, 8 (2008) 1310-1314.

[16] M. Teramoto, H. Matsuyama, T. Yamashiro, Y. Katayama, Separation of ethylene from ethane by supported liquid membranes containing silver nitrate as a carrier, Journal of Chemical Engineering of Japan, 19 (1986) 419-424.

[17] I. Pinnau, L.G. Toy, Solid polymer electrolyte composite membranes for olefin/paraffin separation, Journal of Membrane Science, 184 (2001) 39-48.

[18] H.S. Kim, S.J. Park, D.Q. Nguyen, J.Y. Bae, H.W. Bae, H. Lee, S.D. Lee, D.K. Choi, Multi-functional zwitterionic compounds as new membrane materials for separating olefinparaffin mixtures, Green Chemistry, 9 (2007) 599-604. 
[19] J.C. Davis, R.J. Valus, R. Eshraghi, A.E. Velikoff, Facilitated transport membrane hybrid systems for olefin purification, Separation Science and Technology, 28 (1993) 463 476.

[20] O.I. Eriksen, E. Aksnes, I.M. Dahl, Facilitated transport of ethene through Nafion membranes. Part I. Water swollen membranes, Journal of Membrane Science, 85 (1993) 8997.

[21] O.I. Eriksen, E. Aksnes, I.M. Dahl, Facilitated transport of ethene through Nafion membranes. Part II. Glycerine treated, water swollen membranes, Journal of Membrane Science, 85 (1993) 99-106.

[22] S.U. Hong, J.Y. Kim, Y.S. Kang, Effect of water on the facilitated transport of olefins through solid polymer electrolyte membranes, Journal of Membrane Science, 181 (2001) 289-293.

[23] J. Müller, K.V. Peinemann, Development of facilitated transport membranes for the separation of olefins from gas streams, Desalination, 145 (2002) 339-345.

[24] S.L. James, Metal-organic frameworks, Chem. Soc. Rev., 32 (2003) 276-288.

[25] J.R. Long, O.M. Yaghi, The pervasive chemistry of metal-organic frameworks, Chem. Soc. Rev., 38 (2009) 1213-1214.

[26] B. Chen, N.W. Ockwig, A.R. Millward, D.S. Contreras, O.M. Yaghi, High H2 adsorption in a microporous metal-organic framework with open metal sites, Angewandte Chemie - International Edition, 44 (2005) 4745-4749.

[27] A.G. Wong-Foy, A.J. Matzger, O.M. Yaghi, Exceptional H2 saturation uptake in microporous metal-organic frameworks, Journal of the American Chemical Society, 128 (2006) 3494-3495.

[28] H. Furukawa, O.M. Yaghi, Storage of hydrogen, methane, and carbon dioxide in highly porous covalent organic frameworks for clean energy applications, Journal of the American Chemical Society, 131 (2009) 8875-8883.

[29] S. Ma, H.C. Zhou, Gas storage in porous metal-organic frameworks for clean energy applications, Chemical Communications, 46 (2010) 44-53.

[30] S. Achmann, G. Hagen, M. Hämmerle, I. Malkowsky, C. Kiener, R. Moos, Sulfur removal from low-sulfur gasoline and diesel fuel by metal-organic frameworks, Chemical Engineering and Technology, 33 (2010) 275-280.

[31] D. Zacher, O. Shekhah, C. Wöll, R.A. Fischer, Thin films of metal-organic frameworks, Chem. Soc. Rev., 38 (2009) 1418-1429.

[32] Y. Liu, Z. Ng, E.A. Khan, H.K. Jeong, C.b. Ching, Z. Lai, Synthesis of continuous MOF-5 membranes on porous $\alpha$-alumina substrates, Microporous and Mesoporous Materials, 118 (2009) 296-301.

[33] Y. Yoo, Z. Lai, H.K. Jeong, Fabrication of MOF-5 membranes using microwaveinduced rapid seeding and solvothermal secondary growth, Microporous and Mesoporous Materials, 123 (2009) 100-106.

[34] W.J. Koros, R. Mahajan, Pushing the limits on possibilities for large scale gas separation: Which strategies?, Journal of Membrane Science, 175 (2000) 181-196.

[35] S. Basu, A. Cano-Odena, I.F.J. Vankelecom, Asymmetric Matrimid®/[Cu3(BTC)2] mixed-matrix membranes for gas separations, Journal of Membrane Science, 362 (2010) 478487.

[36] S. Basu, A. Cano-Odena, I.F.J. Vankelecom, MOF-containing mixed-matrix membranes for $\mathrm{CO} 2 / \mathrm{CH} 4$ and $\mathrm{CO} 2 / \mathrm{N} 2$ binary gas mixture separations, Separation and Purification Technology, 81 (2011) 31-40.

[37] H. Bux, C. Chmelik, R. Krishna, J. Caro, Ethene/ethane separation by the MOF membrane ZIF-8: Molecular correlation of permeation, adsorption, diffusion, Journal of Membrane Science, 369 (2011) 284-289. 
[38] T.H. Bae, J.S. Lee, W. Qiu, W.J. Koros, C.W. Jones, S. Nair, A high-performance gasseparation membrane containing submicrometer-sized metal-organic framework crystals, Angewandte Chemie - International Edition, 49 (2010) 9863-9866.

[39] H.B. Tanh Jeazet, C. Staudt, C. Janiak, Metal-organic frameworks in mixed-matrix membranes for gas separation, DOI: 10.1039/c2dt31550e, Dalton Transactions, 41 (2012).

[40] Y. Dai, J.R. Johnson, O. Karvan, D.S. Sholl, W.J. Koros, Ultem®/ZIF-8 mixed matrix hollow fiber membranes for CO2/N2 separations, Journal of Membrane Science, 401-402 (2012) 76-82.

[41] C. Zhang, Y. Dai, J.R. Johnson, O. Karvan, W.J. Koros, High performance ZIF-8/6FDADAM mixed matrix membrane for propylene/propane separations, Journal of Membrane Science, 389 (2012) 34-42.

[42] S. Kunz, O. Tangermann, M. Hartmann, C4 olefin/paraffin separation over the metal organic framework material Cu3BTC2, in, Hamburg, 2007, pp. 95-104.

[43] M.G. Plaza, A.F.P. Ferreira, J.C. Santos, A.M. Ribeiro, U. Müller, N. Trukhan, J.M. Loureiro, A.E. Rodrigues, Propane/propylene separation by adsorption using shaped copper trimesate MOF, Microporous and Mesoporous Materials.

[44] M.G. Plaza, A.M. Ribeiro, A. Ferreira, J.C. Santos, Y.K. Hwang, Y.K. Seo, U.H. Lee, J.S. Chang, J.M. Loureiro, A.E. Rodrigues, Separation of C3/C4 hydrocarbon mixtures by adsorption using a mesoporous iron MOF: MIL-100(Fe), Microporous and Mesoporous Materials, 153 (2012) 178-190.

[45] T. Visser, N. Masetto, M. Wessling, Materials dependence of mixed gas plasticization behavior in asymmetric membranes, Journal of Membrane Science, 306 (2007) 16-28.

[46] T. Visser, Mixed Gas Plasticization Phenomena in Asymmetric Membranes, in: Membrane Science and Technology, University of Twente, Enschede, 2006, pp. 189.

[47] T.T. Moore, R. Mahajan, D.Q. Vu, W.J. Koros, Hybrid Membrane Materials Comprising Organic Polymers with Rigid Dispersed Phases, AIChE Journal, 50 (2004) 311-321.

[48] T.T. Moore, W.J. Koros, Non-ideal effects in organic-inorganic materials for gas separation membranes, Journal of Molecular Structure, 739 (2005) 87-98.

[49] R. Sips, On the structure of a catalyst surface, The Journal of Chemical Physics, 16 (1948) 490-495.

[50] D.D. Do, Adsorption analysis equilibria and kinetics, Imperial College Press, London, 1998.

[51] J.G. Wijmans, R.W. Baker, The solution-diffusion model: A review, Journal of Membrane Science, 107 (1995) 1-21.

[52] Y. Yampolskii, I. Pinnau, B.D. Freeman, Materials Science of Membranes, John Wiley \& Sons Ltd., Chichester, 2007.

[53] J.N. Barsema, G.C. Kapantaidakis, N.F.A. Van Der Vegt, G.H. Koops, M. Wessling, Preparation and characterization of highly selective dense and hollow fiber asymmetric membranes based on BTDA-TDI/MDI co-polyimide, Journal of Membrane Science, 216 (2003) 195-205.

[54] Sigma-Aldrich website, in.

[55] S.S.-Y. Chui, S.M.-F. Lo, J.P.H. Charmant, A.G. Orpen, I.D. Williams, A Chemically Functionalizable Nanoporous Material [Cu3(TMA)2(H2O)3]n, Science, 283 (1999) 11481150 .

[56] A. Einstein, Does the inertia of a body depend upon its energy-content, Annalen der Physik, 18 (1905).

[57] S. Biswas, T. Ahnfeldt, N. Stock, New functionalized flexible Al-MIL-53-X (X = -Cl, $\mathrm{Br},-\mathrm{CH} 3$, -NO 2, $-(\mathrm{OH})$ 2) solids: Syntheses, characterization, sorption, and breathing behavior, Inorganic Chemistry, 50 (2011) 9518-9526. 
[58] Z. Liang, M. Marshall, A.L. Chaffee, $\mathrm{CO} 2$ adsorption-based separation by metal organic framework (Cu-BTC) versus zeolite (13X), Energy and Fuels, 23 (2009) 2785-2789.

[59] W.A. Herrmann, G. Brauer, Synthetic Methods of Organometallic and Inorganic Chemistry, Georg Thieme Verlag, Stuttgart, 1996.

[60] J. Xia, T.-S. Chung, P. Li, N.R. Horn, D.R. Paul, Aging and carbon dioxide plasticization of thin polyetherimide films, Polymer, 53 (2012) 2099-2108.

[61] R. Mahajan, W.J. Koros, Mixed matrix membrane materials with glassy polymers. Part 2, Polymer Engineering \& Science, 42 (2002) 1432-1441.

[62] H.B.T. Jeazet, C. Staudt, C. Janiak, A method for increasing permeability in O2/N2 separation with mixed-matrix membranes made of water-stable MIL-101 and polysulfone, Chemical Communications, 48 (2012) 2140-2142.

[63] V. Stannett, The transport of gases in synthetic polymeric membranes. An historic perspective, Journal of Membrane Science, 3 (1978) 97-115.

[64] D.R. Paul, Gas Sorption and Transport in Glassy Polymers, Berichte der Bunsengesellschaft für physikalische Chemie, 83 (1979) 294-302. 
Chapter 5. 


\section{Chapter 6}

\section{Mixed matrix membranes containing MOFs for $\mathrm{C}_{2} \mathrm{H}_{4} / \mathrm{C}_{2} \mathrm{H}_{6}$ separation: Effect of $\mathrm{Cu}_{3} \mathrm{BTC}_{2}$ on membrane transport properties}

This chapter has been published as:

J.Ploegmakers, S. Japip and K. Nijmeijer, Mixed matrix membranes containing MOFs for ethylene/ethane separation, part $\mathrm{B}$ : Effect of $\mathrm{Cu}_{3} \mathrm{BTC}_{2}$ on membrane transport properties, Journal of Membrane Science, 2013, 428(1), pp 331-340 


\section{Abstract}

Mixed matrix membranes (MMMs) containing various amounts of the Molecular Organic Framework (MOF) $\mathrm{Cu}_{3} \mathrm{BTC}_{2}$ as filler in P84 were characterized in terms of their $\mathrm{C}_{2} \mathrm{H}_{4}$ and $\mathrm{C}_{2} \mathrm{H}_{6}$ separating performance. Previous research showed that especially the use of the MOF $\mathrm{Cu}_{3} \mathrm{BTC}_{2}$ improves the $\mathrm{C}_{2} \mathrm{H}_{4} / \mathrm{C}_{2} \mathrm{H}_{6}$ separating ability due its selective interaction with the olefin. Although the $\mathrm{C}_{2} \mathrm{H}_{4}$ permeability remained constant, the $\mathrm{C}_{2} \mathrm{H}_{4} / \mathrm{C}_{2} \mathrm{H}_{6}$ permeability selectivity significantly increased to a value of 7.1 with increasing $\mathrm{Cu}_{3} \mathrm{BTC}_{2}$ loading. Experiments show that the $\mathrm{C}_{2} \mathrm{H}_{4}$ solubility coefficient increased from 1.0 to $2.910^{-3} \mathrm{~mol} /\left(\mathrm{m}^{3}\right.$ $\mathrm{Pa}$ ) with increasing $\mathrm{Cu}_{3} \mathrm{BTC}_{2}$ loading up to $20 \mathrm{w} \%$. Since the $\mathrm{C}_{2} \mathrm{H}_{4}$ permeability coefficient remained constant at $17 \cdot 10^{-18} \mathrm{~mol} \cdot \mathrm{m} /\left(\mathrm{m}^{2} \cdot \mathrm{s} \cdot \mathrm{Pa}\right)$ with increasing $\mathrm{Cu}_{3} \mathrm{BTC}_{2}$ loading, the $\mathrm{C}_{2} \mathrm{H}_{4}$ diffusion coefficient was calculated to decrease by a factor of three. Evaluation of the reason for the strong increase in permeability selectivity with increasing $\mathrm{Cu}_{3} \mathrm{BTC}_{2}$ loading revealed that this is the result of an increase in diffusion selectivity by a factor of two. These results suggest immobilization of $\mathrm{C}_{2} \mathrm{H}_{4}$ inside the MOF particles as the result of strong $\mathrm{C}_{2} \mathrm{H}_{4}$ copper(II) MOF interactions. 


\subsection{Introduction}

$\mathrm{C}_{2} \mathrm{H}_{4}$ is one of the most important components in the petrochemical industry and used as resource for many products [1]. Due to their rather similar boiling points, both $\mathrm{C}_{2} \mathrm{H}_{6}$ and $\mathrm{C}_{2} \mathrm{H}_{4}$ accumulate in the same naphta fraction and highly selective separation processes are required to obtain high purity $\mathrm{C}_{2} \mathrm{H}_{4}$. Currently distillation is used, which is an energy intensive process. Although membrane technology is a potential alternative, due to the Robeson permeability-selectivity tradeoff, polymer membrane performance is not sufficient yet and has to be improved to be an economically interesting alternative [2-4]. Addition of metal organic framework (MOF) particles as additive to polymer membranes has already shown that permeability and selectivity can be simultaneously increased [5-11], but very little is known about the effect of these particles on the mechanism of gas transport and separation inside mixed matrix membranes (MMMs). Adams et al. studied the effect of CuTPA particles in PVA MMMs on not only the permeability and selectivity of various gasses, but also on the diffusion coefficient [12]. It was found that the diffusion coefficient decreased when particles were added as a result of penetrant immobilization. Unfortunately, only single gasses were tested and only low feed pressures ( $<5$ bar) were considered.

This chapter will thoroughly study the effect of the use of the $\mathrm{MOF} \mathrm{Cu}_{3} \mathrm{BTC}_{2}$ [13] as additive in polymeric MMMs based on $\mathrm{P} 84$ on the $\mathrm{C}_{2} \mathrm{H}_{4}$ and $\mathrm{C}_{2} \mathrm{H}_{6}$ transport properties. The structural formula of P84 can be found elsewhere [14]. $\mathrm{Cu}_{3} \mathrm{BTC}_{2}$ was chosen as the previous chapter showed that especially the use of this $\mathrm{Cu}$ (II) MOF showed selective interaction with the olefin and as such enhanced the separating ability of the membranes[15]. Here we extend this study and elucidate the mechanism of the improved performance in terms of solubility, diffusion and permeability coefficients. We investigate the effect of the MOF loading on these properties. In addition, the effect of the feed pressures on the performance is investigated, to reveal the effect of the addition of MOFs on the high pressure stability of the polymer membranes. 


\subsection{Theory}

\subsubsection{Sorption}

In order to examine the transport properties in MMMs, two aspects have to be considered. Firstly, static sorption experiments can reveal the maximum sorption capacity of a certain gas in a polymer, which helps to understand why MOFs can enhance the performance of MMMs compared to native polymer membranes. Secondly, dynamic sorption experiments reveal information on the kinetics of the sorption behavior from which diffusion coefficients can be determined.

\subsubsection{Static sorption}

Gas sorption in glassy polymeric membranes can be described by the dual mode sorption model [16], which assumes two different sorption mechanisms to take place simultaneously: sorption directly proportional to the pressure following Henry`s law, and Langmuir sorption, which relies on a hole-filling mechanism. In that case, the gas concentration inside the membrane, $\mathrm{C}(\mathrm{kmol} / \mathrm{g})$, can be described by Equation 6.1:

$$
C=k_{D} \cdot p+\frac{C_{H}^{\prime} \cdot b \cdot p}{1+b \cdot p}
$$

where $\mathrm{k}_{\mathrm{D}}$ is Henry`s constant $\left(\mathrm{kmol} /\left(\mathrm{g}\right.\right.$ bar), $\mathrm{p}$ the pressure (bar), $\mathrm{C}_{\mathrm{H}}$ the Langmuir capacity constant $(\mathrm{kmol} / \mathrm{g})$ and $\mathrm{b}$ the Langmuir affinity constant $(1 / \mathrm{bar})$. When gas mixtures are used or when the single gas parameters of two gasses are known, the two component dual-mode sorption can be applied if competitive sorption takes place and both gasses show dual mode sorption behavior. The concentration of component $i\left(\mathrm{C}_{i}(\mathrm{kmol} / \mathrm{g})\right)$ inside the membrane is described by:

$$
C_{i}=k_{D i} \cdot p_{i}+\frac{C_{H i}^{\prime} \cdot b_{i} \cdot p_{i}}{1+\left(b_{i} \cdot p_{i}\right)+\left(b_{j} \cdot p_{j}\right)}
$$


where $\mathrm{k}_{\mathrm{Di}}$ is Henry`s constant $(\mathrm{kmol} /(\mathrm{g}$ bar $)), \mathrm{p}_{\mathrm{i}}$ the partial pressure (bar), $\mathrm{C}_{\mathrm{Hi}}$ the Langmuir capacity constant $(\mathrm{kmol} / \mathrm{g})$ and $\mathrm{b}_{\mathrm{i}}$ the Langmuir affinity constant (1/bar) for component $\mathrm{i}$ and $b_{j}$ and $p_{j}$ the Langmuir affinity constant (1/bar) and the partial pressure (bar) of component $j$ respectively. When multiple molecules adsorb on a single site, which often happens in case of metals, the Sips sorption model can be applied, which is a combination of Langmuir and Freundlich sorption, and is described by [17]:

$$
C=\frac{C_{S}^{\prime} \cdot\left(b_{S} \cdot p\right)^{1 / n}}{1+\left(b_{S} \cdot p\right)^{1 / n}}
$$

where C's $(\mathrm{kmol} / \mathrm{g})$ is the Sips capacity constant $(\mathrm{kmol} / \mathrm{g})$, b the Sips affinity constant (1/bar), p the pressure (bar) and $n(-)$ the sorption intensity. Although Equation 6.3 can be extended, analogous to Equation 6.2, into a two component system, it must be stressed that even though single component Sips parameters can be accurately obtained from Equation 6.3, multi-component sorption behavior cannot necessarily be predicted [18]. For this reason, Equation 6.2 will be used throughout this report to predict multi-component sorption data in MMMs, while Equation 6.3 will be used to create single component isotherms in MOFs. More information on the sorption models can be found elsewhere [19].

Once the concentration of a gas at a specific pressure is known, the solubility coefficient $\mathrm{S}$ $\left(\mathrm{cm}^{3} /\left(\mathrm{cm}^{3} \mathrm{cmHg}\right)\right)$ is defined by:

$$
S=\frac{C}{p}
$$

\subsubsection{Dynamic sorption}

Diffusion coefficients can be determined from dynamic sorption experiments. The analytical solution for gas diffusion $\mathrm{D}\left(\mathrm{cm}^{2} / \mathrm{s}\right)$, in uniform spherical particles, was given by Crank [20]: 


$$
\frac{m_{t}}{m_{\infty}}=1-\frac{6}{\pi^{2}} \sum_{n=1}^{\infty} \frac{1}{n^{2}} \exp \left[-\frac{4 D n^{2} \pi^{2} t}{d^{2}}\right]
$$

where $\mathrm{m}_{\mathrm{t}}$ is the mass uptake $(\mathrm{g})$ of a gas at time $\mathrm{t}(\mathrm{s}), \mathrm{m}_{\infty}$ mass uptake $(\mathrm{g})$ at infinite time and $\mathrm{d}$ the particle diameter $(\mathrm{cm})$. The diffusion coefficient can be accurately obtained given that the diffusion is constant and obeys Fick`s laws throughout the entire experiment. Similar to Equation 6.5, Crank showed that the Fickian mass uptake $\mathrm{m}_{\mathrm{f}}$, in a polymer film, can be written by Equation 6.6:

$$
\frac{m_{t}}{m_{\infty}}=1-\frac{8}{\pi^{2}} \sum_{n=0}^{\infty} \frac{1}{(2 n+1)^{2}} \exp \left[-\frac{D(2 n+1)^{2} \pi^{2} t}{l^{2}}\right]
$$

where 1 is the film thickness $(\mathrm{cm})$ [21]. For both Equation 6.5 and 6.6 it is assumed that the gas concentration at the start of the experiment is 0 and that it is instantaneously increased after which there is a homogenous vapor phase concentration in equilibrium with the surface of the material. Berends and Hopfenberg showed that the model could also account for nonFickian relaxation controlled swelling which often occurs in glassy polymers [22]:

$\frac{m_{t}}{m_{\infty}}=m_{F, \infty}\left\{1-\frac{8}{\pi^{2}} \sum_{n=0}^{\infty} \frac{1}{(2 n+1)^{2}} \exp \left[-\frac{D(2 n+1)^{2} \pi^{2} t}{l^{2}}\right]\right\}+\sum_{i=1}^{\infty} m_{r, i}\left[1-\exp \left(-\frac{t}{\tau_{r i}}\right)\right]$

where $\mathrm{m}_{\mathrm{F}, \infty}$ is the contribution of Fickian mass uptake at infinite time, $\mathrm{m}_{\mathrm{r}, \mathrm{i}}$ the contribution of mass uptake due to additional relaxation $\mathrm{i}$ and $\tau_{\mathrm{ri}}$ is the characteristic time for relaxation $\mathrm{i}(\mathrm{s})$. Usually it is sufficient for glassy polymers to describe $\mathrm{m}_{t} / \mathrm{m}_{\infty}$ by the addition of two relaxation regimes. It is assumed that the mass uptake of the relaxation regimes is independent of the Fickian sorption and both take place at different time scales. If the difference in timescale between the Fickian diffusion and the first, fast relaxational regime is 
too short, it is impossible to separate the two processes. To overcome this problem, membranes with a sufficiently low film thickness have to be selected to allow the Fickian mass uptake to be completed quickly. On the other hand, if the film thickness is too low, the Fickian mass uptake happens so quickly that it cannot be accurately measured as a result of instabilities in the electronic signal of the magnetic suspension balance caused by temperature fluctuations [23]. Given these difficulties, an appropriate film thickness has to be chosen to obtain reliable diffusion coefficients.

In case of MMMs it is assumed that the film is a homogeneous layer in which all gas adsorbs equally. Although this assumption is by definitions not valid for MMMs, it enables the observation of trends in the diffusion coefficient and this will yield insights in the transport behavior of MMMs. Alternatively it is possible to make a model which more accurately resembles the MMMs by separating the mass-uptake in a linear contribution of a fractional $\mathrm{C}_{2} \mathrm{H}_{4}$ uptake by both the polymer and the $\mathrm{Cu}_{3} \mathrm{BTC}_{2}$. However, by doing so, it proved to be impossible to gain accurate diffusion coefficients in $\mathrm{Cu}_{3} \mathrm{BTC}_{2}$ particles for a number of reasons. Firstly the size distribution of the particles proved to be quite broad which would allow discussion for the validity of Equation 6.5. A similar argument can be made regarding the instantaneous pressure increase, which does not occur inside the membrane where the $\mathrm{Cu}_{3} \mathrm{BTC}_{2}$ particles reside. Additionally, the mass uptake in and on the particles might be limited by the presence of polymer material around the $\mathrm{Cu}_{3} \mathrm{BTC}_{2} \mathrm{MOF}$. Lastly, a distinct contribution of the mass uptake of the $\mathrm{Cu}_{3} \mathrm{BTC}_{2}$ particles in the $10 \mathrm{w} \% \mathrm{MMM}$ was too low, causing correlation between the fitting parameters, like the $\mathrm{C}_{2} \mathrm{H}_{4}$ diffusion coefficients in the polymer and in the particles.

\subsubsection{Gas permeation}

Gas permeation through a dense membrane takes place according to the well-known solutiondiffusion mechanism [24]:

$$
P_{i}=S_{i} \cdot D_{i}
$$

where the permeability coefficient $P_{i}$ in Barrer $\left(1\right.$ Barrer $=10^{-10} \mathrm{~cm}^{3}(\mathrm{STP}) \mathrm{cm} /\left(\mathrm{cm}^{2} \mathrm{~s}\right.$ bar $)=$ $\left.3.34 \cdot 10^{-16} \mathrm{~mol} \mathrm{~m} /\left(\mathrm{m}^{2} \mathrm{~s} \mathrm{~Pa}\right)\right)$ is the product of the solubility coefficient $\left(\mathrm{S}_{\mathrm{i}}\right)\left(\mathrm{cm}^{3}(\mathrm{STP}) /\left(\mathrm{cm}^{3}\right.\right.$ 
bar) and the diffusion coefficient $\left(\mathrm{D}_{\mathrm{i}}\right)\left(\mathrm{cm}^{2} / \mathrm{s}\right)$ of component $\mathrm{i}$. The selectivity of a gas pair is the ratio of their permeability coefficients:

$$
\alpha_{i j}=\frac{P_{i}}{P_{j}}=\left(\frac{D_{i}}{D_{j}}\right) \cdot\left(\frac{S_{i}}{S_{j}}\right)
$$

where $D_{i} / D_{j}$ is the diffusion selectivity and $S_{i} / S_{j}$ the solubility selectivity of components $i$ and $\mathrm{j}$ respectively. Diffusion coefficients increase with decreasing penetrant size, increasing polymeric fractional free volume, increasing polymer chain flexibility, increasing temperature and decreasing polymer-penetrant interactions [25]. On the other hand, solubility coefficients increase with increasing polymer-penetrant interactions, decreasing temperature and increasing condensability of the penetrant. 


\subsection{Experimental}

\subsubsection{Materials}

The matrix polymer Lenzing P84 polyimide (325 mesh, STD) was supplied by HP Polymer GmbH, Austria. N-methyl-2-pyrrolidinone (NMP, 99\% extra pure) was supplied by Acros Organics, Belgium, whereas the MOF copper benzene-1,3,5-tricarboxylate $\left(\mathrm{Cu}_{3} \mathrm{BTC}_{2}\right)$ was obtained from Sigma-Aldrich (Basolite C300). A binary gas mixture of $\mathrm{C}_{2} \mathrm{H}_{4} / \mathrm{C}_{2} \mathrm{H}_{6}(80 / 20 \pm$ $0.4 \mathrm{v} / \mathrm{v} \%$ ) was used for gas permeation experiments and supplied by Praxair, the Netherlands. All chemicals were used as received.

\subsubsection{Membrane preparation}

\subsubsection{Native P84 membranes}

Before use, P84 polyimide powder was dried in a Heraus Instruments Vacutherm vacuum oven at $100{ }^{\circ} \mathrm{C}$ overnight. 15\% (w/w\%) P84 was dissolved in NMP and stirred at room temperature overnight, after which it was filtered through a $15 \mu \mathrm{m}$ metal filter and degassed using an ultrasound bath for at least 30 minutes. The filtered and degassed solution was cast on a glass plate using a $0.47 \mathrm{~mm}$ casting knife. The remaining film was dried at room temperature under nitrogen for at least 3 days. Subsequently, the membrane was dried in a WTC Binder oven at $150{ }^{\circ} \mathrm{C}$ and nitrogen flow for 24 hours. Finally, the dried membrane was peeled off from the glass plate and dried in an oven at $60^{\circ} \mathrm{C}$ under nitrogen flow for at least 3 days.

\subsubsection{Mixed matrix membranes}

For MMM preparation, first a suspension of the MOF in NMP was prepared by mixing a certain amount of $\mathrm{Cu}_{3} \mathrm{BTC}_{2}$ in NMP. This suspension was stirred for 1 hour and subsequently sonicated using a Branson 5210 ultrasound bath $(40 \mathrm{kHz})$ for 15 minutes. After that, $10 \%$ of the total amount of dry P84 powder to be added, was mixed with the MOF/NMP suspension and stirred until completely dissolved. The remaining 90\% of P84 powder was added subsequently and the mixture was stirred at least overnight. The suspension was degassed using an ultrasound bath for at least 30 minutes. The remaining suspension was used for membrane casting. Membranes were cast on a glass plate using a $0.47 \mathrm{~mm}$ casting knife. The cast membrane was dried at room temperature under nitrogen flow for at least 2 days, and 
subsequently in a WTC Binder oven at $150{ }^{\circ} \mathrm{C}$ under nitrogen flow as well for 24 hours to remove residual solvent. The dried membrane was peeled off from the glass plate and further dried in an oven at $60{ }^{\circ} \mathrm{C}$ under nitrogen flow for at least 3 days. MMMs with 10, 20 and 40 $\mathrm{w} \% \mathrm{Cu}_{3} \mathrm{BTC}_{2}$ were prepared and used for the experiments.

All prepared membrane samples were cut into circles with a diameter of $47 \mathrm{~mm}$. The thickness of the final membranes, as determined using an IP65 Coolant Proof digital Micrometer from Mitutoyo, ranged between 45 and $69 \mu \mathrm{m}$.

\subsubsection{SEM}

Scanning electron microscopy (SEM) was used to investigate the homogeneity of the MOF distribution throughout the MMMs and compatibility between the MOFs and the polymer phase. After freezing and subsequent breaking of the membranes, the samples were dried in a vacuum oven at $30{ }^{\circ} \mathrm{C}$ overnight and coated with a thin gold layer using a Balzers Union SCD040 sputtering device under argon flow. SEM images of the cross-sectional membrane area using a JEOL JSM-5600LV Scanning Electron Microscope were taken. Data were processed using Semaphore software.

\subsubsection{TGA}

The thermal stability of the native P84 membrane, the $\mathrm{Cu}_{3} \mathrm{BTC}_{2} \mathrm{MOF}$ and the $\mathrm{Cu}_{3} \mathrm{BTC} / \mathrm{P} 84$ MMMs with various loadings was performed using thermogravimetrical analysis (TGA) on a Perkin Elmer TGA 4000. At least $5 \mathrm{mg}$ of each sample was placed into a small aluminum sample holder. First the sample was held at $30{ }^{\circ} \mathrm{C}$ for 1 minute. Finally, the sample was heated to $900{ }^{\circ} \mathrm{C}$ at a heating rate of $20{ }^{\circ} \mathrm{C}$ per minute under a constant nitrogen flow of 20 $\mathrm{mL}$ per minute.

\subsubsection{DSC}

To determine the glass transition temperature $\left(\mathrm{T}_{\mathrm{g}}\right)$ of native $\mathrm{P} 84$ and the $\mathrm{Cu}_{3} \mathrm{BTC}_{2} \mathrm{MMMs}$, differential scanning calorimetry (DSC) was performed on a Perkin Elmer DSC 8000. At least $2 \mathrm{mg}$ of each sample was collected in an aluminum sample holder. The sample was held at $30{ }^{\circ} \mathrm{C}$ for 1 minute after which it was heated to the desired temperature. P84 polymer 
membrane samples were heated to $400{ }^{\circ} \mathrm{C}$, while the MMMs were heated till $350{ }^{\circ} \mathrm{C}$ only at a constant heating rate of $100{ }^{\circ} \mathrm{C}$ per minute. After reaching the end temperature, the sample was held for 1 minute at this temperature and then cooled down to $30{ }^{\circ} \mathrm{C}$, again at a cooling rate of $100{ }^{\circ} \mathrm{C}$ per minute. This cycle was repeated three times, and only the data from the last heating scan were used to determine the $\left(\mathrm{T}_{\mathrm{g}}\right)$, which is defined as the midpoint of the heat capacity transition.

\subsubsection{Gas sorption}

Static and dynamic sorption measurements were performed on a magnetic suspension balance (MSB) (Rubotherm). Static sorption measurements allow determination of the sorption isotherms and the capacity and affinity constants for $\mathrm{Cu}_{3} \mathrm{BTC}_{2} \mathrm{MOF}$ according to Equation 6.1 and native P84 and MMMs according to Equation 6.3. Dynamic sorption measurements can be used to determine the diffusion constant of gas inside the $\mathrm{Cu}_{3} \mathrm{BTC}_{2}$ MOFs using to Equation 6.5 and native P84 and the MMMs by means of Equation 6.7. The mass uptake of the sample $\left(\mathrm{m}_{\mathrm{t}}\right)$ was calculated according to Equation 6.10:

$$
m_{t}=w_{t}-\left(w_{0}-V_{t} \cdot \rho_{\text {gas }}\right)
$$

where $\mathrm{w}_{0}$ is the weight of the sample $(\mathrm{g})$ at zero sorption, $\mathrm{V}_{\mathrm{t}}$ is the volume $\left(\mathrm{cm}^{3}\right.$ of the sample at time $\mathrm{t}(\mathrm{s})$ and $\rho_{\mathrm{gas}}$ is the density of the gas $\left(\mathrm{g} / \mathrm{cm}^{3}\right)$. Archimedes principle was used to correct the recorded weight $\left(\mathrm{w}_{\mathrm{t}}(\mathrm{g})\right)$ for buoyancy effects.

\subsubsection{Static sorption experiments}

The pure $\mathrm{C}_{2} \mathrm{H}_{4}$ and $\mathrm{C}_{2} \mathrm{H}_{6}$ concentration of gas in the sample was calculated from the volume of the sample (calculated from the density of the sample as determined using a Micromeritics AccuPyc 1330 pycnometer at $26.0{ }^{\circ} \mathrm{C} \pm 0.8{ }^{\circ} \mathrm{C}$ ), the mass uptake of gas of the sample, and the molar volume and molecular weight of the gas. The molar volume of the gas was calculated using the Peng-Robinson equation of state. 
A minimum of $50 \mathrm{mg}$ of sample was used. Before each sorption run, the sample was degassed at $35{ }^{\circ} \mathrm{C}$. A sorption run consisted of a stepwise increase in pressure until equilibrium was reached. When equilibrium was not reached within 24 hours, a pseudoequilibrium was taken at 24 hours. All measurements were performed at a constant temperature of $35^{\circ} \mathrm{C} \pm 0.5^{\circ} \mathrm{C}$.

Mixed gas solubility selectivities in native P84 and MMMs were calculated using single gas parameters and Equation 2, while taking into account the appropriate partial pressures during gas permeation measurements $\left(\mathrm{C}_{2} \mathrm{H}_{4} / \mathrm{C}_{2} \mathrm{H}_{6} 80 / 20 \mathrm{v} \%\right)$.

\subsubsection{Dynamic sorption experiments}

To determine the diffusion coefficient of $\mathrm{C}_{2} \mathrm{H}_{4}$ in $\mathrm{P} 84, \mathrm{Cu}_{3} \mathrm{BTC}_{2} \mathrm{MOF}$ and $\mathrm{Cu}_{3} \mathrm{BTC}_{2}$ MMMs, dynamic sorption experiments were performed. Before the start of each experiment, the thickness of the membrane samples was measured and turned out to be 47, 48, 58 and 69 $\mu \mathrm{m}$ for P84 with 0, 10, 20 and $40 \mathrm{w} \%$ respectively. Prior to pressurization at 4 bar, the sample was evacuated for 10 hours. Subsequently, the ratio of $\mathrm{m}_{t} / \mathrm{m}_{\infty}$ was obtained as a function of time (s). Since in the case of membranes, complete equilibrium could not be established within the time scale of the experiment, in that case, the pseudo infinite mass uptake after 14 hours was used. The obtained data were fitted using Equation 6.7 to obtain the diffusion coefficients for the membrane samples while Equation 6.5 was used to obtain the diffusion coefficient of $\mathrm{C}_{2} \mathrm{H}_{4}$ in $\mathrm{Cu}_{3} \mathrm{BTC}_{2}$ MOFs.

\subsubsection{Gas permeation}

Gas permeation experiments using the constant volume, variable pressure method with vacuum at the permeate side as described elsewhere [26] were performed to evaluate the $\mathrm{C}_{2} \mathrm{H}_{4} / \mathrm{C}_{2} \mathrm{H}_{6}$ separating ability of native P84 membranes and all $\mathrm{Cu}_{3} \mathrm{BTC}_{2}$ MMMs. Partial pressures higher than 1 bar were replaced by their corresponding fugacities to correct for nonideal behavior.

Alternating nitrogen and $\mathrm{C}_{2} \mathrm{H}_{4} / \mathrm{C}_{2} \mathrm{H}_{6}$ gas permeation measurements were performed on the same membrane samples. The nitrogen feed pressure was kept constant at 5 bar to investigate plasticization effects. The $\mathrm{C}_{2} \mathrm{H}_{4} / \mathrm{C}_{2} \mathrm{H}_{6}$ feed pressure was increased from 5 bar, to 10 bar and eventually to 15 bar. 
For mixed gas experiments, both feed and permeate were analyzed using a Varian 3900GC gas chromatograph equipped with an Alltech Alumina F-1 60/80 packed bed column at 150 ${ }^{\circ} \mathrm{C}$. Enough permeate was collected to achieve a signal/noise $(\mathrm{S} / \mathrm{N})$ ratio of at least 10 . Mixed gas selectivity was calculated according to Equation 6.11:

$$
\alpha_{i j}=\frac{y_{i} / y_{j}}{x_{i} / x_{j}}
$$

where $y_{j}$ and $x_{j}$ are the downstream and upstream mole fractions of compound $\mathrm{j}$ respectively. 


\subsection{Results and discussion}

\subsubsection{Membrane characterization}

\subsubsection{SEM}

The morphologies of the cross-sectional membrane areas are investigated using SEM and shown in Figure 6.1. A membrane made of pure P84 shows nothing except a dense polymer layer of approximately $53 \mu \mathrm{m}$, as can be seen in Figure 6.1a. Figure 6.1b shows that when $10 \% \mathrm{Cu}_{3} \mathrm{BTC}_{2}$ is added to the polymer matrix, a layer of $\mathrm{Cu}_{3} \mathrm{BTC}_{2}$ and P84 forms at the bottom of the membrane. White circles indicate the location of particles. The MOF crystals deposit at the bottom of the membrane during the membrane fabrication process when the solvent evaporates, creating an inhomogeneous membrane. Figure 6.1c and Figure 6.1d, with $20 \%$ and $40 \% \mathrm{Cu}_{3} \mathrm{BTC}_{2}$ respectively, show an increasingly thicker MOF-P84 layer with a decreasingly thinner pure P84 layer.

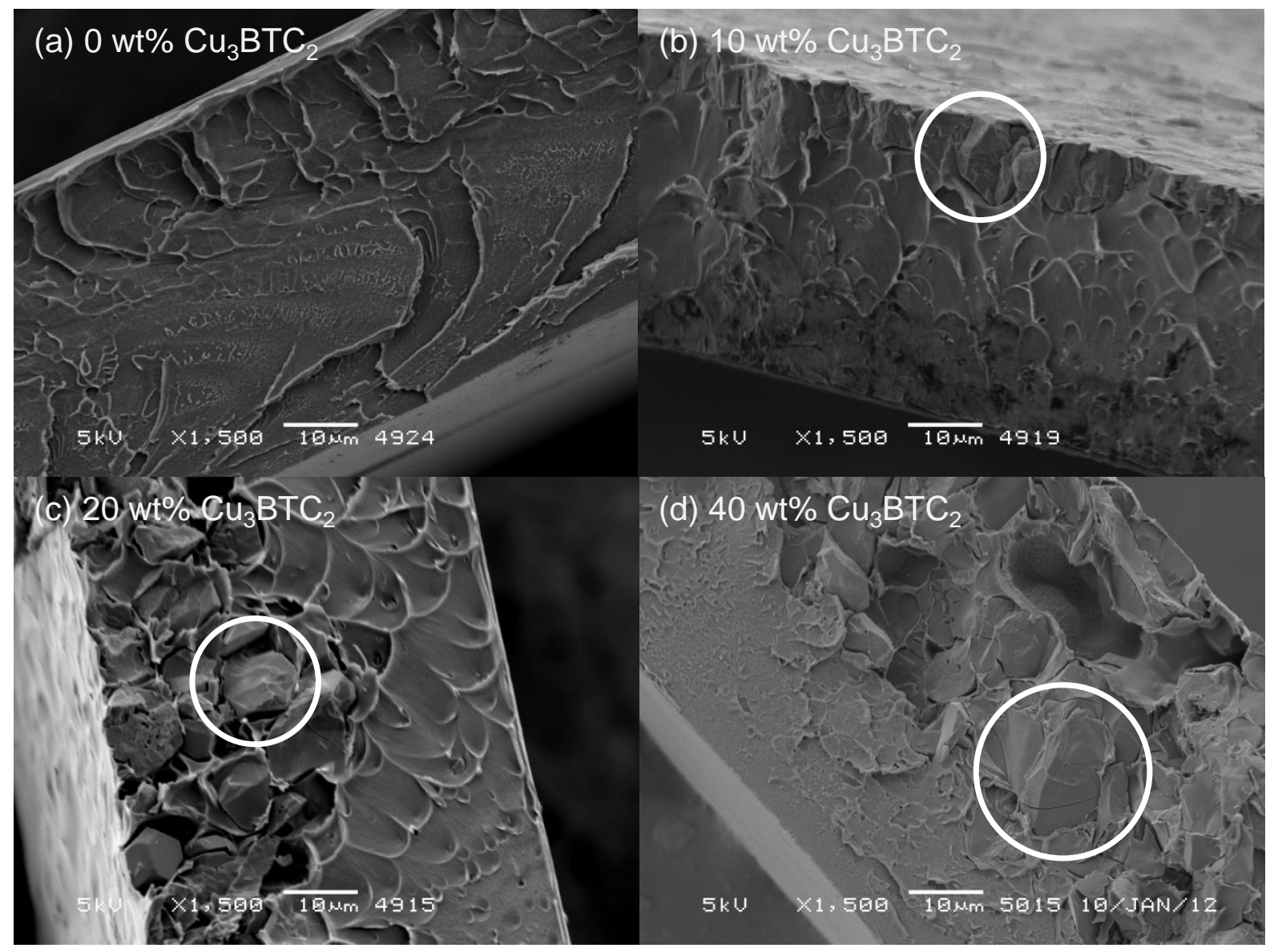

Figure 6.1. SEM images of P84 MMMs with (a) $0 \mathrm{w} \% \mathrm{Cu}_{3} \mathrm{BTC}_{2}$, (b) $10 \mathrm{w} \% \mathrm{Cu}_{3} \mathrm{BTC}_{2}$, (c) 20 w\% $\mathrm{Cu}_{3} \mathrm{BTC}_{2}$ and (d) $40 \mathrm{w} \% \mathrm{Cu}_{3} \mathrm{BTC}_{2}$. Particles are indicated by a white circle. 


\subsubsection{TGA}

The effect of temperature on the degradation of native P84, MMMs at various loadings of $\mathrm{Cu}_{3} \mathrm{BTC}_{2}$ and pure $\mathrm{Cu}_{3} \mathrm{BTC}_{2}$ MOFs is shown in Figure 6.2.

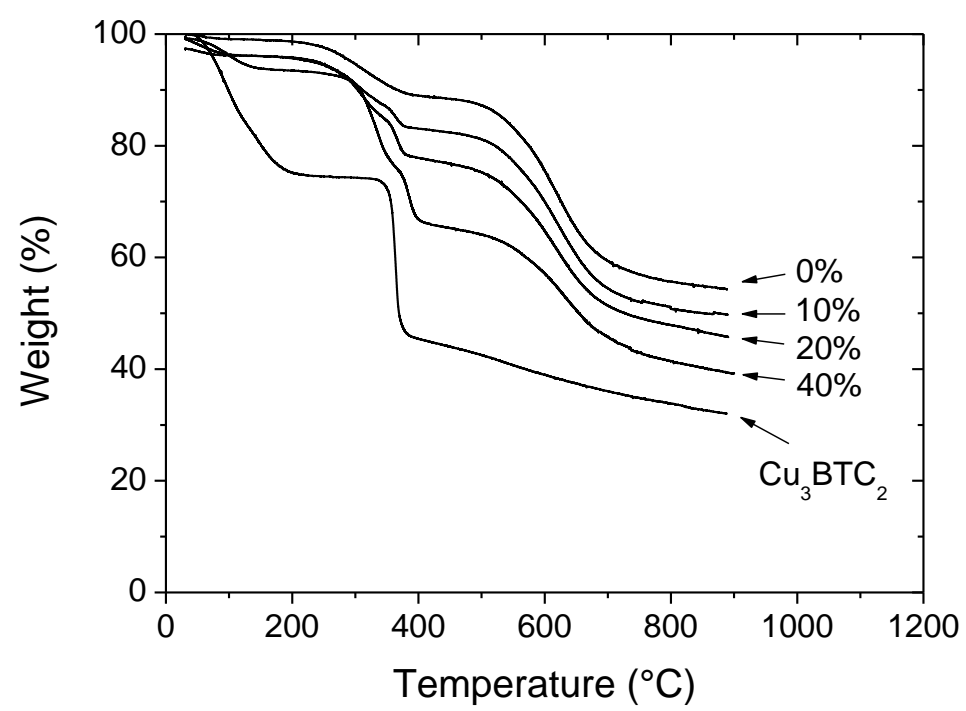

Figure 6.2. TGA of $\mathrm{Cu}_{3} \mathrm{BTC}_{2}$ and $\mathrm{P} 84$ with various loadings of $\mathrm{Cu}_{3} \mathrm{BTC}_{2}$.

The native $\mathrm{P} 84$ membrane $\left(0 \% \mathrm{Cu}_{3} \mathrm{BTC}_{2}\right)$ has a weight loss of only $1.2 \%$ up to $175{ }^{\circ} \mathrm{C}$. This is caused by evaporation of adsorbed solvent. An additional $9.5 \%$ of the weight is lost when the temperature is increased to $400{ }^{\circ} \mathrm{C}$, which marks the start of the degradation process. P84 has lost $46 \%$ of its original weight at the final temperature of $900{ }^{\circ} \mathrm{C}$.

Pure $\mathrm{Cu}_{3} \mathrm{BTC}_{2}$ MOFs show a weight loss of up to $26 \%$ when the temperature is increased to $200{ }^{\circ} \mathrm{C}$. This indicated a loss of hydrated water [13]. At $350{ }^{\circ} \mathrm{C}, \mathrm{Cu}_{3} \mathrm{BTC}_{2}$ loses $27 \%$ of its initial weight, which marks the start of the degradation process that last till the final temperature of $900{ }^{\circ} \mathrm{C}$ where only $32 \%$ of its initial weight is left.

The MMMs with 10, 20 and $40 \mathrm{w} \% \mathrm{Cu}_{3} \mathrm{BTC}_{2}$ show similar decomposition stages compared to the P84 membrane. When the temperature is increased up to $175{ }^{\circ} \mathrm{C}$, they suffer from a weight loss of 1.3, 3.2 and $5.7 \%$ due to the evaporation of hydrated water, respectively. This increasingly higher weight loss is related to the increased loading of hydrated $\mathrm{Cu}_{3} \mathrm{BTC}_{2}$ MOFs in the MMMs. Due to $\mathrm{Cu}_{3} \mathrm{BTC}_{2}$ `s hygroscopic property as shown in $[13,15]$, MMMs containing higher loadings of $\mathrm{Cu}_{3} \mathrm{BTC}_{2}$ have higher concentrations of water adsorbed. When 
the temperature is increased up to $400{ }^{\circ} \mathrm{C}$, an additional 12,18 and $27 \%$ of the starting weight is lost respectively. It is also visible that an extra decomposition stage appears between 350 and $380{ }^{\circ} \mathrm{C}$ when compared to P84. This extra stage is caused by the decomposition of $\mathrm{Cu}_{3} \mathrm{BTC}_{2}$ particles since it coincides with the $\mathrm{Cu}_{3} \mathrm{BTC}_{2}$ decomposition temperature. Therefore higher $\mathrm{Cu}_{3} \mathrm{BTC}_{2}$ loadings in the MMM cause higher weight losses. The degradation of the MMM continues, as the temperature is increased to $900{ }^{\circ} \mathrm{C}$, and a final weight loss of 50,54 , $68 \%$ is recorded. This is a larger weight loss than the native P84 membrane because of the additional $\mathrm{Cu}_{3} \mathrm{BTC}_{2}$ added.

\subsubsection{DSC}

DSC analysis was performed on small pieces of P84 with $0,10,20$ and $40 \mathrm{w} \% \mathrm{Cu}_{3} \mathrm{BTC}_{2}$ to determine the glass transition temperature and to investigate changes in chain flexibility when MOFs are added to the polymer matrix. As shown in Table 6.1, the $\mathrm{T}_{\mathrm{g}}$ of P84 is visible at 345 ${ }^{\circ} \mathrm{C}$.

Table 6.1. Tg of P84 MMMs with various $\mathrm{Cu}_{3} \mathrm{BTC}_{2}$ loadings.

\begin{tabular}{cccc}
\hline Polymer & MOF type added & MOF loading $(\mathrm{w} \%)$ & $\mathrm{T}_{\mathrm{g}}\left({ }^{\circ} \mathrm{C}\right)$ \\
\hline P84 & - & 0 & 345 \\
P84 & $\mathrm{Cu}_{3} \mathrm{BTC}_{2}$ & 10 & 330 \\
P84 & $\mathrm{Cu}_{3} \mathrm{BTC}_{2}$ & 20 & 329 \\
P84 & $\mathrm{Cu}_{3} \mathrm{BTC}_{2}$ & 40 & 338 \\
\hline
\end{tabular}

When $10 \mathrm{w} \% \mathrm{Cu}_{3} \mathrm{BTC}_{2}$ is added to the polymer matrix, a decrease in $\mathrm{T}_{\mathrm{g}}$ of $15{ }^{\circ} \mathrm{C}$ to $330{ }^{\circ} \mathrm{C}$ is visible. This decrease in $\mathrm{T}_{\mathrm{g}}$ is caused by disruption of physical crosslinks between the polymer chains due to the introduction of $\mathrm{Cu}_{3} \mathrm{BTC}_{2}$ crystals, which results in the formation of a more flexible intermediate phase between the polymer and the MOF. When the $\mathrm{Cu}_{3} \mathrm{BTC}_{2}$ loading is increased to $20 \mathrm{w} \%$, the $\mathrm{T}_{\mathrm{g}}$ remains constant within the experimental error of the experiment. This suggests that the compatibility between the polymer and the MOF phase is still satisfactory. However, when the MOF loading is increased to $40 \%$, the $\mathrm{T}_{\mathrm{g}}$ increases again to $338^{\circ} \mathrm{C}$, which implies that there is less disruption of the physical crosslinks between 184 
the polymer chains. The deposition of high loadings of $\mathrm{Cu}_{3} \mathrm{BTC}_{2}$ limits interaction between P84 and all of the MOF crystals. This results in the possibility for P84 to form more physical crosslinks with itself compared to a loading of $20 \mathrm{w} \%$ as was the case in native P84. This is expressed by a $\mathrm{T}_{\mathrm{g}}$ between the native P84 and the $20 \mathrm{w} \% \mathrm{MMM}$ and even suggests the introduction of non-selective voids, as the interaction between the two phases is reduced.

Since the $\mathrm{T}_{\mathrm{g}}$ of P84 is equal to the decomposition temperature of $\mathrm{Cu}_{3} \mathrm{BTC}_{2}$ as shown in Figure 6.2, it is not possible to anneal the membranes and erase their history. In order to obtain comparable results, all membranes were fabricated such that all samples had the same history. Differences in sample history can affect permeabilities and selectivities as the result of physical aging [27].

\subsubsection{Static gas sorption}

Static gas sorption measurements were performed to characterize the sorption behavior of native P84 membranes and this is shown in Figure 6.3.

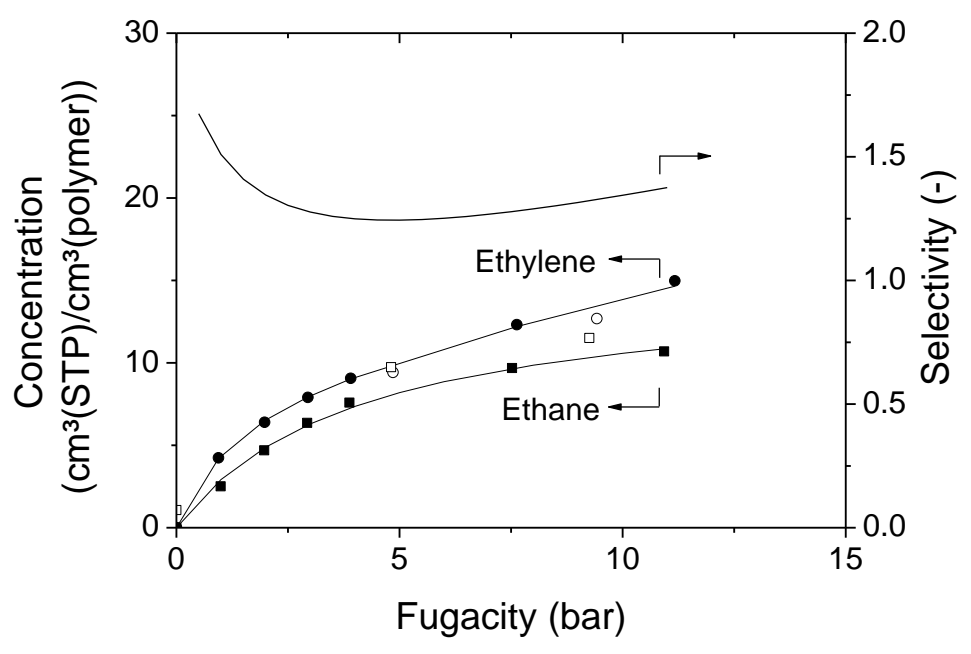

Figure 6.3. Sorption isotherms (closed symbols) of $\mathrm{C}_{2} \mathrm{H}_{4}$ (circle) and $\mathrm{C}_{2} \mathrm{H}_{6}$ (square) in native $\mathrm{P} 84$, corresponding desorption data (open symbols) and the ideal $\mathrm{C}_{2} \mathrm{H}_{4} / \mathrm{C}_{2} \mathrm{H}_{6}$ selectivity of native P84 as function of feed fugacities. Isotherms are fitted using the dual-mode sorption model (Equation 6.1). 
A dual mode sorption isotherm can be observed for both $\mathrm{C}_{2} \mathrm{H}_{4}$ and $\mathrm{C}_{2} \mathrm{H}_{6}$ and the desorption data coincide with the sorption isotherm. This lack of hysteresis suggests that both $\mathrm{C}_{2} \mathrm{H}_{4}$ and $\mathrm{C}_{2} \mathrm{H}_{6}$ do not induce plasticization in $\mathrm{P} 84$. When both sorption isotherms of $\mathrm{C}_{2} \mathrm{H}_{4}$ and $\mathrm{C}_{2} \mathrm{H}_{6}$ are fitted with the dual-mode sorption model (Equation 6.1), the Henry`s constants, the Langmuir capacity constants and the Langmuir affinity constants can be obtained and these are shown in Table 6.2. The low Henry constants for both $\mathrm{C}_{2} \mathrm{H}_{4}$ and $\mathrm{C}_{2} \mathrm{H}_{6}$ indicate that the major sorption mechanism inside P84 is Langmuir sorption which takes place in the nonequilibrium excess volume occurring in glassy polymers [16]. Addition of MOF particles to the polymer matrix could affect and possibly disturb or alter this excess volume. This will be investigated hereafter with static gas sorption measurements in MMMs. The ideal $\mathrm{C}_{2} \mathrm{H}_{4} / \mathrm{C}_{2} \mathrm{H}_{6}$ sorption selectivity of P84 is almost constant at 1.5 over the whole fugacity range. This indicates that any form of selectivity present in native P84 membranes is mainly governed by diffusion selectivity. Therefore, enhancement of the solubility selectivity by addition of MOFs in MMMs could greatly enhance the selectivity.

The effect of $\mathrm{Cu}_{3} \mathrm{BTC}_{2}$ on the $\mathrm{C}_{2} \mathrm{H}_{4}$ and $\mathrm{C}_{2} \mathrm{H}_{6}$ solubility in MMMs with 10 and $20 \mathrm{w} \%$ $\mathrm{Cu}_{3} \mathrm{BTC}_{2}$ are shown in Figure 6.4 as well as the $\mathrm{C}_{2} \mathrm{H}_{4}$ and $\mathrm{C}_{2} \mathrm{H}_{6}$ solubility in native P84 and pure $\mathrm{Cu}_{3} \mathrm{BTC}_{2}$ MOFs.

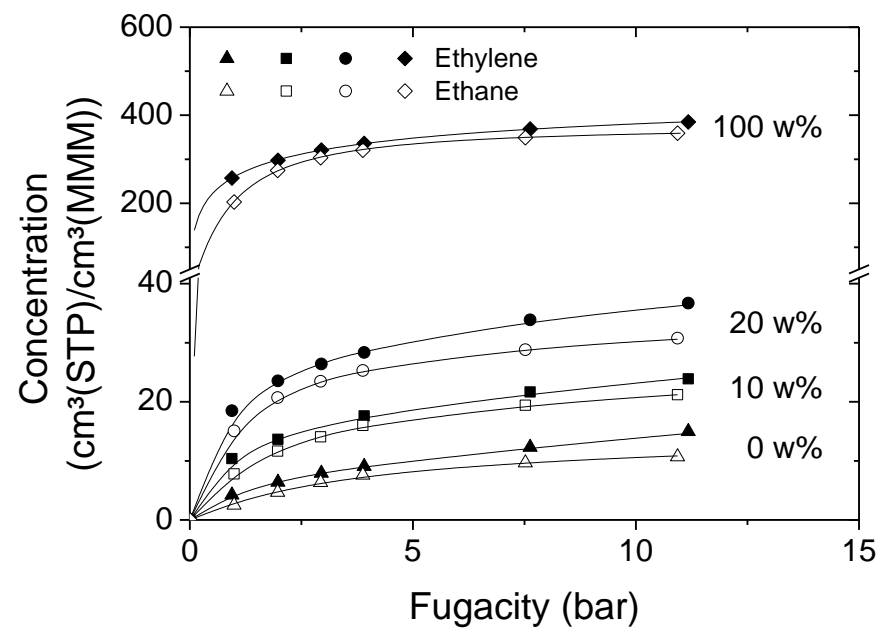

Figure 6.4. Sorption isotherms of $\mathrm{C}_{2} \mathrm{H}_{4}$ (closed) and $\mathrm{C}_{2} \mathrm{H}_{6}$ (open) in $\mathrm{P} 84$ with 0, 1020 w\% $\mathrm{Cu}_{3} \mathrm{BTC}_{2}$ and pure $\mathrm{Cu}_{3} \mathrm{BTC}_{2}$ particles $(100 \%)$ as function of their corresponding fugacities. Isotherms displayed were fitted using Equation 6.1 for native P84 and MMMs and Equation 6.3 for pure $\mathrm{Cu}_{3} \mathrm{BTC}_{2}$ MOFs. 
Since the MMMs contain both polymer and MOF particles, the total amount of sorption is a combination of dual-mode and Sips sorption. Fitting the data with a linear combination of Equation 6.1 and 6.3 was not possible; there are too many variables in that case to get noncorrelated solutions. Therefore, to compare the obtained results with the sorption in pure $\mathrm{Cu}_{3} \mathrm{BTC}_{2}$ and native P84, the sorption isotherms of $\mathrm{C}_{2} \mathrm{H}_{6}$ and $\mathrm{C}_{2} \mathrm{H}_{4}$ in the MMMs were fitted using both the dual mode sorption (Equation 6.1) and the Sips model (Equation 6.3) separately, where it was assumed that the MMMs consisted of one homogeneous phase. The obtained parameters for the dual mode sorption model and the Sips model are shown in Table 6.2 .

Table 6.2. Fitted dual mode sorption and SIPS parameters in $\mathrm{P} 84$ with various $\mathrm{w} \% \mathrm{Cu}_{3} \mathrm{BTC} \mathrm{C}_{2}$ of $\mathrm{C}_{2} \mathrm{H}_{4}$ and $\mathrm{C}_{2} \mathrm{H}_{6}$ sorption isotherms.

\begin{tabular}{|c|c|c|c|c|c|c|c|}
\hline \multirow[t]{2}{*}{ Feed gas } & \multirow[t]{2}{*}{$\mathrm{w} \% \mathrm{Cu}_{3} \mathrm{BTC}_{2}$} & \multicolumn{3}{|c|}{ Dual mode sorption model } & \multicolumn{3}{|c|}{ SIPS model } \\
\hline & & $\mathrm{C}_{\mathrm{H}}$ & $b_{i}$ & $\mathrm{k}_{\mathrm{D}}$ & $\mathrm{C}_{\mathrm{S}}^{\prime}$ & $b_{S}$ & $\mathrm{n}$ \\
\hline \multirow{4}{*}{$\mathrm{C}_{2} \mathrm{H}_{4}$} & 0 & 8.82 & 0.73 & 0.64 & - & - & - \\
\hline & 10 & 18.8 & 1.10 & 0.60 & 45.5 & 0.11 & 1.85 \\
\hline & 20 & 29.2 & 1.59 & 0.84 & 68.6 & 0.12 & 2.17 \\
\hline & 100 & - & - & - & 513 & 1.07 & 2.25 \\
\hline \multirow{4}{*}{$\mathrm{C}_{2} \mathrm{H}_{6}$} & 0 & 14.9 & 0.24 & 0.00 & - & - & - \\
\hline & 10 & 23.9 & 0.47 & 0.11 & 26.6 & 0.39 & 1.07 \\
\hline & 20 & 31.4 & 0.92 & 0.20 & 35.5 & 0.72 & 1.13 \\
\hline & 100 & - & - & - & 337 & 1.16 & 0.85 \\
\hline
\end{tabular}

When the dual mode sorption parameters for different $\mathrm{w} \%$ of $\mathrm{Cu}_{3} \mathrm{BTC}_{2}$ are compared in Table 6.2, an increase with increasing $\mathrm{Cu}_{3} \mathrm{BTC}_{2}$ loading is visible for all parameters for both $\mathrm{C}_{2} \mathrm{H}_{4}$ and $\mathrm{C}_{2} \mathrm{H}_{6}$. This implies that the addition of $\mathrm{Cu}_{3} \mathrm{BTC}_{2}$ increases the maximum sorption capacity and the affinity towards $\mathrm{C}_{2} \mathrm{H}_{4}$ and $\mathrm{C}_{2} \mathrm{H}_{6}$, but does not provide any additional sorption selectivity, since the ideal sorption selectivity does not increase. 
Similar to the comparison of the dual mode sorption parameters, the Sips parameters of the MMMs in Table 6.2 can be compared to the Sips parameters of $\mathrm{Cu}_{3} \mathrm{BTC}_{2} \mathrm{MOF}$. The maximum sorption capacity, C's, in $20 \mathrm{w} \% \mathrm{P} 84 \mathrm{MMM}$ is decreased by a factor 9 and 10 for $\mathrm{C}_{2} \mathrm{H}_{4}$ and $\mathrm{C}_{2} \mathrm{H}_{6}$ respectively compared to the sorption in pure $\mathrm{Cu}_{3} \mathrm{BTC}_{2}$ MOFs. This reduction suggests that approximately $10 \%$ of the MMM sorption capacity is caused by the addition of MOFs, even though $20 \mathrm{w} \%$ was added. This difference can be explained by sorption limitations in the $\mathrm{Cu}_{3} \mathrm{BTC}_{2}$ particles due to the surrounding polymer. DSC experiments shown in Table 6.1 showed that there is interaction between the polymer phase and the $\mathrm{Cu}_{3} \mathrm{BTC}_{2}$ particles up to $20 \mathrm{w} \%$. This might reduce the sorption capacity on the outside of the MOF where interaction with the polymer takes place, or limits the diffusion into $\mathrm{Cu}_{3} \mathrm{BTC}_{2}$. The Sips affinity parameter of $\mathrm{C}_{2} \mathrm{H}_{4}$ and $\mathrm{C}_{2} \mathrm{H}_{6}$ for the MMM is lower than that for pure $\mathrm{Cu}_{3} \mathrm{BTC}_{2}$, because $80 \mathrm{w} \%$ of the MMM consists of P84 which has low affinity towards $\mathrm{C}_{2} \mathrm{H}_{4}$ and $\mathrm{C}_{2} \mathrm{H}_{6}$ as is also shown in Table 6.2 for the dual-mode sorption model of native P84. Finally, the sorption intensity for $\mathrm{C}_{2} \mathrm{H}_{4}$ decreases from 2.25 to 1.82 since the majority of the membrane consists of P84, which is assumed to adsorb only one molecule per sorption site according to the Langmuir model.

Addition of $\mathrm{Cu}_{3} \mathrm{BTC}_{2}$ particles to the $\mathrm{P} 84$ membranes appears to increase the maximum sorption capacity by a factor $2-3$, while the ideal $\mathrm{C}_{2} \mathrm{H}_{4} / \mathrm{C}_{2} \mathrm{H}_{6}$ sorption selectivity is not significantly increased. Also, addition of $\mathrm{Cu}_{3} \mathrm{BTC}_{2}$ particles might have an influence on the diffusion coefficient, which will be discussed in the next paragraph.

\subsubsection{Dynamic sorption}

Dynamic sorption experiments were performed to determine the kinetic diffusion coefficients of the MMMs with various $\mathrm{w}_{0} \mathrm{Cu}_{3} \mathrm{BTC}_{2}$. It is important to verify whether all fitting parameters can be accurately obtained with the given film thickness. Therefore, data of a typical dynamic sorption experiment are shown in Figure 6.5 and subdivided into its Fickian and relaxational contributions. 


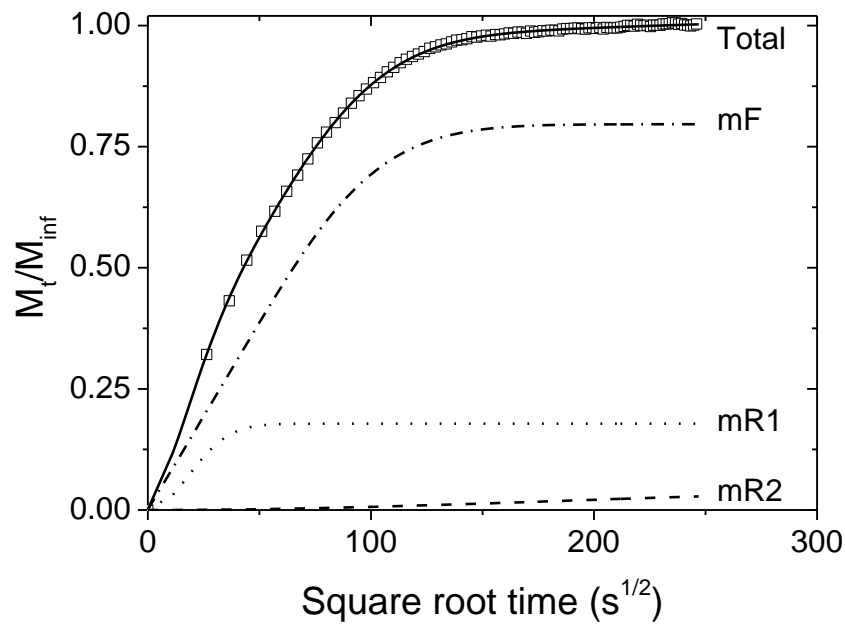

Figure 6.5. Relative $\mathrm{C}_{2} \mathrm{H}_{4}$ mass uptake (squares) as function of time. Solid black line is the best fit using Equation 6.7, which is broken down into individual contributions of the Fickian, $\mathrm{mF}$, (dash-dot line) first relaxational, mR1, (dot line) and second relaxational, mR2, (dash line) contribution.

Figure 6.5 shows that both relaxational contributions $\mathrm{mR} 1$ and $\mathrm{mR} 2$, can be separated from the Fickian mass uptake, which is necessary to accurately determine the diffusion coefficient. In case individual contributions would overlap, the fitted diffusion coefficient would be dependent on other fit parameters and not reflect the actual value. Although usually the relaxational contribution is a consequence of the Fickian absorption, it can be seen that in this case, the Fickian mass uptake continues while the first relaxational contribution is completed. However, this phenomenon is attributed to nano-scale defects or casting induced relaxed stresses in the polymer film, which allow for additional mass uptake once the Fickian diffusion process has started. Although this is technically not a relaxation process and would require additional experiments to fully understand, it is not relevant for the determination of trends of the Fickian diffusion coefficient.

Figure 6.6 shows the $\mathrm{C}_{2} \mathrm{H}_{4}$ concentration in $\mathrm{P} 84 \mathrm{MMMs}$ with various $\mathrm{w} \%$ of $\mathrm{Cu}_{3} \mathrm{BTC}_{2}$. As expected from the static sorption experiments, higher loadings of $\mathrm{Cu}_{3} \mathrm{BTC}_{2}$ in P84 allow higher concentrations of $\mathrm{C}_{2} \mathrm{H}_{4}$ to adsorb into the MMMs. It can also be seen that the $\mathrm{C}_{2} \mathrm{H}_{4}$ concentrations at pseudo equilibrium are lower than reported in Figure 6.4, which is due to 
variations in sample history caused by different measurement protocols for static and dynamic sorption measurements.

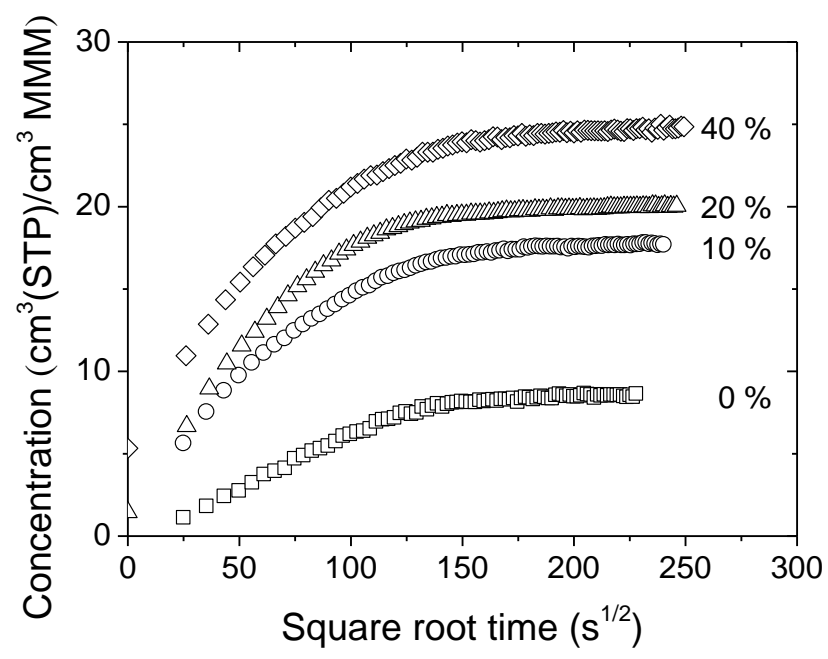

Figure 6.6. Concentration of $\mathrm{C}_{2} \mathrm{H}_{4}$ in native P84 and P84 with 10, 20 and $40 \mathrm{w} \% \mathrm{Cu}_{3} \mathrm{BTC}_{2}$ as function of time.

When the $\mathrm{C}_{2} \mathrm{H}_{4}$ sorption in the MMMs is expressed in $\mathrm{m}_{\mathrm{t}} / \mathrm{m}_{\infty}$ as a function of time, diffusion coefficients can be fitted using Equation 6.7. Based on these parameters, a theoretical permeability coefficient can be calculated according to Equation 6.8 and it can be estimated what the theoretical effect of the added particles on the $\mathrm{C}_{2} \mathrm{H}_{4}$ permeability is supposed to be. The solubility and diffusion coefficients of $\mathrm{C}_{2} \mathrm{H}_{4}$ obtained from these dynamic sorption experiments are shown in Table 6.3, as well as the theoretical permeability in Barrer $\left(\mathrm{P}_{\mathrm{B}}\right)$ and SI units $\left(\mathrm{P}_{\mathrm{SI}}\right)$. 
Table 6.3. Solubility coefficients, diffusion coefficients and theoretical permeability coefficients of $\mathrm{C}_{2} \mathrm{H}_{4}$ in MMMs with various loadings of $\mathrm{Cu}_{3} \mathrm{BTC}_{2}$.

\begin{tabular}{lcccc}
$\mathrm{w} \% \mathrm{Cu}_{3} \mathrm{BTC}_{2}$ & $\mathrm{~S}$ & $\mathrm{D}$ & $\mathrm{P}_{\mathrm{B}}$ & $\mathrm{P}_{\mathrm{SI}}$ \\
\hline 0 & 2.8 & 2.8 & 0.08 & 27 \\
10 & 5.7 & 3.2 & 0.18 & 60 \\
20 & 6.6 & 6.1 & 0.40 & 134 \\
40 & 8.2 & 272 & 22.30 & 7458 \\
${ }^{*} \mathrm{~S}$ in $\left(10^{-2} \mathrm{~cm}^{3} /\left(\mathrm{cm}^{3} \mathrm{cmHg}\right)\right), \mathrm{D}$ in $\left(10^{-10} \mathrm{~cm}^{2} / \mathrm{s}\right), \mathrm{P}_{\mathrm{B}}$ in Barrer and \\
$\mathrm{P}_{\mathrm{SI}}$ in $\left(10^{-18} \mathrm{~mol} \cdot \mathrm{m} /\left(\mathrm{m}^{2} \cdot \mathrm{s} \cdot \mathrm{Pa}\right)\right)$
\end{tabular}

Table 6.3 shows that the increase in solubility is accompanied by an exponential increase in diffusion coefficient. As a result, the theoretical permeability coefficient of the $\mathrm{Cu}_{3} \mathrm{BTC}_{2}$ MMMs is expected to show an even stronger exponential increase. When the results are investigated more closely, it can be deducted that the increase in theoretical permeability coefficient due to the addition of $10 \mathrm{w} \% \mathrm{Cu}_{3} \mathrm{BTC}_{2}$ is mainly caused by the increase in solubility. When higher $\mathrm{Cu}_{3} \mathrm{BTC}_{2}$ loadings are added to the polymer matrix, the increase in diffusion coefficient becomes the primary contribution to the increasing theoretical permeability coefficient. These findings imply that in theory, MMM permeabilities should increase with increasing $\mathrm{Cu}_{3} \mathrm{BTC}_{2}$ loading as a result of either removed diffusion limitations in the polymer or by introduction of non-selective voids. Experimental determination of the gas permeation behavior could resolve this question as the removal of diffusion limitations will show enhanced selectivities, opposite to the introduction of non-selective voids which will reduce selectivities to values close to the native membrane material. This will be further discussed in the next paragraph.

\subsubsection{Gas permeation measurements}

\subsection{Effect of $\mathrm{Cu}_{3} \mathrm{BTC}_{2}$ loading}

Figure 6.7 shows the $\mathrm{C}_{2} \mathrm{H}_{4}$ permeability and $\mathrm{C}_{2} \mathrm{H}_{4} / \mathrm{C}_{2} \mathrm{H}_{6}$ selectivity at various loadings of $\mathrm{Cu}_{3} \mathrm{BTC}_{2}$ added to P84. Figure $6.7 \mathrm{a}$ shows that the $\mathrm{C}_{2} \mathrm{H}_{4}$ permeability of $17 \cdot 10^{-18} \mathrm{~mol}$. $\mathrm{m} /\left(\mathrm{m}^{2} \cdot \mathrm{s} \cdot \mathrm{Pa}\right)$ does not increase with increasing $\mathrm{Cu}_{3} \mathrm{BTC}_{2}$ loading up to $20 \mathrm{w} \%$. Especially 
when the standard deviation between the samples is considered, the small permeability increase at $20 \% \mathrm{Cu}_{3} \mathrm{BTC}_{2}$ can be considered insignificant. The measured $\mathrm{C}_{2} \mathrm{H}_{4}$ permeability of native P84 is very close compared to the calculated $\mathrm{C}_{2} \mathrm{H}_{4}$ permeability of $27 \cdot 10^{-18} \mathrm{~mol}$. $\mathrm{m} /\left(\mathrm{m}^{2} \cdot \mathrm{s} \cdot \mathrm{Pa}\right)$, which was based on the solubility and diffusion coefficients shown in Table 6.3. Discrepancies between these two permeability values are most likely the result of differences in measurement techniques. Mainly the fact that for the theoretical permeability, the solubility parameter was determined using feed gas on all sides of the membrane, while the experimental permeability was determined using vacuum at the permeate side, could contribute to this. An increasingly larger discrepancy occurs when the $\mathrm{Cu}_{3} \mathrm{BTC}_{2}$ loading is further increased due to the different operating conditions.

The effect of $\mathrm{Cu}_{3} \mathrm{BTC}_{2}$ loading on the $\mathrm{C}_{2} \mathrm{H}_{4} / \mathrm{C}_{2} \mathrm{H}_{6}$ selectivity is shown in Figure $6.7 \mathrm{~b}$. There is a clear correlation visible between the selectivity and the amount of $\mathrm{Cu}_{3} \mathrm{BTC}_{2}$; when the $\mathrm{Cu}_{3} \mathrm{BTC}_{2}$ loading is increased from $0 \%$ to $20 \%$, the $\mathrm{C}_{2} \mathrm{H}_{4} / \mathrm{C}_{2} \mathrm{H}_{6}$ selectivity increases from 4.1 to 7.1 respectively. These findings are consistent with a combination of Case 0 (ideal polymer-particle interaction) and Case I (rigidified polymer layer around particle) or Case IV (clogged porous particles), which would result in a constant permeability and an increasing selectivity as the particle loading increases. However, the absence of an increase in $\mathrm{T}_{\mathrm{g}}$ and a calculated reduction in diffusion coefficient eliminates the possibility of a Case I situation and makes a combination of Case 0 and Case IV more probable. When the $\mathrm{Cu}_{3} \mathrm{BTC}_{2}$ loading is even further increased to $40 \mathrm{w} \%$, the $\mathrm{C}_{2} \mathrm{H}_{4} / \mathrm{C}_{2} \mathrm{H}_{6}$ selectivity drops to 5.0, which is a significant reduction. At the same time, the $\mathrm{C}_{2} \mathrm{H}_{4}$ permeability increases dramatically to 25.5 . $10^{-18} \mathrm{~mol} \cdot \mathrm{m} /\left(\mathrm{m}^{2} \cdot \mathrm{s} \cdot \mathrm{Pa}\right)$. These results indicate, that due to the large amount of $\mathrm{Cu}_{3} \mathrm{BTC}_{2}$ added to the polymer matrix, in combination with their inhomogeneous distribution, nonselective voids are created when $40 \%$ MOF is added to the polymer (Case II). 

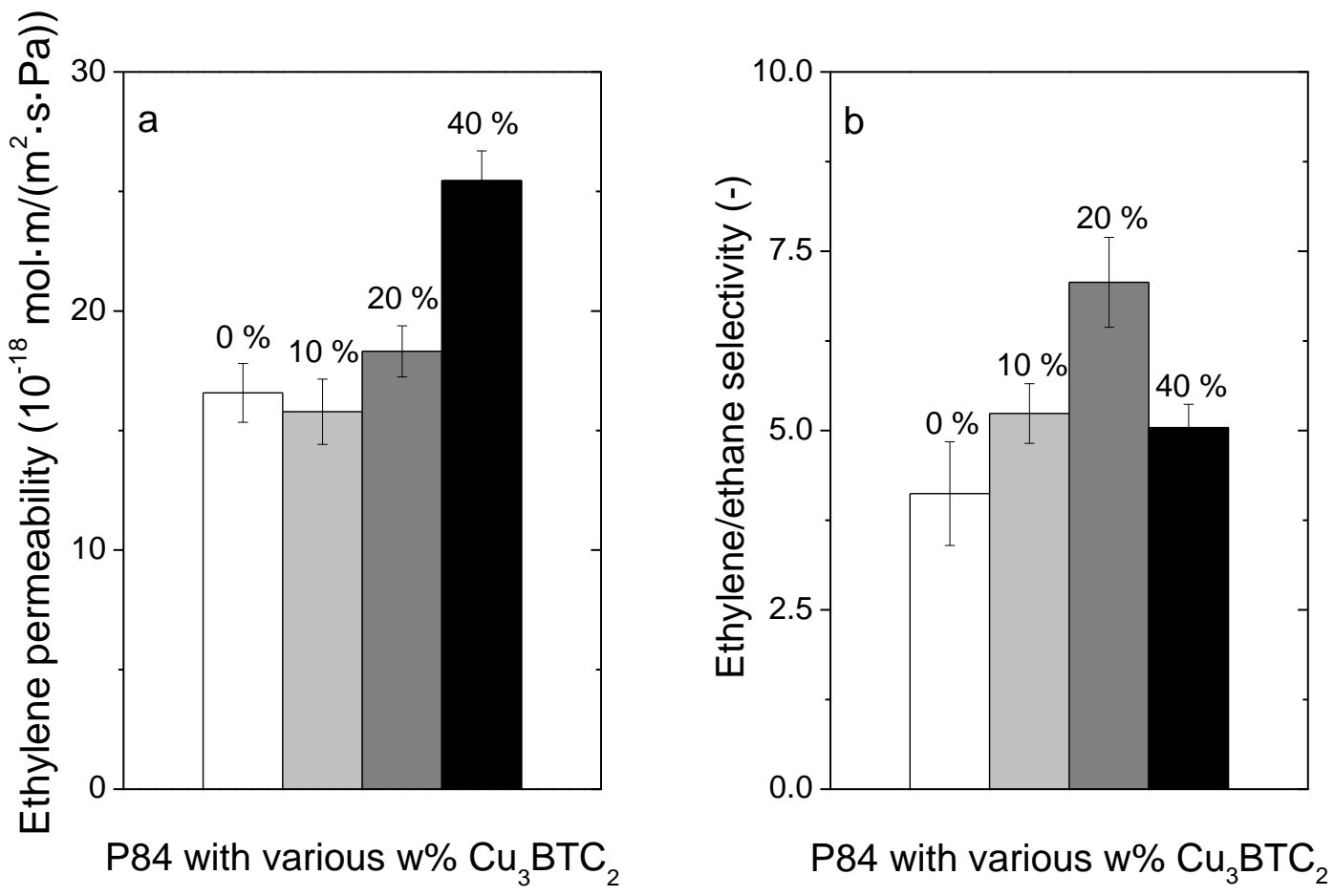

Figure 6.7. (a) $\mathrm{C}_{2} \mathrm{H}_{4}$ permeability and (b) $\mathrm{C}_{2} \mathrm{H}_{4} / \mathrm{C}_{2} \mathrm{H}_{6}$ selectivity $( \pm 2 \sigma)$ of $\mathrm{P} 84$ with various amounts of $\mathrm{Cu}_{3} \mathrm{BTC}_{2}$ MMMs at 5 bar mix gas feed pressure.

The lack of increase in permeability up to $20 \mathrm{w} \%$ is surprising because numerous reports mention a simultaneous increase in both selectivity and permeability or permeance of the fast moving component when MOFs are added to the polymer matrix [5-7, 11, 28, 29]. Although many researchers investigate different, sometimes self-synthesized MOFs, the increase in permeability or permeance has also been observed for the commercially available MOFs used in this study [5, 28]. Basu et al. observed a minor increase in carbon dioxide/nitrogen selectivity with a strongly increasing carbon dioxide permeance, as well as an increasing carbon dioxide/methane selectivity accompanied by an increasing carbon dioxide permeance [5]. Although the authors used Matrimid as polymer matrix as opposed to P84, no significant changes would be expected since both materials are polyimides. In addition, the inherent low permeability of $\mathrm{P} 84$ towards $\mathrm{C}_{2} \mathrm{H}_{4}$ is expected to give an even larger enhanced permeability when $\mathrm{Cu}_{3} \mathrm{BTC}_{2}$ is added as dispersed phase. The constant $\mathrm{C}_{2} \mathrm{H}_{4}$ permeability with varying amounts of $\mathrm{Cu}_{3} \mathrm{BTC}_{2}$ demonstrates the absence of non-selective voids between the MOF particles and the polymer matrix. If non-selective voids were present, a clear correlation 
between the $\mathrm{C}_{2} \mathrm{H}_{4}$ permeability and the MOF loading in the MMM would have been observed. Because of this lack of defects, and the fact that the difference in polymer matrix used cannot explain the observed constant permeability, only differences in penetrant-MMM interaction can explain these findings. Although it was shown by dynamic sorption measurements that the $\mathrm{C}_{2} \mathrm{H}_{4}$ diffusion coefficient in MMMs, shown in Table 6.3, increases with increasing $\mathrm{Cu}_{3} \mathrm{BTC}_{2}$ loading, this is not related to the rate of desorption and therefore only confirms that $\mathrm{C}_{2} \mathrm{H}_{4}$ diffuses faster in and not per definition through the MMM. $\mathrm{C}_{2} \mathrm{H}_{4}$ could exhibit strong interactions with the MMM and be slowed or immobilized and consequently clog the porous $\mathrm{Cu}_{3} \mathrm{BTC}_{2}$ MOFs causing Case IV. Because of $\mathrm{Cu}_{3} \mathrm{BTC}_{2}$ s high sorption capacity for $\mathrm{C}_{2} \mathrm{H}_{4}$ as shown in Figure 6.4, it is very likely that interactions of $\mathrm{C}_{2} \mathrm{H}_{4}$ with $\mathrm{Cu}_{3} \mathrm{BTC}_{2}$ take place, which in turn, might lower the diffusion coefficient during permeation experiments if these interactions are strong. Future work will need to be done to better understand the transport mechanism of gasses through MMMs.

Given the above, it is clear that facilitated $\mathrm{C}_{2} \mathrm{H}_{4}$ transport does not take place through the $\mathrm{Cu}_{3} \mathrm{BTC}_{2}$ crystals. Since the sorption capacity of $\mathrm{Cu}_{3} \mathrm{BTC}_{2}$ is an order of magnitude higher than for P84, it is evident that the gas can enter all or part of the pores present in the crystals. Although larger amounts of gas can adsorb into MMMs, diffusion through the MMMs is not enhanced and even reduced with increasing $\mathrm{Cu}_{3} \mathrm{BTC}_{2}$ loading added to the polymer matrix, which results in a constant $\mathrm{C}_{2} \mathrm{H}_{4}$ permeability. As shown with dynamic sorption measurements, the fact that $\mathrm{C}_{2} \mathrm{H}_{4}$ diffuses faster in $\mathrm{MMMs}$ with higher $\mathrm{Cu}_{3} \mathrm{BTC}_{2}$ loadings, shows that this unrelated to the diffusion behavior of penetrants through a MMM in gas permeation experiments.

\subsection{Effect of feed pressure}

Plasticization increases the permeability of the membranes while reducing the selectivity as a result of excessive polymer swelling. To investigate this effect in MMMs, feed pressures were varied and selectivities and permeabilities were measured for $\mathrm{Cu}_{3} \mathrm{BTC}_{2} \mathrm{MMMs}$. The results of the $\mathrm{C}_{2} \mathrm{H}_{4}$ permeabilities and the $\mathrm{C}_{2} \mathrm{H}_{4} / \mathrm{C}_{2} \mathrm{H}_{6}$ selectivities are presented in Figure $6.8 \mathrm{a}$ and Figure $6.8 \mathrm{~b}$ respectively. Figure 6.8a shows a slight decrease in $\mathrm{C}_{2} \mathrm{H}_{4}$ permeability for native P84 with increasing feed pressure. This is consistent with the dual-mode behavior in glassy polymers and P84 shows no signs of induced plasticization [16, 30]. A similar permeability reduction is observed when various $\mathrm{w} \%$ of $\mathrm{Cu}_{3} \mathrm{BTC}_{2}$ are added to the P84 
matrix, showing that adding $\mathrm{Cu}_{3} \mathrm{BTC}_{2}$ does not induce plasticization effects up to 15 bar mixed gas feed pressure. Figure $6.8 \mathrm{~b}$ shows no significant decrease in selectivity of the native P84 with increasing feed pressure up to 15 bar. This indicates that no significant plasticization takes place in the pressure range investigated, which is in agreement with similar studies for other gasses [31, 32]. Also, no reduction in selectivity is observed when various $\mathrm{w} \%$ of $\mathrm{Cu}_{3} \mathrm{BTC}_{2}$ are added to the polymer matrix. This, in combination with the absence of an increasing permeability with increasing feed pressure, indicates that plasticization phenomena do not occur within this study.
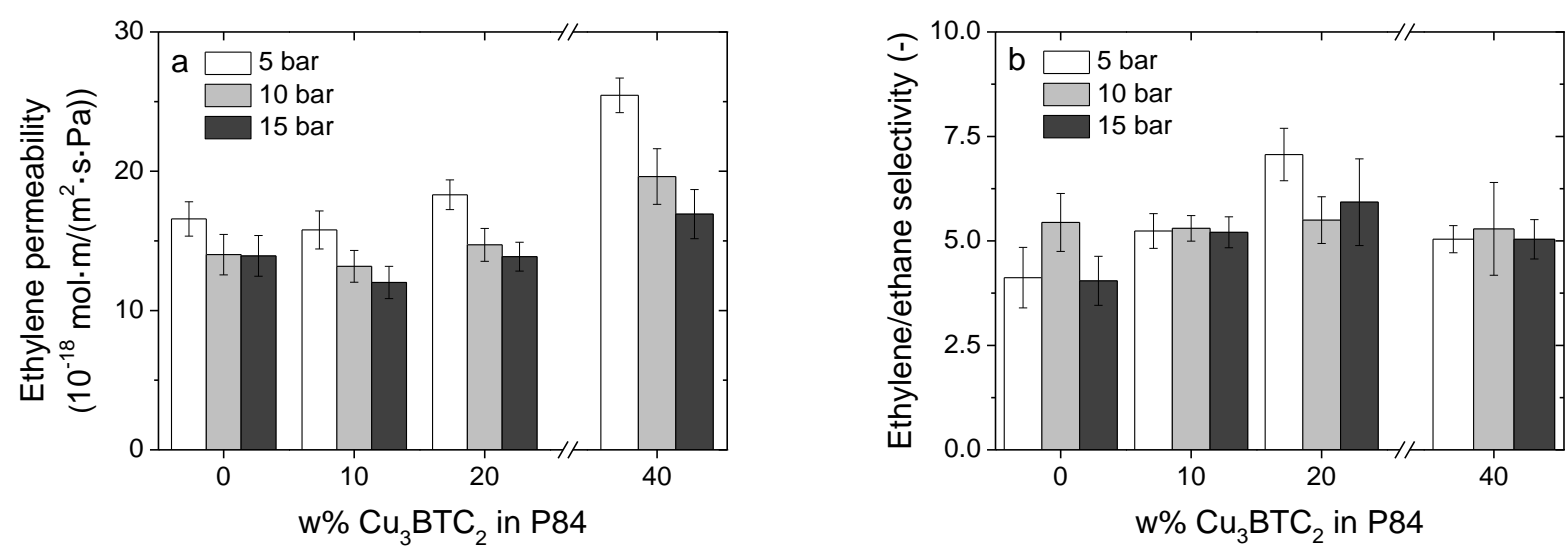

Figure 6.8. Effect of mixed gas feed pressure on the (a) $\mathrm{C}_{2} \mathrm{H}_{4}$ permeability and (b) $\mathrm{C}_{2} \mathrm{H}_{4} / \mathrm{C}_{2} \mathrm{H}_{6}$ selectivity $( \pm 2 \sigma)$ for P84 MMMs with various $w \%$ of $\mathrm{Cu}_{3} \mathrm{BTC}_{2}$.

Since both the permeability (Figure 6.8a) and solubility (Figure 6.4) are now determined over a pressure range up to 15 bar mixed gas feed pressure, it is possible to calculate the diffusion coefficients of $\mathrm{C}_{2} \mathrm{H}_{4}$ at various mixed gas feed pressures according to Equation 6.8 and compare these with the diffusion coefficients obtained by dynamic sorption experiments. These results are shown in Table 6.4. Since the solubility coefficient of $\mathrm{C}_{2} \mathrm{H}_{4}$ at 5 bar mixed feed gas increases $190 \%$ to 2.9 when $20 \mathrm{w} \% \mathrm{Cu}_{3} \mathrm{BTC}_{2}$ is added, the constant permeability coefficient of $\mathrm{C}_{2} \mathrm{H}_{4}$ consequently lowers the diffusion coefficient to 6.3 at 5 bar mixed feed pressure. Similarly, at 10 and 15 bar mixed gas feed pressure, the $\mathrm{C}_{2} \mathrm{H}_{4}$ solubility increases with increasing $\mathrm{Cu}_{3} \mathrm{BTC}_{2}$ loading and therefore, the diffusion coefficient decreases with increasing $\mathrm{Cu}_{3} \mathrm{BTC}_{2}$ loading. As mentioned in the introduction, a decrease in diffusion 
coefficient with increasing particle loading has also been observed in literature by Adams et al. for carbon dioxide, oxygen, nitrogen and methane when $15 \mathrm{w} \% \mathrm{Cu}$ TPA MOF was added to a poly(vinyl acetate) matrix and attributed this to immobilization of penetrant inside the MMMs [12]. However, the solubility coefficient is decreasing with increasing feed pressure at constant $\mathrm{Cu}_{3} \mathrm{BTC}_{2}$ loading. As a result, the diffusion coefficient increases with increasing feed pressure.

Table 6.4. Measured permeability coefficients $\left(10^{-18} \mathrm{~mol} \mathrm{~m} /\left(\mathrm{m}^{2} \mathrm{~s} \mathrm{~Pa}\right)\right)$, calculated solubility coefficient $\left(10^{-3} \mathrm{~mol} /\left(\mathrm{m}^{3} \mathrm{~Pa}\right)\right.$ based on Equations 6.2 and 6.4 , and calculated diffusion coefficient $\left(10^{-15} \mathrm{~m}^{2} / \mathrm{s}\right)$ based on Equation 6.8 for $\mathrm{C}_{2} \mathrm{H}_{4}$ in $\mathrm{P} 84$ with various loadings of $\mathrm{Cu}_{3} \mathrm{BTC}_{2}$ at various mixed gas feed pressures.

w\% $\mathrm{Cu}_{3} \mathrm{BTC}_{2} \quad 5 \mathrm{bar} \quad 10 \mathrm{bar} \quad 15$ bar

\begin{tabular}{ccccccccccc}
$\mathrm{P}$ & $\mathrm{S}$ & $\mathrm{D}$ & & $\mathrm{P}$ & $\mathrm{S}$ & $\mathrm{D}$ & & $\mathrm{P}$ & $\mathrm{S}$ & $\mathrm{D}$ \\
\cline { 1 - 3 } \cline { 8 - 9 } 16.6 & 1.0 & 16.8 & & 14.0 & 0.7 & 20.3 & & 13.9 & 0.6 & 24.2 \\
15.8 & 1.9 & 8.5 & & 13.2 & 1.2 & 11.4 & & 12.0 & 0.9 & 13.4 \\
18.3 & 2.9 & 6.3 & & 14.7 & 1.8 & 8.4 & & 13.9 & 1.3 & 10.4 \\
\hline
\end{tabular}

Similar to $\mathrm{C}_{2} \mathrm{H}_{4}$, the mixed gas permeability, solubility and diffusion coefficients of $\mathrm{C}_{2} \mathrm{H}_{6}$ can be determined for various $\mathrm{Cu}_{3} \mathrm{BTC}_{2}$ loadings at various pressures. This leads subsequently to the calculations of the mixed gas permeability, solubility and diffusion selectivity, shown in Table 6.5 for P84 with $\mathrm{Cu}_{3} \mathrm{BTC}_{2}$ loadings up to $20 \%$ at feed pressures from 5 to 15 bar. At constant pressure, the permeability selectivity increases with increasing $\mathrm{Cu}_{3} \mathrm{BTC}_{2}$ loading. At 10 bar feed pressure, this effect is only slightly visible because of the relatively large standard deviations. Furthermore, the solubility selectivities decrease with increasing $\mathrm{Cu}_{3} \mathrm{BTC}_{2}$ loading which in return, lead to an increase in diffusion selectivity up to $120 \%$. When the $\mathrm{Cu}_{3} \mathrm{BTC}_{2}$ loading remains constant, it can be observed that the permeability selectivity is slightly reduced with increasing feed pressure. However, the solubility selectivity increases with increasing feed pressure, which results in a reduction of the diffusion selectivity.

From these data, it is clear that the main mechanism responsible for the increase in selectivity with increasing $\mathrm{Cu}_{3} \mathrm{BTC}_{2}$ loading is due to an increase in diffusion selectivity caused by the 
$\mathrm{Cu}_{3} \mathrm{BTC}_{2}$ particles. Sorption experiments shown in Figure 6.4 already revealed that the ideal sorption selectivity in $\mathrm{Cu}_{3} \mathrm{BTC}_{2}$ was low and therefore, no increase in selectivity based on enhanced solubility selectivity could be expected.

Table 6.5. Calculated mixed gas permeability and diffusivity selectivities based on Equation 6.9 and solubility selectivity based on Equations 6.2 and 6.4, for P84 MMMs with various loadings of $\mathrm{Cu}_{3} \mathrm{BTC}_{2}$ at various mixed gas feed pressures.

\begin{tabular}{|c|c|c|c|c|c|c|c|c|c|}
\hline \multirow[t]{2}{*}{${ }_{\mathrm{w}} \% \mathrm{Cu}_{3} \mathrm{BTC}_{2}$} & \multicolumn{3}{|c|}{5 bar } & \multicolumn{3}{|c|}{10 bar } & \multicolumn{3}{|c|}{15 bar } \\
\hline & $\alpha_{\mathrm{P}}$ & $\alpha_{S}$ & $\alpha_{D}$ & $\alpha_{\mathrm{P}}$ & $\alpha_{S}$ & $\alpha_{D}$ & $\alpha_{P}$ & $\alpha_{S}$ & $\alpha_{D}$ \\
\hline $0 \%$ & 4.1 & 2.5 & 1.7 & 5.4 & 3.0 & 1.8 & 4.0 & 3.5 & 1.2 \\
\hline $10 \%$ & 5.2 & 2.0 & 2.6 & 5.3 & 2.2 & 2.4 & 5.2 & 2.3 & 2.3 \\
\hline $20 \%$ & 7.1 & 1.7 & 4.0 & 5.5 & 1.9 & 3.0 & 5.9 & 1.9 & 3.0 \\
\hline
\end{tabular}

Sorption experiments shown in Figure 6.4 showed an increase in $\mathrm{C}_{2} \mathrm{H}_{4}$ concentration when $\mathrm{Cu}_{3} \mathrm{BTC}_{2}$ particles were added to the P84 matrix. It is hypothesized that this increased concentration of $\mathrm{C}_{2} \mathrm{H}_{4}$ is immobilized inside the MMMs and hinders the diffusion of $\mathrm{C}_{2} \mathrm{H}_{6}$ through the MMM. This would ultimately result in constant permeabilities and increased selectivities with increased loadings of $\mathrm{Cu}_{3} \mathrm{BTC}_{2}$ added to the polymer matrix. 


\subsection{Conclusions}

P84 MMMs with various amounts of $\mathrm{Cu}_{3} \mathrm{BTC}_{2}$ have been successfully prepared. $\mathrm{C}_{2} \mathrm{H}_{4} / \mathrm{C}_{2} \mathrm{H}_{6}$ selectivity increased up to $73 \%$ from 4.1 to 7.1 with increasing $\mathrm{Cu}_{3} \mathrm{BTC}_{2}$ loading up to 20 $\mathrm{w} \%$, while the permeability remained constant at $17 \cdot 10^{-18} \mathrm{~mol} \cdot \mathrm{m} /\left(\mathrm{m}^{2} \cdot \mathrm{s} \cdot \mathrm{Pa}\right)$, which confirms, in combination with DSC data, the absence of non-selective voids in the MMMs. The $\mathrm{C}_{2} \mathrm{H}_{4}$ solubility coefficient increased from 1.0 to $2.9 \cdot 10^{-3} \mathrm{~mol} /\left(\mathrm{m}^{3} \mathrm{~Pa}\right)$ with increasing loading of $\mathrm{Cu}_{3} \mathrm{BTC}_{2}$, while the diffusion coefficient decreased from 16.8 to $6.3 \cdot 10^{-15} \mathrm{~m}^{2} / \mathrm{s}$. This indicates that a large part of the $\mathrm{C}_{2} \mathrm{H}_{4}$ is immobilized inside the MMM, hindering the diffusion of $\mathrm{C}_{2} \mathrm{H}_{6}$ and to some extend its own. This is reflected in the increase in diffusion selectivity and the reduction of solubility selectivity with increasing $\mathrm{Cu}_{3} \mathrm{BTC}_{2}$ loading. Increasing the loading beyond $20 \mathrm{w} \%$ led to the formation of non-selective voids, which resulted in increased permeabilities up to $26 \cdot 10^{-18} \mathrm{~mol} \cdot \mathrm{m} /\left(\mathrm{m}^{2} \cdot \mathrm{s} \cdot \mathrm{Pa}\right)$ with selectivities being reduced to that of native P84. Increasing the feed pressure from 5 to 15 bar resulted in slight reductions of permeabilities, which is typical dual-mode behavior in glassy polymers. In addition, the increase in feed pressure showed an increase in solubility selectivity and therefore, a reduction in diffusion selectivity.

\section{Acknowledgements}

This project is financially supported by AgentschapNL. The authors would like to thank ECN, Dow and SolSep for the fruitful discussions. 


\section{Bibliography}

1. $232^{\text {nd }}$ ACS National Meeting, San Francisco, Sept. 10-14. Chemical and Engineering News 2006. 84(34): p. 59-236.

2. $\quad$ Robeson, L.M., The upper bound revisited. Journal of Membrane Science, 2008. 320: p. 390-400.

3. Robeson, L.M., et al., High performance polymers for membrane separation. Polymer, 1994. 35(23): p. 4970-4978.

4. Motelica, A., et al., Membrane retrofit option for paraffin/olefin separation-a technoeconomic evaluation. Industrial and Engineering Chemistry Research, 2012. 51(19): p. 6977-6986.

5. Basu, S., A. Cano-Odena, and I.F.J. Vankelecom, MOF-containing mixed-matrix membranes for $\mathrm{CO} 2 / \mathrm{CH} 4$ and $\mathrm{CO} 2 / \mathrm{N} 2$ binary gas mixture separations. Separation and Purification Technology, 2011. 81(1): p. 31-40.

6. Zhang, C., et al., High performance ZIF-8/6FDA-DAM mixed matrix membrane for propylene/propane separations. Journal of Membrane Science, 2012. 389: p. 34-42.

7. Dai, Y., et al., Ultem $® / Z I F-8$ mixed matrix hollow fiber membranes for CO2/N2 separations. Journal of Membrane Science, 2012. 401-402(0): p. 76-82.

8. Hu, J., et al., Mixed-matrix membrane hollow fibers of $\mathrm{Cu} 3(\mathrm{BTC}) 2 \mathrm{MOF}$ and polyimide for gas separation and adsorption. Industrial and Engineering Chemistry Research, 2010. 49(24): p. 12605-12612.

9. Nik, O.G., X.Y. Chen, and S. Kaliaguine, Functionalized metal organic frameworkpolyimide mixed matrix membranes for CO2/CH4 separation. Journal of Membrane Science, (0).

10. Thompson, J.A., et al., Sonication-induced Ostwald ripening of ZIF-8 nanoparticles and formation of ZIF-8/polymer composite membranes. Microporous and Mesoporous Materials, 2012. 158(0): p. 292-299.

11. Tanh Jeazet, H.B., C. Staudt, and C. Janiak, Metal-organic frameworks in mixedmatrix membranes for gas separation. Dalton Transactions, 2012. 41(46): p. 1399114212.

12. Adams, R., et al., Metal organic framework mixed matrix membranes for gas separations. Microporous and Mesoporous Materials, 2010. 131(1-3): p. 13-20.

13. Chui, S.S.-Y., et al., A Chemically Functionalizable Nanoporous Material [Cu3(TMA)2(H2O)3]n. Science, 1999. 283(5405): p. 1148-1150.

14. Kopeć, K.K., et al., Chemistry in a spinneret-On the interplay of crosslinking and phase inversion during spinning of novel hollow fiber membranes. Journal of Membrane Science, 2011. 369(1-2): p. 308-318.

15. Ploegmakers, J., S. Japip, and K. Nijmeijer, Mixed matrix membranes containing MOFs for ethylene/ethane separation Part A: Membrane preparation and characterization. Journal of Membrane Science, 2013. 428: p. 445-453.

16. Paul, D.R., Gas Sorption and Transport in Glassy Polymers. Berichte der Bunsengesellschaft für physikalische Chemie, 1979. 83(4): p. 294-302.

17. Sips, R., On the structure of a catalyst surface. The Journal of Chemical Physics, 1948. 16(5): p. 490-495.

18. Do, D.D., Adsorption analysis equilibria and kinetics. Vol. 2. 1998, London: Imperial College Press.

19. Al-Asheh, S., et al., Predictions of binary sorption isotherms for the sorption of heavy metals by pine bark using single isotherm data. Chemosphere, 2000. 41(5): p. 659665.

20. Crank, J., The Mathematics of Diffusion 2nd edition ed1979, Oxford Clarendon Press. 
21. Crank, J. and G.S. Park, Diffusion in polymers 1968, London and New York: Academic Press.

22. Berens, A.R. and H.B. Hopfenberg, Diffusion and relaxation in glassy polymer powders: 2. Separation of diffusion and relaxation parameters. Polymer, 1978. 19(5): p. 489-496.

23. Visser, T. and M. Wessling, When do sorption-induced relaxations in glassy polymers set in? Macromolecules, 2007. 40(14): p. 4992-5000.

24. Wijmans, J.G. and R.W. Baker, The solution-diffusion model: A review. Journal of Membrane Science, 1995. 107(1-2): p. 1-21.

25. Yampolskii, Y., I. Pinnau, and B.D. Freeman, Materials Science of Membranes2007, Chichester: John Wiley \& Sons Ltd.

26. Barsema, J.N., et al., Preparation and characterization of highly selective dense and hollow fiber asymmetric membranes based on BTDA-TDI/MDI co-polyimide. Journal of Membrane Science, 2003. 216(1-2): p. 195-205.

27. Xia, J., et al., Aging and carbon dioxide plasticization of thin polyetherimide films. Polymer, 2012. 53(10): p. 2099-2108.

28. Basu, S., A. Cano-Odena, and I.F.J. Vankelecom, Asymmetric Matrimid®/[Cu3(BTC)2] mixed-matrix membranes for gas separations. Journal of Membrane Science, 2010. 362(1-2): p. 478-487.

29. Bae, T.H., et al., A high-performance gas-separation membrane containing submicrometer-sized metal-organic framework crystals. Angewandte Chemie International Edition, 2010. 49(51): p. 9863-9866.

30. Stannett, V., The transport of gases in synthetic polymeric membranes. An historic perspective. Journal of Membrane Science, 1978. 3(2-3 4): p. 97-115.

31. Bos, A., et al., Suppression of gas separation membrane plasticization by homogeneous polymer blending. AIChE Journal, 2001. 47(5): p. 1088-1093.

32. Visser, T., N. Masetto, and M. Wessling, Materials dependence of mixed gas plasticization behavior in asymmetric membranes. Journal of Membrane Science, 2007. 306(1-2): p. 16-28. 
Chapter 6. 


\section{Chapter 7}

Epilogue 
The last chapter of this work reflects on the obtained conclusions. In addition, the implications of these findings will be discussed, as well as the direction for future research

\subsection{Commercial feasibility of membranes in hybrid membrane- distillation plants}

Chapter 2 of this thesis presents an economical evaluation of membranes in hybrid membrane-distillation plants. A hybrid membrane-distillation plant was modeled and compared to cryogenic distillation using Honeywell`s UniSim Design Suite R390. Three different hybrid membrane-distillation setups were investigated, i.e. a $1500 \mathrm{kmol} / \mathrm{h}$ parallel, a $1500 \mathrm{kmol} / \mathrm{h}$ series and a 2,500 kmol/h series configuration. For each configuration, the $\mathrm{C}_{2} \mathrm{H}_{4}$ permeance and $\mathrm{C}_{2} \mathrm{H}_{4} / \mathrm{C}_{2} \mathrm{H}_{6}$ selectivity of the membrane were varied independently of each other.

The 2,500 $\mathrm{kmol} / \mathrm{h}$ series configuration was found to be the most promising, as the flow towards the membrane unit is more significant than the membrane feed stream composition that can be varied in the parallel configuration. A potential financial saving of $16 \%$ can be obtained with this configuration containing membranes with a $\mathrm{C}_{2} \mathrm{H}_{4}$ permeance of $2.8 \times 10^{-5}$ $\mathrm{mol} /\left(\mathrm{m}^{2} \mathrm{~s} \mathrm{kPa}\right)$ and $\mathrm{a}_{2} \mathrm{H}_{4} / \mathrm{C}_{2} \mathrm{H}_{6}$ selectivity of 300 . A minimum membrane $\mathrm{C}_{2} \mathrm{H}_{4}$ permeance of $2.8 \times 10^{-5} \mathrm{~mol} /\left(\mathrm{m}^{2} \mathrm{~s} \mathrm{kPa}\right)$ and $\mathrm{C}_{2} \mathrm{H}_{4} / \mathrm{C}_{2} \mathrm{H}_{6}$ selectivity of 30 is required to break even. For membrane researchers it is recommended to shift focus towards increasing the membrane selectivity, once a $\mathrm{C}_{2} \mathrm{H}_{4}$ permeance of $1.0 \times 10^{-5} \mathrm{~mol} /\left(\mathrm{m}^{2} \mathrm{~s} \mathrm{kPa}\right)$ is obtained, as that will yield significantly higher savings.

This economical evaluation of membranes in a hybrid membrane-distillation plant shows that an increase in both selectivity and permeance is necessary to obtain a commercially viable process. An increase in $\mathrm{C}_{2} \mathrm{H}_{4}$ permeance can be obtained by reducing the membrane thickness, using e.g. interfacial polymerization (IP) or layer by layer (LbL) technology. However, little is known about thin film behavior (i.e. swelling, sorption) under $\mathrm{C}_{2} \mathrm{H}_{4}$ and $\mathrm{C}_{2} \mathrm{H}_{6}$ atmospheres and to what extend it can be compared to the more thoroughly investigated penetrant $\mathrm{CO}_{2}$. This is the focus of Chapter 3 and Chapter 4. Purely polymer membranes are unlike to reach the required selectivity considering the Robeson plot, as explained in Chapter 1 of this thesis. Therefore, alternative strategies to improve the $\mathrm{C}_{2} \mathrm{H}_{4} / \mathrm{C}_{2} \mathrm{H}_{6}$ 
selectivity are applied in Chapter $\mathbf{5}$ and Chapter 6, which describe the utilization of mixed matrix membranes as a method to increase the $\mathrm{C}_{2} \mathrm{H}_{4} / \mathrm{C}_{2} \mathrm{H}_{6}$ selectivity.

\subsection{The effect of $\mathrm{C}_{2} \mathrm{H}_{4}$ and $\mathrm{C}_{2} \mathrm{H}_{6}$ on thin polymer layers}

Membranes become increasingly thinner to enhance the permeance. Therefore, understanding thin film interactions with various penetrants becomes increasingly important. Chapter 3 described the investigation of $100 \mathrm{~nm}$ thin PPO swelling behavior under $\mathrm{N}_{2}, \mathrm{CO}_{2}, \mathrm{C}_{2} \mathrm{H}_{4}$ and $\mathrm{C}_{2} \mathrm{H}_{6}$ atmospheres with spectroscopic ellipsometry. A new optical model for data analysis was introduced, that included the pressure dependency of the density and refractive indices of the penetrants, as in a gaseous phase.

$\mathrm{C}_{2} \mathrm{H}_{6}$ was found to swell the thin PPO films the most, followed by $\mathrm{C}_{2} \mathrm{H}_{4}$ and $\mathrm{CO}_{2}$. Secondary relaxations occur, after a certain penetrant induced swelling threshold has been reached. The maximum $\mathrm{CO}_{2}, \mathrm{C}_{2} \mathrm{H}_{4}$ and $\mathrm{C}_{2} \mathrm{H}_{6}$ induced secondary relaxations were found to be similar to each other. Since polymer swelling is dependent on the LJ diameter or Van der Waals volume, and the concentration of the sorbed penetrant, the concentration of $\mathrm{CO}_{2}$ in thin PPO films is considered to be significantly higher than that of $\mathrm{C}_{2} \mathrm{H}_{4}$ and $\mathrm{C}_{2} \mathrm{H}_{6}$. Penetrant concentrations were estimated in thin PPO films and compared to penetrant sorption in bulk PPO films using gravimetric sorption. For $\mathrm{CO}_{2}$ penetrants, slightly lower concentrations were found in the thin films as compared to the thick. A lower $\mathrm{CO}_{2}$ concentration was estimated for thin PPO films as compared to bulk PPO film, which was contributed to accelerated physical aging. The enhanced diffusion of free volume in the glassy polymer thin film, led to reduced Langmuir sorption. Consequently, no significant concentration differences between thin and bulk PPO films could be observed for $\mathrm{N}_{2}$ and $\mathrm{C}_{2} \mathrm{H}_{6}$, which was attributed to the significantly lower Langmuir sorption of these penetrants.

Chapter 4 extends the investigation of thin film behavior by investigating penetrant interactions in four different polymers. $\mathrm{N}_{2}, \mathrm{CO}_{2}, \mathrm{C}_{2} \mathrm{H}_{4}$ and $\mathrm{C}_{2} \mathrm{H}_{6}$ induced swelling of PPO, PDMS, P84 and SPPO was examined using spectroscopic ellipsometry. $\mathrm{N}_{2}$ did not significantly swell any of the polymers, due to its low $\mathrm{T}_{\mathrm{c}}$ and small $\mathrm{LJ}$ diameter and Van der Waals volume. $\mathrm{CO}_{2}, \mathrm{C}_{2} \mathrm{H}_{4}$ and $\mathrm{C}_{2} \mathrm{H}_{6}$ induced swelling was most distinct in the rubbery PDMS films. $\mathrm{C}_{2} \mathrm{H}_{6}$ induced the largest amount of swelling due to a high LJ diameter and Van der Waals volume and favorable Van der Waals interactions with PDMS. PDMS showed mostly 
Fickian sorption of $\mathrm{CO}_{2}, \mathrm{C}_{2} \mathrm{H}_{4}$ and $\mathrm{C}_{2} \mathrm{H}_{6}$, opposite to PPO and P84 where the non-Fickian sorption contribution to the total swelling was found to increase with increasing pressure. $\mathrm{CO}_{2}$ induced swelling in SPPO was significantly higher as compared to PPO (, due to additional favorable interactions with $\mathrm{SO}_{3} \mathrm{H}$ groups in SPPO. In addition, the sorption mechanism in SPPO changed from Fickian to non-Fickian at high concentrations of penetrant inside the polymer. This resulted in a decrease in film thickness when the pressure was increased from 25 to 30 bar.

Partial molar volumes were estimated in all investigated polymers for all penetrants. No partial molar volumes could be calculated for $\mathrm{N}_{2}$, because of insufficient polymer swelling. Langmuir sorption of $\mathrm{CO}_{2}, \mathrm{C}_{2} \mathrm{H}_{4}$ and $\mathrm{C}_{2} \mathrm{H}_{6}$ in the glassy polymers P84, PPO and SPPO was found to contribute to the total swelling. However, a deviation from a linear relation between polymer swelling and penetrant concentration was found, indicating that Langmuir sorbed penetrants contribute in different quantities to swelling as compared to Henry sorbed penetrants. Consequently, a concentration dependency of the partial molar volume is observed.

Lastly, opposite to $\mathrm{CO}_{2}$, no thickness dependency was observed when $\mathrm{C}_{2} \mathrm{H}_{6}$ concentrations in thin PDMS, PPO, P84 and SPPO films, measured by spectroscopic ellipsometry, were compared to bulk film, as measured by gravimetric sorption. These results suggest that accelerated thin film physical aging, which is responsible for reduced Langmuir sorption and consequently, reduced permeabilities, is less significant when penetrants mainly sorb due to Henry sorption.

The results shown in Chapter $\mathbf{3}$ and Chapter $\mathbf{4}$ are important for the development of thin membranes for $\mathrm{C}_{2} \mathrm{H}_{4}$ and $\mathrm{C}_{2} \mathrm{H}_{6}$ separation. Excessive polymer swelling should be prevented as much as possible, as this leads to plasticization, resulting in a loss of selectivity [1]. In this respect, PPO and P84 seemed the most suitable materials as the $\mathrm{C}_{2} \mathrm{H}_{4}$ and $\mathrm{C}_{2} \mathrm{H}_{6}$ induced swelling in these membranes was found to be the lowest.

Besides the use of low swelling polymers like P84, crosslinking of the polymer matrix can also reduce plasticization effects [1-3]. Additional crosslinks in the polymer network restrict excessive expansion of the matrix. Crosslinking usually also increases the polymers selectivity at the expense of a reduction in permeability [2-4]. The increased selectivity would be an additional benefit. Additionally, a $\mathrm{C}_{2} \mathrm{H}_{4}$ solubility selective crosslinker can be selected to increase the overall selectivity even further. Introduction of $\mathrm{NHCO}$ groups, $\mathrm{or}^{+} / \mathrm{Ag}^{+}$ 
metallo-organic complexes are known to exhibit such selectivity. Recently it was shown that crosslinking can occur during the hollow fiber spinning process, which eliminates the need for expensive and time consuming post-treatment steps [5].

As mentioned earlier, thin selective layers can be obtained by e.g. IP and LbL technologies. Yet a point of concern remains the fabrication of large defect free surfaces. From this point of view, LbL technology seems more practical for industrial applications than IP, as additional layers can be easily applied when necessary. Not only can additional layers plug defects, the membrane permeance and selectivity can be tuned as well [6].

\subsection{Mixed matrix membranes as strategy to improve membrane selectivity}

Three commercially available MOFs $\left(\mathrm{Cu}_{3} \mathrm{BTC}_{2}, \mathrm{FeBTC}\right.$ and MIL-53 (Al)) have been selected and incorporated in a P84 polymer matrix. The characterization of these MMMs is presented in Chapter 5. The $\mathrm{C}_{2} \mathrm{H}_{4} / \mathrm{C}_{2} \mathrm{H}_{6}$ selectivity increased $73 \%$ in the $20 \mathrm{w} \% \mathrm{Cu}_{3} \mathrm{BTC}_{2}$ MMM, as compared to the native P84 material, while the $\mathrm{C}_{2} \mathrm{H}_{4}$ permeability remained constant at $17 \times 10^{-18} \mathrm{~mol} \mathrm{~m} /\left(\mathrm{m}^{2} \mathrm{~s} \mathrm{~Pa}\right)$. The increase in selectivity, in combination with DSC data, confirmed the absence of non-selective voids with the addition of $\mathrm{Cu}_{3} \mathrm{BTC}_{2}$, opposite to the addition of MIL-53. The combination of no observed selectivity increase, an increase in $\mathrm{C}_{2} \mathrm{H}_{4}$ permeability, and no change in $\mathrm{T}_{\mathrm{g}}$ compared to the native P84, indicated that nonselective voids were present. This was attributed to the lack of possible polar interactions between the MIL-53 MOF and the polymer P84 phase. Addition of $20 \mathrm{w} \%$ FeBTC reduced the $\mathrm{C}_{2} \mathrm{H}_{4}$ permeability to $10 \times 10^{-18} \mathrm{~mol} \mathrm{~m} /\left(\mathrm{m}^{2} \mathrm{~s} \mathrm{~Pa}\right)$ without a significant increase in selectivity. The $\mathrm{C}_{2} \mathrm{H}_{4}$ permeability decreased with increasing feed pressure, as predicted by the dual-mode sorption model for glassy polymers. Finally, no plasticization was observed within the investigated pressure range.

Chapter 6 presented a thorough investigation of the $\mathrm{C}_{2} \mathrm{H}_{4}$ permeability, solubility and diffusion coefficients in P84 MMMs with an increasing concentration of $\mathrm{Cu}_{3} \mathrm{BTC}_{2}$. The combination of static sorption, dynamic sorption and mixed gas permeation experiments showed, that the observed $\mathrm{C}_{2} \mathrm{H}_{4} / \mathrm{C}_{2} \mathrm{H}_{6}$ selectivity increase found in Chapter 5 was the result of an increase in diffusivity selectivity. Both the $\mathrm{C}_{2} \mathrm{H}_{4}$, and the $\mathrm{C}_{2} \mathrm{H}_{6}$ concentration in the MMMs was found to increase with increasing $\mathrm{Cu}_{3} \mathrm{BTC}_{2}$ concentration. Combining these 
results with the results from the previous chapter led to the hypothesis that $\mathrm{C}_{2} \mathrm{H}_{4}$ remains immobilized in the $\mathrm{Cu}_{3} \mathrm{BTC}_{2}$ MOFs, thereby hindering the $\mathrm{C}_{2} \mathrm{H}_{6}$ diffusion.

Increasing the $\mathrm{Cu}_{3} \mathrm{BTC}_{2} \mathrm{MOF}$ loading to $40 \mathrm{w} \%$ led to the introduction of non-selective voids as evidenced by an increase in $\mathrm{C}_{2} \mathrm{H}_{4}$ permeability and a reduction in $\mathrm{C}_{2} \mathrm{H}_{4} / \mathrm{C}_{2} \mathrm{H}_{6}$ selectivity. Increasing the feed pressure from 5 to 15 bar showed minor reductions in $\mathrm{C}_{2} \mathrm{H}_{4}$ permeability, which is in agreement with the dual-mode sorption model. Additionally, the increase in feed pressure led to an increase in the solubility selectivity and consequently, to a reduction in diffusivity selectivity.

\subsubsection{Future directions of $M M M s$ for $\mathrm{C}_{2} \mathrm{H}_{4} / \mathrm{C}_{2} \mathrm{H}_{6}$ separation}

Although the increase in $\mathrm{C}_{2} \mathrm{H}_{4} / \mathrm{C}_{2} \mathrm{H}_{6}$ selectivity from 4.1 to 7.1 shows potential for MMMs, it is still not sufficient for an economically viable process. Therefore, future research should be directed to the development of MOFs with an intrinsically higher $\mathrm{C}_{2} \mathrm{H}_{4} / \mathrm{C}_{2} \mathrm{H}_{6}$ selectivity. A possible route is the synthesis of MOFs with $\mathrm{Ag}^{+}$ions incorporated in them [7]. $\mathrm{Ag}^{+}$ions show a significantly stronger complexation with olefins as compared to $\mathrm{Cu}^{+}$, according to the Dewar-Chatt-Duncanson model. Consequently, the $\mathrm{C}_{2} \mathrm{H}_{4} / \mathrm{C}_{2} \mathrm{H}_{6}$ selectivity would be even further increased.

The MMM fabrication method, as described in this thesis, can introduce non-selective free voids between the MOFs and the polymer matrix. The occurrence of non-selective free voids is highly dependent on compatibility between the MOF and polymer. As shown in Chapter 3, non-selective voids were absent between P84 and $\mathrm{Cu}_{2} \mathrm{BTC}_{3}$, but very significant for P84 and MIL-53(Al) MMMs. Chemical bonding between the MOF and polymer phase can resolve this issue. Not only will it avoid the formation of non-selective voids, it enlarges the number of possible polymer matrices that can be used for a particular MOF. Additionally, the MOF could be used as crosslinker and as such, reduce plasticization effects.

In this respect, the development of new MOF materials is of utmost importance. Not only should attention be paid to the metal ion used, the use of an appropriate organic linker is equally important. Certain MOFs of the MIL-53 family show 'breathing' effects as penetrants sorp into its porous structure, thereby changing the 3D structure and consequently, the sorption behavior, of the MOF [8]. Since the 'breathing' effect itself is currently not well understood, the influence of these MOFs in MMMs is an unexplored area. Potentially, gas 
permeabilities and selectivities can be tuned by process conditions, such as pressure, which increases the flexibility of membrane based separation processes. 


\section{Bibliography}

1. Staudt-Bickel, C. and W. J. Koros, Improvement of CO2/CH4 separation characteristics of polyimides by chemical crosslinking. Journal of Membrane Science, 1999. 155(1): p. 145-154.

2. Shao, L., et al., Polyimide modification by a linear aliphatic diamine to enhance transport performance and plasticization resistance. Journal of Membrane Science, 2005. 256(1-2): p. 46-56.

3. Shao, L., et al., Comparison of diamino cross-linking in different polyimide solutions and membranes by precipitation observation and gas transport. Journal of Membrane Science, 2008. 312(1-2): p. 174-185.

4. Shao, L., et al., Transport properties of cross-linked polyimide membranes induced by different generations of diaminobutane $(D A B)$ dendrimers. Journal of Membrane Science, 2004. 238(1-2): p. 153-163.

5. Kopeć, K.K., et al., Chemistry in a spinneret-On the interplay of crosslinking and phase inversion during spinning of novel hollow fiber membranes. Journal of Membrane Science, 2011. 369(1-2): p. 308-318.

6. Leväsalmi, J.M. and T.J. McCarthy, Poly(4-methyl-1-pentene)-supported polyelectrolyte multilayer films: Preparation and gas permeability. Macromolecules, 1997. 30(6): p. 1752-1757.

7. Nayak, S., K. Harms, and S. Dehnen, New Three-Dimensional Metal-Organic Framework with Heterometallic [Fe-Ag] Building Units: Synthesis, Crystal Structure, and Functional Studies. Inorganic Chemistry, 2011. 50(7): p. 2714-2716.

8. Ferey, G. and C. Serre, Large breathing effects in three-dimensional porous hybrid matter: facts, analyses, rules and consequences. Chemical Society Reviews, 2009. 38(5): p. 1380-1399. 
Chapter 7. 
Summary 
This thesis investigated the feasibility of membranes in a hybrid membrane-distillation plant, aiming to reduce the energy consumption of the currently used, energy intensive, cryogenic distillation.

Chapter 1 started with a brief overview of alternatives for cryogenic distillation as technology to separate $\mathrm{C}_{2} \mathrm{H}_{4}$ from $\mathrm{C}_{2} \mathrm{H}_{6}$. Alternatives like extractive distillation and chemical and physical adsorption currently exhibit insufficient selectivity. This leads, in combination with additional drawbacks like the need for solvent recovery, pressure and/or temperature swings and large footprints, to excessive capital or operational expenses. Membrane based separation can be an interesting alternative, as it has a low energy consumption and footprint resulting in generally lower capital and operational costs. However, polymer membranes suffer from the intrinsic drawback that separation is based on diffusion and solubility differences between the target components, which are exceptionally small in case of $\mathrm{C}_{2} \mathrm{H}_{4}$ and $\mathrm{C}_{2} \mathrm{H}_{6}$.

The economic evaluation of membranes in a hybrid membrane-distillation plant was presented in Chapter 2. The energy requirement for the base case cryogenic distillation was compared to a parallel and series configuration, modeled in UniSim Design Suite. The membrane $\mathrm{C}_{2} \mathrm{H}_{4}$ permeance and $\mathrm{C}_{2} \mathrm{H}_{4} / \mathrm{C}_{2} \mathrm{H}_{6}$ selectivity were independently varied between $2.8 \cdot 10^{-6} \mathrm{~mol} /\left(\mathrm{m}^{2} \mathrm{~s} \mathrm{kPa}\right)-2.8 \cdot 10^{-5} \mathrm{~mol} /\left(\mathrm{m}^{2} \mathrm{~s} \mathrm{kPa}\right)$ and $3-1000$, respectively. The 2,500 series configuration was the best performing configuration and was further optimized with respect to membrane feed pressure, permeate feed pressure and membrane area. An optimized process required a membrane selectivity of 30 and $\mathrm{C}_{2} \mathrm{H}_{4}$ permeance of $2.8 \cdot 10^{-5}$ $\mathrm{mol} /\left(\mathrm{m}^{2} \mathrm{~s} \mathrm{kPa}\right)$ to break even. Financial savings of $16 \%$ were possible with a membrane selectivity of 300 and a $\mathrm{C}_{2} \mathrm{H}_{4}$ permeance of $2.8 \cdot 10^{-5} \mathrm{~mol} /\left(\mathrm{m}^{2} \mathrm{~s} \mathrm{kPa}\right)$.

Chapter 3 described the $\mathrm{N}_{2}, \mathrm{CO}_{2}, \mathrm{C}_{2} \mathrm{H}_{4}$ and $\mathrm{C}_{2} \mathrm{H}_{6}$ induced swelling and sorption effects on thin PPO films using spectroscopic ellipsometry. The used optical model for data processing included pressure dependent refractive indices and densities of the penetrants, thereby assuming that penetrants reside in the polymer matrix in a gaseous state as opposed to a liquid. $\mathrm{C}_{2} \mathrm{H}_{6}$ showed the highest swelling, followed by $\mathrm{C}_{2} \mathrm{H}_{4}$ and $\mathrm{CO}_{2}$, while $\mathrm{N}_{2}$ showed the least amount of swelling with $0.5 \%$ at 30 bar. Swelling was found to be related to the concentration of the sorbed penetrant and its Van der Waals volume. Gravimetric sorption confirmed significantly higher $\mathrm{CO}_{2}$ concentrations in PPO as compared to the other penetrants. A reduction in penetrant concentration was found in thin films as compared to 
bulk films for $\mathrm{CO}_{2}$, but not for $\mathrm{C}_{2} \mathrm{H}_{6}$. Finally pressure dependent partial molar volumes for $\mathrm{CO}_{2}, \mathrm{C}_{2} \mathrm{H}_{4}$ and $\mathrm{C}_{2} \mathrm{H}_{6}$ were estimated.

Penetrant-polymer interactions were further examined in Chapter 4, where the $\mathrm{N}_{2}, \mathrm{CO}_{2}$, $\mathrm{C}_{2} \mathrm{H}_{4}$ and $\mathrm{C}_{2} \mathrm{H}_{6}$ induced swelling and sorption phenomena were investigated on thin P84, PPO, SPPO and PDMS films. The rubbery PDMS showed only Henry sorption and absence of non-Fickian sorption upon pressurization for all investigated gases. On the other hand, the glassy PPO, P84 and SPPO thin films showed dual-mode like sorption and both Fickian and non-Fickian sorption. PDMS swelled the most when exposed to $\mathrm{C}_{2} \mathrm{H}_{6}$, due to Van der Waals interactions and the high Van der Waals volume of $\mathrm{C}_{2} \mathrm{H}_{6}$. Significantly higher $\mathrm{CO}_{2}$ swelling was observed for SPPO as compared to PPO indicating that sulfon groups enhance $\mathrm{CO}_{2}$ sorption due to quadrupole-dipole interactions. Langmuir sorption was found to contribute to polymer swelling, which contradicts the dual-mode sorption model. However, the amount of swelling per mol sorbed gas caused by Langmuir sorption, differs from the amount of swelling caused by Henry sorption. Consequently, the estimated partial molar volume of the penetrants in the polymer was concentration dependent, which suggested that the solutiondiffusion model is an oversimplification. $\mathrm{C}_{2} \mathrm{H}_{6}$ concentrations in thin PPO, PDMS, P84 and SPPO films were compared to bulk films and no significant difference was found.

Chapter 5 reported about the preparation and characterization of mixed matrix membranes (MMMs). Three different commercial metal organic frameworks (MOFs) were selected (i.e. $\mathrm{Cu}_{3} \mathrm{BTC}_{2}, \mathrm{FeBTC}$ and MIL-53) and incorporated in a P84 polymer matrix. SEM, TGA and DSC experiments indicated the absence of non-selective voids for the $\mathrm{Cu}_{3} \mathrm{BTC}_{2}$ and FeBTC MMMs. This was confirmed by mixed gas permeation experiments, that showed an increase in $\mathrm{C}_{2} \mathrm{H}_{4} / \mathrm{C}_{2} \mathrm{H}_{6}$ selectivity of $73 \%$ to 7.1 for the $20 \mathrm{wt} \% \mathrm{Cu}_{3} \mathrm{BTC}_{2}$ MMMs, while the $\mathrm{C}_{2} \mathrm{H}_{4}$ permeability remained constant at $17 \cdot 10^{-18} \mathrm{~mol} \mathrm{~m} /\left(\mathrm{m}^{2} \mathrm{~s} \mathrm{~Pa}\right) .20 \mathrm{wt} \%$ FeBTC MMMs showed no significant change in selectivity. However, the $\mathrm{C}_{2} \mathrm{H}_{4}$ permeability was significantly reduced due to the formation of a denser intermediate layer. Addition of MIL-53 resulted in the formation of non-selective voids, which consequently increased the $\mathrm{C}_{2} \mathrm{H}_{4}$ permeability, and showed equal selectivities as compared to the native P84 membranes.

As incorporation of $\mathrm{Cu}_{3} \mathrm{BTC}_{2}$ showed the most promising results to increase the $\mathrm{C}_{2} \mathrm{H}_{4} / \mathrm{C}_{2} \mathrm{H}_{6}$ selectivity, the effect of the $\mathrm{Cu}_{3} \mathrm{BTC}_{2}$ concentration in P84 MMMs was further investigated. These results, as well as a thorough investigation on the transport mechanism of $\mathrm{C}_{2} \mathrm{H}_{4}$ through $\mathrm{Cu}_{3} \mathrm{BTC}_{2} \mathrm{MMMs}$, was presented in Chapter 6. MMMs with various $\mathrm{Cu}_{3} \mathrm{BTC}_{2}$ 
concentrations were prepared and the solubility, diffusivity and permeability coefficients of $\mathrm{C}_{2} \mathrm{H}_{4}$ and $\mathrm{C}_{2} \mathrm{H}_{6}$ were investigated. The $\mathrm{C}_{2} \mathrm{H}_{4}$ and $\mathrm{C}_{2} \mathrm{H}_{6}$ solubility coefficient was found to increase with increasing $\mathrm{Cu}_{3} \mathrm{BTC}_{2}$ loading, while the permeability coefficient was found to remain constant. Consequently, the diffusion coefficient was calculated to be significantly reduced with increasing $\mathrm{Cu}_{3} \mathrm{BTC}_{2}$ concentration. The $\mathrm{C}_{2} \mathrm{H}_{4} / \mathrm{C}_{2} \mathrm{H}_{6}$ selectivity was found to increase with increasing $\mathrm{Cu}_{3} \mathrm{BTC}_{2}$ concentration up to $20 \mathrm{wt} \%$. Higher $\mathrm{Cu}_{3} \mathrm{BTC}_{2}$ loadings resulted in the formation of non-selective voids. Since the solubility selectivity remained constant with increasing $\mathrm{Cu}_{3} \mathrm{BTC}_{2}$ concentration, the diffusivity selectivity is responsible for the increase in permeability selectivity. The combination of these results also suggest that $\mathrm{C}_{2} \mathrm{H}_{4}$ is immobilized inside the $\mathrm{Cu}_{3} \mathrm{BTC}_{2} \mathrm{MOF}$ as the result of Dewar-Chatt-Duncanson complexation.

The results and conclusions reported in this thesis are summarized and presented in Chapter 7. The implications of the results were discussed. Polymer swelling was found to be dependent on penetrant-polymer interactions. Crosslinking could be utilized to reduce polymer swelling, while simultaneously introducing functional groups, which could improve the selectivity. Layer by layer technology seems an interesting method to produce defect free thin membranes, allowing for higher permeances while the selectivity can be kept constant. Future research regarding MOF-mixed matrix membranes should focus on the development of novel MOF materials. Apart from optimizing the metal ion, attention should be paid to the organic linker as this was shown to alter the MOFs structure and sorption behavior. Chemical bonding of the MOF to the polymer matrix is expected to eliminate non-selective voids and would enable more polymer-MOF combinations. Additionally, the MOF could be utilized as crosslinker, thereby reducing plasticization effects. 
Samenvatting 
Dit proefschrift onderzocht de haalbaarheid van membrane in een hybride membraandistillatie plant met het doel om de energieconsumptie van het huidige, energie intensieve crygene distillatie proces, te verminderen.

Hoofdstuk 1 begon met een kort overzicht van alternatieve technologien voor cryogene distillatie om $\mathrm{C}_{2} \mathrm{H}_{4}$ van $\mathrm{C}_{2} \mathrm{H}_{6}$ te scheiden. Alternatieven zoals extractie distillatie en chemische en fysische adsorptie vertonen momenteel onvoldoende selectiviteit. Dit leidt, in combinatie met additionele nadelen, zoals de noodzaak voor het terugwinnen van het oplossmiddel, druk en/of temperatuur schommelingen en de grootschaligheid van de benodigde apparatuur, tot excessieve kapitale of operationele kosten. Scheiding met membranen can een interessant alternatief zijn, vanwege het lage energieverbruik en de kleinschaligheid, wat in het algemeen leidt tot lagere kapitale en operationele kosten. Helaas lijden polymeer membranen onder het intrinsieke nadeel dat de scheiding gebaseerd is op verschillen in de oplosbaarheid en diffusie van de te scheiden componenten, welke uitzonderlijk klein zijn in het geval van $\mathrm{C}_{2} \mathrm{H}_{4}$ en $\mathrm{C}_{2} \mathrm{H}_{6}$.

De economische evaluatie van membranen in een hybride membraan-distillatie plant werd gepresenteerd in Hoofdstuk 2. De benodigde energy voor cryogene distillatie werd gebruikt als basis en vergeleken met een parallele en seriele hybride configuratie, dit alles gemodelleerd in UniSim Design Suite. De $\mathrm{C}_{2} \mathrm{H}_{4}$ permeance en de $\mathrm{C}_{2} \mathrm{H}_{4} / \mathrm{C}_{2} \mathrm{H}_{6}$ selectiviteit van het membraan, werden onafhankelijk gevarieerd tussen respectievelijk $2,8 \cdot 10^{-6} \mathrm{~mol} /\left(\mathrm{m}^{2} \mathrm{~s}\right.$ $\mathrm{kPa})-2,8 \cdot 10^{-5} \mathrm{~mol} /\left(\mathrm{m}^{2} \mathrm{~s} \mathrm{kPa}\right)$ en de $3-1000$. De 2500 serie configuratie presteerde het beste en werd verder geoptimaliseerd wat betreft de membraan voedingsdruk, de permeaatdruk en het membraan oppervlak. Een geoptimaliseerd proces vereiste een membraan selectiviteit van 30 en een $\mathrm{C}_{2} \mathrm{H}_{4}$ permeance van $2,8 \cdot 10^{-5} \mathrm{~mol} /\left(\mathrm{m}^{2} \mathrm{~s} \mathrm{kPa}\right)$ om quitte te draaien. Financiele besparingen van $16 \%$ waren mogelijk met een membraan selectiviteit van 300 en een $\mathrm{C}_{2} \mathrm{H}_{4}$ permeance van $2,8 \cdot 10^{-5} \mathrm{~mol} /\left(\mathrm{m}^{2} \mathrm{~s} \mathrm{kPa}\right)$.

Hoofdstuk 3 beschreef de door $\mathrm{N}_{2}, \mathrm{CO}_{2}, \mathrm{C}_{2} \mathrm{H}_{4}$ en $\mathrm{C}_{2} \mathrm{H}_{6}$ geinduceerde swelling en sorptie effecten in dunne PPO films, gebruik makende van spectroscopische ellipsometrie. Het gebruikte optische model voor de dataverwerking bevatte drukafhankelijke brekingsindices en dichtheiden van de penetranten, waardoor aangenomen werd dat de penetranten zich als gas in de polymeer matrix bevinden in plaats van een vloeistof. $\mathrm{C}_{2} \mathrm{H}_{6}$ vertoonde de meeste zwelling, gevolgd door $\mathrm{C}_{2} \mathrm{H}_{4}$ en $\mathrm{CO}_{2}$, terwijl $\mathrm{N}_{2}$ het minste zwelling liet zien met $0.5 \%$ bij 30 bar. Zwelling was afhankelijk van de concentratie van de gesorbeerde penetrant en zijn Van 
der Waals volume. Gravimetrische sorptie bevestigde significant hogere $\mathrm{CO}_{2}$ concentraties in PPO in vergelijking tot de andere penetranten. In vergelijking met bulk films werd een lagere penetrant concentratie gevonden in dunne films voor $\mathrm{CO}_{2}$, maar niet voor $\mathrm{C}_{2} \mathrm{H}_{6}$. Tenslotte werden de drukafhankelijke partieel molaire volumes van $\mathrm{CO}_{2}, \mathrm{C}_{2} \mathrm{H}_{4}$ en $\mathrm{C}_{2} \mathrm{H}_{6}$ geschat.

Penetrant-polymeer interacties werden verder onderzocht in Hoofdstuk 4, waar de $\mathrm{N}_{2}, \mathrm{CO}_{2}$, $\mathrm{C}_{2} \mathrm{H}_{4}$ en $\mathrm{C}_{2} \mathrm{H}_{6}$ geinduceerde swelling en sorptie effecten werden bestudeerd in dunne P84, PPO, SPPO en PDMS films. Het rubberachtige PDMS vertoonde alleen Henry sorptie en geen niet-Fickiaanse sorptie bij hoge drukken van alle onderzochte gassen. Dit in tegenstelling tot de glasachtige PPO, P84 en SPPO dunne films die dual-mode sorptie en zowel Fickiaanse en niet-Fickiaanse sorptie lieten zien. PDMS zwelde het meeste wanneer het werd bloot gesteld aan $\mathrm{C}_{2} \mathrm{H}_{6}$, vanwege de Van der Waals interacties en het hoge Van der Waals volume van $\mathrm{C}_{2} \mathrm{H}_{6}$. Significant hogere $\mathrm{CO}_{2}$ geinduceerde zwelling werd geobserveerd voor SPPO in vergelijking tot PPO, wat duidt op verhoogde $\mathrm{CO}_{2}$ sorptie door de mogelijkheid tot quadrupool-dipool interacties met de sulfon groepen. Langmuir sorptie vertoonde polymeer zwelling, wat het dual-mode sorptie model tegenspreekt. Toch verschilde de door Langmuir sorptie veroorzaakte zwelling per mol gesorbeerd gas van de hoeveelheid zwelling veroorzaakt door Henry sorptie. Zodoende was het geschatte partieel molair volume van de penetranten afhankelijke van de concentratie, wat suggereerd dat het solutiondiffusion model een oversimplificatie is. $\mathrm{C}_{2} \mathrm{H}_{6}$ concentraties in dunne PPO, PDMS, P84 en SPPO films werden vergelijken met bulk films en geen significant verschil werd gevonden.

Hoofdstuk 5 rapporteerde over de preparatie en karakterisatie van mixed matrix membranen (MMMs). Drie verschillende, commercieel verkrijgbare, metal organic frameworks (MOFs) werden gekozen (i.e. $\mathrm{Cu}_{3} \mathrm{BTC}_{2}$, FeBTC en MIL-53) en gemengd in een P84 polymeer matrix. SEM, TGA en DSC experimenten toonden de afwezigheid van niet-selectieve ruimtes aan in het geval van $\mathrm{Cu}_{3} \mathrm{BTC}_{2}$, FeBTC MMMs. Dit werd bevestigd door mixed gas permeatie experimenten, die een stijging van de $\mathrm{C}_{2} \mathrm{H}_{4} / \mathrm{C}_{2} \mathrm{H}_{6}$ selectiviteit lieten zien met $73 \%$ tot 7,1 voor de $20 \mathrm{wt} \% \mathrm{Cu}_{3} \mathrm{BTC}_{2} \mathrm{MMMs}$, terwijl de $\mathrm{C}_{2} \mathrm{H}_{4}$ permeabiliteit constant bleef met $17 \cdot 10^{-18} \mathrm{~mol}$ $\mathrm{m} /\left(\mathrm{m}^{2} \mathrm{~s} \mathrm{~Pa}\right) .20 \mathrm{wt} \%$ FeBTC MMMs lieten geen significante verhoging van de selectiviteit zien. Toch werd de $\mathrm{C}_{2} \mathrm{H}_{4}$ permeabiliteit sterk gereduceerd door de formatie van een dichte tussenlaag. Toevoeging van MIL-53 resulteerde wel in de formatie van niet-selectieve ruimtes, waardoor de $\mathrm{C}_{2} \mathrm{H}_{4}$ permeabiliteit steeg, terwijl de selectiviteiten gelijk bleven aan die van de basis P84 membranen. 
Omdat het toevoegen van $\mathrm{Cu}_{3} \mathrm{BTC}_{2}$ veel belovende resultaten opleverde om de $\mathrm{C}_{2} \mathrm{H}_{4} / \mathrm{C}_{2} \mathrm{H}_{6}$ selectiviteit te verhogen, werd het effect van de $\mathrm{Cu}_{3} \mathrm{BTC}_{2}$ concentratie in P84 MMMs verder onderzocht. Deze resultaten, alsmede een diepgaand onderzoek naar het transport mechanisme van $\mathrm{C}_{2} \mathrm{H}_{4}$ door $\mathrm{Cu}_{3} \mathrm{BTC}_{2}$ MMMs werd gepresenteerd in Hoofdstuk 6. MMMs met verschillende concentraties $\mathrm{Cu}_{3} \mathrm{BTC}_{2}$ werden gemaakt en de oplosbaarheids-, diffusie- en $\begin{array}{lllllll}\text { permeabiliteitscoefficenten werden onderzocht. De } & \mathrm{C}_{2} \mathrm{H}_{4} & \text { en } & \mathrm{C}_{2} \mathrm{H}_{6}\end{array}$ oplosbaarheidscoefficienten steeg als als functie van de concentratie $\mathrm{Cu}_{3} \mathrm{BTC}_{2}$, terwijl de permeabiliteitscoefficenten gelijk bleven. Derhalve werd berekend dat de diffusiecoefficienten significant daalden als functie van de $\mathrm{Cu}_{3} \mathrm{BTC}_{2}$ concentratie. De $\mathrm{C}_{2} \mathrm{H}_{4} / \mathrm{C}_{2} \mathrm{H}_{6}$ selectiviteit steeg als functie van de $\mathrm{Cu}_{3} \mathrm{BTC}_{2}$ concentratie tot $20 \mathrm{wt} \%$. Hogere $\mathrm{Cu}_{3} \mathrm{BTC}_{2}$ concentraties resulteerde in de formatie van non-selective ruimtes. Doordat de oplosbaarheidsselectiviteit constant bleef als functie van de $\mathrm{Cu}_{3} \mathrm{BTC}_{2}$ concentratie, was de diffusieselectiviteit verantwoordlijk voor de stijging in de permeabiliteitsselectiviteit. De combinatie van deze resultaten suggereerde ook dat $\mathrm{C}_{2} \mathrm{H}_{4}$ geimmobiliseerd is binnen in de $\mathrm{Cu}_{3} \mathrm{BTC}_{2} \mathrm{MOF}$, ten gevolge van de Dewar-Chatt-Duncanson complexatie.

De resultaten en conclusies die gerapporteerd worden in dit proefschrift zijn samengevat en gepresenteerd in Hoofdstuk 7. De implicaties van deze resultaten zijn hier bediscussieerd. Polymeerzwelling was afhankelijk van penetrant-polymeer interacties. Crosslinken can gebruikt worden om polymeerzwelling te reduceren, terwijl zo gelijktijdig functionele groepen geintroduceerd kunnen worden, die de selectiviteit kunnen verbeteren. Layer by layer technologie lijkt een interesante methode om defectvrije membranen te produceren, waardoor hogere permeances mogelijk zijn terwijl de selectiviteit constant blijft. Toekomstig onderzoek aan MOF-mixed matrix membranen zou zich moeten focussen op de ontwikkeling van nieuwe MOF materialen. Afgezien van de optimalizatie van het metaal ion, zou aandacht moeten gaan naar de organische linker, omdat het aangetoond is dat deze zowel de MOF structuur als het oplosbaarheidsgedrag beinvloed. Het chemisch binden van MOFs aan de polymeer matrix zou niet-selectieve ruimtes moeten elimineren en kan zodoende het aantal polymeer-MOF combinaties verhogen. Ook zou de MOF zo gebruikt kunnen worden als crosslinker om plastificeringseffecten te verminderen. 
Acknowledgments 
Finally I can start writing the last chapter of this thesis, which will be read by almost everybody as first and most probably also a last. I would like to start by thanking my daily supervisor, who herself got promoted in the meantime to my promotor, prof. dr. ir. Dorothea Catharina Nijmeijer. Kitty, thank you for giving me the opportunity to do my Ph.D. within the membrane group. I enjoyed working together with you for the past 4 year. Im also very grateful for the freedom you gave me, especially in the last 2 years, to organize, plan, conduct, analyze and write down all my research. Im sure we will keep in touch in the future.

I would also like to thank my promotion committee for reading my thesis and allowing me to defend it. Prof. dr. S.R.A. Kersten, prof. dr. K. Seshan, prof. dr. G. Mul, thank you for accepting to take part in my committee. Special thanks to the members from abroad, prof. dr. ir. I.F.J. Vankelecom and prof. dr. B.D. Freeman. I would also like to thank the chairman, prof. dr. ir. R.G.H. Lammertink. Rob, thank you for the fun conversations. I will not easily forget my interview with you, where we mainly discussed poker and go-karts instead of science and my suitability for the Ph.D. project.

Furthermore, I thank my project committee members, AgentschapNL, ECN, Dow and SolSep members for their valuable financial and intellectual support.

Special thanks go to my current boss, Herr dr. Jens Potreck. Thank you for giving me the opportunity to combine my job and the finalization of my thesis. I hope these first months of working together were a good indication of things to come.

As member of the MST group, I would express my gratitude towards my fellow group members: Zandrie, it was always a pleasure heaving a break with you. Antoine, our trip with Kitty through the wilderness surrounding Boise, was legendary, despite (or maybe thanks to) the locals and the environment. Harmen, it was great biking with you all these years. Listening to your many great stories and eventually, protecting you in the middle of the night from potential robbers. Everything was definitely more fun with you around, whether it was work or party related. Erik, Erik, Herman, Lydia, Ineke and Marcel, thank you all for your assistance and conversations during the past years. Wika, it is my pleasure to be your colleague once again. John, thank you for all the help regarding Swagelok and ordering related affairs. Greet, although I can't thank you for all the forms you filled in regarding my thesis, I am ever grateful for your help during NYM. It was a pleasure being around you and I m sure you will be severely missed, not only my me, but my everyone, when (if) you retire. 
Also gratitude to my fellow membrane Ph.D students and post docs, Yusuf, Harro, Enver, Nazely, Nicolas, Al-Hadidi, Szymon, Karina, Geraldine, Schwan, Katja and Mayur. It was great meeting you and visiting the countless conferences, having borrels and celebrating the many parties. Speaking about parties, Can, Sinem, Erik and Wojciech, it was awesome hanging out and partying with you. Thanks for the great memories.

Then we end up thanking my office mates Jigar and Jumeng, it was great having such reliable, calm, hard working office mates. Joanna, your visit was short but intense. I wish you all the best. Krzysztof/Pierre, it was great having you around. Although your unofficial office (and maybe even your unofficial residence) was the lab, I saw you fortunately plenty of times outside of working hours. Salman, thanks to you it was possible to go to SalmanSchool, where I have learned a lot about Can`s genitals during diner, and that a barrette and baguette make you French instantly. Sandra, it was great talking to you, and the highlight was definitely your wedding in Porto, were we could go to the beach while others were already freezing in Enschede. Anne Corine thank you for all the breaks, talks and dinners, where we discussed a broad range of topics. It definitely made my Ph.D. time here in Enschede a lot more fun. I wish you all the best in the future.

Furthermore, I want to thank my students for their hard word, which in one way or another, led to this thesis. Jens, Ton, Thom, Michiel, Adriaan and Susilo: it was great supervising you guys and your efforts are much appreciated.

I also want to thank the IM and SFI people. Frank, Louis, Ana, Martin, Bas, Michiel, Emiel, Yali and Sander, I want to thank you especially for the help, discussions and overall good times.

Marjolein, Ruben, Kees, en Claes, fijn dat jullie me niet helemaal vergeten zijn in dit verre Tukkerstan, of zoals vaak gezegd, West-Duitsland. Hoewel een aantal van jullie nooit heeft begrepen waarom ik me in hemelsnaam ten oosten van de A10 heb gewaagd, kan ik alleen maar zeggen dat ik iets van mijn leven probeer te maken. Bier is op mijn rekening vanavond (ja wijn ook), dus geniet er van.

Ook jij bent me gelukkig niet vergeten Marloes. En ondanks dat onze lichamen steeds ouder worden, en dus de drank minder goed kunnen verwerken, hoop ik dat we nog veel wilde avonden hebben, hangend voor de tv, klagend dat we moe zijn. 
Joris, thank you for all the discussions and help. I know for sure I would not have achieved progressing to the level at which I operate today so quickly, without your constant input. So on that note, it gives me great joy that we will continue to cooperate together in the future, even though I left the UT.

Marlon, from the moment I started my Ph.D. in Enschede, we have always been on the same page. You moving to another building was nothing but a pleasant excuse to leave my office for a break. I've always enjoyed our conversations and breaks. Therefore, I am very happy that you agreed to be my paranymph on this day.

Olga, I had prepared 1 A4 of acknowledgements about you, long before you finished writing yours. Unfortunately, they will be locked inside my head forever. Yet I am happy that you will stand beside me during this day. We have spent a lot time on various important things: coffee breaks, gossips, discussions, parties, HICOM and BYECOM, conferences and courses, lunch breaks and extended summer lunch breaks. We even hugged once. You are one of the few people owning a 'cool car' membership and in return, I am looking forward to my guestroom in Deventer. The result of your Ph.D. title motivated me like never before to find a job also suited to my abilities. So once again, I would like to thank you for everything and I hope that...sorry, no more space for that.

Mamma, Pappa, Youp, Dennis en Romy, bedankt voor alle steun die jullie mij gegeven hebben en interesse die jullie getoond hebben. Het is erg fijn om te weten dat jullie er altijd voor me zijn. Het is dan ook altijd weer prettig om bij jullie thuis te komen.

Beata, dzieki Tobie jestem pewny, ze przeprowadzka do Enschede byla najlepsza decyzja w moim zyciu. Ciesze sie z kazdego momentu spedzonego z Toba, czy to na dyskusji o nauce i technologii czy na temat mandatow na zle parkowanie. Dziekuje Ci za Twoje stale wsparcie, chociaz ja ciagle rosne. Kocham Cie i nasz specjalny chłopiec. 
